\title{
Abdominal wall hernia repair : intraperitoneal mesh and adhesions
}

Citation for published version (APA):

Schreinemacher, M. H. F. (2015). Abdominal wall hernia repair : intraperitoneal mesh and adhesions. [Doctoral Thesis, Maastricht University]. Maastricht University. https://doi.org/10.26481/dis.20150410ms

Document status and date:

Published: 01/01/2015

DOI:

10.26481/dis.20150410ms

Document Version:

Publisher's PDF, also known as Version of record

\section{Please check the document version of this publication:}

- A submitted manuscript is the version of the article upon submission and before peer-review. There can be important differences between the submitted version and the official published version of record.

People interested in the research are advised to contact the author for the final version of the publication, or visit the DOI to the publisher's website.

- The final author version and the galley proof are versions of the publication after peer review.

- The final published version features the final layout of the paper including the volume, issue and page numbers.

Link to publication

\footnotetext{
General rights rights.

- You may freely distribute the URL identifying the publication in the public portal. please follow below link for the End User Agreement:

www.umlib.nl/taverne-license

Take down policy

If you believe that this document breaches copyright please contact us at:

repository@maastrichtuniversity.nl

providing details and we will investigate your claim.
}

Copyright and moral rights for the publications made accessible in the public portal are retained by the authors and/or other copyright owners and it is a condition of accessing publications that users recognise and abide by the legal requirements associated with these

- Users may download and print one copy of any publication from the public portal for the purpose of private study or research.

- You may not further distribute the material or use it for any profit-making activity or commercial gain

If the publication is distributed under the terms of Article $25 \mathrm{fa}$ of the Dutch Copyright Act, indicated by the "Taverne" license above, 


\section{Abdominal Wall Hernia Repair}

Intraperitoneal Mesh and Adhesions

Marc H.F. Schreinemacher 
Abdominal Wall Hernia Repair: Intraperitoneal Mesh and Adhesions Thesis, Maastricht University, The Netherlands

Author \& Cover M.H.F. Schreinemacher

Lay out \& Print $\quad$ Off Page, Amsterdam, The Netherlands

ISBN

978-94-6182-530-8

All rights reserved 2015

No part of this publication may be stored, reproduced or transmitted in any form or by any means, without prior written permission of the author.

The printing of this thesis was financially supported by:

Acelity, Afdeling Chirurgie Atrium-Orbis Medisch Centrum, AMC Wetenschapsfonds Chirurgie, Applied Medical, Bard Netherlands, Care10, Chipsoft, Convatec, Cousin Biotech, Covidien, Duomed, Dutch Hernia Society, Erbe Benelux, Eurotec, Maquet Getinge Group, Medisse, Mediq Combicare, Nordic Pharma, Nederlandse Vereniging voor Endoscopische Chirurgie, Nederlandse Vereniging voor Gastro-enterologie, Oldekamp Medisch, Olympus Nederland, Sanofi, Stöpler, Tergooiziekenhuizen, W.L. Gore \& Associates. 


\title{
Abdominal Wall Hernia Repair
}

\author{
Intraperitoneal Mesh and Adhesions
}

PROEFSCHRIFT

ter verkrijging van de graad van doctor

aan de Universiteit Maastricht,

op gezag van de rector magnificus, prof. dr. L.L.G. Soete,

volgens het besluit van het College van Decanen,

in het openbaar te verdedigen op

vrijdag 10 april 2015 om 14.00 uur

door

Marc Henri François Schreinemacher 


\section{Promotor}

Prof. dr. N.D. Bouvy

\section{Copromotoren}

Dr. S.O. Breukink

Dr. J.-W.M. Greve (Atrium Medisch Centrum Heerlen)

\section{Beoordelingscommissie}

Prof. dr. L.P.S. Stassen, voorzitter

Prof. dr. W.A. Bemelman (Academisch Medisch Centrum Amsterdam)

Prof. dr. C.H.C. Dejong

Prof. dr. J.F. Lange (Erasmus Universiteit Rotterdam) 


\section{TABLE OF CONTENTS}

Chapter 1 General introduction and outline of the thesis

PART 1 Clinical problem and awareness

Chapter 2 Enterotomy risk in abdominal wall repair: a prospective study

Annals of Surgery 2012

Chapter 3 Adhesion awareness: a national survey of surgeons

45

World Journal of Surgery 2010

PART 2 Experimental findings on intraperitoneal mesh related adhesions

Chapter 4 Degradation of mesh coatings and intraperitoneal adhesion

formation in an experimental model

British Journal of Surgery 2009

Chapter 5 Coated meshes for hernia repair provide comparable

intraperitoneal adhesion prevention

Surgical Endoscopy 2013

Chapter 6 Adhesions to sutures, tackers, and glue for intraperitoneal mesh fixation: an experimental study

Hernia 2014

Chapter 7 Polypropylene meshes to prevent abdominal herniation:

can stable coatings prevent adhesions in the long term?

Annals of Biomedical Engineering 2009

Chapter 8 Preoperative, oral cromolyn treatment for adhesion

reduction to intraperitoneal meshes: an experimental study

Submitted

PART 3 A human model for the evaluation of adhesions to meshes

Chapter 9 Incisional hernias in temporary stoma wounds: a cohort study

Archives of Surgery 2011

Chapter 10 Prophylactic intraperitoneal mesh placement to prevent

incisional hernia after stoma reversal: a feasibility study

Surgical Endoscopy 2013 
$\begin{array}{lll}\text { Appendices } & \text { Summary } & 189\end{array}$

Samenvatting (Summary, in Dutch) 193

$\begin{array}{ll}\text { Valorisation } & 197\end{array}$

List of publications 203

Dankwoord (Acknowledgements, in Dutch) 205

$\begin{array}{ll}\text { Curriculum vitae auctoris } & 209\end{array}$ 


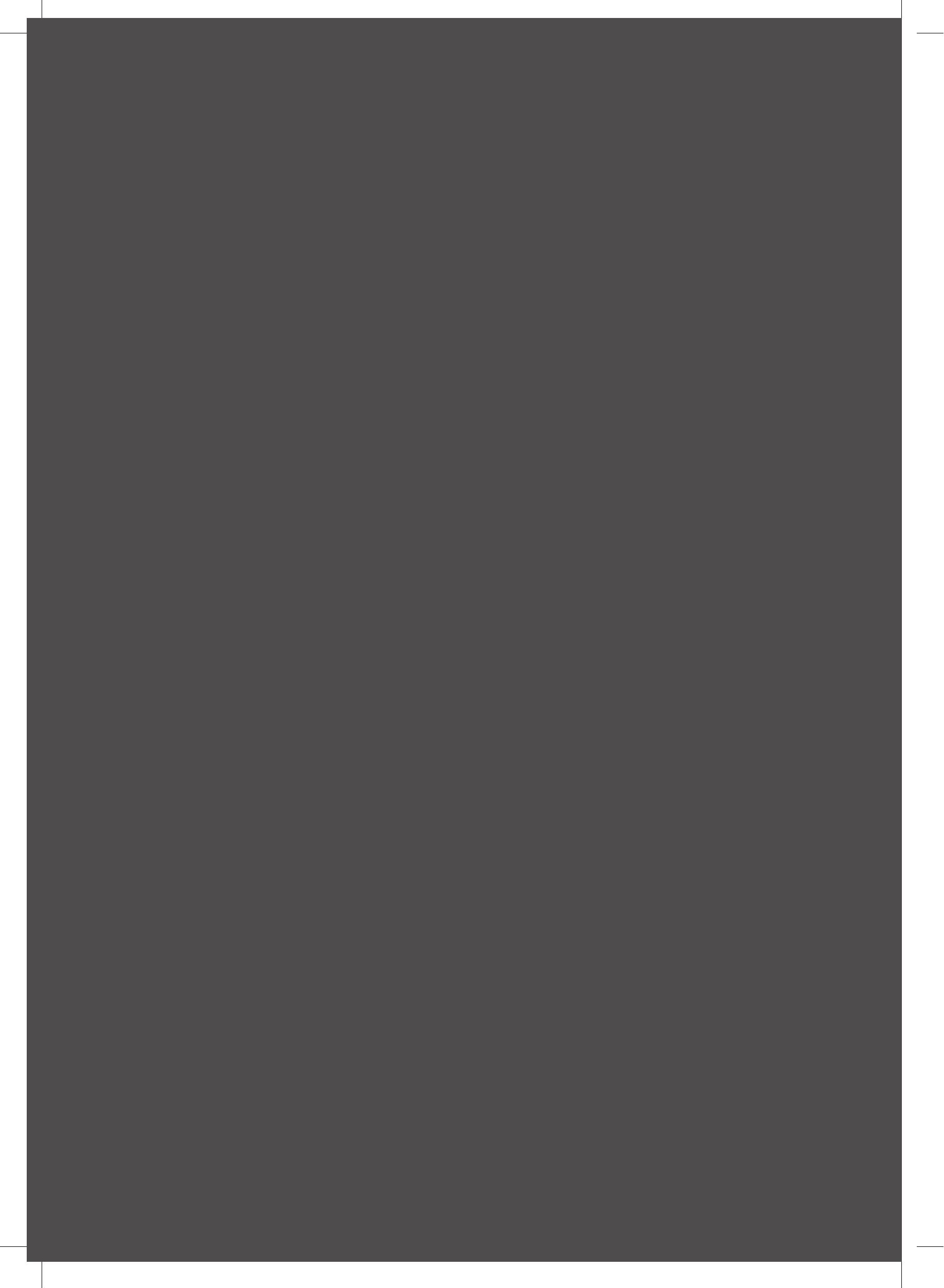




\section{GENERAL INTRODUCTION AND OUTLINE OF THE THESIS}

Chapter 1

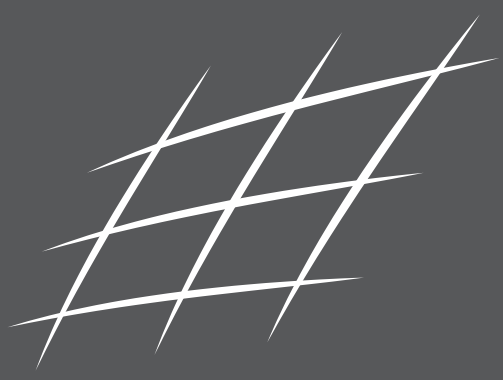


With the introduction of general anaesthesia in 1846 abdominal surgery became possible'. One and a half centuries later, techniques and outcomes in abdominal surgery have improved tremendously. Yet still up to $32-52 \%$ of surgical patients experience one or more complications in the early days after their operation ${ }^{2-4}$. The most common of these are wound, bladder and pulmonary infections that occur typically within 30 days after the operation.

Since emphasis is generally put on short-term complications, less interest has been paid to the complications of abdominal surgery occurring months or even years after the operation. The most common of these, unrelated to specific procedures, are pain, adhesion related bowel obstruction and abdominal wall hernia ${ }^{5-10}$.

This thesis investigates intraperitoneal mesh placement and adhesion formation in the repair of abdominal wall hernias.

\section{Abdominal wall hernias}

The abdomen is walled mostly by muscles enclosed in aponeuroses, fibrous sheets, that together provide strength and flexibility as a harness for the intraperitoneal organs. An abdominal wall hernia consists of a defect in all layers of the abdominal wall through which intraperitoneal content, most frequently parts of omentum or bowel may protrude (Figure 1, A). As a result, a bulge may be visible on the outside of the abdomen. The presence of an abdominal wall hernia may also give rise to physical complaints and negatively influences the quality of life and body image ${ }^{11-13}$.

In some cases, especially when the defect itself is rather small in diameter, a loop of bowel may become stuck in the hernia and blood supply to that part of the bowel can become cut off. Such condition is called strangulation and requires direct surgical intervention to prevent bowel necrosis.

\section{Incisional hernias}

In abdominal surgery, the surgical armamentarium offers a wide variety of incisions with the midline incision being one of the most commonly used. The midline incision provides access over the entire craniocaudal length of the abdomen. The incision goes through an avascular plane, the linea alba, which is the fusion of the aponeuroses of the left and right rectus muscles. At the end of the procedure, the defect is suture closed so that a close approximation of both wound edges is obtained and wound healing may start. Even though this principle seems utterly simple, still up to almost a quarter of these abdominal wall closures fail to heal over the full length of the incision ${ }^{14}$. Over the years, incisional hernia rates have remained as high as $22 \%$ and continue to develop up to 10 years after the operation ${ }^{10,15}$. Incisional hernia rates might be reduced by using paramedian, transverse or pfannenstiel incisions ${ }^{9,16}$.

Special types of incisional hernias include trocar site hernias after laparoscopic procedures and acute wound failures resulting in a burst abdomen. 


\section{Primary abdominal wall hernias}

In addition to the incisional hernias discussed above, abdominal wall hernias may already be present at birth or develop spontaneously throughout the course of life. These hernias are named after their location relative to structures of the abdominal wall. Epigastric, umbilical, and paraumbilical occur most frequently with a prevalence of up to $10 \%$ in the general population ${ }^{17}$.

\section{Abdominal wall hernia repair}

Pain, functional and aesthetic complaints, or strangulation are the main reasons for performing an operative repair of abdominal wall hernias ${ }^{12,18}$. Factors like the size, content and location of the hernia defect, as well as patient comorbidity define the risks of surgery and the chances of success. In general, hernias up to $2 \mathrm{~cm}$ large might be considered for suture repair. This way, recurrence rates of up to $4 \%$ have been reported, at least in the absence of risk factors for recurrence such as obesity, smoking, heavy lifting or known collagen disorders ${ }^{15,19}$. However, suture repair of larger defects results in unacceptably high recurrence rates of up to $63 \%{ }^{20}$. For these cases, surgical meshes have shown to reduce the recurrence rates by $50 \%$ and more and are therefore regarded the standard of surgical care ${ }^{20}$.

\section{Mesh positioning}

Within the abdominal wall multiple layers can be distinguished between which the mesh can be positioned. For this thesis we will focus on the position relative to the peritoneum, i.e. extraperitoneally or intraperitoneally.

For the extraperitoneal position, the mesh is commonly placed in a retromuscular plane (Figure 1, B). This position entails an anterior approach with reopening of the skin incision and developing the plane between the muscle and the posterior aponeurosis. By closing the defect in the aponeurosis, the mesh is in no direct contact with the intraperitoneal organs.

For the intraperitoneal position, the mesh is placed against the peritoneum and facing the viscera (Figure 1, C). For this position, a posterior approach by using laparoscopy or an anterior approach with reopening of the skin incision are both available. The laparoscopic approach offers shorter hospital stays, fewer wound infections and better recognition of multiple hernias ${ }^{21,22}$. However, in the case of a laparoscopic repair the procedure may take more time to perform and complications can be more serious ${ }^{23}$. Recurrence rates and postoperative pain seem to differ only minimally between an open or laparoscopic approach.

\section{Mesh materials}

Surgical meshes were first introduced around 1900 in the form of metal based prosthetics ${ }^{24}$. These materials were far from ideal because of their stiffness and fragility after repeated bending. During the Second World War, the plastics industry flourished and some surgeons adopted meshes made out of woven plastic strands. The plastics used in those days (i.e. polypropylene, polyester and expanded polytetrafluoroethylene (ePTFE)) are still the basis 


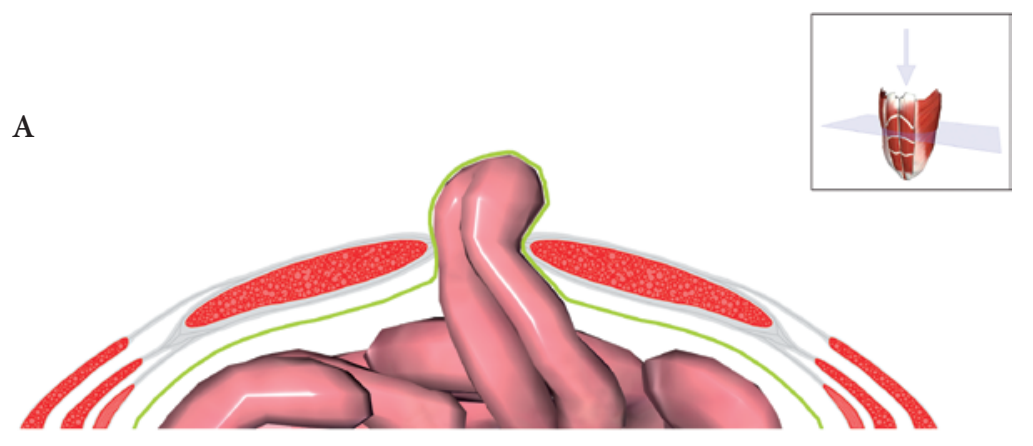

B

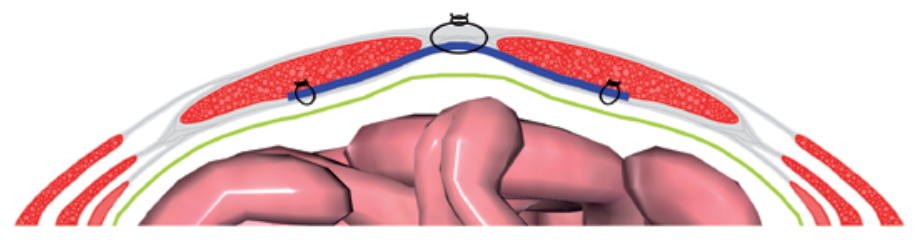

$\mathrm{C}$

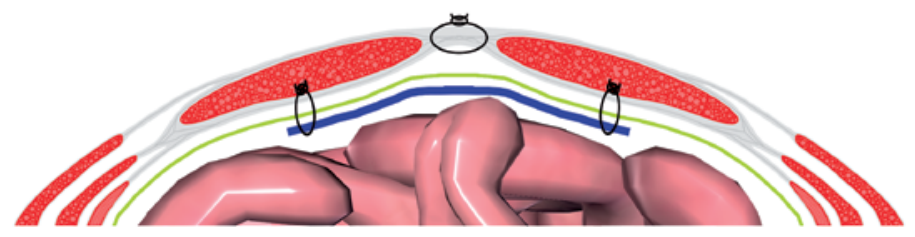

Figure 1. In A, a transverse section of an abdominal wall hernia through the midline is depicted. A loop of small bowel passes through a defect in the midline. Together with the bowel, the peritoneum (green) bulges out, covering the bowel loop. In B, hernia repair has been performed with a mesh (blue) placed between the posterior aponeurosis (grey) and the muscles (red). This is an extraperitoneal repair where the mesh is not in direct contact with the bowel. In $\mathrm{C}$, hernia repair has been performed with a mesh placed between the peritoneum and the bowel. This is an intraperitoneal repair where the mesh is in direct contact with the bowel.

of many of the currently used meshes. However, there have been many modifications in order to optimize biocompatibility and handling of the meshes.

Some of the properties for the ideal mesh are to provide sufficient strength without compromising physiological function of the abdominal wall, to be non-carcinogenic, to not induce any pain and to resist infection ${ }^{25}$. Most of the aforementioned properties are likely to be related to the amount of implanted material and the extent of the inflammatory reaction. Therefore, enlarging pore size and incorporating absorble strands in the mesh design have been important steps in reducing the extent of mesh-tissue interaction (Figure 2). In order to further enhance biocompatibility of meshes under specific circumstances, the addition of coatings and replacement of prosthetic materials by biological materials has been tried with different degrees of success. 

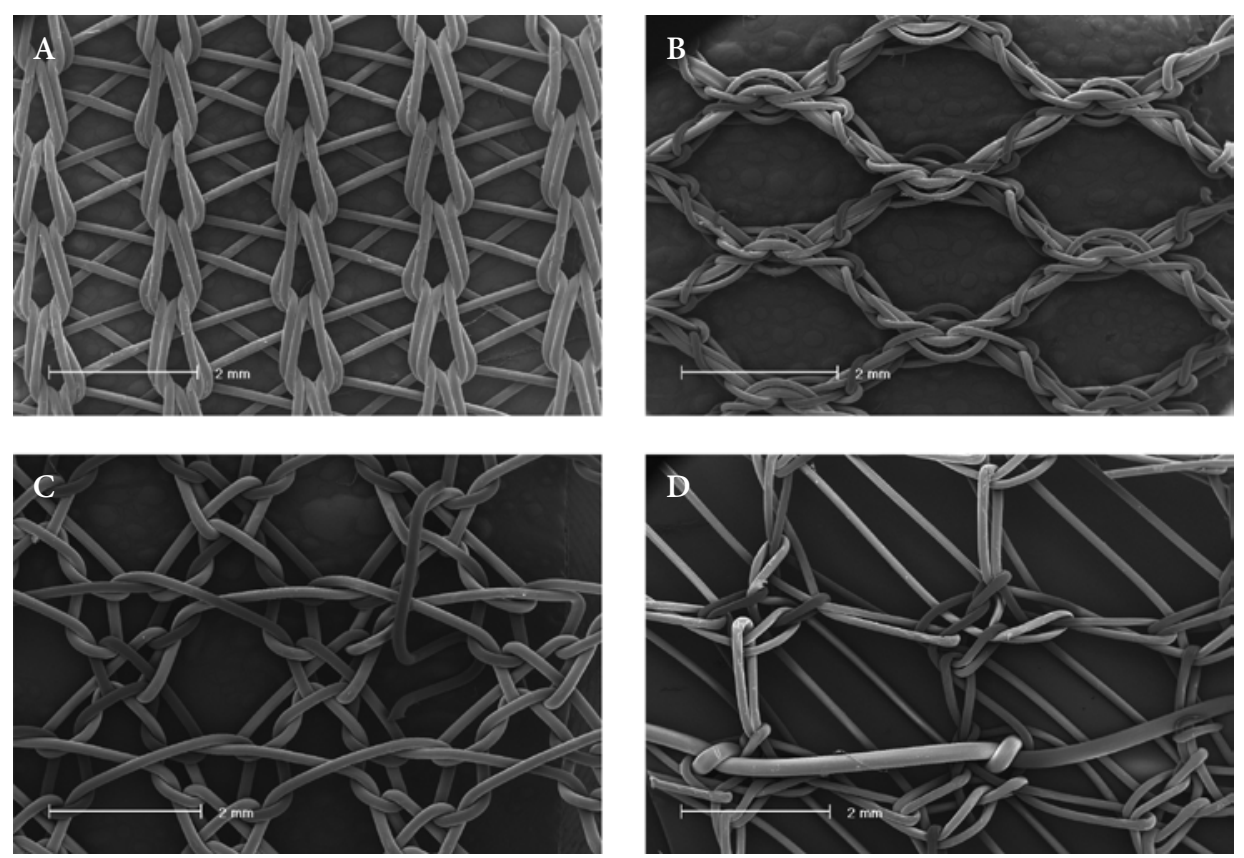

Figure 2. Scanning electron microscopy images of several commercially available meshes for hernia repair. Different weaves result in different pore sizes.

\section{Postoperative adhesion formation}

Together with incisional hernias, intraperitoneal adhesions are the most common postoperative complications. Postoperative adhesions occur in about $90 \%$ of all patients undergoing abdominal surgery and may lead to at least one readmission for a third of these patients in the following 10 years ${ }^{6,26}$.

Adhesions develop as scar tissue that connects formerly unconnected serosal surfaces. This way organs can become adhesive to each other or the abdominal wall and hollow organs may become obstructed (Figure 3). Clinically, these events can translate to infertility, bowel obstruction, chronic pain and a high risk for inadvertent bowel injuries at future operations ${ }^{7}$. Endometriosis, radiotherapy or foreign bodies may trigger adhesion formation, but the majority is caused by surgically inflicted peritoneal damage. In the ensuing cascade of peritoneal inflammation the balance between fibrinogenesis and fibrinolysis has been confirmed to be of crucial importance ${ }^{27}$.

It is important to note that the surgical treatment of adhesions induces reformation of the adhesions together with the formation of even new adhesions ${ }^{28,29}$. Therefore, the prevention of adhesions is of paramount importance.

In abdominal wall hernia repair, adhesions between bowel and the hernia sac are frequently encountered together with intraperitoneal adhesions in case of earlier operations. 


\section{Intraperitoneal mesh and adhesions}

In case of abdominal wall hernia repair, solid incorporation of the mesh in the abdominal wall is desired in order to prevent mesh shrinkage, migration or enlarging of the hernia defect which may lead to hernia recurrence. Importantly, this reaction should be limited to the abdominal wall since mesh ingrowth into bowel is highly undesirable. For instance, partial bowel resections were required in up to $21 \%$ of patients when unmodified meshes were used for intraperitoneal use $\mathrm{e}^{30}$. This process of ingrowth is considered to be the worst form of adhesion formation ${ }^{31}$.

As foreign bodies like meshes are a specific lead point for adhesion formation, the prevention of adhesions is of concern when meshes are placed intraperitoneally ${ }^{32}$. This has been achieved both experimentally and clinically by interposition of omentum or degradable compounds such as polyglactin, hyaluronate and cellulose among others ${ }^{33-35}$. Most commonly, the design includes the addition of a sheet-like barrier shielding the mesh structure from the viscera. These barriers are available both in absorbable and permanent forms. Apart from these composite meshes, other designs have focused on constructing more chemically inert materials such as titanium coated plastics or new polymers. Today, several hundreds of different meshes are available for clinical use ${ }^{36}$. Nevertheless, even with meshes designed specifically for intraperitoneal use, adhesions are still encountered in differing degrees of extent and intensity ${ }^{37}$.

\section{Outline of the thesis}

This thesis is divided into three parts. The first part explores adhesion related complications in abdominal wall surgery, together with adhesion awareness among surgeons. The second part contains a set of experimental findings on adhesion reduction with intraperitoneal meshes. The final part establishes a human model that allows for future translation of our experimental results.

\section{Part 1: Clinical problem and awareness}

In abdominal wall hernia repair, adhesiolysis is an expected part of the hernia repair, especially if the hernia is a result of a former abdominal intervention. Due to adhesions and the close proximity of skin and peritoneum in the hernia sac, the bowel is believed to be at a higher risk for surgically inflicted injury ${ }^{38,39}$. So far, only studies were available that lacked an in-depth appreciation of the incidence, risk factors and outcomes of inadvertent enterotomies in abdominal wall hernia repair. Therefore, a prospective study in abdominal wall hernia repair was initiated focusing on these outcomes. The results are presented in Chapter 2.

In contrast to most surgical complications, adhesion-related morbidity accumulates steadily over many years. In addition, signs and symptoms vary and a fully effective remedy has not yet been discovered. However, knowledge about the incidence and impact of postoperative adhesions is important to establish awareness about the problem and to improve shared 


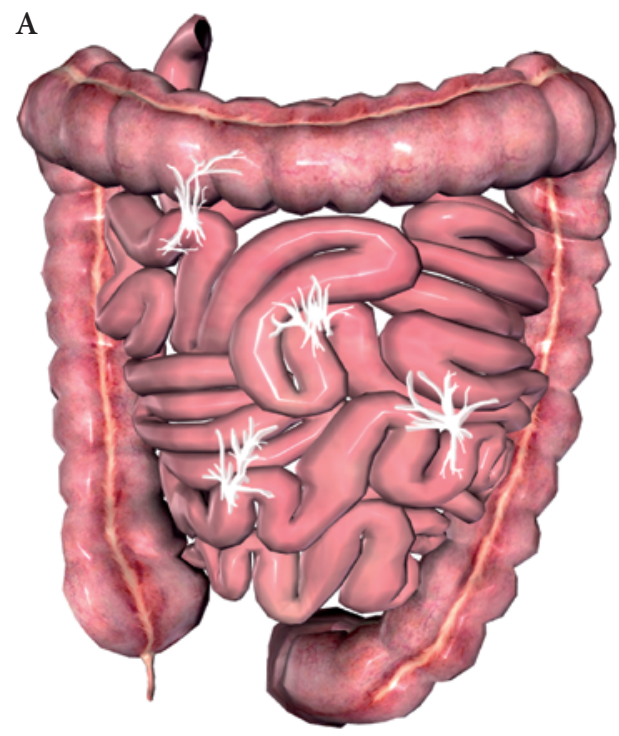

B

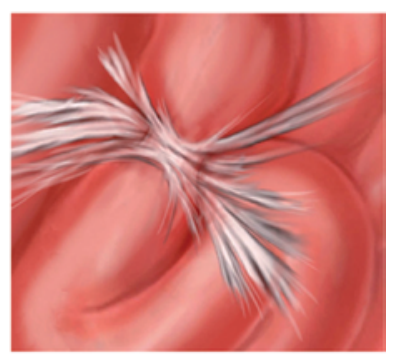

$\mathrm{C}$

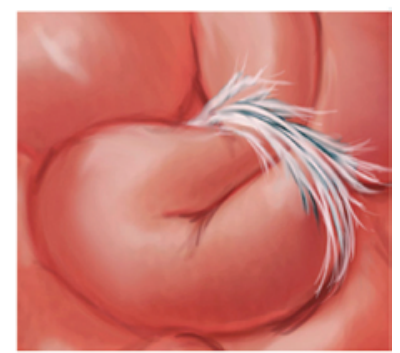

$\mathrm{D}$

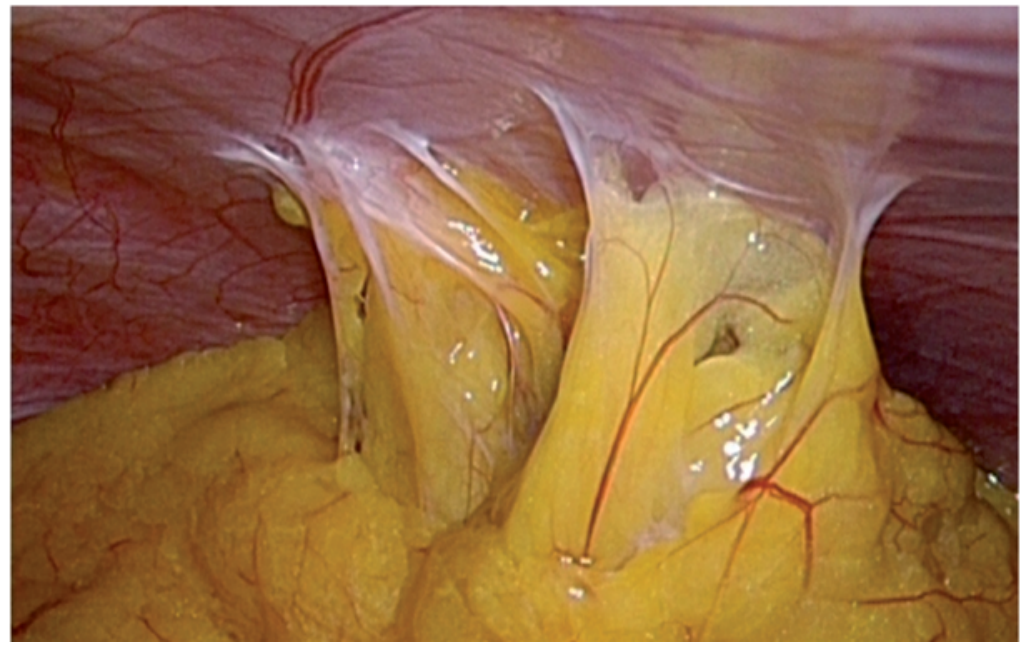

Figure 3. Intraperitoneal adhesions are scar tissues that connect formerly unconnected serosal surfaces (A, white strands between bowel loops). Small bowel obstruction is commonly caused by postoperative adhesions. In such case the lumen of the bowel becomes obstructed due to adhesions that fixate a bowel loop which may lead to twisting and kinking of the loop (B and C). In D, adhesions between the omentum and the abdominal wall in a patient are shown. (On 5 November 2014, A was retrieved from http://www. biodigitalhuman.com, B and C were retrieved from http://www.clearpassage.com. Images are used with permission of their respective authors.) 
A

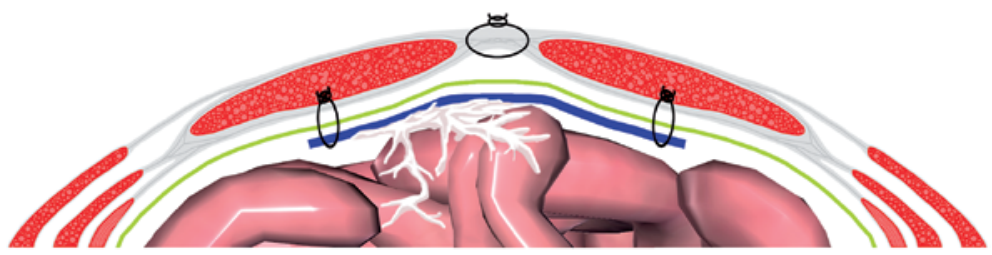

B

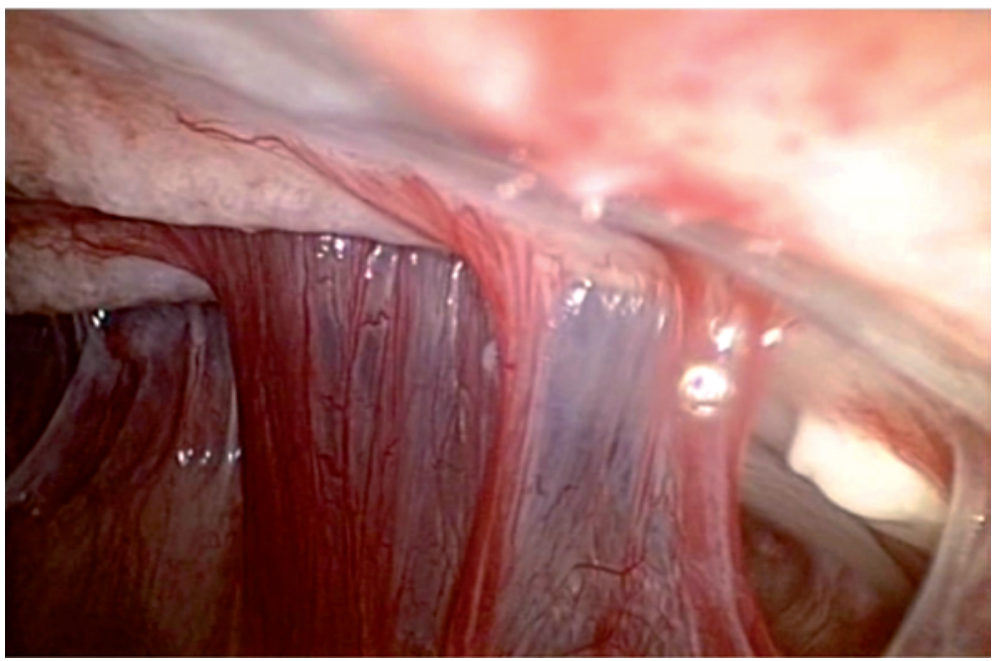

Figure 4. Intraperitoneal positioning of the mesh results in direct contact between the mesh and bowel. This may induce the formation of adhesions ( $\mathrm{A}$, white strands between mesh and bowel). In $\mathrm{B}$, adhesions between the mesh (top) and bowel (bottom) in a patient are shown.

decision making. In Chapter 3 we present the results of a national survey among surgeons that investigated knowledge, attitudes and behaviour towards postoperative adhesion formation.

\section{Part 2: Experimental findings on intraperitoneal mesh related adhesions}

A considerable part of meshes are placed intraperitoneally because the laparoscopic repair seems to hold some benefits over an open repair. In addition, sometimes meshes can not be placed completely extraperitoneally. When the mesh is in direct contact with the viscera it is a specific lead point for adhesion formation. For this, meshes were constructed that should be able to withstand adhesion formation and in the meantime incorporate firmly into the abdominal wall. Although these meshes are commercially available, most have not been thoroughly tested in an experimental or clinical setting. Moreover, a solid understanding of the mechanisms leading to adhesion formation with meshes is still lacking. In Chapters 4 and 5 several commercially available meshes were evaluated in a rat model on both short and long term follow up. Since we observed a tendency for adhesions to form at the site of 
1 the mesh fixation point, we also compared adhesiogenic properties of a set of commercially available fixation devices in Chapter 6.

An important finding was the correlation between inflammation caused by absorption of coatings and adhesion formation. Consequently, in Chapter 7 we prepared a new, non absorbable coating and showed the beneficial results in terms of adhesion reduction. Finally, we reviewed some of the recent breakthroughs in the pathogenesis of intraperitoneal adhesions and the immune response against biomaterials. Two of these concepts have been shown to be applicable to humans as well were selected for further investigation ${ }^{40,41}$. In Chapter 8 a series of experiments is presented that shows a systemic, preoperative treatment with cromolyn, a supposed mast stabiliser, to significantly reduce adhesion formation with meshes.

\section{Part 3: A human model for the evaluation of adhesions to meshes}

The findings from the second part of this thesis seem to be of clinical value but were only performed in an experimental setting. Unfortunately, no clinical model for inserting biomaterials intraperitoneally and evaluating adhesions at a later time point was available. The most important reason for this is the lack of any accurate, validated and non-invasive technique for adhesion quantification. Direct visualization by reoperation is therefore necessary.

In Chapters 9 and 10 we developed a clinical model for adhesion assessment. In Chapter 9 we established the need for mesh placement in the event of temporary stoma reversal. Consequently, meshes were placed prophylactically at the time of temporary stoma creation in Chapter 10. After a fixed time interval, stoma reversal allowed us to assess the extent of adhesion formation to the intraperitoneal meshes. In the future, this model might be used to perform clinical studies on intraperitoneal mesh and related adhesions.

In Chapter 11 the combined results from this thesis are discussed, together with future perspectives on the matter of intraperitoneal mesh and adhesions in abdominal wall hernia repair. 


\section{References}

1 Gawande A. Two Hundred Years of Surgery. $N$ Engl J Med 2012;366(18):1716-23.

2 Wanzel KR, Jamieson CG, Bohnen JM. Complications on a general surgery service: incidence and reporting. Can J Surg 2000;43(2): 113-7.

3 Guillou PJ, Quirke P, Thorpe H, Walker J, Jayne DG, Smith AMH, Heath RM, Brown JM, MRC CLASICC trial group. Short-term endpoints of conventional versus laparoscopic-assisted surgery in patients with colorectal cancer (MRC CLASICC trial): multicentre, randomised controlled trial. Lancet 2005;365(9472):171826.

4 Møller AM, Villebro N, Pedersen T, Tønnesen $\mathrm{H}$. Effect of preoperative smoking intervention on postoperative complications: a randomised clinical trial. Lancet 2002;359(9301):114-7.

5 Macrae WA. Chronic pain after surgery. $\mathrm{Br} J$ Anaesth 2001;87(1):88-98.

6 Ellis H, Moran BJ, Thompson JN, Parker MC, Wilson MS, Menzies D, McGuire A, Lower AM, Hawthorn RJ, O’Brien F, Buchan S, Crowe AM. Adhesion-related hospital readmissions after abdominal and pelvic surgery: a retrospective cohort study. Lancet 1999;353(9163):1476-80.

7 Broek ten RPG, Issa Y, van Santbrink EJP, Bouvy ND, Kruitwagen RFPM, Jeekel J, Bakkum EA, Rovers MM, van Goor H. Burden of adhesions in abdominal and pelvic surgery: systematic review and met-analysis. BMJ 2013;347:f5588.

8 Kuhry E, Schwenk WF, Gaupset R, Romild U, Bonjer HJ. Long-term results of laparoscopic colorectal cancer resection. Cochrane Database Syst Rev 2008;(2):CD003432.

9 Bartels SAL, Vlug MS, Hollmann MW, Dijkgraaf MGW, Ubbink DT, Cense HA, van Wagensveld BA, Engel AF, Gerhards MF, Bemelman WA, Collaborative LAFA Study Group. Small bowel obstruction, incisional hernia and survival after laparoscopic and open colonic resection (LAFA study). Br J Surg 2014;101(9):1153-9.

10 Fink C, Baumann P, Wente MN, Knebel P, Bruckner T, Ulrich A, Werner J, Büchler MW, Diener MK. Incisional hernia rate 3 years after midline laparotomy. Br J Surg 2014;101(2):51-4.

11 Nieuwenhuizen J, Kleinrensink GJ, Hop WCJ, Jeekel J, Lange JF. Indications for incisional hernia repair: an international questionnaire among hernia surgeons. Hernia 2008;12(3):2235.
12 Courtney CA, Lee AC, Wilson C, O'Dwyer PJ. Ventral hernia repair: a study of current practice. Hernia 2003;7(1):44-6.

13 van Ramshorst GH, Eker HH, Hop WCJ, Jeekel J, Lange JF. Impact of incisional hernia on health-related quality of life and body image: a prospective cohort study. Am J Surg 2012;204(2):144-50.

14 Mudge $M$, Hughes LE. Incisional hernia: a 10 year prospective study of incidence and attitudes. Br J Surg 1985;72(1):70-1.

15 Hoer J, Lawong G, Klinge U, Schumpelick V. Factors influencing the development of incisional hernia. A retrospective study of 2,983 laparotomy patients over a period of 10 years. Chirurg 2002;73(5):474-80.

16 Bickenbach KA, Karanicolas PJ, Ammori JB, Jayaraman S, Winter JM, Fields RC, Govindarajan A, Nir I, Rocha FG, Brennan MF. Up and down or side to side? A systematic review and meta-analysis examining the impact of incision on outcomes after abdominal surgery. Am J Surg 2013;206(3):400-9.

17 Ponten JEH, Somers KYA, Nienhuijs SW. Pathogenesis of the epigastric hernia. Hernia 2012;16(6):627-33.

18 Nieuwenhuizen J, Halm JA, Jeekel J, Lange JF. Natural course ofincisionalhernia andindications for repair. Scand J Surg 2007;96(4):293-6.

19 Schumacher OP, Peiper C, Lörken M, Schumpelick V. Long-term results after Spitzy's umbilical hernia repair. Chirurg 2003;74(1):50-4.

20 Burger JWA, Luijendijk RW, Hop WCJ, Halm JA, Verdaasdonk EGG, Jeekel J. Long-term followup of a randomized controlled trial of suture versus mesh repair of incisional hernia. Ann Surg 2004;240(4):578-83.

21 Hawn MT, Snyder CW, Graham LA, Gray SH, Finan KR, Vick CC. Long-term follow-up of technical outcomes for incisional hernia repair. J Am Coll Surg 2010;210(5):648-57.

22 Sauerland S, Walgenbach M, Habermalz B, Seiler CM, Miserez M. Laparoscopic versus open surgical techniques for ventral or incisional hernia repair. Cochrane Database Syst Rev 2011;(3):CD007781.

23 Eker HH, Hansson BME, Buunen M, Janssen IMC, Pierik REGJM, Hop WC, Bonjer HJ, Jeekel J, Lange JF. Laparoscopic vs. open incisional hernia repair: a randomized clinical trial. JAMA Surg 2013;148(3):259-63. 
24 Sanders DL, Kingsnorth AN. Prosthetic mesh materials used in hernia surgery. Expert Rev Med Dev 2012;9(2):159-79.

25 Bringman S, Conze J, Cuccurullo D, Deprest J, Junge K, Klosterhalfen B, Parra-Davila E, Ramshaw B, Schumpelick V. Hernia repair: the search for ideal meshes. Hernia 2010;14(1):81-7.

26 Parker MC, Ellis H, Moran BJ, Thompson JN, Wilson MS, Menzies D, McGuire A, Lower AM, Hawthorn RJ, O’Briena F, Buchan S, Crowe AM. Postoperative adhesions: ten-year follow-up of 12,584 patients undergoing lower abdominal surgery. Dis Colon Rectum 2001;44(6):822-9.

27 Hellebrekers BWJ, Kooistra T. Pathogenesis of postoperative adhesion formation. Br J Surg 2011;98(11):1503-16.

28 Szomstein S, Menzo Lo E, Simpfendorfer C, Zundel N, Rosenthal RJ. Laparoscopic lysis of adhesions. World J Surg 2006;30(4):535-40.

29 Wiseman DM, Trout JR, Diamond MP. The rates of adhesion development and the effects of crystalloid solutions on adhesion development in pelvic surgery. Fertil Steril 1998;70(4):702-11.

30 Halm JA, de Wall LL, Steyerberg EW, Jeekel J, Lange JF. Intraperitoneal polypropylene mesh hernia repair complicates subsequent abdominal surgery. World J Surg 2007;31(2):423-9.

31 Zühlke HV, Lorenz EM, Straub EM, Savvas V. Pathophysiology and classification of adhesions. Langenbecks Arch Chir Suppl II Verh Dtsch Ges Chir 1990;:1009-16.

32 Luijendijk RW, de Lange DC, Wauters CC, Hop WC, Duron JJ, Pailler JL, Camprodon BR, Holmdahl L, van Geldorp HJ, Jeekel J. Foreign material in postoperative adhesions. Ann Surg 1996;223(3):242-8.

33 de Vos van Steenwijk PJ, Bonthuis F, Marquet RL, Steyerberg EW, Jeekel J, Bonjer HJ. Prevention of adhesion to prosthetic mesh: comparison of different barriers using an incisional hernia model. Ann Surg 2003;237(1):123-8.
34 Karabulut B, Sönmez K, Türkyilmaz Z, Demiroğullari B, Karabulut R, Sezer C, Sultan N, Başaklar AC, Kale N. Omentum prevents intestinal adhesions to mesh graft in abdominal infections and serosal defects. Surg Endosc 2006;20(6):978-82.

35 Conze J, Junge K, Klinge U, Weiss C, Polivoda M, Oettinger AP, Schumpelick V. Intraabdominal adhesion formation of polypropylene mesh. Influence of coverage of omentum and polyglactin. Surg Endosc 2005;19(6):798-803.

36 Klinge U, Klosterhalfen B. Modified classification of surgical meshes for hernia repair based on the analyses of 1,000 explanted meshes. Hernia 2012;16(3):251-8.

37 Jenkins ED, Yom V, Melman L, Brunt LM, Eagon JC, Frisella MM, Matthews BD. Prospective evaluation of adhesion characteristics to intraperitoneal mesh and adhesiolysisrelated complications during laparoscopic reexploration after prior ventral hernia repair. Surg Endosc 2010;24(12):3002-7.

38 Gray SH, Vick CC, Graham LA, Finan KR, Neumayer LA, Hawn MT. Risk of complications from enterotomy or unplanned bowel resection during elective hernia repair. Arch Surg 2008;143(6):582-6.

39 LeBlanc KA, Elieson MJ, Corder JM. Enterotomy and mortality rates of laparoscopic incisional and ventral hernia repair: a review of the literature. JSLS 2007;11(4):408-14.

40 Kosaka H, Yoshimoto $\mathrm{T}$, Yoshimoto $\mathrm{T}$, Fujimoto J, Nakanishi K. Interferon-gamma is a therapeutic target molecule for prevention of postoperative adhesion formation. Nat Med 2008;14(4):437-41.

41 Thevenot PT, Baker DW, Weng H, Sun M-W, Tang L. The pivotal role of fibrocytes and mast cells in mediating fibrotic reactions to biomaterials. Biomaterials 2011;32(33):8394-403. 


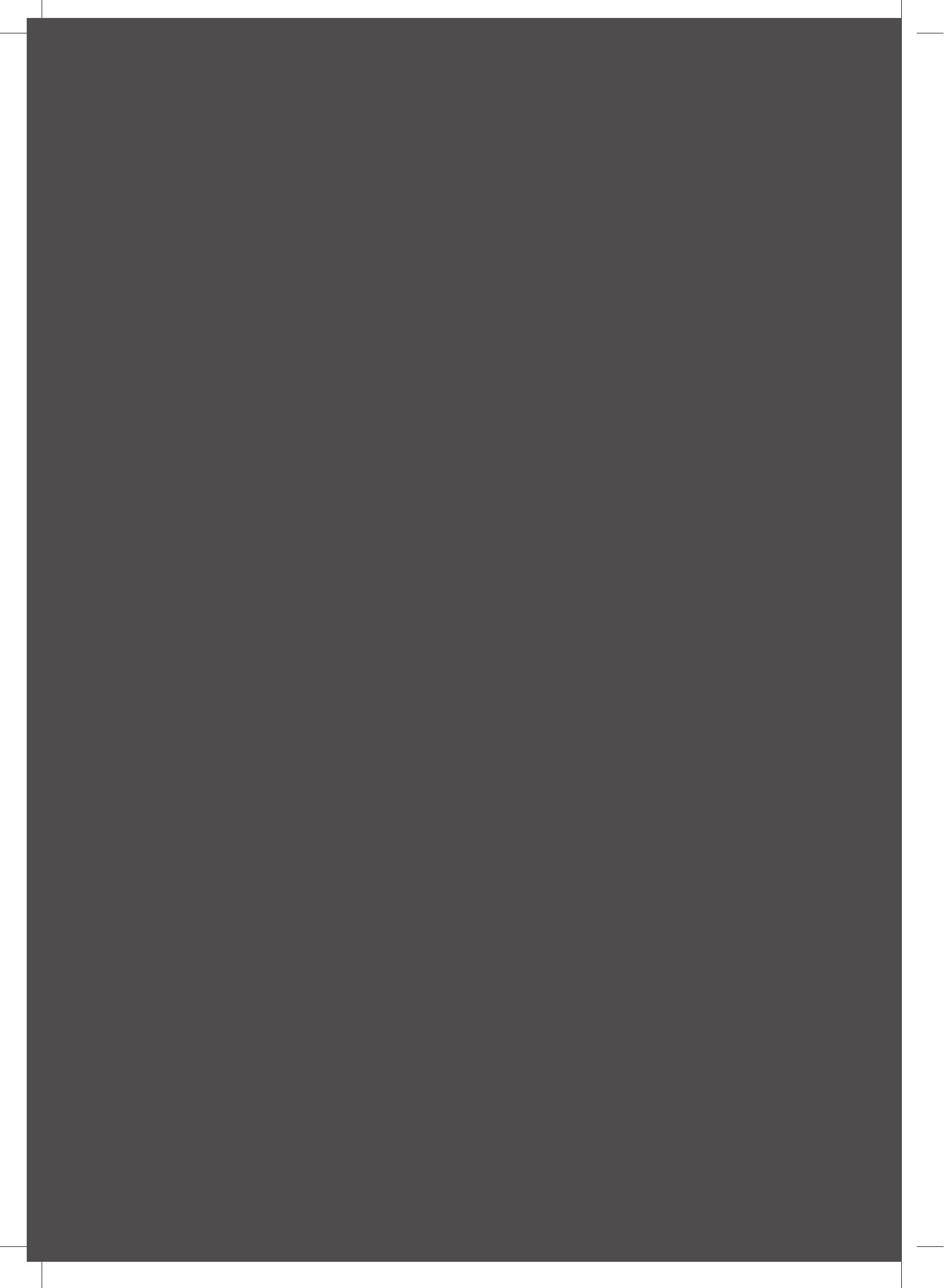




\section{PART 1}

Clinical problem

and awareness

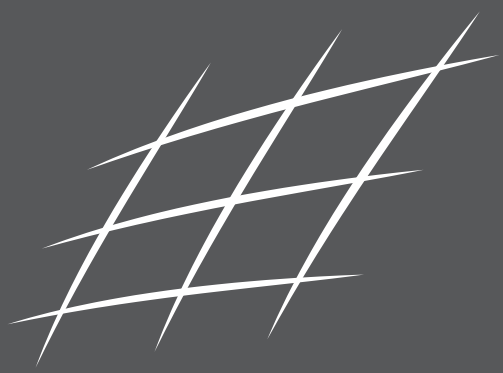




\title{
Chapter 2
}

\author{
Enterotomy risk \\ in abdominal wall repair: \\ a prospective study
}

M. H. Schreinemacher ${ }^{1, *}$

R. P. ten Broek ${ }^{2, *}$

A. P. Jilesen ${ }^{2}$

N. D. Bouvy ${ }^{1}$

R. P. Bleichrodt ${ }^{2}$

H. van Goor ${ }^{2}$

Annals of Surgery 2012

\section{Affiliations}

${ }^{1}$ Department of Surgery, Maastricht University Medical Centre, Maastricht, The Netherlands. ${ }^{2}$ Department of Surgery, Radboud University Nijmegen Medical Centre, Nijmegen, The Netherlands.

* contributed equally 


\section{Abstract}

\section{Objectives}

To establish the incidence and predictive factors of enterotomy made during adhesiolysis in abdominal wall repair and to assess the impact of enterotomies and long-lasting adhesiolysis on postoperative morbidity such as sepsis, wound infection, abdominal complications and pneumonia, and socioeconomic costs.

\section{Background}

Adhesions frequently complicate surgical repair of abdominal wall hernia. Enterotomies made during adhesiolysis specifically have a large impact on morbidity of patients, especially surgical site infections. Little is known on the incidence and burden of enterotomies and long-lasting adhesiolysis in abdominal wall repair.

\section{Methods}

Between June 2008 and June 2010 demographics, disease characteristics and perioperative data of all patients undergoing elective abdominal wall repair were included in a prospective cohort study that was focused on adhesiolysis-related problems. A trained researcher observed all surgeries and collected data on adhesion location, tenacity, adhesiolysis time, and inadvertent organ damage such as enterotomies. Primary outcome was the incidence of enterotomy, and predictive factors for enterotomy were assessed through univariate and multivariate analyses. In addition, we evaluated the impact of adhesiolysis and enterotomy on morbidity.

\section{Results}

A cohort of 133 abdominal wall repairs was analysed. Adhesiolysis was required in 124 (93.2\%), with a mean adhesiolysis time of $35.7 \pm 29.8$ minutes. Thirty-three enterotomies were made in 17 patients (12.8\%). Two patients had a delayed diagnosed bowel perforation. Adhesiolysis time, hernia size greater than $10 \mathrm{~cm}$, and fistula were significant predictive factors in univariate analysis. In multivariate analysis, only adhesiolysis time was a significant and independent predictive factor for enterotomy $(P=0.004)$. Trends toward an increased risk were seen for patients with mesh in situ and hernia size greater than $10 \mathrm{~cm}$. Patients with enterotomy had significantly more urgent reoperations $(P=0.029)$, and they more often required parenteral feeding $(P=0.037)$. Moreover, patients with extensive adhesiolysis (adhesiolysis time, $>30$ minutes) more often suffered from wound infection ( $9 / 63$ vs $2 / 70 ; P=0.025$ ), abdominal complications (5/63 vs $0 / 70 ; P=0.022)$, and sepsis ( $4 / 63$ vs $0 / 70 ; P=0.048)$. 


\section{Conclusions}

One in 8 patients undergoing abdominal wall repair suffer inadvertent enterotomy following adhesiolysis. Adhesiolysis time predicts enterotomy. Morbidity in patients with extensive

adhesiolysis and adhesiolysis complicated by enterotomy is high, inducing longer hospital stay and increased health care utilization. 


\section{Introduction}

Abdominal wall defect is a common indication for surgery and poses a significant health problem. Incisional ventral hernia is the most frequent abdominal wall defect and occurs in about $10 \%$ to $20 \%$ of patients undergoing open surgery ${ }^{1,2}$. The incidence might even by higher in obese patients and after recurrent abdominal surgeries ${ }^{1-3}$. Symptoms of incisional ventral hernia include pain and discomfort at the hernia site, limitations in daily activities, and intestinal obstruction. A complex incisional ventral wall hernia may present with enterocutaneous fistula-associated problems such as skin infection, wound care difficulties, and malnutrition ${ }^{4}$.

About one third of patients with ventral hernia undergo surgical repair by synthetic mesh, autologous tissue repair, or a combination of both ${ }^{5-7}$. Short-term complications of repairs are frequent and include postoperative haemorrhage, seroma formation, surgical site infection, and mesh infection ${ }^{7-11}$.

A largely neglected intraoperative complication of both open and laparoscopic abdominal wall repair is an inadvertent enterotomy following adhesiolysis ${ }^{12}$. Enterotomy increases the risk for unplanned enterectomy, wound infection, reoperations, and fistula formation and jeopardizes reconstruction with mesh. In a retrospective study of repeat laparotomy after all types of abdominal surgery, inadvertent enterotomy was correlated with a high number of complications, urgent reoperations, intensive care unit (ICU) admissions, and need for parenteral feeding ${ }^{13}$. The mortality rate of patients with inadvertent enterotomies varies between $8 \%$ and $50 \%$, depending on whether the enterotomy is recognized immediately during surgery or with delay in the postoperative phase ${ }^{9}$.

With a reported incidence of $90 \%$ adhesions after intraperitoneal surgery, adhesiolysis is an expected part of incisional ventral hernia repair ${ }^{14,15}$. The close proximity of the scarred skin, peritoneum, and bowel in patients with ventral hernia poses the bowel at risk to be injured at open abdominal entry or trocar insertion for laparoscopic repair. Inadvertent enterotomy has been reported in about $2 \%$ to $7 \%$ of patients with elective hernia repair, but in case of recurrent and complicated hernia surgery, this percentage seemed even higher ${ }^{9,10,16,17}$.

Little is known about the clinical and socioeconomic burden of adhesiolysis and inadvertent enterotomy in ventral hernia repair. One review reported the combined incidence of enterotomies from a multitude of mostly smaller series of ventral hernia repair ${ }^{9}$. Two studies specifically reviewed the incidence in larger cohorts of patients on the basis of operation codes and notes of mortality and morbidity rounds ${ }^{10,18}$. However, bias due to self-reporting and the retrospective nature of these studies might have led to an underestimation of the problem.

Knowing the impact of adhesiolysis and the incidence and morbidity of inadvertent enterotomy is important to make decisions in abdominal wall repair and to increase the awareness of adhesions, inducing complications during peritoneal surgery. In addition, the patient consent process requires surgeons to adequately inform patients undergoing incisional ventral hernia repair of risks associated with adhesiolysis.

We aimed to prospectively assess the incidence of inadvertent enterotomy in a large group of consecutive patients undergoing abdominal wall repair and to identify possible 
predictive factors. We analysed the impact of adhesiolysis and inadvertent enterotomy on morbidity and mortality, and health care utilization.

\section{Methods and Materials}

\section{Study design}

This was a prospective observational study as part of the LAParotomy or LAParoscopy and ADhesions (LAPAD) study (clinicaltrials.gov registration number NCT01236625). The LAPAD study was designed to assess the incidence and impact of adhesiolysis on operative and postoperative complications, quality of life, and socioeconomic costs. All adult competent patients undergoing elective laparotomy or laparoscopy admitted to the surgical ward between June 1, 2008, and June 2, 2010, at the Department of Surgery of the Radboud University Nijmegen Medical Centre, Nijmegen, the Netherlands, were eligible for participation in the LAPAD study. Surgical patients treated in day care were not screened for eligibility because early postoperative follow-up for complications was not adequate. During the operation, detailed information of adhesions, adhesiolysis, and inadvertent organ damage was collected through direct observation by a trained researcher (R.B.) not taking part in the surgery. Relevant data related to patients and to surgical and medical procedures were prospectively assessed during hospital stay and at the outpatient clinic until 6 months after discharge. Operative and treatment decisions were taken according to department guidelines or at the discretion of the surgical staff. In all cases, both sharp dissection and electrocautery were used for adhesiolysis. As a rule, however, electrocautery was avoided in dense adhesions (Zühlke score 3 and 4 ) to prevent bowel injury from thermal injury and necrosis ${ }^{19,20}$. The study was approved by the local medical ethical committee and conducted according to the revised version of the Declaration of Helsinki (October 2008, Seoul).

\section{Cohort selection}

For each patient participating in the LAPAD study, the planned and actual operative procedures were noted using the hospitals operation coding system. The indications for the procedure were defined following the International Statistical Classification of Diseases and Related Health Problems, version 10 (ICD-10). The current study group was selected by actual operative procedure codes related to the ventral abdominal wall. Consecutive patients with the diagnosis ventral hernia or abdominal wall defect, who consented, were included. The last repair in patients who underwent more than 1 ventral abdominal wall repair in the study period was analysed and the other repairs were regarded previous operations.

Our department is a tertiary referral centre for patients with abdominal wall defects complicated by infection, enterocutaneous fistula, loss of domain, and severe comorbidity. Therefore, overall results might overestimate those obtained in an average population of ventral hernia repair. To address this potential bias, we separately analysed all primary and secondary outcomes in a subgroup of patients who underwent repair of an uncomplicated 
midline incisional hernia. Uncomplicated was defined as no wound infection, no enterocutaneous fistula, and no further surgical procedure at repair.

\section{Outcome measures}

Primary outcome was the incidence of inadvertent enterotomy.

Inadvertent enterotomy was defined as every iatrogenic unintended full-thickness bowel defect detected during operation. Bowel defects from pre-existing fistulas or created while dissecting the bowel loop that harboured the fistula were not scored as inadvertent enterotomy.

Secondary outcomes were a delayed diagnosed perforation (DDP), the occurrence of serious adverse events (SAEs), and health care utilization. DDP was defined as a bowel defect with spill of gastrointestinal content that was diagnosed postoperatively by imaging, at reoperation or at autopsy, and which was not explained by anastomotic leakage or bowel ischemia.

SAEs were scored for their presence and number. Postoperative complications scored as a SAE were death, wound infection, urinary tract infection, pneumonia, sepsis, anastomotic leakage, bleeding, fistula, and abscess. SAEs were diagnosed according to the criteria of the ICD-10, the National Nosocomial Infections Surveillance System, the Center for Disease Control and Prevention, or according to the opinion of the senior medical staff of the department.

Health care utilization data included the number of patients requiring urgent surgical reintervention, parental feeding and admission to the ICU, total hospital stay, and ICU stay. Medication costs were calculated according to the standardized price list by the Dutch College of Health Insurance Companies updated for June 2008. Health care utilization outcomes were analysed for the subgroups of patients with and without enterotomy and patients with an adhesiolysis time shorter or longer than 30 minutes.

\section{Possible risk variables}

Demographic characteristics were gender (male, female), age (years), body mass index (BMI, $\mathrm{kg} / \mathrm{m}^{2}$ ), smoking habit (smoker, ex-smoker, non-smoker), and the Physiologic and Operative Severity Score for the enumeration of Mortality and Morbidity (P-POSSUM) (0\%-100\%).

Preoperative variables included use of corticosteroids, a history of peritonitis, presence of intestinal fistula, the number of previous abdominal operations, and the anatomical site of the last operation before the first hernia repair (lower abdominal, upper abdominal, gynaecological, urological, and none) according to the classification used by the Surgical and Clinical Adhesions Research group ${ }^{16,21}$. Hernia characteristics were obtained from the patient records and operation notes and the patient history including the number of previous repairs, the type of hernia (midline, not midline), the largest diameter of the hernia ( $\leq 10 \mathrm{~cm}$ or $>10 \mathrm{~cm}$ ), and the type (coated, non-coated) and location (intraperitoneal, extraperitoneal) of mesh used in previous repairs. Intraoperative variables included adhesiolysis time and adhesion score according to Zühlke et al: 0, no adhesions; 1, filmy adhesions; 2, stronger adhesions requiring some sharp dissection; 3 , dense vascularized adhesions requiring sharp dissection; 4 , extreme dense adhesions with high risk for organ 
damage during dissection ${ }^{22}$. Patients with a Zühlke score of 3 and 4 were compared with those with a score of 0,1 , or 2 .

\section{Statistical analysis}

Univariate and multivariate regression analyses were performed to identify risk factors for all patients suffering from one or more inadvertent enterotomies and separately for the subgroup of patients with an uncomplicated midline incisional hernia. Risk factors with $P \leq 0.300$ in univariate were selected as candidate risk factors for multivariate analysis. In multivariate analysis, a stepwise forward selection procedure was used with a $P$-entry $\leq 0.300$ and $P$-stay $\leq 0.100$. Discriminative value of the regression model was assessed by determining receiver operative characteristic (ROC) curve. We calculated the incidence of enterotomies per total adhesiolysis time, expressed as the time needed to harm. Characteristics of a continuous nature were reduced to a dichotomous nature with the median as cut-off. Health care utilization and SAE data were analysed with Kruskal-Wallis and Fisher's exact tests for continuous and dichotomous characteristics, respectively. SAEs and health care data were compared between patients with and without an enterotomy and between patients with and without extensive adhesiolysis. Extensive adhesiolysis was defined by adhesiolysis time, using the methods to determine the optimal cut point for research purposes described by Magder et $\mathrm{al}^{23}$. This method was applied on the odds ratio (OR) for incidence of SAE with cut points rounded at 5 minutes. We used SPSS for Windows ${ }^{\circledR}$ version 17.0 software (SPSS Inc., Chicago, IL) for statistical analysis. $P<0.050$ was considered significant.

\section{Results}

\section{Patient characteristics}

A total of 844 planned operations were eligible for inclusion in the LAPAD study. One hundred forty-three operations met the inclusion criteria repair of ventral hernia or abdominal wall defect. Eight patients were excluded because informed consent could not be obtained. Two patients had incisional hernia repair twice in the study period, resulting in 133 patients for analysis.

Five experienced surgeons performed all abdominal wall repairs either as primary surgeon or as assisting surgeon supervising a resident. No data were missing. Fourteen (10.5\%) patients underwent hernia repair by primary closure, 29 (21.8\%) by component separation technique, $66(49.6 \%)$ by mesh repair, and $24(18.0 \%)$ by a combination of component separation technique and mesh repair. Nine patients (6.7\%) underwent laparoscopic ventral hernia repair. Laparoscopy was converted in $2(22.2 \%)$ patients, for complicated adhesiolysis in one and difficulty with fixation of the mesh in the other.

One hundred twenty-nine patients (97.0\%) had a ventral incisional hernia, in 107 (82.9\%) in the midline. Three patients $(2.3 \%)$ had a parastomal hernia and one patient $(0.8 \%)$ had a primary umbilical hernia. In 20 patients (15.0\%), the hernia was complicated by enterocutaneous fistula. The hernia was larger than $10 \mathrm{~cm}$ in length or width in $69(51.8 \%)$ patients. 
Additional surgical procedures were done in $12(9.0 \%)$ patients, a bowel resection in 3 , a pancreas resection in 3, a liver resection in 3, an oesophageal resection in 1 , and a cholecystectomy and placement of a feeding jejunostomy each in 1 patient. Seventy-eight (58.6\%) patients had an uncomplicated incisional midline hernia and formed the subgroup.

Sixty-six (47.5\%) patients underwent repair of a recurrent hernia, 35 patients had one and 31 patients had multiple previous repairs. Forty-four (66.7\%) patients with recurrent hernia had a mesh in situ from a previous hernia repair, 18 (40.9\%) in an intraperitoneal and 26 (59.1\%) in an extraperitoneal position. Most intraperitoneal meshes contained an absorbable (50.0\%) or non-absorbable $(27.8 \%)$ antiadhesive layer. Fully absorbable mesh and mesh without antiadhesive properties were used in $11.1 \%$ of intraperitoneal mesh repair.

The anatomical area of the initial operation was lower abdominal in 74 (55.6\%), upper abdominal in $36(27.1 \%)$, gynaecological in 13 (9.8\%), and urological in $9(6.8 \%)$ patients. One patient with umbilical hernia $(0.8 \%)$ had no prior surgery (Table 1$)$.

\section{Inadvertent enterotomy, DDP, and adhesiolysis time}

A median number of 1 (range 1-9) enterotomies occurred in 17 of 133 patients (12.8\%). Eleven patients had small bowel enterotomies, 4 had large bowel enterotomies, and 2 patients had enterotomies in both small and large bowel. DDP occurred in 2 patients, one in whom also an enterotomy was detected during surgery. There were no enterotomies or DDPs in the laparoscopic group.

Surgical history was comparable between patients with and without an enterotomy. Nine (52.9\%) patients with enterotomy had a previous abdominal wall defect repair compared with 47 (49.1\%) patients without enterotomy; the number of patients with multiple repairs were 5 and 26, respectively $(P=0.814)$.

Enterotomies were made during the opening of the abdominal cavity in 4 patients. Two patients suffered enterotomies both during opening of the abdominal cavity and during subsequent adhesiolysis deeper in the abdominal cavity or along the peritoneal sidewalls. The remaining 11 patients had enterotomies after opening of the abdominal cavity, in 6 of them following resection of a previously placed mesh.

Adhesiolysis was done in 124 patients $(93.2 \%)$. Mean $( \pm$ SD) adhesiolysis time was $66.9 \pm 32.4$ minutes in patients with enterotomy versus $31 \pm 26.6$ minutes in patients without enterotomy $(P<0.001)$. Thirty-three inadvertent enterotomies were caused in 4750 minutes of adhesiolysis, corresponding with a cumulative incidence of 1 enterotomy after every 144 minutes of adhesiolysis. Adhesiolysis times were comparable for patients with intraperitoneal mesh, extraperitoneal mesh, or no mesh in situ (35.1 \pm 26.8 minutes, $39.4 \pm$ 32.0 minutes, and $34.8 \pm 30$ minutes, respectively; $P=0.747)$.

Tenacity of adhesions was high with 85 (63.9\%) patients having Zühlke scores more than 2 under the scar and 75 (56.4\%) further away. Extreme dense adhesions (Zühlke score 4) were found under the scar in 27 (20.3\%) patients and at the operative areas in 26 (19.5\%) patients. Fifty (37.6\%) patients had dense adhesions both under the scar and distant of the scar. 
Table 1. Patients with enterotomy and crude odds ratios from univariate logistic regression of risk factors for inadvertent enterotomy in the total group.

\begin{tabular}{|c|c|c|c|c|c|}
\hline & \multicolumn{2}{|c|}{ Inadvertent Enterotomy } & \multicolumn{3}{|c|}{ Univariate Analysis } \\
\hline & Yes & No & OR & $95 \% \mathrm{CI}$ & $P$ \\
\hline \multicolumn{6}{|l|}{ Demographics } \\
\hline \multicolumn{6}{|l|}{ Gender (female vs male) } \\
\hline Male & $11(14.3 \%)$ & $77(85.7 \%)$ & Ref. & & \\
\hline Female & $6(18.2 \%)$ & $33(87.2 \%)$ & 1.00 & $0.34-2.90$ & 0.998 \\
\hline $\operatorname{Age}^{\star}$ (each year increase) & $62 \pm 11.9$ & $58.5 \pm 12.1$ & 1.03 & $0.98-1.08$ & 0.267 \\
\hline Body Mass Index $\left(\mathrm{kg} / \mathrm{m}^{2}\right.$, each point increase) & $25.8 \pm 3.3$ & $27.9 \pm 5.1$ & 0.90 & $0.79-1.02$ & 0.098 \\
\hline \multicolumn{6}{|l|}{ Smoking } \\
\hline Non-smoker & $5(11.1 \%)$ & $40(88.9 \%)$ & Ref. & & \\
\hline ex-smoker & $10(16.7 \%)$ & $50(83.3 \%)$ & 1.60 & $0.51-5.06$ & 0.424 \\
\hline smoker & $2(7.4 \%)$ & $25(92.6 \%)$ & 0.64 & $0.12-3.55$ & 0.610 \\
\hline \multicolumn{6}{|l|}{ Patient history } \\
\hline \multicolumn{6}{|l|}{ Previous hernia corrections } \\
\hline None & $8(11.9 \%)$ & $59(88.1 \%)$ & Ref. & & \\
\hline Single & $4(11.4 \%)$ & $31(88.6 \%)$ & 0.95 & $0.27-3.41$ & 0.940 \\
\hline Multiple & $5(16.1 \%)$ & $26(83.9 \%)$ & 1.42 & $0.42-4.75$ & 0.570 \\
\hline Number of previous operations (each $\mathrm{n}$ increase) & $4(2-7)$ & $3(0-14)$ & 1.15 & $0.93-1.41$ & 0.193 \\
\hline \multicolumn{6}{|l|}{ Surgical experience } \\
\hline Surgeon & $11(13.6 \%)$ & $70(86.4 \%)$ & Ref. & & \\
\hline Resident & $6(11.5 \%)$ & $46(88.5 \%)$ & 0.83 & $0.29-2.40$ & 0.731 \\
\hline P-Possum score ${ }^{\star}$ (\% increase) & $4.0 \pm 5.3$ & $3.4 \pm 6.9$ & 1.01 & $0.95-1.10$ & 0.704 \\
\hline \multicolumn{6}{|l|}{ Corticosteroid use } \\
\hline No & $17(13.4 \%)$ & $110(86.6 \%)$ & Ref. & & \\
\hline Yes & $0(0 \%)$ & $6(100 \%)$ & 0.00 & $0.00-\mathrm{NA}$ & $>0.999$ \\
\hline \multicolumn{6}{|l|}{ Peritonitis in history } \\
\hline No & $12(11.7 \%)$ & $91(88.3 \%)$ & Ref. & & \\
\hline Yes & $5(16.7 \%)$ & $25(83.3 \%)$ & 1.52 & $0.49-4.71$ & 0.471 \\
\hline \multicolumn{6}{|l|}{ Index operation } \\
\hline Lower abdominal & $10(13.5 \%)$ & $64(86.5 \%)$ & Ref. & & \\
\hline Upper abdominal & $4(11.1 \%)$ & $32(88.9 \%)$ & 0.80 & $0.23-2.75$ & 0.800 \\
\hline Gynaecological & $2(15.4 \%)$ & $11(84.6 \%)$ & 1.16 & $0.22-6.04$ & 0.857 \\
\hline Urological & $1(11.1 \%)$ & $8(88.9 \%)$ & 0.84 & $0.09-7.10$ & 0.800 \\
\hline None & $0(0 \%)$ & $1(12.8 \%)$ & 0.00 & $0.00-\mathrm{NA}$ & $>0.999$ \\
\hline \multicolumn{6}{|l|}{ Operative characteristics } \\
\hline \multicolumn{6}{|l|}{ Type of hernia } \\
\hline Other & $2(6.5 \%)$ & $29(93.5 \%)$ & Ref. & & \\
\hline Median & $15(14.7 \%)$ & $87(85.3 \%)$ & 2.50 & $0.54-11.59$ & 0.242 \\
\hline Adhesiolysis time $^{*}$ (each minute increase) & $66.9 \pm 32.4$ & $31.1 \pm 26.6$ & 1.03 & $1.02-1.05$ & $<0.001$ \\
\hline \multicolumn{6}{|l|}{ Zühlke score ${ }^{* *}$} \\
\hline$\leq 2$ & $8(9.6 \%)$ & $75(90.4 \%)$ & Ref. & & \\
\hline$>2$ & $9(18.0 \%)$ & $41(82.0 \%)$ & 2.06 & $0.73-5.73$ & 0.168 \\
\hline \multicolumn{6}{|l|}{ Mesh in situ } \\
\hline no & $9(10.1 \%)$ & $80(89.9 \%)$ & Ref. & & \\
\hline yes & $8(18.2 \%)$ & $36(81.8 \%)$ & 1.95 & $0.70-5.47$ & 0.204 \\
\hline \multicolumn{6}{|l|}{ Fistula } \\
\hline No & $10(8.8 \%)$ & $103(91.2 \%)$ & Ref. & & \\
\hline Yes & $7(35.0 \%)$ & $13(65 \%)$ & 5.55 & $1.80-17.08$ & 0.003 \\
\hline \multicolumn{6}{|l|}{ Size } \\
\hline$\leq 10 \mathrm{~cm}$ & $2(3.1 \%)$ & $62(96.9 \%)$ & Ref. & & \\
\hline$>10 \mathrm{~cm}$ & $15(21.7 \%)$ & $54(78.3 \%)$ & 8.61 & $1.88-39.37$ & 0.005 \\
\hline
\end{tabular}

${ }^{\star}$ Values are mean $(\mathrm{SD})$ or ${ }^{* \star}$ median (range). Ref.: Reference. 
Adhesiolysis time, the presence of a fistula, and hernia size greater than $10 \mathrm{~cm}$ were significant risk factors in the univariate analysis (Table 1). These and the factors age, BMI, the number of previous abdominal operations, a midline hernia, and the presence of mesh, with a $P<0.300$, were included in the multivariate analysis. Subdivision of the location of the mesh (ie, intraperitoneal or extraperitoneal) was not presented in the final multivariate analysis because it did not result in any significant changes and did not improve the model (intraperitoneal vs extraperitoneal mesh, OR 0.84; 95\% Confidence Interval [CI] 0.17-4.0-7; $P=0.828$ ).

Multivariate stepwise regression analysis revealed adhesiolysis time as independent and significant risk factor for incidence of inadvertent enterotomy [OR (95\% CI): 1.03 (1.011.05) for each minute increase in adhesiolysis time]. There was a trend toward a higher incidence of enterotomy in patients with mesh in situ and a hernia size greater than $10 \mathrm{~cm}$. A trend toward a lower incidence was found in patients with higher BMI (Table 2). The area under the ROC curve of the multivariate model was 0.87 (95\% CI 0.79-0.96).

Eight $(10.3 \%)$ patients had a median of one enterotomy (range 1-9) in the subgroup of patients with uncomplicated midline incisional hernia. Again, adhesiolysis time was a significant risk factor in univariate analysis with an OR 1.04 (95\% CI 1.02-1.07; $P=0.002$ ) for each minute increase in adhesiolysis time. There was a trend toward increased enterotomy incidence in patients with mesh present [mesh 5/25 (20\%) vs no mesh 3/53 (5.7\%); OR 4.2; 95\% CI 0.9-19.1; $P=0.066$ ]. In multivariate analysis, adhesiolysis time and mesh presence were significant risk factors (OR 1.05; 95\% CI 1.02-1.09; $P=0.004$ and OR 7.4; $95 \%$ CI $1.0-53.0 ; P=0.047$, respectively). The area under the ROC curve was 0.90 (95\% CI 0.81-0.98).

Table 2. Adjusted odds ratios from stepwise multivariate logistic regression of risk factors for inadvertent enterotomy in the total group and subgroup.

\begin{tabular}{|c|c|c|c|c|c|c|}
\hline & \multicolumn{3}{|c|}{ Total group } & \multicolumn{3}{|c|}{ Subgroup } \\
\hline & OR & $95 \% \mathrm{CI}$ & $P$ & OR & $95 \% \mathrm{CI}$ & $P$ \\
\hline \multicolumn{7}{|l|}{ Demographics } \\
\hline Age (each year increase) & NS & NS & NS & NA & NA & NA \\
\hline BMI $\left(\mathrm{kg} / \mathrm{m}^{2}\right.$, each point increase $)$ & 0.86 & $0.72-1.02$ & 0.076 & NA & NA & NA \\
\hline \multicolumn{7}{|l|}{ Patient history } \\
\hline Number of previous operations (each $\mathrm{n}$ increase) & NS & NS & NS & NS & NS & NS \\
\hline \multicolumn{7}{|l|}{ Operative characteristics } \\
\hline Type of hernia (median vs other) & NS & NS & NS & NA & NA & NA \\
\hline Adhesiolysis time (each minute increase) & 1.03 & $1.01-1.05$ & 0.004 & 1.04 & $1.02-1.07$ & 0.002 \\
\hline Zühlke score ( $>2$ vs $\leq 2$ ) & NS & NS & NS & NS & NS & NS \\
\hline Mesh in situ (yes vs no) & 3.28 & $0.93-11.61$ & 0.066 & 7.371 & $1.03-53.0$ & 0.047 \\
\hline Fistula (yes vs no) & NS & NS & NS & NA & NA & NA \\
\hline Size $(>10 \mathrm{~cm}$ vs $\leq 10 \mathrm{~cm})$ & 5.19 & $0.97-27.68$ & 0.054 & NS & NS & NS \\
\hline
\end{tabular}

OR: Odds Ratio. CI: Confidence Interval. NS: not selected for model in stepwise multivariate analysis. NA: not applicable as candidate risk factor in the subgroup analysis $(P>0.300$ in univariate). 


\section{Impact of enterotomy}

Eight $(47.1 \%)$ patients with an enterotomy underwent enterectomy. Bowel resection in patients without enterotomy was mostly done as part of resection of an enterocutaneous fistula. There were no anastomotic leakages related to bowel resection for enterotomy. Two patients (1.5\%) died during hospital admission; one of these patients had experienced an enterotomy and a DDP. Cause of death was haemorrhage after a long and complicated ICU stay. The other patient died from pneumonia.

Patients with an inadvertent enterotomy experienced significantly higher rates of complications requiring urgent surgical reintervention and parenteral feeding (38.9\% vs $12.9 \% ; P=0.029$ and $35.6 \%$ vs $13.8 \% ; P=0.037$, respectively) than patients without an enterotomy (Table 3 ). Total hospital stay of patients with enterotomy was significantly longer (20.8 \pm 35.0 vs $8.6 \pm 10.6$ days, $P=0.002)$ and costs of in-hospital prescribed medication were higher ( $€ 1178 \pm 3207$ vs $€ 250 \pm 475, P<0.001)$. The increase in medication costs was mainly due to increased use of intravenous antibiotics.

In $6(35 \%)$ patients with an enterotomy but no gross spillage of intestinal content, an extraperitoneal mesh was placed during hernia repair. In one of the patients, the mesh was removed 2 days after surgery in an acute setting because of a DDP. In another patient, the mesh was removed after 3 months because of fistula formation. One patient presented at the emergency department 2 weeks postoperatively with wound infection, but no excision of mesh was required. The other 3 patients did not suffer from any complications.

Optimal cut point for extensive adhesiolysis was 30 minutes. Sixty-three (47.4\%) patients had an adhesiolysis time longer than 30 minutes, and these patients had significantly more complications than those with adhesiolysis time shorter than 30 minutes (38.1\% vs $21.4 \%$; $P=0.038$ ). Patients with adhesiolysis more than 30 minutes experienced a significantly

Table 3. Impact of adhesiolysis complicated by enterotomy on clinical outcomes and costs.

\begin{tabular}{lccc}
\hline Outcome & $\begin{array}{c}\text { Enterotomy } \\
(\mathbf{n}=\mathbf{1 7})\end{array}$ & $\begin{array}{c}\text { No enterotomy } \\
(\mathbf{n}=\mathbf{1 1 6})\end{array}$ & $P$ \\
\hline Patients with SAE (n) & $7(41.2 \%)$ & $32(27.6 \%)$ & 0.264 \\
Sepsis & $2(11.8 \%)$ & $2(1.7 \%)$ & 0.079 \\
Wound infection & $2(11.8 \%)$ & $9(7.8 \%)$ & 0.632 \\
Abscess/ fistula/ leakage & $2(11.8 \%)$ & $3(2.6 \%)$ & 0.122 \\
Urinary tract infection & $1(5,6 \%)$ & $5(4.3 \%)$ & 0.567 \\
Pneumonia & $3(17.6 \%)$ & $15(12.9 \%)$ & 0.702 \\
Haemorrhage & $1(5.9 \%)$ & $10(8.6 \%)$ & $>0.999$ \\
Death & $1(5.9 \%)$ & $1(0.9 \%)$ & 0.240 \\
ICU admissions $(\mathrm{n})$ & $5(29.4 \%)$ & $17(14.7 \%)$ & 0.159 \\
Reinterventions $(\mathrm{n})$ & $\mathbf{6}(\mathbf{3 5 . 3 \% )}$ & $\mathbf{1 5}(\mathbf{1 2 . 9 \% )}$ & $\mathbf{0 . 0 2 9}$ \\
Parenteral feeding $(\mathrm{n})$ & $\mathbf{6}(\mathbf{3 5 . 3} \%)$ & $\mathbf{1 6}(\mathbf{1 3 . 8 \% )}$ & $\mathbf{0 . 0 3 7}$ \\
Hospital stay (days) & $\mathbf{2 0 . 8 \pm 3 5 . 0}$ & $\mathbf{8 . 6 \pm 1 0 . 6}$ & $\mathbf{0 . 0 0 2}$ \\
ICU stay (days) & $10.7 \pm 36.2$ & $1.0 \pm 4.0$ & 0.096 \\
Medication costs $(€)$ & $\mathbf{1 1 7 8 \pm 3 2 0 7}$ & $250 \pm 475$ & $<\mathbf{0 . 0 0 1}$ \\
\hline
\end{tabular}

Means \pm SD 
higher rate of sepsis (6.3\% vs $0 \% ; P=0.048)$, wound infection ( $14.3 \%$ vs $2.9 \% ; P=0.025)$, and abdominal complications (fistula, abdominal abscess, and anastomotic leakage; $7.9 \%$ 2 vs $0 \% ; P=0.022$ ) than those with an adhesiolysis less than 30 minutes (Table 4). Excluding patients with an enterotomy or DDP, adhesiolysis of 30 minutes or longer still was associated with a higher number of ICU admissions (25.0\% vs 7.4\%; $P=0.015$ ), a greater need for parenteral feeding $(29.2 \%$ vs $2.9 \% ; P<0.001)$, a longer total hospital stay $(12.8 \pm 14.7$ vs 5.6 \pm 4.5 days; $P=0.001)$ and ICU stay $(2.1 \pm 5.9$ vs $0.2 \pm 1.2$ days; $P=0.006)$ and higher costs from in-hospital prescribed medication ( $€ 421 \pm 644$ vs $€ 129 \pm 248 ; P<0.001$ ).

In the subgroup of 78 patients with an uncomplicated incisional hernia, no significant differences in the incidence of SAEs could be found between enterotomy and no enterotomy (Table 5). The 8 patients with enterotomy had a longer hospital stay (26.0 \pm 51.4 vs $17.4 \pm$ 10.7 days; $P=0.030)$ and higher medication costs $(€ 1887 \pm 4690$ vs $€ 215 \pm 395 ; P=0.030)$ compared with those without enterotomy. Patients with adhesiolysis time longer than 30 minutes were admitted more frequently to the ICU (22.9\% vs $4.7 \% ; P=0.037)$, had longer ICU stay ( $5.8 \pm 25.5$ vs $0.2 \pm 1.1$ days; $P<0.001)$, a longer total hospital stay $(14.7 \pm 28.0$ vs $4.9 \pm 2.9$ days; $P<0.001)$, and higher medication cost $(€ 720 \pm 228$ vs $€ 114 \pm 176 ; P<0.001)$.

\section{Discussion}

Open abdominal wall hernia repair is associated with extensive adhesiolysis leading to inadvertent organ damage in about 1 of 8 patients. Adhesiolysis time, most likely reflecting the difficulty of the repair procedure, was a significant and independent risk factor for enterotomy both in the whole group and in patients with uncomplicated midline incisional

Table 4. Impact of adhesiolysis ( $\geq 30 \mathrm{~min}$ ) on clinical outcomes and costs in the total group.

\begin{tabular}{|c|c|c|c|c|c|}
\hline Outcome & $\begin{array}{l}\text { Adhesiolysis } \\
<30 \mathrm{~min} \\
(\mathrm{n}=70)\end{array}$ & $\begin{array}{l}\text { Adhesiolysis } \\
\quad \geq 30 \text { min } \\
(n=63)\end{array}$ & $P$ & $\begin{array}{l}\text { Adhesiolysis } \geq 30 \mathrm{~min} \text {, } \\
\text { without enterotomy or DDP } \\
(\mathrm{n}=48)\end{array}$ & $P$ \\
\hline Patients with SAE (n) & $15(21.4 \%)$ & $24(38.1 \%)$ & 0.038 & $17(35.4 \%)$ & 0.141 \\
\hline Sepsis & $0(0 \%)$ & $4(6.3 \%)$ & 0.048 & $2(4.2 \%)$ & 0.169 \\
\hline Wound infection & $2(2.9 \%)$ & $9(14.3 \%)$ & 0.025 & $7(14.6 \%)$ & 0.032 \\
\hline Abscess/ fistula/ leakage & $0(0 \%)$ & $5(7.9 \%)$ & 0.022 & $3(6.2 \%)$ & 0.068 \\
\hline Urinary tract infection & $1(1.4 \%)$ & $5(7.9 \%)$ & 0.101 & $4(8.3 \%)$ & 0.158 \\
\hline Pneumonia & $7(10 \%)$ & $11(17.5 \%)$ & 0.310 & $8(16.7 \%)$ & 0.402 \\
\hline Haemorrhage & $6(8.6 \%)$ & $5(7.9 \%)$ & $>0.999$ & $4(8.3 \%)$ & $>0.999$ \\
\hline Death & $1(1.4 \%)$ & $1(1.6 \%)$ & $>0.999$ & $0(0.0 \%)$ & $>0.999$ \\
\hline ICU admissions (n) & $5(7.1 \%)$ & $17(27.0 \%)$ & 0.002 & $12(25.0 \%)$ & 0.015 \\
\hline Reinterventions (n) & $5(7.1 \%)$ & $16(25.4 \%)$ & 0.004 & $10(20.8 \%)$ & 0.048 \\
\hline Parenteral feeding (n) & $2(2.9 \%)$ & $20(31.7 \%)$ & 0.001 & $14(29.2 \%)$ & $<0.001$ \\
\hline Hospital stay (days) & $5.6 \pm 4.5$ & $15.2 \pm 22.2$ & $<0.001$ & $12.8 \pm 14.7$ & $<0.001$ \\
\hline ICU stay (days) & $0.2 \pm 1.2$ & $4.5 \pm 22.2$ & 0.002 & $2.1 \pm 5.9$ & 0.006 \\
\hline Medication costs $(€)$ & $128 \pm 244$ & $636 \pm 1754$ & $<0.001$ & $421 \pm 644$ & $<0.001$ \\
\hline
\end{tabular}

Means \pm SD. DDP: delayed diagnosed perforation. 
Table 5. Impact of adhesiolysis complicated by enterotomy and of adhesiolysis ( $\geq 30 \mathrm{~min}$ ) on clinical outcomes and costs in the subgroup.

\begin{tabular}{|c|c|c|c|c|c|c|}
\hline Outcome & $\begin{array}{l}\text { Adhesiolysis } \\
<30 \mathrm{~min} \\
(\mathrm{n}=43)\end{array}$ & $\begin{array}{l}\text { Adhesiolysis } \\
\geq 30 \mathrm{~min} \\
(\mathrm{n}=35)\end{array}$ & $P$ & $\begin{array}{c}\text { No } \\
\text { enterotomy } \\
(n=70)\end{array}$ & $\begin{array}{l}\text { enterotomy } \\
\quad(n=8)\end{array}$ & $P$ \\
\hline Patients with SAE (n) & $11(25.6 \%)$ & $9(25.7 \%)$ & $>0.999$ & $17(24.3 \%)$ & $3(37.5 \%)$ & 0.416 \\
\hline Sepsis & $0(0.0 \%)$ & $2(5.7 \%)$ & 0.198 & $1(1.4 \%)$ & $1(12.5 \%)$ & 0.196 \\
\hline Wound infection & $1(2.3 \%)$ & $2(5.7 \%)$ & 0.585 & $2(2.9 \%)$ & $1(12.5 \%)$ & 0.280 \\
\hline Abscess/ fistula/ leakage & $0(0.0 \%)$ & $1(2.9 \%)$ & 0.449 & $0(0 \%)$ & $1(12.5 \%)$ & 0.103 \\
\hline Urinary tract infection & $1(2.3 \%)$ & $1(2.3 \%)$ & 0.585 & $3(4.3 \%)$ & $0(0 \%)$ & $>0.999$ \\
\hline Pneumonia & $6(14.0 \%)$ & $5(14.3 \%)$ & $>0.999$ & $9(12.9 \%)$ & $2(25.0 \%)$ & 0.314 \\
\hline Haemorrhage & $3(7.0 \%)$ & $2(5.7 \%)$ & $>0.999$ & $4(5.7 \%)$ & $1(12.5 \%)$ & 0.427 \\
\hline Death & $1(2.3 \%)$ & $1(2.9 \%)$ & $>0.999$ & $1(1.4 \%)$ & $1(12.5 \%)$ & 0.196 \\
\hline ICU admissions ( $\mathrm{n}$ ) & $1(2.3 \%)$ & $5(14.3 \%)$ & 0.037 & $8(11.4 \%)$ & $2(25.0 \%)$ & 0.271 \\
\hline Reinterventions (n) & $3(7.0 \%)$ & $6(17.1 \%)$ & 0.285 & $7(10.0 \%)$ & $2(25.0 \%)$ & 0.229 \\
\hline Parenteral feeding (n) & $1(2.3 \%)$ & $5(14.3 \%)$ & 0.084 & $5(7.1 \%)$ & $1(12.5 \%)$ & 0.496 \\
\hline Hospital stay (days) & $4.9 \pm 2.9$ & $14.7 \pm 28.0$ & $<0.001$ & $17.4 \pm 10.7$ & $26.0 \pm 51.4$ & 0.212 \\
\hline ICU stay (days) & $0.20 \pm 1.1$ & $5.8 \pm 25.5$ & $<0.001$ & $0.73 \pm 3.0$ & $20.1 \pm 52.6$ & 0.030 \\
\hline Medication costs $(€)$ & $114 \pm 176$ & $720 \pm 228$ & $<0.001$ & $215 \pm 395$ & $1887 \pm 4690$ & 0.030 \\
\hline
\end{tabular}

Means \pm SD.

hernia. Adhesiolysis complicated by enterotomy and a long during adhesiolysis adversely affected important clinical and socioeconomic aspects of patient convalescence.

The incidence of enterotomy was unexpectedly high. Jenkins et al evaluated laparoscopic repairs of 69 recurrent hernias and found only $3 \%$ patients with an enterotomy ${ }^{24}$. In a recent study, Wara et $\mathrm{al}^{25}$ found a $4 \%$ incidence of enterotomy during laparoscopic repair of 72 parastomal hernias. In a large cohort of 114 laparoscopic hernia and 1009 open hernia repairs, $8 \%$ and $7 \%$ enterotomies, respectively, were reported ${ }^{10}$. The higher rate in the present study most likely reflects a more difficult patient population as may be concluded from the small proportion of laparoscopic repairs and the high proportion of patients with complex hernia and comorbidity. One in 6 patients had a fistula at the time of hernia repair and almost all surgeries were (clean-)contaminated. More complexity, however, does not fully explain the high incidence because uncomplicated midline incisional hernia repair still had a $10 \%$ enterotomy rate. Perhaps the lower incidence of enterotomies reported in laparoscopic hernia repair is an underestimate because delayed bowel perforation was not included in those series ${ }^{12,20,26}$. Delayed detection of operative bowel injury seems to occur more frequently in laparoscopic than in open repair and is associated with marked morbidity and mortality ${ }^{12}$.

The prospective nature of the study enabled us to accurately evaluate adhesiolysis-related factors predicting an enterotomy. Adhesiolysis time was found to be a strong predictor for enterotomy in both complicated and uncomplicated hernia repair; a large defect and mesh presence were weak predictors. Obviously, adhesiolysis time cannot be accurately predicted before operation. The finding of enterotomy associated with adhesiolysis time, however, is of value during patient counselling for informed consent. 
Highly dense adhesions are prone for inadvertent injury when lysed. Yet, the impact of tenacity on enterotomy risk was not significant in our study. The scoring of adhesion tenacity was an estimate because adhesion tenacity varied between adhesions in the abdomen and adhesion quantity was not assessed. This likely explains the lack of significance of the single variable tenacity. Adhesiolysis time encompasses tenacity and quantity of adhesions and better reflects the complexity of adhesiolysis.

In a previous retrospective study from our group that predominantly included repeat colorectal surgeries and revealed a risk for enterotomy of 19\%, one third of enterotomies occurred at abdominal entry ${ }^{13}$. In that series, lower pelvis adhesiolysis had the highest risk for enterotomy, which is an area not commonly dissected in ventral hernia repair. The number of previous laparotomies predicted the risk of enterotomy, a finding not reproduced in the present series. Most likely, the percentage of multiple recurrent hernia repairs $(<25 \%)$ was too low to allow appropriate analysis.

The attendance of an observer in the operating room might have raised vigilance of surgeons to meticulously do adhesiolysis and avoid bowel opening. This would imply that the enterotomy incidence would be higher when unobserved. We noticed, however, that the operating team became rapidly habituated to the presence of an observer during the study period of 2 years. So, the observer effect seems limited.

We introduced the "adhesiolysis time needed to harm" in this analysis. This outcome measure does not provide a better understanding of the patient's individual risk but gives a qualitative assessment of the difficulty surgeons face while cutting adhesions in a homogeneous group of patients. Calculation of the "time needed to harm" might facilitate comparison between studies of factors that influence the difficulty of adhesiolysis and has value for health economists involved in cost price calculation of surgical interventions.

Halm et al reported a significant difference in bowel resection between patients with intraperitoneal mesh (21\%) and those with extraperitoneal mesh (0\%) and related this observation to bowel injury cutting adhesions between bowel and mesh ${ }^{17}$. We found a higher incidence of enterotomy with mesh regardless of intraperitoneal or extraperitoneal mesh position. Notably, antiadhesive coatings were used in 4 of 5 patients with intraperitoneal mesh in our series, and the majority of meshes in Halm's study were made of non-absorbable polypropylene. One should also be cautious to take bowel resection as a measure of adhesion severity and injury after adhesiolysis as Halm et al did. Only half of our patients with enterotomy required bowel resection. In a recent large retrospective study of 1444 patients in 16 Veterans Affairs hospitals examining the effect of repair type and technique on the difficulty and complications of subsequent surgery (two third re-repair of ventral hernia), no significant effect of repair type, mesh type, or position on risk of inadvertent enterotomy was demonstrated ${ }^{27}$. These results correspond with our findings indicating that extraperitoneal mesh position does not prevent adhesiolysis induced injury. We have regularly encountered a peritoneal protrusion of an extraperitoneal mesh with adhesive attachments giving similar operative difficulty as an intraperitoneal mesh at re-repair. One might speculate to use antiadhesive meshes when placed in the extraperitoneal space after open abdominal wall 
repair on the basis of the assumption that the peritoneal layer takes part in the inflammatory response elicited by the surgery and the foreign body implanted and becomes adhesiogenic.

Placing a mesh in a contaminated environment is known to increase the risk of mesh infection and fistula formation ${ }^{28}$. In a retrospective cohort of 42 mesh infections, early infection correlated with $\mathrm{DDP}^{29}$. Half of the patients in our study who received a mesh after an inadvertent enterotomy was repaired suffered from complications, even though there was no gross spillage from the enterotomy and meshes were not placed in the intraperitoneal cavity. The difficult and long adhesiolysis rather than the enterotomy probably accounts for the mesh related complications. Our limited data of patients with enterotomy and mesh placement suggest avoiding mesh repair after long during complicated adhesiolysis.

Patients with adhesiolysis complicated by enterotomy had a significantly higher incidence of unplanned bowel resection, sepsis, urgent reoperation, parenteral feeding, and prolonged hospital stay underlining the huge impact of inadvertent enterotomy on postoperative complications. The results accord with those of a previous retrospective study of all types of reoperations from our department ${ }^{13}$. A new finding is the higher incidence of postoperative surgical complications, the longer hospital stay, and increased medication costs after more than half an hour of adhesiolysis. This finding was independent of enterotomy occurrence or complexity of the abdominal wall defect. In a large prospective randomized study of 1701 patients undergoing colorectal resection for benign causes, every 30 minutes of adhesiolysis was correlated with an increase of postoperative stay by one day $^{30}$. This and our results demonstrated the large adverse effect of adhesiolysis time alone on morbidity and health care utilization.

Prolonged adhesiolysis and adhesiolysis complicated by bowel injury introduced high direct hospital costs given the twofold increase in hospital stay, the higher number of patients needing ICU treatment, the higher number of reoperations, and the almost fivefold increase in medication costs. Available literature on the socioeconomic burden of adhesions has focused only on direct hospital costs caused by adhesive small bowel obstruction. In a recent study, Wilson et al estimated the cumulative costs of readmission for adhesive small bowel obstruction after abdominal surgery at $€ 960$ per patient ${ }^{31}$. Comparison has not been done, but we speculate that the costs of adhesiolysis and subsequent inadvertent organ damage are higher than those of adhesive small bowel obstruction.

Although adhesiolysis-related organ damage is common during repeat surgery and accounts for a huge burden of morbidity, it is one of the most neglected and poorly investigated complications of abdominal surgery. This is the first large prospective cohort study giving detailed information on the morbidity of adhesions in open abdominal wall repair. Although our series encompass patients with complex abdominal wall defects, most findings were similar for relatively simple midline ventral incisional hernias. Therefore, the results are representative for open ventral hernia repair.

This study provides the first important epidemiological data on incidence, predictive factors, and impact of adhesiolysis in surgical repair of abdominal wall defects. The high incidence and large impact of adhesions emphasizes the need for adhesion prevention in all abdominal surgeries 
potentially complicated by a hernia. Unfortunately, only a minority of surgeons routinely use antiadhesion barriers ${ }^{32}$. Use of antiadhesive coating on meshes is recommended when repairing a 2 ventral wall hernia to reduce bowel adherence to the mesh with fistula formation and troublesome separation of viscera from the intraperitoneal mesh at recurrent hernia repair ${ }^{1733,34}$.

Having established in a prospective way the incidence and intra- and postoperative burden of adhesions in ventral hernia repair, surgeons can properly inform their patients before consent. In addition, hospitals, health care economists, insurances companies, and manufacturers of hernia meshes may use these findings for organizational and economic purposes and cost benefit analyses. 


\section{References}

1 Hoer J, Lawong G, Klinge U, Schumpelick V. Factors influencing the development of incisional hernia. A retrospective study of 2,983 laparotomy patients over a period of 10 years. Chirurg 2002;73(5):474-80.

2 Sugerman HJ, Kellum JM, Reines HD, DeMaria EJ, Newsome HH, Lowry JW. Greater risk of incisional hernia with morbidly obese than steroid-dependent patients and low recurrence with prefascial polypropylene mesh. Am J Surg 1996;171(1):80-4.

3 Flum DR, Horvath K, Koepsell T. Have outcomes of incisional hernia repair improved with time? A population-based analysis. Ann Surg 2003;237(1):129-35.

4 Martinez JL, Luque-de-Leon E, Mier J, Blanco-Benavides R, Robledo F. Systematic management of postoperative enterocutaneous fistulas: factors related to outcomes. World J Surg 2008;32(3):436-43.

5 Burger JWA, Luijendijk RW, Hop WCJ, Halm JA, Verdaasdonk EGG, Jeekel J. Long-term followup of a randomized controlled trial of suture versus mesh repair of incisional hernia. Ann Surg 2004;240(4):578-83.

6 Ramirez OM, Ruas E, Dellon AL. "Components separation" method for closure of abdominalwall defects: an anatomic and clinical study. Plast Reconstr Surg 1990;86(3):519-26.

7 de Vries Reilingh TS, van Goor H, Charbon JA, Rosman C, HesselinkEJ, van der Wilt GJ, Bleichrodt RP. Repair of giant midline abdominal wall hernias: "components separation technique" versus prosthetic repair : interim analysis of a randomized controlled trial. World J Surg 2007;31(4):756-63.

8 McGreevy JM, Goodney PP, Birkmeyer CM, Finlayson SRG, Laycock WS, Birkmeyer JD. A prospective study comparing the complication rates between laparoscopic and open ventral hernia repairs. Surg Endosc 2003;17(11):1778-80.

9 LeBlanc KA, Elieson MJ, Corder JM. Enterotomy and mortality rates of laparoscopic incisional and ventral hernia repair: a review of the literature. JSLS 2007;11(4):408-14.

10 Gray SH, Vick CC, Graham LA, Finan KR, Neumayer LA, Hawn MT. Risk of complications from enterotomy or unplanned bowel resection during elective hernia repair. Arch Surg 2008;143(6):582-6.

11 Forbes SS, Eskicioglu C, McLeod RS, Okrainec A. Meta-analysis of randomized controlled trials comparing open and laparoscopic ventral and incisional hernia repair with mesh. Br J Surg 2009;96(8):851-8.

12 van Goor H. Consequences and complications of peritoneal adhesions. Colorectal Dis 2007;9 Suppl 2(s2):25-34.

13 VanDer Krabben AA, Dijkstra FR, Nieuwenhuijzen M, Reijnen MM, Schaapveld M, van Goor H. Morbidity and mortality of inadvertent enterotomy during adhesiotomy. Br J Surg 2000;87(4):467-71.

14 Menzies D, Ellis H. Intestinal obstruction from adhesions-how big is the problem? Ann R Coll Surg Engl 1990;72(1):60-3.

15 Beck DE. The role of Seprafilm bioresorbable membrane in adhesion prevention. Eur J Surg Suppl 1997;(577):49-55.

16 Parker MC, Ellis H, Moran BJ, Thompson JN, Wilson MS, Menzies D, McGuire A, Lower AM, Hawthorn RJ, O’Briena F, Buchan S, Crowe AM. Postoperative adhesions: ten-year follow-up of 12,584 patients undergoing lower abdominal surgery. Dis Colon Rectum 2001;44(6):822-9.

17 Halm JA, de Wall LL, Steyerberg EW, Jeekel J, Lange JF. Intraperitoneal polypropylene mesh hernia repair complicates subsequent abdominal surgery. World J Surg 2007;31(2):423-9.

18 Binenbaum SJ, Goldfarb MA. Inadvertent enterotomy in minimally invasive abdominal surgery. JSLS 2006;10(3):336-40.

19 Janssen IMC, Swank DJ, Boonstra O, Knipscheer BC, Klinkenbijl JHG, van Goor H. Randomized clinical trial of ultrasonic versus electrocautery dissection of the gallbladder in laparoscopic cholecystectomy. Br J Surg 2003;90(7):799-803.

20 Broek ten RPG, van Goor H. Laparoscopic reintervention in colorectal surgery. Minerva Chir 2008;63(2):161-8.

21 Ellis H, Moran BJ, Thompson JN, Parker MC, Wilson MS, Menzies D, McGuire A, Lower AM, Hawthorn RJ, O’Brien F, Buchan S, Crowe AM. Adhesion-related hospital readmissions after abdominal and pelvic surgery: a retrospective cohort study. Lancet 1999;353(9163):1476-80.

22 Zühlke HV, Lorenz EM, Straub EM, Savvas V. Pathophysiology and classification of adhesions. Langenbecks Arch Chir Suppl II Verh Dtsch Ges Chir 1990;:1009-16.

23 Magder LS, Fix AD. Optimal choice of a cut point for a quantitative diagnostic test performed for research purposes. J Clin Epidemiol 2003;56(10):956-62. 
24 Jenkins ED, Yom V, Melman L, Brunt LM, Eagon JC, Frisella MM, Matthews BD. Prospective evaluation of adhesion characteristics to intraperitoneal mesh and adhesiolysisrelated complications during laparoscopic reexploration after prior ventral hernia repair. Surg Endosc 2010;24(12):3002-7.

25 Wara P, Andersen LM. Long-term follow-up of laparoscopic repair of parastomal hernia using a bilayer mesh with a slit. Surg Endosc 2011;25(2):526-30. Szomstein S, Menzo Lo E, Simpfendorfer C, Zundel N, Rosenthal RJ. Laparoscopic lysis of adhesions. World J Surg 2006;30(4):535-40.

27 Snyder CW, Graham LA, Gray SH, Vick CC, Hawn MT. Effect of mesh type and position on subsequent abdominal operations after incisional hernia repair. J Am Coll Surg 2011;212(4):496-502.

28 Choi JJ, Palaniappa NC, Dallas KB, Rudich TB, Colon MJ, Divino CM. Use of Mesh During Ventral Hernia Repair in CleanContaminated and Contaminated Cases. Ann Surg 2012;255(1):176-80.

29 Swenson BR, Camp TR, Mulloy DP, Sawyer RG. Antimicrobial-impregnated surgical incise drapes in the prevention of mesh infection after ventral hernia repair. Surg Infect (Larchmt) 2008;9(1):23-32.

30 Fazio VW, Cohen Z, Fleshman JW, van Goor H, Bauer JJ, Wolff BG, Corman M, Beart RW, Wexner SD, Becker JM, Monson JRT, Kaufman HS, Beck DE, Bailey HR, Ludwig KA, Stamos MJ, Darzi A, Bleday R, Dorazio R, et al. Reduction in adhesive small-bowel obstruction by Seprafilm adhesion barrier after intestinal resection. Dis Colon Rectum 2006;49(1):1-11.

31 Wilson MS. Practicalities and costs of adhesions. Colorectal Dis 2007;9 Suppl 2:60-5.

32 Schreinemacher MHF, Broek ten RP, Bakkum EA, van Goor H, Bouvy ND. Adhesion awareness: a national survey of surgeons. World J Surg 2010;34(12):2805-12.

33 Schreinemacher MHF, Emans PJ, Gijbels MJJ, Greve JWM, Beets GL, Bouvy ND. Degradation of mesh coatings and intraperitoneal adhesion formation in an experimental model. Br J Surg 2009;96(3):305-13.

34 Burger JWA, Halm JA, Wijsmuller AR, Raa ten S, Jeekel J. Evaluation of new prosthetic meshes for ventral hernia repair. Surg Endosc 2006;20(8):1320-5. 


\section{Supplementary data}

Table 1. Overview of intraperitoneal meshes used.

\begin{tabular}{lc}
\hline Intraperitoneal meshes & $\mathbf{n}$ \\
\hline Uncoated polypropylene & $2(11.1 \%)$ \\
Non-absorbable coating and ePTFE & $5(27.8 \%)$ \\
$\quad$ Bard Composix $^{\circledR}$ & 2 \\
Timesh $^{\circledR}$ & 1 \\
Dualmesh $^{\circledR}$ & 2 \\
Absorbable coating $_{\text {Parietex Composite }}{ }^{\circledR}$ & $9(50.0 \%)$ \\
Proceed $^{\circledR}$ & 4 \\
Sepramesh $^{\circledR}$ & 3 \\
Ultrapro $^{\circledR}$ & 1 \\
Absorbable mesh & $2(11.1 \%)$ \\
\hline
\end{tabular}

Table 2. Comparison of key variables between intraperitoneal and extraperitoneal mesh.

\begin{tabular}{lccc}
\hline & $\begin{array}{c}\text { No mesh } \\
(\mathbf{n}=\mathbf{8 9})\end{array}$ & $\begin{array}{c}\text { Intraperitoneal mesh } \\
(\mathbf{n}=\mathbf{1 8})\end{array}$ & $\begin{array}{c}\text { Extraperitoneal mesh } \\
(\mathbf{n}=\mathbf{2 6})\end{array}$ \\
\hline Adhesion scores (median, IQR) & & & \\
$\quad$ Within operating field & $3(2.5-4)$ & $4(3-4)$ & $4(3-5)$ \\
$\quad$ Outside operating field & $3(1-4)$ & $3(3-4)$ & $3(1-4)$ \\
Time for adhesiolysis (mean, 95\% CI) & $33 \mathrm{~min}$ & $36 \mathrm{~min}$ & $41 \mathrm{~min}$ \\
& $(26-35)$ & $(20-39)$ & $(25-44)$ \\
Time needed to harm (mean, 95\% CI) & $280 \mathrm{~min}$ & $78 \mathrm{~min}^{*}$ & $(47-149)$ \\
& $(157-562)$ & $(41-170)$ & $178 \mathrm{~min}^{*}$ \\
Total operative time (mean, 95\% CI) & $171 \mathrm{~min}$ & $170 \mathrm{~min}$ & $(148-207)$ \\
& $(150-192)$ & $(130-209)$ & \\
\hline
\end{tabular}

IQR: interquartile range. CI: confidence interval; min: minutes. ${ }^{\star} P<.010$ compared to "No mesh". No other significant differences were observed between intraperitoneal or extraperitoneal mesh position, nor between mesh in situ or not. 


\title{
Chapter 3
}

\section{Adhesion awareness: \\ a national survey of surgeons}

\author{
M. H. Schreinemacher ${ }^{1}$ \\ R. P. ten Broek ${ }^{2}$ \\ E. A. Bakkum ${ }^{3}$ \\ H. van Goor ${ }^{2}$ \\ N. D. Bouvy ${ }^{1}$
}

World Journal of Surgery 2010

\section{Affiliations}

${ }^{1}$ Department of Surgery, Maastricht University Medical Centre, Maastricht, The Netherlands.

${ }^{2}$ Department of Surgery, Radboud University Nijmegen Medical Centre, Nijmegen, The Netherlands.

${ }^{3}$ Department of Obstetrics and Gynecology, Onze Lieve Vrouwe Gasthuis, Amsterdam, The Netherlands. 


\section{Abstract}

\section{Background}

Postoperative adhesions are the most frequent complication of abdominal surgery, leading to high morbidity, mortality, and costs. However, the problem seems to be neglected by surgeons for largely unknown reasons.

\section{Methods}

A survey assessing knowledge and personal opinion about the extent and impact of adhesions was sent to all Dutch surgeons and surgical trainees. The informed consent process and application of antiadhesive agents were questioned in addition.

\section{Results}

The response rate was $34.4 \%$. Two thirds of all respondents (67.7\%) agreed that adhesions exert a clinically relevant, negative effect. A negative perception of adhesions correlated with a positive attitude regarding adhesion prevention $(\rho=0.182, P<0.001)$. However, underestimation of the extent and impact of adhesions resulted in low knowledge scores (mean test score 37.6\%). Lower scores correlated with more uncertainty about indications for antiadhesive agents which, in turn, correlated with never having used any of these agents ( $\rho=0.140, P=0.002 ; \rho=0.095, P=0.035$; respectively). Four in 10 respondents $(40.9 \%)$ indicated that they never inform patients on adhesions and only $9.8 \%$ informed patients routinely. A majority of surgeons (55.9\%) used antiadhesive agents in the past, but only a minority (13.4\%) did in the previous year. Of trainees, $82.1 \%$ foresaw an increase in the use of antiadhesive agents compared to $64.5 \%$ of surgeons $(P<0.001)$.

\section{Conclusions}

The magnitude of the problem of postoperative adhesions is underestimated and informed consent is provided inadequately by Dutch surgeons. Exerting adhesion prevention is related to the perception of and knowledge about adhesions. 


\section{Introduction}

Postoperative adhesions occur in about $90 \%$ of all patients undergoing abdominal surgery and lead to at least one readmission for a third of these patients in the following 10 years ${ }^{1,2}$. Adhesions become clinically apparent in the form of chronic abdominal pain, female infertility, and small bowel obstruction ${ }^{3,4}$. Furthermore, adhesions can seriously complicate subsequent surgery $y^{5,6}$. Therefore, postoperative adhesions should not merely be regarded as a side effect of abdominal surgery but as the most common complication caused by abdominal surgery.

Regardless of an open or a laparoscopic approach, the surgical treatment of adhesions induces the reformation as well as new formation of adhesions ${ }^{7,8}$. Hence, adhesion prevention is of key importance. For obvious reasons, reducing surgical trauma by meticulous surgical technique is the primary step that needs to be exerted at all times. However, performing surgery implies surgical trauma to some extent but it can be further reduced by other means, e.g., using powder-free gloves, wetting tissues, and reducing operative time ${ }^{9}$. The use of adhesion barriers seems inevitable to obtain further adhesion prevention. A local barrier composed of hyaluronic acid and carboxymethylcellulose (Seprafilm ${ }^{\circledR}$, Genzyme, Cambridge, MA, USA) has proven effective in reducing adhesions in various open general surgery studies ${ }^{10}$. Previous reviews have also shown significant benefit with the use of Interceed ${ }^{\circledR}$ membrane (Ethicon, Johnson \& Johnson, New Brunswick, NJ, USA), composed of oxidized regenerated cellulose, in open gynaecologic surgery ${ }^{11}$. Administration of an icodextrin solution (Adept ${ }^{\circledR}$, Baxter Healthcare Corp., Deerfield, IL, USA) that spreads throughout the peritoneal cavity has shown adhesion reductive capacity in benign laparoscopic gynaecologic surgery ${ }^{12}$.

In contrast to most surgical complications, the risk of adhesion related morbidity remains for many years and complications are often not followed up by the primary surgeon. In addition, symptoms of adhesion related complications vary and a fully effective remedy has not yet been discovered. All these factors have probably resulted in an undervaluation of postoperative adhesions by surgeons. This in turn explains why adhesions are mentioned only sporadically during the informed consent process ${ }^{13,14}$. Nevertheless, failure to do so can be regarded as an omission of the doctor's duty of care and has already resulted in successful negligence claims ${ }^{15}$.

In spite of the extent and impact of postoperative adhesions, we are under the impression that surgeons lack sufficient awareness about this most common complication. Moreover, they seem to provide inadequate informed consent on and take insufficient preventive actions against adhesions. However, until now, no data has been available to substantiate these assumptions. Therefore, we conducted a nationwide survey assessing the awareness of and behaviour toward adhesions among Dutch surgeons and surgical trainees. 


\section{Methods and Materials}

\section{Design of the survey}

A steering group of 11 general and gynaecologic surgeons with a special interest in adhesions and its associated morbidity (Dutch Adhesion Group) conceived a first set of survey questions. These questions were edited by two independent researchers, both experts in survey and multiple-choice test construction. Subsequently, five surgeons and three surgical trainees tested the survey for indistinctness and leading questions. After making adjustments, the survey was reviewed again and consecutively approved by the steering group, the independent researchers, and the test group of surgeons and trainees. The survey consisted of 55 multiple choice questions, four open-ended questions, and four optional questions with a total word count of 716. In its final layout, both an electronic online version (six web pages) and a printed version (three pages) were available in Dutch (see the Appendix for a translated version).

\section{Knowledge test}

Eight multiple-choice questions concerning the prevalence and morbidity of adhesions were formulated based on up-to-date and best-available evidence. The following statements were considered correct:

- Approximately $70 \%$ of small bowel obstructions are due to postoperative adhesions ${ }^{16-18}$.

- The 5-year readmission rate after operative procedures of the colon or rectum directly related to postoperative adhesions is approximately $5 \%{ }^{19-21}$.

- The 10-year readmission rate after any abdominal surgery probably or directly related to postoperative adhesions is approximately $30 \%{ }^{1,2}$.

- Inadvertent enterotomy during adhesiolysis occurs in $20 \%$ of patients with a history of abdominal surgery ${ }^{5,6}$.

- A total colonic resection has the highest risk of adhesion related morbidity compared with a partial small bowel resection, an appendectomy, or a resection of the rectum ${ }^{2,21}$.

- Age above 60 years is associated with fewer adhesions, a history of abdominal surgery with more adhesions, and a history of Crohn's disease with no difference in adhesion formation ${ }^{2,21}$.

\section{Survey distribution}

We aimed to distribute the survey among all officially registered Dutch surgeons and trainees ( $n=1282$ and 432, respectively). Contact details were retrieved from the 2008 annual report of the Dutch Association for Surgery from the section of regular members $(n=1009)$ and members of the association of surgical trainees $(n=446)$. We approached the surgeons and trainees by electronic mail (e-mail) or by postal mail when no or no valid e-mail address was available. A personalized mail was sent on Tuesday (at 6:00 a.m. in case of e-mail) and a reminder sent the next Tuesday (at 7:00 p.m. in case of e-mail) when no response was recorded yet. As an incentive, five portable audio players and 40 pens with inbuilt laser pointer and USB stick were raffled among all respondents. The survey closed 3 weeks after the first mailing. 


\section{Data analysis}

Only surveys more than $80 \%$ complete, excluding optional questions, were included. We defined subgroups of respondents as trainees, general surgeons, gastrointestinal surgeons, or other surgeons. Proportions were compared using Chi square tests. Comparisons between groups were performed using the Mann-Whitney $U$ test, the Wilcoxon signed-rank test, or the Kruskal-Wallis test with post-hoc Bonferroni correction. Knowledge test scores were compared with Student's t-tests and ANOVA with post-hoc Bonferroni correction. Correlations were calculated using Spearman's rank correlation and a $P<0.050$ was considered significant. Statistics were performed using SPSS ${ }^{\circledR}$ version 15.0 (SPSS Inc., Chicago, IL, USA).

\section{Results}

A total of 1455 surgeons and trainees were contacted by email $(83.8 \%)$ or postal mail (16.2\%). Twenty-three physicians indicated not to participate. After 1 week, 352 surveys were collected, and there were 523 surveys at close of the survey. Of these, 22 incomplete surveys (4.2\%) were rejected, resulting in a response rate of $34.4 \%$ (501 surveys, $98 \%$ complete) representing $90.7 \%$ of all Dutch surgical departments (98.3\% of all teaching and $81.3 \%$ of all non-teaching departments). Response rates were comparable for e-mail and postal mail (35.3 vs. $29.8 \%$, respectively, $P=0.102$ ), but higher for surgeons than for trainees (Table 1 ). The survey was completed by a comparable number of trainees $(\mathrm{n}=131)$, general surgeons ( $\mathrm{n}=130)$, gastrointestinal surgeons $(\mathrm{n}=116)$, and other surgeons $(\mathrm{n}=124)(P=0.767)$.

Table 1. Respondents $(\mathrm{n}=501)$

\begin{tabular}{lccc}
\hline & Trainees & Surgeons & $P$ \\
\hline Response rate, \% (n) & $29.4 \%(131$ of 446$)$ & $36.7 \%(370$ of 1009) & 0.007 \\
Experience, mean (sd), y & $4.3(1.6)$ & $13.2(9.6)$ & n.a. \\
Full time employment, \% (n) & $89.9 \%(116)$ & $88.8 \%(316)$ & 0.718 \\
Academic hospital employment, \% (n) & $33.6 \%(44)$ & $25.8 \%(95)$ & 0.088 \\
\hline
\end{tabular}

SD: standard deviation. n.a.: not applicable.

\section{Opinion on adhesions}

About two thirds (67.7\%) of all respondents agreed that adhesions exert a clinically relevant and predominantly negative effect. The proportion was significantly higher for trainees than for surgeons (75.6 vs. $64.9 \%$, respectively, $P=0.025)$. A small group $(6.0 \%)$ indicated that adhesions exert a clinically relevant and predominantly positive effect. Half of all respondents (50.6\%) considered adhesiolysis for treating pain not effective, whereas $26.2 \%$ considered it effective. 


\section{Awareness of adhesions and their associated morbidity}

Respondents scored a mean of $37.6 \%$ correct answers on the knowledge test, with trainees scoring slightly but significantly higher than general surgeons ( 39.9 vs. $34.6 \%, P=0.032$ ). Only $6.9 \%$ of respondents reported a correct 10 -year readmission rate after abdominal surgery probably or directly related to adhesions (30\%), whereas $69.0 \%$ thought it was $10 \%$ or lower. Also, $62.9 \%$ underestimated the percentage of small bowel obstructions caused by adhesions, reporting a percentage of $50 \%$ or lower. On the other hand, a vast majority of respondents $(87.6 \%)$ correctly indicated that a history of abdominal operations is associated with increased adhesion related morbidity. The knowledge test score did not correlate with respondents' opinion on adhesions $(\rho=0.010, P=0.830)$.

\section{Informed consent}

One in 10 respondents $(9.8 \%)$ reported that they routinely include adhesions or related morbidity in the informed consent information for both laparotomies and laparoscopies. Yet, $40.9 \%$ of all respondents reported that they never mention it at all (Figure 1). No correlation was observed with opinion on adhesions or knowledge test score $(\rho=0.031, P$ $=0.497 ; \rho=0.016, P=0.730$; respectively). Trainees and non-academic surgeons provided adhesion information during informed consent less often than surgeons and academic surgeons, respectively (both $P=0.002$ ). Furthermore, providing information on adhesions before a laparoscopic procedure was done less often in comparison with laparotomy $(P<$ 0.001). Informing fewer patients before a laparoscopy correlated with a greater belief that laparoscopy is a means to limit adhesion formation $(\rho=0.186, P<0.001)$.

\section{Adhesion prevention}

Four in 10 respondents (39.1\%) expressed a positive opinion on adhesion prevention, $22.4 \%$ expressed a negative one. In addition, a positive opinion correlated with a negative view of

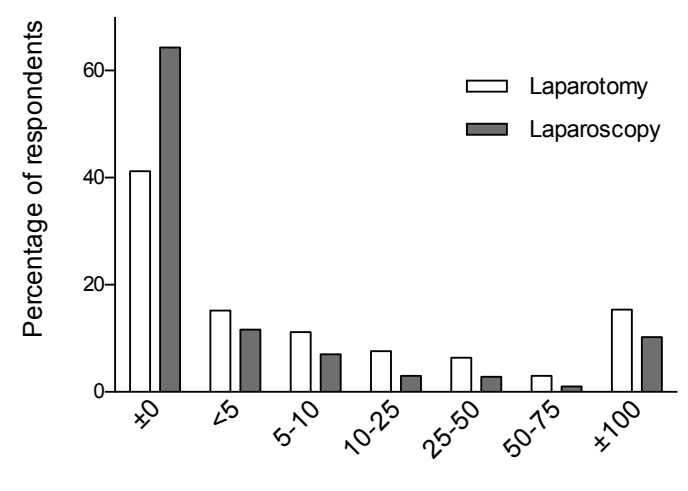

Percentage of patients informed

Figure 1. Informed Consent. 
adhesions ( $\rho=0.182, P<0.001)$. All respondents, except gastrointestinal surgeons, believed more strongly in adhesion prevention for specific indications than for all abdominal surgery $(P<0.001)$. Significantly more surgeons than trainees believed that a meticulous surgical technique minimizes adhesions ( 83.5 vs. $65.6 \%, P<0.001)$. Similarly, significantly more gastrointestinal than non-gastrointestinal surgeons believed that laparoscopy reduces adhesion formation (90.5 vs. $72.0 \%, P<0.001$ ) (Figure 2, A).

\section{Antiadhesive agents}

Of all respondents, 26.5\% expressed a positive attitude toward antiadhesive agents and $29.1 \%$ expressed a negative one (Figure 2, B). Although a majority of surgeons (55.9\%) had used at least one of these agents, only a minority did in the previous year (13.4\%). Significantly higher proportions of gastrointestinal and academic surgeons used an antiadhesive agent in the previous year compared to general and non-academic surgeons, respectively ( $23.0 \mathrm{vs.}$ $9.0 \%, P=0.001 ; 23.9$ vs. $10.5 \%, P<0.0001$; respectively). Not using antiadhesive agents any longer showed no significant associations with knowledge test score, opinion on adhesions, adhesion prevention, or antiadhesive agents $(P=0.622, P=0.431, P=0.283, P=0.209$, respectively). Most surgeons used $\operatorname{Adept}^{\circledR}\left(8.9 \%\right.$ ever, $8.5 \%$ last year) and Seprafilm ${ }^{\circledR}(33.7 \%$ ever, $5.4 \%$ last year). In the group of surgeons who used antiadhesive agents, $78.8 \%$ did so in adhesion related laparotomies, $29.2 \%$ in abdominal wall surgery, and $21.8 \%$ in (sub) total colectomies. In general, use of products for high-risk operations regarding adhesion

A

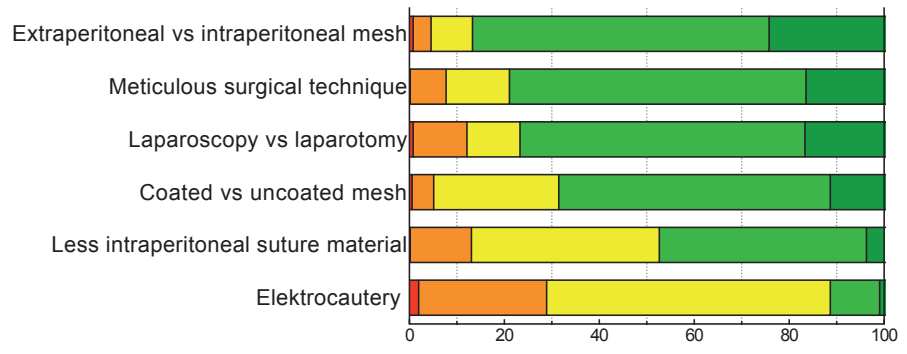

B

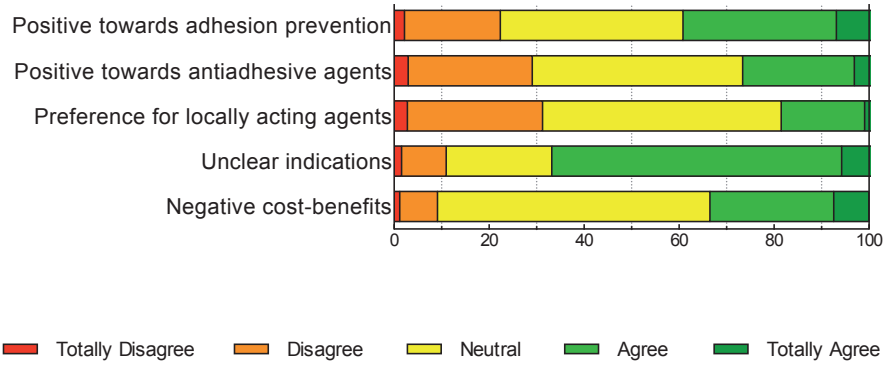

Figure 2. Techniques to minimize adhesions (A) and opinion on antiadhesive agents (B). 
formation was higher than for low-risk operations $(P<0.001)$. Uncertainty about when to use these products correlated with never having used any products $(\rho=0.095, P=0.035)$ and lower knowledge test scores $(\rho=0.140, P=0.002)$.

Of all trainees, $82.1 \%$ predicted that the use of antiadhesive agents will increase compared with $64.5 \%$ of all surgeons $(P<0.001)$. Such opinion correlated with a negative view of adhesions ( $\rho=0.141, P=0.002)$ and with a more positive view in terms of cost benefits $(\rho=$ $0.148, P=0.001)$. Most respondents anticipated that new antiadhesive agents would come to the market and that the evidence either for or against adhesion prevention would increase.

\section{Discussion}

Adhesions and related complications lead to substantial morbidity and mortality, with increased medical $\operatorname{costs}^{22,23}$. This nationwide survey shows that two of three Dutch surgeons recognize adhesions as a clinically relevant and negative entity. However, readmission rates and small bowel obstructions caused by adhesions are heavily underestimated. Moreover, the informed consent process and application of antiadhesive agents are not in line with the extent and impact of postoperative adhesions. Therefore, it can be concluded that the knowledge and awareness of and the behaviour toward adhesions is limited among Dutch surgeons and surgical trainees.

At least $40 \%$ of respondents did not inform any patients about postoperative adhesions or related morbidity and only very few informed patients routinely. This corresponds with the recent finding that more than $90 \%$ of consent forms lack this information ${ }^{13}$. In contrast, the risks for haemorrhage and infection after abdominal surgery are almost invariably discussed during the informed consent process. Adhesion related complications share nearly all features of these complications, including the risk of death, but may occur many years after the operation. Thus, it is essential to discuss adhesions as a possible complication during the informed consent process. In addition, in case of any reoperation, a high risk of inadvertent organ damage exists and should be discussed prior to surgery as well. These recommendations apply also for laparoscopic procedures since laparoscopy has not been proven to reduce adhesion related morbidity compared with laparotomy, though definite studies are lacking ${ }^{24}$.

Current surgical trainees consider adhesions a negative drawback of surgery more often, have a slightly better understanding of the extent of the problem, rely less on surgical technique to reduce adhesions, and have a higher belief in an increasing use of antiadhesive agents, compared to surgeons. In contrast, they seem to inform fewer patients about adhesions or adhesion related morbidity compared to current surgeons. The reason for this is unclear, but this behavior may change when they have more responsibilities and follow-up their own patients more closely. The finding is of interest for the future and might mandate (educational) interventions with this group of young surgeons before they face legal claims. The significantly lower response rate of surgical trainees compared to surgeons can be explained by the higher number of trainees' contact details than the number of officially registered trainees for general surgery. This is probably due to the fact that plastic and orthopaedic surgery trainees share the first 2 years of training. 
The current study is the first to evaluate awareness and behaviour of surgeons regarding adhesions. Recently, two similar studies reported on adhesion awareness among gynaecologic surgeons in the United Kingdom and Germany ${ }^{14,25}$. Little over half of those respondents agreed that adhesions are the most common complication after abdominal surgery. This is in line with our finding that the impact of adhesions is underestimated. Yet, around three in four gynaecologic surgeons indicated that they inform patients routinely about adhesions and about half of the respondents stated that they use antiadhesive agents regularly. This clearly surpasses the current behaviour of Dutch surgeons and reflects a higher awareness of adhesions among gynaecologic surgeons. Nevertheless, the $8.8 \%$ response rate of the British gynaecologists and the $33.5 \%$ response rate of German gynaecologic departments might reflect a selection bias.

Approximately $80 \%$ of respondents agreed that an extraperitoneal mesh, meticulous surgical technique, and laparoscopy reduce adhesions. Only a quarter of surgeons expressed a positive opinion toward antiadhesive agents. In addition, only one in 10 surgeons used an agent in the past year, with Adept ${ }^{\circledR}$ taking a small lead over Seprafilm ${ }^{\circledR}$. Adept ${ }^{\circledR}$ is a liquid acting throughout the whole abdomen; Seprafilm ${ }^{\circledR}$ is a site-specific barrier film. The efficacy of Seprafilm ${ }^{\circledR}$ has already been evidenced in general surgery, whereas for Adept ${ }^{\circledR}$ efficacy has been shown in laparoscopic gynaecologic surgery and results in general surgery are awaited ${ }^{12,25}$. Both agents have been shown to be safe in general abdominal surgery, though application of Seprafilm ${ }^{\circledR}$ on bowel anastomoses should be avoided ${ }^{12,25-27}$. Although current agents do not provide complete prevention of postoperative adhesions, it is worth considering their use in high-risk surgery such as colorectal procedures. Even a relative decrease in adhesions might entail benefits for the patient and the surgeon. Interestingly, uncertainty about indications for antiadhesive agents was correlated with never having used any agents and with lower knowledge scores.

This study demonstrates that a change in behaviour is needed among surgeons and trainees. Patients have to be informed of the risks of adhesions routinely and the application of clinically available antiadhesive agents should at least be considered in specific abdominal surgery ${ }^{28}$. However, to obtain changes in behaviour, both knowledge and attitudes have to be addressed ${ }^{29}$. Barriers for improving knowledge include accessibility and volume of information; attitudes can be affected by a lack of agreement or poor methodology in evidence, but also by personal beliefs and experiences. Therefore, attempts to obtain sustainable changes in behaviour have to target multiple aspects. Moreover, breakthrough results from basic research should be translated to clinically applicable agents ${ }^{30}$.

Some limitations of this study should be noted. First of all, the $34.4 \%$ response rate might reflect a selection bias, possibly providing more positive results. Furthermore, no elaborate nonresponse analysis could be performed due to the lack of any central database comprising detailed information on Dutch surgeons. On the other hand, responses were recorded from $90.7 \%$ of all Dutch surgical departments. In addition, response rates were markedly higher than in the recent survey among gynaecologic surgeons in the UK and a survey in the USA on work, stress, and research among academic surgeons (8.8 and 22.7\%, respectively $)^{14,31}$. Our relatively high response rate might be due to the raffle, which is known to increase response rates without affecting response quality ${ }^{32,33}$. 
The knowledge test was based on up-to-date and best available evidence selected by the steering group of general and gynaecologic surgeons. Several rounds of pilot testing were conducted to ensure comprehensibility and face and content validity of the survey. However, although most of the knowledge questions were based on very large cohort studies, some still consider the consistently found high morbidity controversial. Yet, even if the true morbidity would be lower, many of the respondents would still underestimate the magnitude of the problem.

Finally, this study surveyed only Dutch surgeons and surgical trainees, but results are likely to be generalizable to surgeons worldwide; adhesions are encountered after all abdominal surgeries and the associated morbidity, mortality, and costs are comparably high in different countries ${ }^{23,34,35}$.

As for the future, action must be taken to improve knowledge, attitude, and behaviour concerning adhesions among Dutch surgeons and surgical trainees. Specialty courses could be developed and rewarded credits; compulsory classes on adhesions and antiadhesive agents should be embedded in the surgical training program. Nonetheless, surgeons represent only one of the many parties involved in adhesion awareness. Attention must also be given to the other specialists operating in the abdominal cavity, patients, hospitals, antiadhesive agents manufacturers, and health insurance companies in order to improve awareness of and behaviour toward adhesions. In order to follow up on the actions, the results of this survey can serve as a benchmark for later research.

\section{Acknowledgments}

The Dutch Adhesion Group consists of Mrs. E. A. Bakkum (gynaecologic surgeon, Amsterdam), Mrs. N. D. Bouvy (surgeon, Maastricht), F. P. Dijkhuizen (gynaecologic surgeon, Arnhem), H. van Goor (surgeon, Nijmegen), F. W. Jansen (gynaecologic surgeon, Leiden), J. Jeekel (surgeon, Rotterdam), R. F. Kruitwagen (gynaecologic surgeon, Maastricht), M. M. Reijnen (surgeon, Arnhem), E. J. van Santbrink (gynaecologic surgeon, Rotterdam), D. J. Swank (surgeon, Gouda), and Mrs. G. C. Trimbos-Kemper (gynaecologic surgeon, Leiden.

\section{Disclosures}

Portable audio players and pens with built-in laser pointer and USB stick were supplied unconditionally and free from any imprints by Johnson \& Johnson Medical, Amersfoort, The Netherlands. None of the authors holds any financial interest in Johnson \& Johnson Medical nor in any of the companies whose products are mentioned in this study. 


\section{References}

1 Ellis H, Moran BJ, Thompson JN, Parker MC, Wilson MS, Menzies D, McGuire A, Lower AM, Hawthorn RJ, O’Brien F, Buchan S, Crowe AM. Adhesion-related hospital readmissions after abdominal and pelvic surgery: a retrospective cohort study. Lancet 1999;353(9163):1476-80.

2 Parker MC, Ellis H, Moran BJ, Thompson JN, Wilson MS, Menzies D, McGuire A, Lower AM, Hawthorn RJ, O'Briena F, Buchan S, Crowe AM. Postoperative adhesions: ten-year follow-up of 12,584 patients undergoing lower abdominal surgery. Dis Colon Rectum 2001;44(6):822-9.

3 Sulaiman H, Gabella G, Davis MC, Mutsaers SE, Boulos P, Laurent GJ, Herrick SE. Presence and distribution of sensory nerve fibers in human peritoneal adhesions. Ann Surg 2001;234(2):256-61.

4 Vrijland WW, Jeekel J, van Geldorp HJ, Swank DJ, Bonjer HJ. Abdominal adhesions: intestinal obstruction, pain, and infertility. Surg Endosc 2003;17(7):1017-22.

5 Van Der Krabben AA, Dijkstra FR, Nieuwenhuijzen M, Reijnen MM, Schaapveld M, van Goor H. Morbidity and mortality of inadvertent enterotomy during adhesiotomy. $\mathrm{Br}$ J Surg 2000;87(4):467-71.

6 Wullstein C, Gross E. Laparoscopic compared with conventional treatment of acute adhesive small bowel obstruction. Br J Surg 2003;90(9):1147-51.

7 Szomstein S, Menzo Lo E, Simpfendorfer C, Zundel N, Rosenthal RJ. Laparoscopic lysis of adhesions. World J Surg 2006;30(4):535-40.

8 Wiseman DM, Trout JR, Diamond MP. The rates of adhesion development and the effects of crystalloid solutions on adhesion development in pelvic surgery. Fertil Steril 1998;70(4):702-11.

9 van den Tol MP, Haverlag R, van Rossen ME, Bonthuis F, Marquet RL, Jeekel J. Glove powder promotes adhesion formation and facilitates tumour cell adhesion and growth. Br J Surg 2001;88(9):1258-63.

10 Kumar S, Wong PF, Leaper DJ. Intra-peritoneal prophylactic agents for preventing adhesions and adhesive intestinal obstruction after nongynaecological abdominal surgery. Cochrane Database Syst Rev 2009;(1):CD005080.

11 Wiseman DM, Trout JR, Franklin RR, Diamond MP. Metaanalysis of the safety and efficacy of an adhesion barrier (Interceed TC7) in laparotomy. J Reprod Med 1999;44(4):325-31.
12 Brown CB, Luciano AA, Martin D, Peers E, Scrimgeour A, diZerega GS, Adept Adhesion Reduction Study Group. Adept (icodextrin 4\% solution) reduces adhesions after laparoscopic surgery for adhesiolysis: a double-blind, randomized, controlled study. Fertil Steril 2007;88(5):1413-26.

13 Rajab TK, Wallwiener M, Talukdar S, Kraemer B. Adhesion-related complications are common, but rarely discussed in preoperative consent: a multicenter study. World J Surg 2009;33(4):748-50.

14 Trew G, Cooke I, Lower A, McVeigh E. Postoperative abdominal adhesions-awareness of UK gynaecologists-a survey of members of the Royal College of Obstetricians and Gynaecologists. Gynecol Surg 2009;6(1):25-37.

15 Ellis H, Crowe A. Medico-legal consequences of post-operative intra-abdominal adhesions. Int $J$ Surg 2009;7(3):187-91.

16 Miller G, Boman J, Shrier I, Gordon PH. Etiology of small bowel obstruction. Am J Surg 2000;180(1):33-6.

17 Miller G, Boman J, Shrier I, Gordon PH. Natural history of patients with adhesive small bowel obstruction. Br J Surg 2000;87(9):1240-7.

18 Bizer LS, Liebling RW, Delany HM, Gliedman ML. Small bowel obstruction: the role of nonoperative treatment in simple intestinal obstruction and predictive criteria for strangulation obstruction. Surgery 1981;89(4):407-13.

19 Edna TH, Bjerkeset T. Small bowel obstruction in patients previously operated on for colorectal cancer. Eur J Surg 1998;164(8):587-92.

20 BeckDE, OpelkaFG, BaileyHR, RauhSM, Pashos CL. Incidence of small-bowel obstruction and adhesiolysis after open colorectal and general surgery. Dis Colon Rectum 1999;42(2):241-8.

21 Parker MC, Wilson MS, Menzies D, Sunderland G, Clark DN, Knight AD, Crowe AM, Surgical and Clinical Adhesions Research (SCAR) Group. The SCAR-3 study: 5-year adhesionrelated readmission risk following lower abdominal surgical procedures. Colorectal Dis 2005;7(6):551-8.

22 Stanciu D, Menzies D. The magnitude of adhesion-related problems. Colorectal Dis 2007;9 Suppl 2(s2):35-8.

23 Wilson MS. Practicalities and costs of adhesions. Colorectal Dis 2007;9 Suppl 2:60-5.

24 Lower AM, Hawthorn RJ, Clark D, Boyd $\mathrm{JH}$, Finlayson AR, Knight AD, Crowe AM. 
Adhesion-related readmissions following gynaecological laparoscopy or laparotomy in Scotland: an epidemiological study of 24046 patients. Hum Reprod 2004;19(8):1877-85.

25 Hackethal A, Sick C, Brueggmann D, Tchartchian G, Wallwiener M, Muenstedt K, Tinneberg HR. Awareness and perception of intra-abdominal adhesions and related consequences: survey of gynaecologists in German hospitals. Eur J Obstet Gynecol Reprod Biol 2010;150(2):180-9.

26 Beck DE, Cohen Z, Fleshman JW, Kaufman HS, van Goor H, Wolff BG. A prospective, randomized, multicenter, controlled study of the safety of Seprafilm adhesion barrier in abdominopelvic surgery of the intestine. Dis Colon Rectum 2003;46(10):1310-9.

27 Menzies D, Pascual MH, Walz MK, Duron JJ, Tonelli F, Knight A. Use of icodextrin 4\% solution in the prevention of adhesion formation following general surgery: from the multicentre ARIEL Registry. Ann R Coll Surg Engl 2006;88(4):375-82.

28 Parker MC, Wilson MS, van Goor H, Moran BJ, Jeekel J, Duron JJ, Menzies D, Wexner SD, Ellis $\mathrm{H}$. Adhesions and colorectal surgery - call for action. Colorectal Dis 2007;9 Suppl 2(s2):66-72.

29 Cabana MD, Rand CS, Powe NR, Wu AW, Wilson MH, AbboudPA, Rubin HR. Whydon't physicians follow clinical practice guidelines? A framework for improvement. JAMA 1999;282(15):1458-65.

30 Kosaka H, Yoshimoto T, Yoshimoto T, Fujimoto J, Nakanishi K. Interferon-gamma is a therapeutic target molecule for prevention of postoperative adhesion formation. Nat Med 2008;14(4):437-41.

31 Chokshi NK, Simeone DM, Chari RS, Dorey F, Guner YS, Upperman JS. A survey of academic surgeons: work, stress, and research. Surgery 2009;146(3):462-8.

32 Dirmaier J, Harfst T, Koch U, Schulz H. Incentives increased return rates but did not influence partial nonresponse or treatment outcome in a randomized trial. J Clin Epidemiol 2007;60(12):1263-70.

33 Edwards PJ, Roberts I, Clarke MJ, Diguiseppi C, Wentz R, Kwan I, Cooper R, Felix LM, Pratap $S$. Methods to increase response to postal and electronic questionnaires. Cochrane Database Syst Rev 2009;(3):MR000008.

34 Jeekel H. Cost implications of adhesions as highlighted in a European study. Eur J Surg Suppl 1997;(579):43-5.

35 Tingstedt B, Isaksson J, Andersson R. Long-term follow-up and cost analysis following surgery for small bowel obstruction caused by intraabdominal adhesions. Br J Surg 2007;94(6):743-8. 


\section{Appendix: Adhesions survey}

\section{Personal data}

- You are a (multiple responses possible): trainee, general surgeon, oncologic surgeon, vascular surgeon, gastrointestinal surgeon, pediatric surgeon, trauma surgeon, other...

- How many years of work experience (as a trainee or as a surgeon) do you have?...

- Do you currently work in an academic or non-academic hospital? Yes / No

- Do you currently work full-time or part-time? Yes / No

\section{Prevalence and morbidity of adhesions}

- Adhesions are not of clinical interest. Totally disagree / Disagree / Neutral / Agree / Totally agree

- Adhesions have more beneficial than detrimental effects. Totally disagree / Disagree / Neutral / Agree / Totally agree

- Adhesiolysis for complaints of pain is not effective. Totally disagree / Disagree / Neutral / Agree / Totally agree

- A proportion of all small bowel obstructions is caused by postoperative adhesions. This proportion is closest to: $30 \% / 50 \% / 70 \% / 90 \%$

- Within 5 years after an operation on the colon or rectum a certain percentage of patients will be readmitted because of morbidity directly related to adhesions. This percentage is closest to: $2 \% / 5 \% / 10 \% / 20 \%$

- Within 10 years after an abdominal operation a certain percentage of patients will be readmitted because of morbidity possibly related to adhesions. This percentage is closest to: $5 \% / 10 \% / 20 \% / 30 \%$

- Inadvertent bowel lesions caused by adhesiolysis occur in a certain percentage of patients with a history of an abdominal operation. This percentage is closest to: $5 \%$ / 10\% / 20\% / 30\%

- Which of the following procedures carries with it the highest risk for adhesion related morbidity? Partial small bowel resection / appendectomy / total (procto)colectomy / proctectomy

- Some patient characteristics have been proven to influence adhesion formation. What do you think is the influence of:

- Age above 60 years: less adhesions / no effect / more adhesions

- History of abdominal operations: less adhesions / no effect / more adhesions

- Crohn's disease: less adhesions / no effect / more adhesions.

\section{Informed consent}

- How many patients do you inform about adhesions or adhesion related morbidity as a possible complication after

- laparotomy? virtually none / 5\% / 5-10\% / 10-25\% / 25-50\% / 50-75\% / virtually all

- laparoscopy? virtually none / 5\% / 5-10\% / 10-25\% / 25-50\% / 50-75\% / virtually all 


\section{Opinion on adhesion prevention}

- You do not believe in adhesion prevention. Totally disagree / Disagree / Neutral / Agree / Totally agree

- You would like to apply adhesion prevention in all abdominal operations. Totally disagree / Disagree / Neutral / Agree / Totally agree

- You would like to apply adhesion prevention only in certain indications. Totally disagree / Disagree / Neutral / Agree / Totally agree

- Laparoscopic surgery causes fewer adhesions than open surgery. Totally disagree / Disagree / Neutral / Agree / Totally agree

- Meticulous surgical technique (tissue handling, avoiding gauzes) reduces adhesions. Totally disagree / Disagree / Neutral / Agree / Totally agree

- Extraperitoneal mesh position causes fewer adhesions than the intraperitoneal mesh position. Totally disagree / Disagree / Neutral / Agree / Totally agree

- A coated mesh causes fewer adhesions than an uncoated mesh. Totally disagree / Disagree / Neutral / Agree / Totally agree

- Electrocautery causes fewer adhesions. Totally disagree / Disagree / Neutral / Agree / Totally agree

- Less intraperitoneal suture material reduces adhesions. Totally disagree / Disagree / Neutral / Agree / Totally agree

\section{Opinion on antiadhesive agents}

- You don’t believe in antiadhesive agents. Totally disagree / Disagree / Neutral / Agree / Totally agree

- You experience a lack of clarity about when to use an antiadhesive agent. Totally disagree / Disagree / Neutral / Agree / Totally agree

- You prefer using a locally acting antiadhesive agent over an agent that acts throughout the whole abdomen. Totally disagree / Disagree / Neutral / Agree / Totally agree

- You think the costs do not outweigh the possible benefits of antiadhesive agents. Totally disagree / Disagree / Neutral / Agree / Totally agree

- Which factors influence your belief in adhesion prevention?...

\section{Using antiadhesive agents}

- Have you ever used: Interceed ${ }^{\circledR}$, Seprafilm $^{\circledR}$, Adept $^{\circledR}$, Spraygel $^{\circledR}$, Hyalobarrier $^{\circledR}$, Prevadh $^{\circledR}$, Ringers lactate (not regarded an antiadhesive agent), Intercoat ${ }^{\circledR}$, Other... For all agents: Never used, but would like to / Never used / Used in the past year / Ever used

- With which operation have you ever used antiadhesive agents? Relaparotomy because of adhesion related morbidity, pancreatic or duodenal surgery, partial small bowel resection, ileostomy creation, appendectomy, partial colectomy, panproctocolectomy, laparoscopic colon surgery, rectal operation, abdominal wall surgery, aortic bifurcation prosthesis, Other... For all operations: Never / Seldom / Regularly / Often / Very often 
- How many times are antiadhesive agents used by you and your colleagues in your hospital?

- $\%$ of all laparotomies...

- $\%$ of all laparoscopies...

- Do you think this percentage will increase? Yes / No

- Why?... 


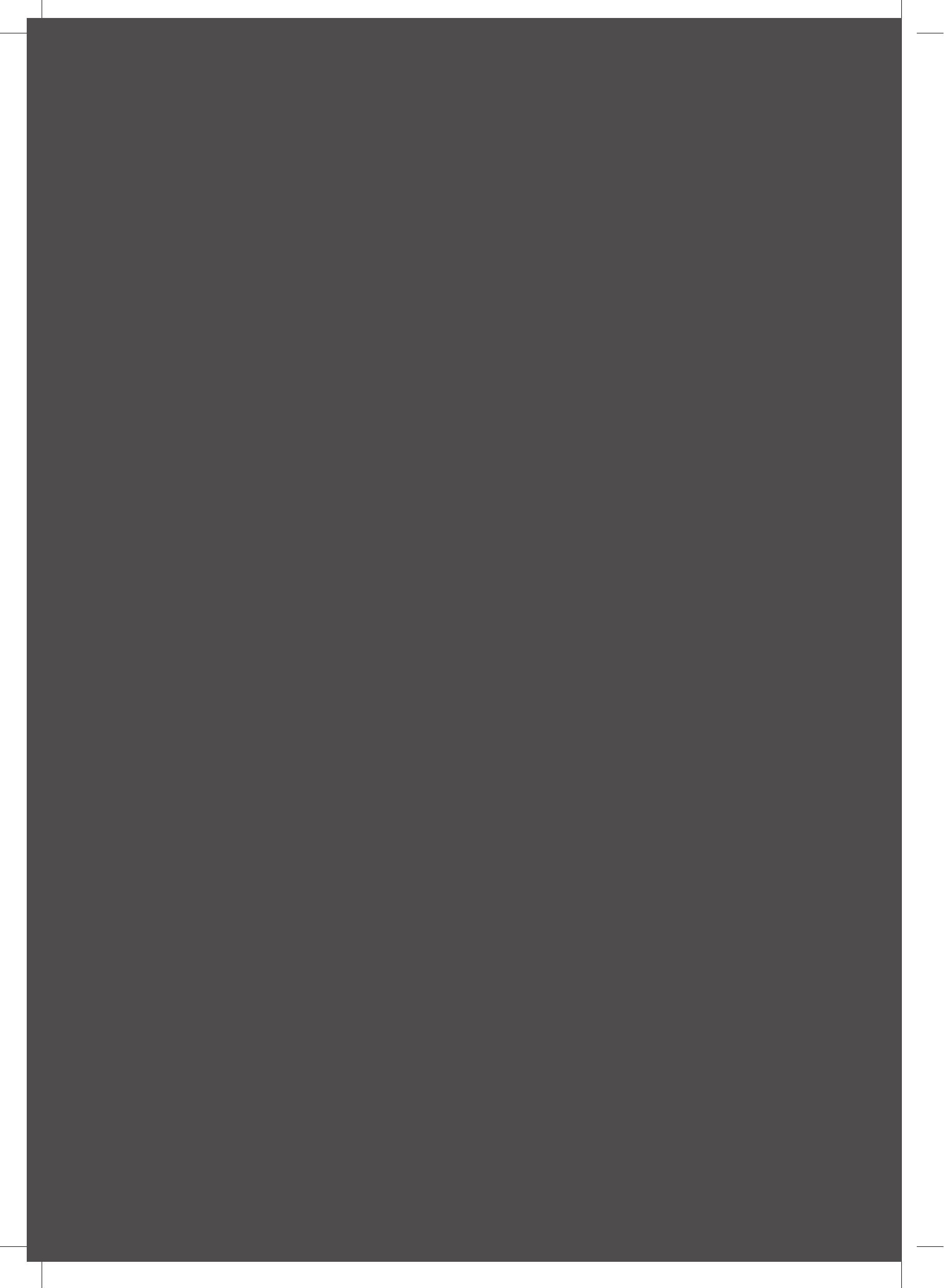




\section{PART 2}

\section{Experimental findings on intraperitoneal mesh related adhesions}

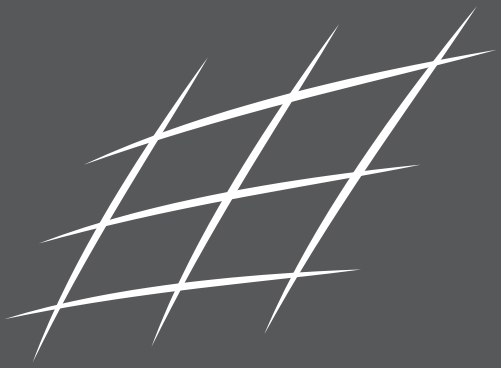




\title{
Chapter 4
}

\author{
Degradation of mesh coatings \\ and intraperitoneal adhesion formation \\ in an experimental model
}

\author{
M. H. Schreinemacher ${ }^{1}$ \\ P. J. Emans ${ }^{1,2}$ \\ M. J. Gijbels ${ }^{3,4}$ \\ J.-W. M. Greve ${ }^{1}$ \\ G. L. Beets ${ }^{1}$ \\ N. D. Bouvy ${ }^{1}$
}

British Journal of Surgery 2009

\section{Affiliations}

${ }^{1}$ Department of Surgery, Maastricht University Medical Centre, Maastricht, The Netherlands.

${ }^{2}$ Department of Orthopaedic Surgery, Maastricht University Medical Centre, Maastricht, The Netherlands.

${ }^{3}$ Department of Molecular Genetics, Maastricht University Medical Centre, Maastricht, The Netherlands.

${ }^{4}$ Department of Pathology, Maastricht University Medical Centre, Maastricht, The Netherlands. 


\section{Abstract}

\section{Background}

In laparoscopic ventral hernia repair a mesh is placed in direct contact with the viscera, often leading to substantial adhesions. In this experimental study the ability of different coated and uncoated meshes to attenuate adhesion formation was examined.

\section{$4 \quad$ Methods}

Six commercially available meshes were placed intraperitoneally against a closed peritoneum in rats: Prolene ${ }^{\circledast}$ (polypropylene), Timesh ${ }^{\circledR}$ and Ultrapro ${ }^{\circledR}$ (polypropylene composites with titanium and polyglecaprone, respectively), Proceed ${ }^{\circledR}$ and Parietex Composite ${ }^{\circledR}$ (polypropylene and polyester meshes coated with a layer of cellulose and collagen, respectively) and C-Qur ${ }^{\circledR}$ (polypropylene mesh coated with a layer of omega-3 fatty acids). Adhesions and incorporation were evaluated macroscopically and microscopically after 7 and 30 days.

\section{Results}

Parietex Composite ${ }^{\circledR}$ and C-Qur ${ }^{\circledast}$ significantly reduced adhesion formation at 7 days follow-up compared with all other meshes. By 30 days, this effect had diminished as a significant increase in adhesions together with phagocytosis of the coating was seen for all meshes with layered coatings (Proceed ${ }^{\circledR}$, Parietex Composite ${ }^{\circledR}$ and C-Qur ${ }^{\circledR}$ ). Incorporation was insufficient for all meshes.

\section{Conclusion}

The absorbable layers of Parietex Composite ${ }^{\circledR}$ and C-Qur ${ }^{\circledR}$ reduce adhesion formation to intraperitoneal mesh in the short term, but the effect diminishes and phagocytosis of absorbable coatings may contribute to adhesion formation. 


\section{Introduction}

At least one in every ten patients develops a ventral hernia after midline laparotomy ${ }^{1,2}$. About a third of these patients experience serious discomfort, aesthetic complaints, intestinal obstruction or acute strangulation warranting hernia repair ${ }^{3,4}$.

In general, suture hernia repair has been abandoned owing to unacceptably high recurrence rates, and mesh placement is now considered the standard technique ${ }^{4-6}$. Mesh placement in the posterior position, rather than anterior placement or within the abdominal musculature, is associated with the lowest recurrence and infection rates ${ }^{7-9}$. The posterior position can be achieved extraperitoneally by open development of a plane between the rectus muscle and the posterior fascia. Laparoscopic positioning of the mesh inside the peritoneal cavity, however, does not necessitate dissection of a large plane, reduces loss of skin integrity and provides the opportunity for ventral abdominal wall inspection for additional hernias. A further reduction in recurrence, infection and length of hospital stay can therefore be achieved ${ }^{10,11}$.

Polypropylene is probably the most widely used prosthetic material in mesh repair owing to its low cost, non-biodegradability and excellent incorporation ${ }^{12,13}$. Placed intraperitoneally, however, the inflammatory reaction can lead to adhesions or even fistula formation ${ }^{14,15}$. There is a strong association between adhesions and small bowel obstruction, infertility and chronic pain ${ }^{16,17}$. Future surgery after intraperitoneal mesh placement may be seriously complicated by adhesions $\mathrm{s}^{18,19}$.

Adhesion reduction is therefore of clinical interest, and this has been achieved both experimentally and clinically by interposition of omentum or degradable compounds such as polyglactin, hyaluronate and cellulose $\mathrm{e}^{20-23}$ among others. It has been hypothesized that degradation of such coatings leads to increased adhesion formation in the long term. Although many of these coatings have been investigated in the past, this was mainly in the experimental setting with resection of the abdominal musculature and peritoneum ${ }^{24,25}$, which leaves an acute wound with an open peritoneum and a mesh covered only by skin. The aim of the present study was to assess adhesion formation associated with various meshes in a rat model of intraperitoneal mesh placement against a closed peritoneum.

\section{Methods and Materials}

Male Wistar rats weighing 250-300 g were housed and cared for at the Central Animal Facilities of Maastricht University with free access to water and food, in accordance with local standards. The experimental protocol complied with the Dutch Animal Experimentation Act and was approved by the Committee of Animal Experiments.

Several commercially available meshes (Table 1) were implanted in the abdomen in contact with the viscera (12 rats per mesh, except that 13 rats received Prolene ${ }^{\circledR}$ ). For meshes with a layered coating (Proceed ${ }^{\circledR}, \mathrm{C}-\mathrm{Qur}^{\circledR}$ and Parietex Composite ${ }^{\circledR}$ ), the coated side was placed adjacent to the viscera. Rats were killed at 7 and 30 days after implantation 
Table 1. Composition of meshes

\begin{tabular}{|c|c|c|c|}
\hline Brand name & Basic material & Composite with & Manufacturer \\
\hline Prolene $^{\circledR}$ & polypropylene & nothing & $\begin{array}{l}\text { Ethicon, Johnson \& Johnson, } \\
\text { Somerville, New Jersey, USA }\end{array}$ \\
\hline $\operatorname{Timesh}^{\circledR}$ & polypropylene & non-absorbable titanium & $\begin{array}{l}\text { GfE Medizintechnik, } \\
\text { Nuremberg, Germany }\end{array}$ \\
\hline Proceed $^{\circledR}$ & polypropylene & $\begin{array}{l}\text { absorbable layer of polydioxanone } \\
\text { and oxidized regenerated cellulose }\end{array}$ & $\begin{array}{l}\text { Ethicon, Johnson \& Johnson, } \\
\text { Somerville, New Jersey, USA }\end{array}$ \\
\hline Ultrapro $^{\circledR}$ & polypropylene & absorbable polyglecaprone & $\begin{array}{l}\text { Ethicon, Johnson \& Johnson, } \\
\text { Somerville, New Jersey, USA }\end{array}$ \\
\hline C-Qur ${ }^{\circledR}$ & polypropylene & absorbable layer of omega-3 fatty acids & $\begin{array}{l}\text { Atrium, Hudson, } \\
\text { New Hampshire, USA }\end{array}$ \\
\hline Parietex Composite $^{\circledR}$ & polyester & $\begin{array}{l}\text { absorbable layer of collagen- } \\
\text { polyethylene glycol-glycerol }\end{array}$ & $\begin{array}{c}\text { Sofradim, Tyco Healthcare, } \\
\text { Trevoux, France }\end{array}$ \\
\hline
\end{tabular}

(six rats per mesh at each time point, except seven in the 30-day Prolene ${ }^{\circledR}$ group), adhesions were scored macroscopically, and the meshes harvested and processed for histology.

\section{Surgical procedures}

Rats were anaesthetized with intraperitoneal $100 \mathrm{mg} / \mathrm{kg}$ ketamine hydrochloride and $5 \mathrm{mg} / \mathrm{kg}$ xylazine. The abdomen was shaved and the skin disinfected with 2 per cent iodine before covering with sterile drapes. The abdomen was opened through a $4 \mathrm{~cm}$ midline incision. A sterile piece of mesh $20 \times 30 \mathrm{~mm}$ in size was fixed to the visceral side of the peritoneum on both sides of the incision with two sutures of polypropylene $4 \times 0$ (Prolene ${ }^{\circledR}$; Ethicon, Johnson \& Johnson, Somerville, New Jersey, USA). Omentum was not deliberately placed over the viscera. The peritoneum and fascia were closed with a running suture of polyglactin $4 \times 0$ (Vicryl ${ }^{\circledR}$; Ethicon, Johnson \& Johnson). The skin was closed intracutaneously with a running suture of polyglecaprone $4 \times 0$ (Monocryl ${ }^{\circledR}$; Ethicon, Johnson \& Johnson). No antibiotics were administered.

Rats were killed by an overdose of inhaled carbon dioxide. After macroscopic evaluation the mesh was excised locally with the adjacent tissue. Each specimen was split into four equal pieces and fixed in 4 per cent formaldehyde solution.

\section{Functional macroscopic evaluation}

The abdomen was opened through a U-shaped incision, extending lateral and caudal to the mesh. Infection was defined as a clinically apparent infection with pus at the time of death. The amount of adhesion formation was scored macroscopically and the organs involved were recorded.

A published quantitative and qualitative scoring system was applied by two independent researchers who were blinded to the study group ${ }^{20,22,26}$. The percentage of mesh covered with adhesions was assessed quantitatively by calculating the mean value for the four equal pieces of each mesh. Qualitatively, total adhesion scores (range 0-11) were calculated by summing three subscores: extent ( 0 , no adhesions; $1,1-25$ per cent of the mesh surface 
involved; 2, 26-50 per cent; 3, 51-75 per cent; 4, 76-100 per cent); type ( 0 , no adhesions; 1, filmy; 2, dense; 3 , capillaries present; 4 , larger vessels) and tenacity ( 0 , no adhesions; 1 , adhesions fall apart easily; 2 , require traction; 3 , require sharp dissection). When different scores were attributed to a sample, the score of a third independent researcher was obtained and the median value recorded. Incorporation of the mesh into the peritoneal surface was graded as 0 (no incorporation), 1 (1-25 per cent of the mesh surface involved), 2 (26-50 per cent), 3 (51-75 per cent) or 4 (76-100 per cent).

\section{Histology}

After dehydration in increasing concentrations of alcohol, the pieces of each specimen were embedded in glycol methacrylate (Technovit 7100 ${ }^{\circledR}$; Heraeus Kulzer, Wehrheim, Germany) so that each slice included a transection of all four pieces of mesh. Slices $5 \mu \mathrm{m}$ thick were stained with haematoxylin and eosin. The samples were evaluated by an experienced animal pathologist who was not familiar with the specific background of the different meshes. Semiquantitative scores were assigned for inflammation at 7 days and granulation tissue at 30 days follow-up: not present, slightly present (only directly around mesh material), moderately present (also in between mesh material) or abundantly present (thick layer of reactive tissue around all mesh material). The presence of fibroblasts, giant cells and macrophages was scored as described previously ${ }^{27,28}$.

\section{Statistical analysis}

Based on a pilot study, a power of 80 per cent and a difference of 25 per cent to be detected, a required sample size of six was calculated. Continuous data are presented as median (interquartile range). Statistical analysis was performed by the Mann-Whitney $U$ test and Fisher's exact test using SPSS ${ }^{\circledR}$ version 15.0 (SPSS Inc., Chicago, Illinois, USA). $P<0.050$ was considered significant.

\section{Results}

Directly after mesh implantation, one rat in the Proceed ${ }^{\circledR}$ (30 days) and one in the Ultrapro ${ }^{\circledR}$ (7 days) group died, probably from an overdose of anaesthetic. All other animals were well.

\section{Functional macroscopic evaluation}

No clinical signs of infection were observed. Mesh adhesions were present in virtually all rats and mostly related to omentum. In some animals, visceral adhesions (bowel, spleen or liver) were also noted and scored separately (Table 2). Regardless of the type of mesh, the fixing sutures and cut edges of the mesh were preferential sites for adhesion formation.

At 7 days follow-up, Prolene ${ }^{\circledR}$, Timesh $^{\circledR}$ andUltrapro ${ }^{\circledR}$ showed the highest percentage of mesh coverage with adhesions. Proceed ${ }^{\circledast}, \mathrm{C}-$ Qur $^{\circledR}$ and Parietex Composite ${ }^{\circledR}$ showed $^{\circledR}$ 
significantly less coverage and had lower adhesion scores than Prolene ${ }^{\circledR}$ (all $P=0.002$ ). Except when compared with Proceed ${ }^{\circledR}$ in terms of total adhesion score, mesh coverage and total adhesion scores were significantly lower for C-Qur ${ }^{\circledR}$ and Parietex Composite ${ }^{\circledR}$ than for all other meshes (percentage of mesh covered with adhesions: both $P=0.002$ vs Prolene ${ }^{\circledR}$ and vs Timesh ${ }^{\circledast}, P=0.009$ and $P=0.041$ respectively vs Proceed ${ }^{\circledast}$, both $P=0.004$ vs Ultrapro $^{\circledR}$; total adhesion scores: both $P=0.002$ vs Prolene ${ }^{\circledR}, P=0.002$ and $P=0.009$ respectively vs Timesh $^{\circledR}$, both $P=0.004$ vs Ultrapro ${ }^{\circledR}$ ). Visceral adhesions occurred in all groups except $4 \quad$ Ultrapro $^{\circledR}$ and Parietex Composite ${ }^{\circledast}$. Statistically significant differences in such adhesions were observed only between these two groups and Proceed ${ }^{\circledR}$ (both $P=0.015$ ).

At 30 days follow-up, C-Qur ${ }^{\circledR}$ and Parietex Composite ${ }^{\circledR}$ meshes had significantly lower percentage coverage with adhesions and total adhesion scores than Prolene ${ }^{\circledR}$ (Figure 1). C-Qur ${ }^{\circledR}$ also showed significantly less mesh coverage than Ultrapro ${ }^{\circledR}$, whereas Parietex Composite $^{\circledast}$ had a lower total adhesion score than Ultrapro ${ }^{\circledR}$ (Figure 1). All animals with Ultrapro ${ }^{\circledast}$ had visceral adhesions, compared with two of seven with Prolene ${ }^{\circledast}$ and none of six with Parietex Composite ${ }^{\circledast}(P=0.021$ and $P=0.002$ respectively) (Table 2). Parietex Composite ${ }^{\circledR}$ was the only mesh with no visceral adhesions at 30 days.

Between 7 and 30 days, the percentage of Proceed ${ }^{\circledR}, \mathrm{C}-\mathrm{Qur}^{\circledR}$ and Parietex Composite ${ }^{\circledR}$ meshes covered with adhesions increased significantly, with a gain of 70, 30 and 58 per cent respectively (Figures 2 and 3 ). Total adhesion scores also worsened $(P=0.004, P=$ 0.015 and $P=0.041$ respectively). Prolene ${ }^{\circledR}$ and Ultrapro ${ }^{\circledR}$ showed a reduction in adhesion coverage between 7 and 30 days of 21 and 15 per cent, but neither change was significant. With C-Qur ${ }^{\circledR}$, an easily detached filmy layer was observed after 7 days, but this layer could no longer be identified as such by 30 days and most meshes showed considerable shrinkage or folding (not quantified) (Figure 3).

Table 2. Functional macroscopic evaluation

\begin{tabular}{lccccc}
\hline Mesh & Day & $\begin{array}{c}\text { \% of mesh covered } \\
\text { with adhesions } \\
\text { (range) }\end{array}$ & $\begin{array}{c}\text { Total adhesion } \\
\text { score }^{\star}(\text { range) }\end{array}$ & $\begin{array}{c}\text { Animals with } \\
\text { adhesions to } \\
\text { viscera (n) }\end{array}$ & $\begin{array}{c}\text { Incorporation } \\
\text { score }^{\star} \text { (range) }\end{array}$ \\
\hline Prolene $^{\circledR}$ & 7 & $97 \%(93-100)$ & $9,5(8-10)$ & $4 / 6$ & $3(0-4)$ \\
Timesh $^{\circledR}$ & 30 & $76 \%(57-100)$ & $7(7-10)$ & $2 / 7$ & $1(1-4)$ \\
& 7 & $65 \%(35-100)$ & $7,5(6-8)$ & $4 / 6$ & $1(0-4)$ \\
Proceed $^{\circledR}$ & 30 & $61 \%(30-83)$ & $7,5(4-8)$ & $3 / 6$ & $1(1-2)$ \\
& 7 & $25 \%(10-50)$ & $4(4-5)$ & $5 / 6$ & $1(0-2)$ \\
Ultrapro $^{\circledR}$ & 30 & $95 \%(65-100)$ & $9(7-10)$ & $3 / 5$ & $1(1-1)$ \\
& 7 & $92 \%(73-100)$ & $8(7-9)$ & $0 / 5$ & $2(1-3)$ \\
C-Qur $^{\circledR}$ & 30 & $77 \%(49-91)$ & $7,5(6-8)$ & $6 / 6$ & $1(1-1)$ \\
& 7 & $8 \%(0-16)$ & $4(0-5)$ & $3 / 6$ & $1(1-1)$ \\
Parietex Composite $^{\circledR}$ & 7 & $38 \%(5-91)$ & $6(4-9)$ & $3 / 6$ & $1,5(1-3)$ \\
& 30 & $1 \%(0-35)$ & $0,5(1-7)$ & $0 / 6$ & $2(0-3)$ \\
\hline
\end{tabular}

${ }^{*}$ Values are median (range). 

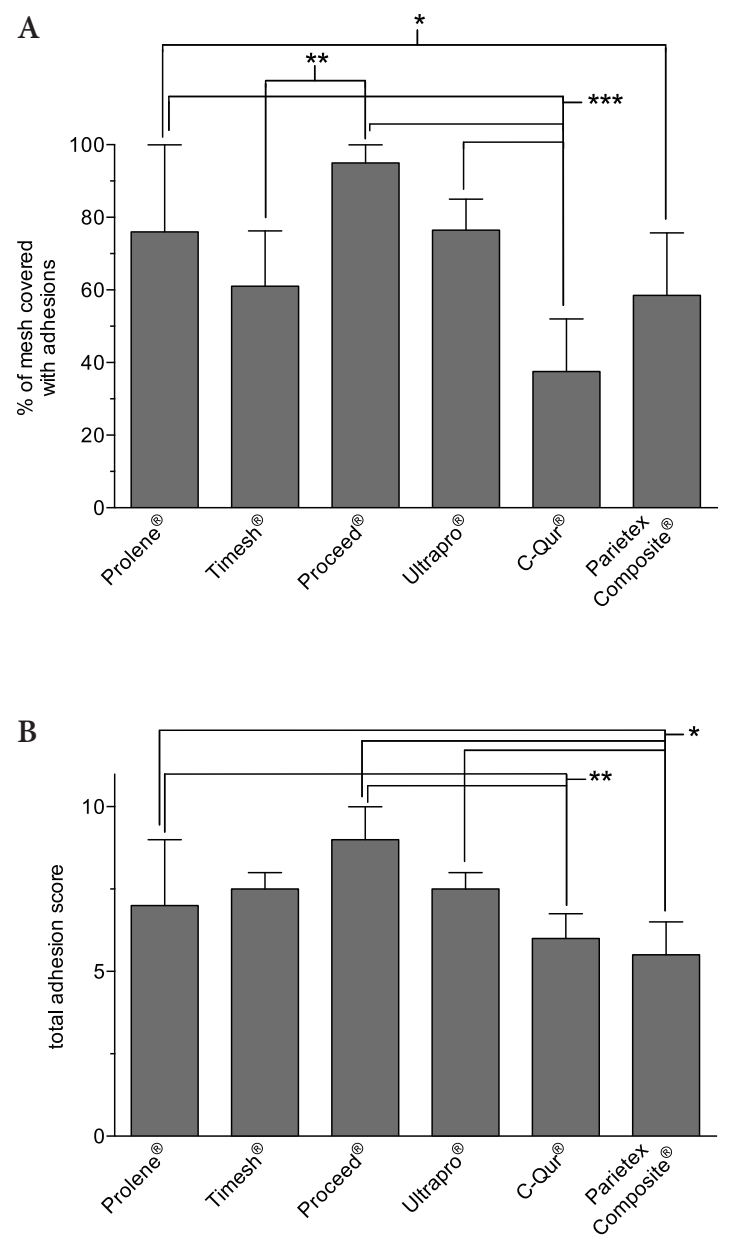

Figure 1. A Comparison of percentage of mesh covered with adhesions at 30 days follow-up. ${ }^{\star} P=0.035$, ${ }^{* *} P=0.017,{ }^{* * *} P=0.014$ (vs Prolene $\left.{ }^{\circledR}\right), P=0.009$ (vs Proceed ${ }^{\circledR}$ ), $P=0.041$ (vs Ultrapro ${ }^{\circledR}$ ). B Comparison of total adhesion scores at 30 days follow-up. ${ }^{\star} P=0.014$ (vs Prolene $\left.{ }^{\circledR}\right), P=0.017$ (vs Proceed $\left.{ }^{\circledR}\right), P=0.041$ (vs Ultrapro ${ }^{\circledR}$ ), ${ }^{* *} P=0.022$ (vs Prolene ${ }^{\circledR}$ ), $P=0.017$ (vs Proceed ${ }^{\circledR}$ ). Values are median (interquartile range), Mann-Whitney U test.

\section{Mesh incorporation}

Only poor incorporation of all meshes with the parietal peritoneum was noted (Table 2). No significant differences were observed between meshes. The best and often only incorporation was at the fixing suture site, where the mesh was held in close contact with the peritoneum.

\section{Histological evaluation}

No ingrowth of muscle fibres was observed in any of the animals. This was probably because the closed peritoneum separated mesh and muscle (Figure 4, A). At 7 days follow-up, most groups 


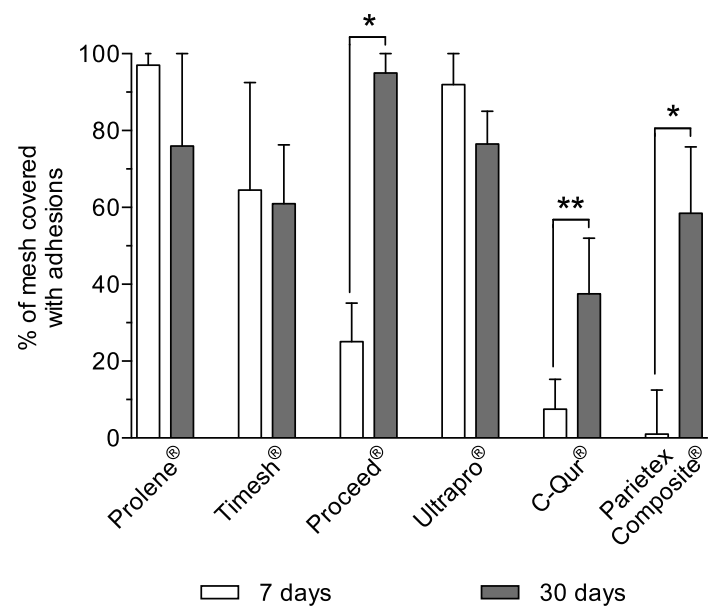

Figure 2. Comparison of percentage of each mesh covered with adhesions between 7 and 30 days follow-up. Values are median (interquartile range). ${ }^{\star} P=0.004,{ }^{* *} P=0.026$ (Mann-Whitney $\mathrm{U}$ test)

showed a similar moderate level of inflammation with mostly granulocytes and fibroblasts (Table 3). However, use of C-Qur ${ }^{\circledR}$ and Timesh ${ }^{\circledR}$ was associated with a low grade of inflammation. In the case of Proceed ${ }^{\circledR}$ and Parietex Composite ${ }^{\circledR}$ many macrophages and giant cells containing foreign material were present, indicating phagocytosis of the still visible, but degrading, coating.

At 30 days follow-up, granulation tissue consisting of organized fibroblasts and few signs of acute inflammation was most apparent with use of Prolene ${ }^{\circledR}$ and Parietex Composite ${ }^{\circledR}$. However, Parietex Composite ${ }^{\circledR}$ still showed many giant cells, now seemingly pulling apart the single fibres of polyester (Figure 4, C and D). Macrophages were virtually absent as the complete collagen coating had been absorbed. In contrast, with Proceed ${ }^{\circledR}$ there were still large numbers of macrophages degrading remnants of the cellulose coating, no sign of granulation and large numbers of disorganized fibroblasts (Figure 4, B). The omega-3 fatty acid coating of C-Qur ${ }^{\circledR}$, however, was still very much intact at 30 days. Here there was only slight evidence of granulation with some macrophages and giant cells (Figure 4, A). The polyglecaprone coating of Ultrapro ${ }^{\circledR}$ was also still present. Granulation was less than with C-Qur ${ }^{\circledR}$, but more than with Proceed ${ }^{\circledR}$.

With Timesh ${ }^{\circledR}$ only a low grade of inflammation with a moderate number of giant cells and fibroblasts was observed at 7 and 30 days. The number of fibroblasts decreased over time. At 30 days there were more giant cells but less granulation formation than with Prolene ${ }^{\circledR}$.

\section{Discussion}

In this experimental model of intraperitoneal adhesion formation to prosthetic meshes against a closed peritoneum, C-Qur ${ }^{\circledR}$ and Parietex Composite ${ }^{\circledR}$ provided the best results in terms of adhesion formation. C-Qur ${ }^{\circledR}$, a new mesh for intraperitoneal use, provided comparable results to Parietex Composite ${ }^{\circledR}$, which is already known for its good biocompatibility ${ }^{20}$. 

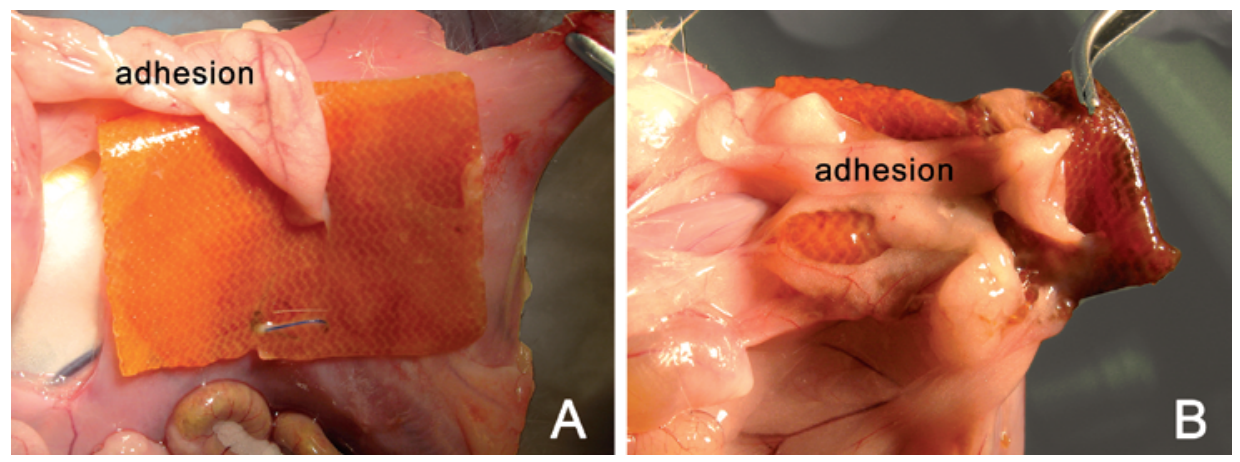

Figure 3. Representative photographs of C-Qur ${ }^{\circledR}$ mesh at A 7 days and B 30 days follow-up. In A an adhesion related to the polypropylene suture underneath it is visible. Note shrinkage of the mesh between $\mathbf{A}$ and $\mathbf{B}$.

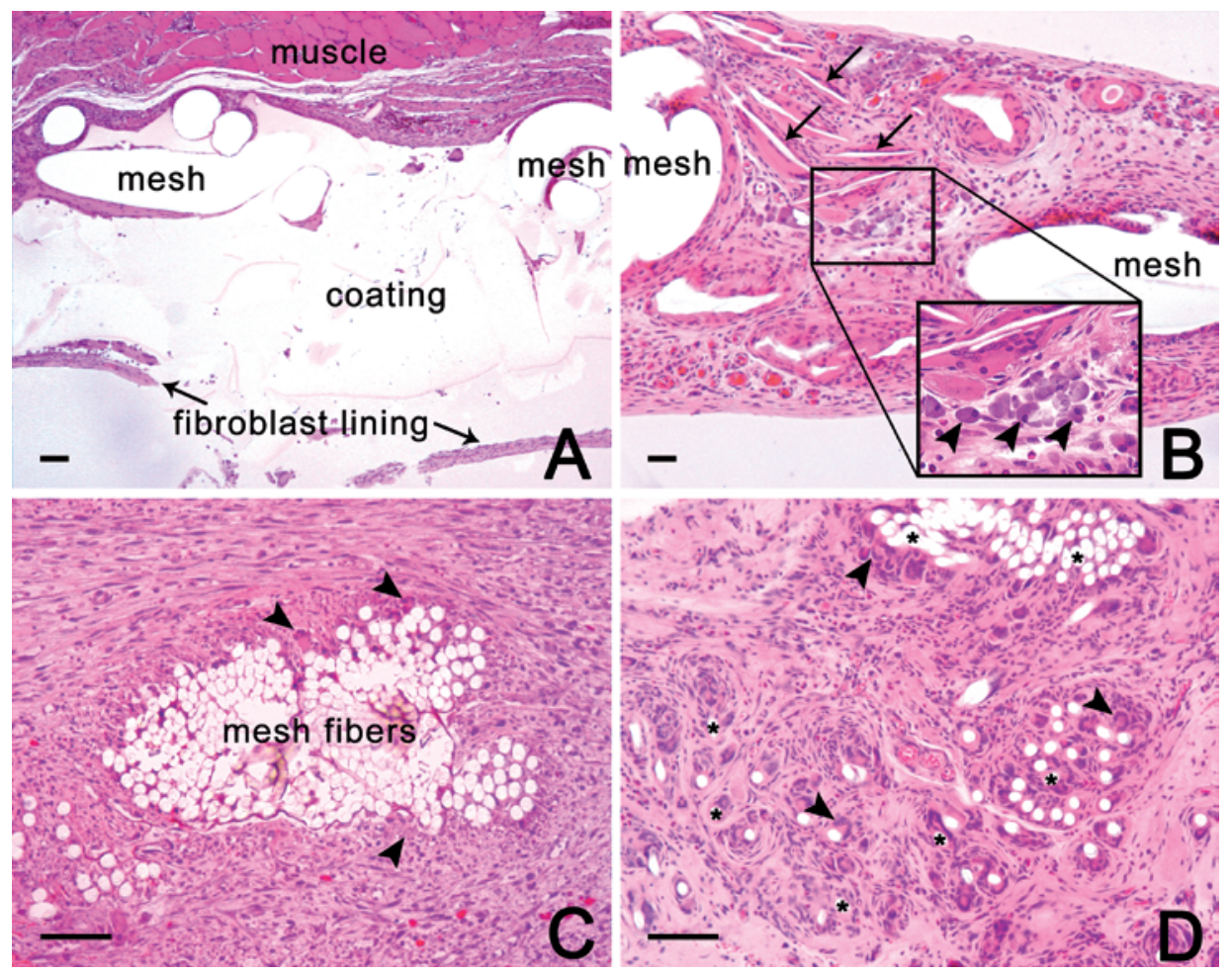

Figure 4. Representative histological samples. A C-Qur ${ }^{\circledR}$ at 30 days follow-up $(40 \times$ original magnification). There is no ingrowth of muscle as peritoneum separates mesh and muscle. B Proceed ${ }^{\circledR}$ at 30 days $\left(40 \times\right.$ original $^{-}$ magnification). Arrows indicate remnants of coating. The insert at higher magnification $(400 \times)$ shows macrophages

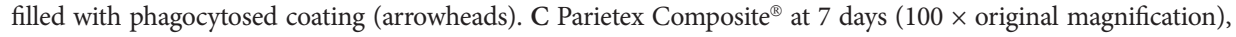
showing many small mesh fibres (polyester) close together. Arrowheads indicate giant cells. D Parietex Composite ${ }^{\circledR}$ at 30 days $(100 \times$ original magnification), mesh fibers are separated and surrounded by giant cells. Arrowheads indicate giant cells and asterisks indicate single mesh fibres (haematoxylin and eosin stain; bars indicate $100 \mu \mathrm{m}$ ). 
Table 3. Histological evaluation

\begin{tabular}{|c|c|c|c|c|c|c|c|c|}
\hline & \multicolumn{4}{|c|}{7 days } & \multicolumn{4}{|c|}{30 days } \\
\hline & 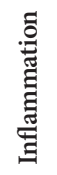 & 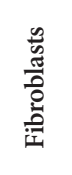 & 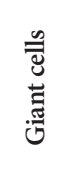 & 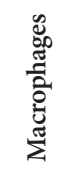 & 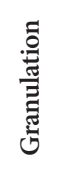 & 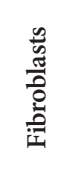 & 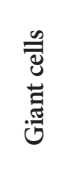 & 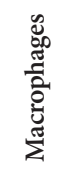 \\
\hline Prolene $\mathrm{e}^{\circledast}$ & ++ & ++ & $-1+$ & $-1+$ & ++ & ++ & + & $-1+$ \\
\hline Timesh $^{\circledR}$ & $-/+$ & ++ & ++ & $-1+$ & + & + & ++ & $-/+$ \\
\hline Proceed $^{\circledR}$ & ++ & +++ & ++ & +++ & - & +++ & ++ & +++ \\
\hline Ultrapro $^{\circledR}$ & ++ & +++ & $-/+$ & $-1+$ & $-/+$ & + & ++ & ++ \\
\hline C-Qur ${ }^{\circledR}$ & $-1+$ & $-1+$ & $-/+$ & $-1+$ & + & ++ & + & + \\
\hline Parietex Composite $^{\circledR}$ & ++ & ++ & +++ & ++ & ++ & +++ & +++ & - \\
\hline
\end{tabular}

- absent, + slightly present, ++ moderately present, +++ abundantly present.

A remarkable finding was the statistically significant increase in adhesion formation over time for all meshes with an absorbable layer (Proceed $^{\circledR}, \mathrm{C}-\mathrm{Qur}{ }^{\circledR}$ and Parietex Composite $\left.^{\circledR}\right)$. This phenomenon was most pronounced with Proceed ${ }^{\circledR}$ where an increase in mesh coverage from 25 to 95 per cent was observed. By 30 days the absorbable layer of Proceed ${ }^{\circledR}$ (oxidized regenerated cellulose) was found only as remnants surrounded by many macrophages. This prolonged active inflammation and the accompanying influx of fibroblasts probably promoted adhesion formation ${ }^{16}$. Less favourable results for Proceed ${ }^{\circledR}$ described in other studies may be related to this finding ${ }^{24,29}$.

In the case of Parietex Composite ${ }^{\circledR}$, macrophages had absorbed the collagen layer by 30 days and were no longer present. However, there were still many fibroblasts, possibly explaining the increased adhesion formation. Nevertheless, Parietex Composite ${ }^{\circledR}$ was the onlymesh that showed no visceral adhesions at either time point. This remarkable property is not yet completely understood, but both the increase in adhesion formation yet absence of visceral adhesions have been confirmed by others ${ }^{24,30}$.

C-Qur ${ }^{\circledR}$, the third mesh with an absorbable layer investigated in this study, has not yet been described in the literature. The mesh consists of a monofilament polypropylene mesh and an absorbable layer of omega-3 fatty acids. Consistent with previous findings showing that omega-3 fatty acids have anti-inflammatory properties ${ }^{31,32}$, use of C-Qur ${ }^{\circledR}$ was associated with a low grade of inflammation. As a result, macrophages were only minimally present, leaving the coating intact after 30 days. However, the number of fibroblasts rose with time, in line with the macroscopic finding of increased adhesions. In contrast to Parietex Composite $^{\circledR}$, visceral adhesions did occur with C-Qur ${ }^{\circledR}$, but the differences between meshes were not statistically significant.

Ultrapro $^{\circledR}$, a mesh with an absorbable non-layered coating of polyglecaprone, was not designed for intraperitoneal use. Polyglecaprone is known to dissolve over a minimal period of 3 months $^{33}$. The inflammatory reaction with Ultrapro ${ }^{\circledR}$ was marked by large numbers 
of fibroblasts at 7 days follow-up, coinciding with extensive adhesions. By 30 days, these numbers had dropped and adhesion scores had improved slightly.

Another notable finding was the preferential site of adhesion formation at the cut edges of the mesh and the anchoring polypropylene sutures, regardless of the mesh type. This has also been observed by others ${ }^{34,35}$. In the case of coated meshes, uncoated parts of the mesh presumably become exposed. However, a similar finding was also noted with Prolene ${ }^{\circledR}$. With Timesh $^{\circledast}$, adhesion formation to the non-absorbable non-layered coating of titanium was substantial. Interestingly, in this and other studies inert materials were confirmed to provoke only a limited inflammatory reaction ${ }^{36,37}$. Our findings indicate however that adhesion formation is determined not only by chemical features but that surface structure is equally important ${ }^{38}$.

Meshes containing an absorbable layer had low adhesion scores at 7 days follow-up. Several mechanisms of action are possible. First, the absorbable substance may modulate the local inflammatory response by prolonging it $\left(\right.$ Proceed $^{\circledR}$ ) or diminishing it $\left(\mathrm{C}-\mathrm{Qur}{ }^{\circledR}\right)$. Second, owing to its mechanical properties, a smooth, completely continuous layer may prevent host tissue penetration and minimize erosion. However, adhesions eventually form as the coating becomes absorbed. Stable biogel coatings that do not degrade may overcome this drawback ${ }^{39}$. From this study it is clear that the process of adhesion formation is not complete by day 7, as supposed by others, but is a dynamic process influenced by multiple factors ${ }^{35}$.

Two opposing properties are required for intraperitoneal meshes: adhesion prevention on the one hand and good incorporation on the other. Good incorporation prevents recurrence, shrinkage and mesh migration. In this study, incorporation between themesh and abdominal wall was insufficient in all groups, and was often noted only at the fixing suture sites. The best incorporation was observed with Parietex Composite ${ }^{\circledR}$ after 30 days. This was possibly related to the separation of mesh fibres and therefore increasing number of potential anchoring sites. Other studies have reported better incorporation, but the mesh was attached to an acute muscle wound, often with continuous sutures, whereas there was no direct muscle contact in the present study ${ }^{20,24}$. A recent study of prosthetic mesh reinforcement of the diaphragmatic hiatus in rabbits has shown that mesh incorporation depends on the type of tissue; the peritoneal surface showed limited incorporation compared with the oesophageal serosal surface ${ }^{40}$. As regards mesh fixation, only two sutures were used in the present study to minimize confounding effects. This study focused mainly on adhesion formation and less on mesh incorporation, whereas future studies should examine both aspects.

Another shortcoming of the present study is that meshes were placed at laparotomy, whereas these meshes are intended especially for laparoscopic use. Important differences in stress response exist between these different operative approaches, the two main factors being carbon dioxide insufflation and the smaller wound surface in laparoscopy ${ }^{41,42}$. The former attenuates peritoneal immunity, and the latter provides a smaller port of entrance for bacteria and reduces local trauma. As both factors seem to limit peritoneal reactivity, adhesion formation to mesh is also likely to be influenced. In the present study, however, all meshes were evaluated in the same model and the results provide useful information about differences in adhesion formation between them. Translation to the clinical situation must nevertheless be carried out with caution. 
In conclusion, absorbable layers on the surface of a mesh are able to prevent adhesion formation at 7 days, but this effect is diminished by 30 days and adhesions to the mesh are substantial. Adhesion formation is a dynamic process influenced not only by the chemical properties of a prosthetic mesh but also its mechanical properties. Cut edges of a mesh should therefore be avoided as much as possible. C-Qur ${ }^{\circledR}$ and Parietex Composite ${ }^{\circledR}$ perform best in terms of prevention of adhesion formation, but further research is needed to examine peritoneal incorporation and fixation, shrinkage and fibre separation of these meshes. Longer follow-up of slowly absorbable coatings $\left(\mathrm{C}-\mathrm{Qur}{ }^{\circledR}\right)$ is also required.

\section{Acknowledgements}

The authors declare no conflict of interest. None of the mesh manufacturers was involved in any way in the study design or analysis of results. 


\section{References}

1 Kuhry E, Schwenk WF, Gaupset R, Romild U, Bonjer HJ. Long-term results of laparoscopic colorectal cancer resection. Cochrane Database Syst Rev 2008;(2):CD003432.

2 Kingsnorth A, LeBlanc K. Hernias: inguinal and incisional. Lancet 2003;362(9395):1561-71.

3 Duepree H-J, Senagore AJ, Delaney CP, Fazio VW. Does means of access affect the incidence of small bowel obstruction and ventral hernia after bowel resection? Laparoscopy versus laparotomy. J Am Coll Surg 2003;197(2):177-81.

4 Burger JWA, Luijendijk RW, Hop WCJ, Halm JA, Verdaasdonk EGG, Jeekel J. Long-term followup of a randomized controlled trial of suture versus mesh repair of incisional hernia. Ann Surg 2004;240(4):578-83.

5 Korenkov M, Sauerland S, Arndt M, Bograd L, Neugebauer EA, Troidl H. Randomized clinical trial of suture repair, polypropylene mesh or autodermal hernioplasty for incisional hernia. Br J Surg 2002;89(1):50-6.

6 Cassar K, Munro A. Surgical treatment of incisional hernia. Br J Surg 2002;89(5):534-45.

7 Binnebosel $\mathrm{M}$, Rosch $\mathrm{R}$, Junge $\mathrm{K}$, Flanagan TC, Schwab R, Schumpelick V, Klinge U. Biomechanical analyses of overlap and mesh dislocation in an incisional hernia model in vitro. Surgery 2007;142(3):365-71.

8 de Vries Reilingh TS, van Geldere D, Langenhorst B, de Jong D, van der Wilt GJ, van Goor H, Bleichrodt RP. Repair of large midline incisional hernias with polypropylene mesh: comparison of three operative techniques. Hernia 2004;8(1):56-9.

9 McLanahan D, King LT, Weems C, Novotney M, Gibson K. Retrorectus prosthetic mesh repair of midline abdominal hernia. Am J Surg 1997;173(5):445-9.

10 Pierce RA, Spitler JA, Frisella MM, Matthews BD, Brunt LM. Pooled data analysis of laparoscopic vs. open ventral hernia repair: 14 years of patient data accrual. Surg Endosc 2007;21(3):378-86.

11 Heniford BT, Park A, Ramshaw BJ, Voeller G. Laparoscopic repair of ventral hernias: nine years' experience with 850 consecutive hernias. Ann Surg 2003;238(3):391-9.

12 Kapischke M, Schulz T, Schipper T, Tensfeldt J, Caliebe A. Open versus laparoscopic incisional hernia repair: something different from a metaanalysis. Surg Endosc 2008;22(10):2251-60.

13 Costello CR, Bachman SL, Ramshaw BJ, Grant SA. Materials characterization of explanted polypropylene hernia meshes. J Biomed Mater Res 2007;83(1):44-9.

14 Brandt CP, McHenry CR, Jacobs DG, Piotrowski JJ, Priebe PP. Polypropylene mesh closure after emergencylaparotomy: morbidity and outcome. Surgery 1995;118(4):736-40.

15 Leber GE, Garb JL, Alexander AI, Reed WP. Long-term complications associated with prosthetic repair of incisional hernias. Arch Surg 1998;133(4):378-82.

16 Ellis H. Intraabdominal and postoperative peritoneal adhesions. J Am Coll Surg 2005;200(5):641-4.

17 Holmdahl L, Risberg B, Beck DE, Burns JW, Chegini N, diZerega GS, Ellis H. Adhesions: pathogenesis and prevention-panel discussion and summary. Eur J Surg Suppl 1997;(577):56-62.

18 Halm JA, de Wall LL, Steyerberg EW, Jeekel J, Lange JF. Intraperitoneal polypropylene mesh hernia repair complicates subsequent abdominal surgery. World J Surg 2007;31(2):423-9.

19 Parker MC, Wilson MS, van Goor H, Moran BJ, Jeekel J, Duron JJ, Menzies D, Wexner SD, Ellis $\mathrm{H}$. Adhesions and colorectal surgery - call for action. Colorectal Dis 2007;9 Suppl 2(s2):66-72.

20 van't Riet M, Burger JW, Bonthuis F, Jeekel J, Bonjer HJ. Prevention of adhesion formation to polypropylene mesh by collagen coating: a randomized controlled study in a rat model of ventral hernia repair. Surg Endosc 2004;18(4):681-5.

21 Karabulut B, Sönmez K, Türkyilmaz Z, Demiroğullari B, Karabulut R, Sezer C, Sultan $\mathrm{N}$, Başaklar AC, Kale N. Omentum prevents intestinal adhesions to mesh graft in abdominal infections and serosal defects. Surg Endosc 2006;20(6):978-82.

22 Conze J, Junge K, Klinge U, Weiss C, Polivoda M, Oettinger AP, Schumpelick V. Intraabdominal adhesion formation of polypropylene mesh. Influence of coverage of omentum and polyglactin. Surg Endosc 2005;19(6):798-803.

23 Bingener J, Kazantsev GB, Chopra S, Schwesinger WH. Adhesion formation after laparoscopic ventral incisional hernia repair with polypropylene mesh: a study using abdominal ultrasound. JSLS 2004;8(2):127-31.

24 Burger JWA, Halm JA, Wijsmuller AR, Raa ten S, Jeekel J. Evaluation of new prosthetic meshes for ventral hernia repair. Surg Endosc 2006;20(8):1320-5. 
25 FelemoviciusI,BonsackME,Hagerman G,Delaney JP. Prevention of adhesions to polypropylene mesh. J Am Coll Surg 2004;198(4):543-8.

26 TheSurgical MembraneStudy Group. Prophylaxis of pelvic sidewall adhesions with Gore-Tex surgical membrane: a multicenter clinical investigation. Fertil Steril 1992;57(4):921-3.

27 Hooker GD, Taylor BM, Driman DK. Prevention of adhesion formation with use of sodium hyaluronate-based bioresorbable membrane in a rat model of ventral hernia repair with polypropylene mesh--a randomized, controlled study. Surgery 1999;125(2):211-6.

28 Matthews BD, Mostafa G, Carbonell AM, Joels CS, Kercher KW, Austin C, Norton HJ, Heniford BT. Evaluation of adhesion formation and host tissue response to intra-abdominal polytetrafluoroethylene mesh and composite prosthetic mesh. J Surg Res 2005;123(2):227-34.

29 Jacob BP, Hogle NJ, Durak E, Kim T, Fowler DL. Tissue ingrowth and bowel adhesion formation in an animal comparative study: polypropylene versus Proceed versus Parietex Composite. Surg Endosc [Internet] 2007;21(4):629-33. Available from: http://www.ncbi.nlm.nih.gov/entrez/query. fcgi? $\mathrm{cmd}=$ Retrieve\&db=PubMed\&dopt=Citation \&list_uids $=17285369$

30 Bellón JM. Abdominal wall hernia repair: a comparison of Sepramesh and Parietex composite mesh in a rabbit hernia model. $\mathrm{J} \mathrm{Am}$ Coll Surg 2007;205(1):192.

31 Simopoulos AP. Omega-3 fatty acids in inflammation and autoimmune diseases. J Am Coll Nutr 2002;21(6):495-505.

32 Calder PC. Immunomodulation by omega-3 fatty acids. Prostaglandins Leukot Essent Fatty Acids 2007;77(5-6):327-35.

33 Schug-Pass C, Tamme C, Sommerer F, Tannapfel A, Lippert H, Köckerling F. A lightweight, partially absorbable mesh (Ultrapro) for endoscopic hernia repair: experimental biocompatibility results obtained with a porcine model. Surg Endosc 2008;22(4):1100-6.

34 Junge K, Binnebösel M, Rosch R, Jansen M, Kämmer D, Otto J, Schumpelick V, Klinge U.
Adhesion formation of a polyvinylidenfluoride/ polypropylene mesh for intra-abdominal placement in a rodent animal model. Surg Endosc 2009;23(2):327-33.

35 Baptista ML, Bonsack ME, Felemovicius I, Delaney JP. Abdominal adhesions to prosthetic mesh evaluated by laparoscopy and electron microscopy. J Am Coll Surg 2000;190(3):271-80.

36 Schug-Pass C, Tamme C, Tannapfel A, Kockerling F. A lightweight polypropylene mesh (TiMesh) for laparoscopic intraperitoneal repair of abdominal wall hernias. Surg Endosc 2006;20(3):402-9.

37 Scheidbach H, Tamme C, Tannapfel A, Lippert $\mathrm{H}$, Köckerling $\mathrm{F}$. In vivo studies comparing the biocompatibility of various polypropylene meshes and their handling properties during endoscopic total extraperitoneal (TEP) patchplasty: an experimental study in pigs. Surg Endosc 2004;18(2):211-20.

38 Bellon JM, Jurado F, Garcia-Honduvilla N, Lopez R, Carrera-San Martin A, Bujan J. The structure of a biomaterial rather than its chemical composition modulates the repair process at the peritoneal level. Am J Surg 2002;184(2):154-9.

39 Emans PJ, Schreinemacher MHF, Gijbels MJJ, Beets GL, Greve J-WM, Koole LH, Bouvy ND. Polypropylene meshes to prevent abdominal herniation. Can stable coatings prevent adhesions in the long term? Ann Biomed Eng 2009;37(2):410-8.

40 Otto J, Kämmer D, Jansen PL, Anurov M, Titkova S, Ottinger A, Rosch R, Schumpelick V, Jansen M. Different tissue reaction of oesophagus and diaphragm after mesh hiatoplasty. Results of an animal study. BMC Surg 2008;8:7.

41 Moehrlen U, Ziegler U, Boneberg E, Reichmann E, Gitzelmann CA, Meuli M, Hamacher J. Impact of carbon dioxide versus air pneumoperitoneum on peritoneal cell migration and cell fate. Surg Endosc 2006;20(10):1607-13.

42 Buunen M, Gholghesaei M, Veldkamp R, Meijer DW, Bonjer HJ, Bouvy ND. Stress response to laparoscopic surgery: a review. Surg Endosc 2004;18(7):1022-8. 


\title{
Chapter 5
}

\section{Coated meshes for hernia repair provide comparable intraperitoneal adhesion prevention}

\author{
M.H. Schreinemacher ${ }^{1}$ \\ K.W. van Barneveld ${ }^{1}$ \\ R.E. Dikmans ${ }^{1}$ \\ M.J. Gijbels',3 \\ J.-W.M. Greve ${ }^{4}$ \\ N.D. Bouvy ${ }^{1}$
}

Surgical Endoscopy 2013

Affiliations

${ }^{1}$ Department of Surgery, Maastricht University Medical Centre, Maastricht, The Netherlands. ${ }^{2}$ Department of Molecular Genetics, Maastricht University Medical Centre, Maastricht, The Netherlands.

${ }^{3}$ Department of Pathology, Maastricht University Medical Centre, Maastricht, The Netherlands.

${ }^{4}$ Department of Surgery, Atrium Medisch Centrum, Heerlen, The Netherlands. 


\section{Abstract}

\section{Background}

Laparoscopic incisional hernia repair with intraperitoneal mesh is associated with a certain degree of adhesion formation to the mesh. This experimental study examined the efficacy of several coated meshes for adhesion reduction.

\section{Methods}

Five commercially available meshes with a layered coating were placed intraperitoneally in rats and followed up for 90 days: polypropylene and polyester meshes, both coated with absorbable collagen (Parietene Composite ${ }^{\circledR}$ and Parietex Composite ${ }^{\circledR}$, respectively), and three polypropylene meshes respectively coated with absorbable omega-3 fatty acids $\left(\mathrm{C}\right.$-Qur Edge ${ }^{\circledR}$ ), absorbable cellulose (Sepramesh $\mathrm{IP}^{\circledR}$ ), and non-absorbable expanded polytetrafluoroethylene (Intramesh $\mathrm{T}^{\circledR}{ }^{\circledR}$ ). Uncoated polypropylene and collagen meshes (Parietene ${ }^{\circledR}$ and Permacol $^{\circledR}$, respectively) served as the control condition. Adhesions, incorporation, and tissue reaction were evaluated macro and microscopically. Additionally, the development of the neoperitoneum was examined.

\section{Results}

All the coated meshes performed equally well in terms of adhesion reduction. The collagen mesh performed comparably, but the uncoated polypropylene mesh performed significantly worse. The different coatings led to very differing degrees of inflammation. Ingrowth was observed only at the place of suture but was comparable for all the meshes except C-Qur Edge $^{\circledast}$, which showed the weakest incorporation. Development of a neoperitoneum on the mesh surface occurred independently of whether an absorbable or non-absorbable coating or no coating at all was present.

\section{Conclusions}

Commercially available meshes with a layered coating deliver comparable adhesion reduction. The physical presence of a layered coating between the intraperitoneal content and the abdominal wall seems to be more important than the chemical properties of the coating in adhesion formation. 


\section{Introduction}

Incisional hernias remain a frequent and significant problem in abdominal surgery ${ }^{1}$. Repair of these hernias should include mesh placement whenever possible to reduce recurrence rates compared with suture repair ${ }^{2}$. Laparoscopic repair is preferred over open repair because of a shorter hospital stay, fewer infections, and better recognition of multiple herniations ${ }^{3,4}$.

In case of laparoscopic repair, the mesh is positioned intraperitoneally and becomes a specific lead point for adhesion formation. Adhesions are clinically relevant because they can lead to chronic pain, bowel obstruction, fistula, and inadvertent enterotomies at reoperation ${ }^{5-8}$. Three in four surgeons therefore aim to prevent adhesions in intraperitoneal mesh implantation?.

It is believed that adhesion prevention can be achieved by rapid restoration of a continuous mesothelial cell layer on top of a mesh (i.e., neoperitonealization) ${ }^{10}$. To support the formation of such a neoperitoneum, both the chemical composition and the morphology of the mesh have been identified as important contributors ${ }^{10,11}$. However, only limited data on the development of the neoperitoneum in relation to adhesion formation are available. Furthermore, the influence of the abdominal wall on adhesion formation has been virtually unstudied, although unlike bowel, it is the only structure continuously in close contact with the mesh.

For this study, we hypothesized that differences in the chemical compositions of the mesh coatings provide different outcomes in terms of adhesion formation. To investigate this, meshes were implanted intraperitoneally in rats and followed up for 90 days. In addition, we studied the influence of the abdominal wall and the development of the neoperitoneum on adhesion formation.

\section{Methods and Materials}

Male Wistar rats weighing 275-325 g had free access to water and food. The experimental protocol complied with the Dutch Animal Experimentation Act and was approved by the local Animal Ethics Committee of Maastricht University, the Netherlands.

\section{Experiment 1}

The first experiment studied the long-term follow-up evaluation of adhesion formation with five meshes that had a continuous coating and two meshes that had no coating (10 rats per group) during a 90 days follow-up period (Table 1). Each rat received one piece of mesh $(3 \times 2 \mathrm{~cm})$. The coated meshes were placed with the coatings facing the viscera. The meshes overlapped the midline incision and were secured to the abdominal wall using four single polypropylene $4 \times 0$ sutures (Prolene ${ }^{\circledR}$; Ethicon, Johnson \& Johnson, Somerville, NJ, USA), one in each corner of the mesh. When the animals were killed, incorporation strength also was assessed. 
Table 1. Overview of meshes used in this study

\begin{tabular}{|c|c|c|c|}
\hline Mesh & Basic material & Surface modification & Manufacturer \\
\hline Parietene $^{\circledR}$ & Polypropylene & None & $\begin{array}{l}\text { Covidien, Mansfield, } \\
\text { Massachussets, USA }\end{array}$ \\
\hline Parietene Composite $^{\circledR}$ & Polypropylene & Collagen-based layer, absorbable & $\begin{array}{l}\text { Covidien, Mansfield, } \\
\text { Massachussets, USA }\end{array}$ \\
\hline Parietex Composite ${ }^{\circledR}$ & Polyester & Collagen-based layer, absorbable & $\begin{array}{l}\text { Covidien, Mansfield, } \\
\text { Massachussets, USA }\end{array}$ \\
\hline C-Qur Edge ${ }^{\circledR}$ & Polypropylene & Omega-3 fatty acids layer, absorbable & $\begin{array}{c}\text { Atrium, Hudson, } \\
\text { New Hampshire, USA }\end{array}$ \\
\hline Sepramesh IP ${ }^{\circledR}$ & Polypropylene & $\begin{array}{l}\text { Carboxymethylcellulose and } \\
\text { hyaluronic acid fibers layer, absorbable }\end{array}$ & $\begin{array}{l}\text { Bard, Covington, } \\
\text { Georgia, USA }\end{array}$ \\
\hline Intramesh $\mathrm{T} 1^{\circledR}$ & Polypropylene & $\begin{array}{l}\text { Expanded polytetrafluoroethylene } \\
\text { (ePTFE) layer }\end{array}$ & $\begin{array}{l}\text { Cousin, } \\
\text { Wervicq-Sud, France }\end{array}$ \\
\hline Permacol $^{\circledR}$ & Crosslinked collagen & None & $\begin{array}{l}\text { Covidien, Mansfield, } \\
\text { Massachussets, USA }\end{array}$ \\
\hline
\end{tabular}

\section{Experiment 2}

The second experiment studied the influence of the abdominal wall on adhesion formation. Two meshes (each $3 \times 1 \mathrm{~cm}$ ) were implanted intraperitoneally in seven rats. The polypropylene mesh without coating (control condition) was placed on one side of the midline, and the coated polypropylene mesh (Intramesh $\mathrm{T} 1^{\circledR}$ ) was placed the other side. The coating was placed upside down (i.e., facing the abdominal wall). This excluded the interaction between the abdominal wall and the polypropylene mesh. Intramesh $\mathrm{T} 1^{\circledR}$ was chosen because it showed one of the least inflammatory reactions in experiment 1 . The follow-up period was 16 days, and the positions of the meshes were alternated after each procedure.

\section{Experiment 3}

The third experiment studied the early host reaction to three of the aforementioned meshes and the development of the neoperitoneum at a follow-up evaluation after 1, 4, 8, and 16 days. A total of 36 rats (3 rats per group per time point) received either a polypropylene mesh with no coating (Parietene ${ }^{\circledR}$ ), a polypropylene mesh with an absorbable coating (Sepramesh $\mathrm{IP}^{\circledR}$ ) or a polypropylene mesh with a non-absorbable coating (Intramesh $\mathrm{T}^{\circledR}$ ) using the same procedures as in experiment 1 .

\section{Operative procedures}

The animals were anesthetized with isoflurane $2.5 \%$. After the abdomen had been shaved and the skin disinfected with $1 \%$ iodine, the abdomen was accessed through a $4 \mathrm{~cm}$ midline incision. Subsequent to mesh implantation, the muscular layers were closed with a running suture of polyglactin $4 \times 0$ (Vicryl ${ }^{\circledR}$; Ethicon, Johnson \& Johnson), and the skin was closed with an intracutaneous running suture of polyglecaprone $4 \times 0$ (Monocryl ${ }^{\circledR}$; Ethicon, Johnson \& Johnson). No antibiotics were administered, and the procedures were performed under sterile 
conditions. The rats were killed with an overdose of carbon dioxide by inhalation. Afterward, the abdomen was opened through an $\mathrm{U}$-shaped incision extending lateral and caudal to the meshes. Thereafter, meshes were scored macroscopically by two blinded and independent observers and excised together with the underlying abdominal wall. In case of disagreement between the observers, a third observer scored the mesh as well, and the median was recorded.

\section{Adhesions}

After opening of the abdomen, a standardized picture of the mesh was taken for computer quantification of the extent of adhesions. Furthermore, we recorded the total adhesion score (range, $0-11$ ) based on the extent ( $0=$ no adhesions, $1=1-25 \%$ involvement of the mesh surface, $2=26-50 \%$ involvement, $3=51-75 \%$ involvement, $4=76-100 \%$ involvement), type ( $0=$ no adhesions, $1=$ filmy, $2=$ dense, 3 = capillaries present, $4=$ larger vessels $)$, and tenacity of adhesions $(0=$ no adhesions, $1=$ adhesions fall apart easily, $2=$ traction required, $3=$ sharp dissection required $)^{12,13}$.

\section{Incorporation}

The mesh surface incorporated into the abdominal wall immediately after the animals were killed was scored as follows: 0 (no incorporation), 1 (1-25\% incorporation of the mesh surface), 2 (26-50\% incorporation), 3 (51-75\% incorporation), and 4 (76-100\% incorporation). Additionally, a piece of mesh overlapping the abdominal wall exactly $1 \mathrm{~cm} 2$ was prepared, and the fixating suture in this region was cut. Incorporation strength was defined as the maximum tensile strength needed to tear the mesh of the abdominal wall at a constant uniaxial pulling rate of $1 \mathrm{~mm} / \mathrm{s}$. A digital tensiometer was used (Advanced Force Gauge ${ }^{\circledR}$; Mecmesin, Slinfold, UK).

\section{Histology}

Specimens were fixated in formaldehyde $4 \%$, dehydrated, and embedded in paraffin. Tissue sections 4-5 $\mu \mathrm{m}$ thick were cut and hematoxylin-eosin stained. Additionally, standard immunohistochemistry was performed for macrophages (monoclonal mouse anti-rat CD68, clone ED-1, 1:50; Hycult Biotech, Uden, the Netherlands) and functional microvilli of mesothelial cells (monoclonal mouse anti-human mesothelial cells, clone HBME-1, 1:50; Dako, Glostrup, Denmark). An experienced animal pathologist evaluated all the sections. A semiquantitative score was assigned as follows: not present, slightly present (only directly around mesh material), moderately present (also between mesh material), or abundantly present (thick layer of reactive tissue around all mesh material) ${ }^{14}$.

\section{Statistical analysis}

All data are expressed as means \pm standard error of the means. Comparisons were calculated using one-way analysis of variance and t tests. A Bonferroni corrected $P<0.050$ was considered statistically significant. All analyses were performed using SPSS $^{\circledR}$ version 17.0 (SPSS Inc., Chicago, IL, USA). 


\section{Results}

All the animals were thriving and well after mesh implantation except for two animals that died immediately after surgery. At the time the animals were killed, no clinical signs of infection such as pus were observed in any animal.

\section{Experiment 1}

In general, adhesions consisted of omental fat and formed mainly at the edges of the mesh and at the fixating sutures. All the meshes performed significantly better than the uncoated polypropylene mesh (Parietene ${ }^{\circledR}$ ) in terms of adhesions at the 90 days follow-up evaluation (Figure 1, A and B). Parietene Composite ${ }^{\circledR}$ and Sepramesh ${ }^{\circledR}$ showed the least coverage with adhesions, although significantly less compared only with Parietene ${ }^{\circledR}$ and Permacol ${ }^{\circledR}$ (Figure 1, A). Qualitatively, Sepramesh ${ }^{\circledR}$ showed significantly better total adhesion scores than the other meshes except for Parietene Composite ${ }^{\circledR}$ (Figure 1, B).
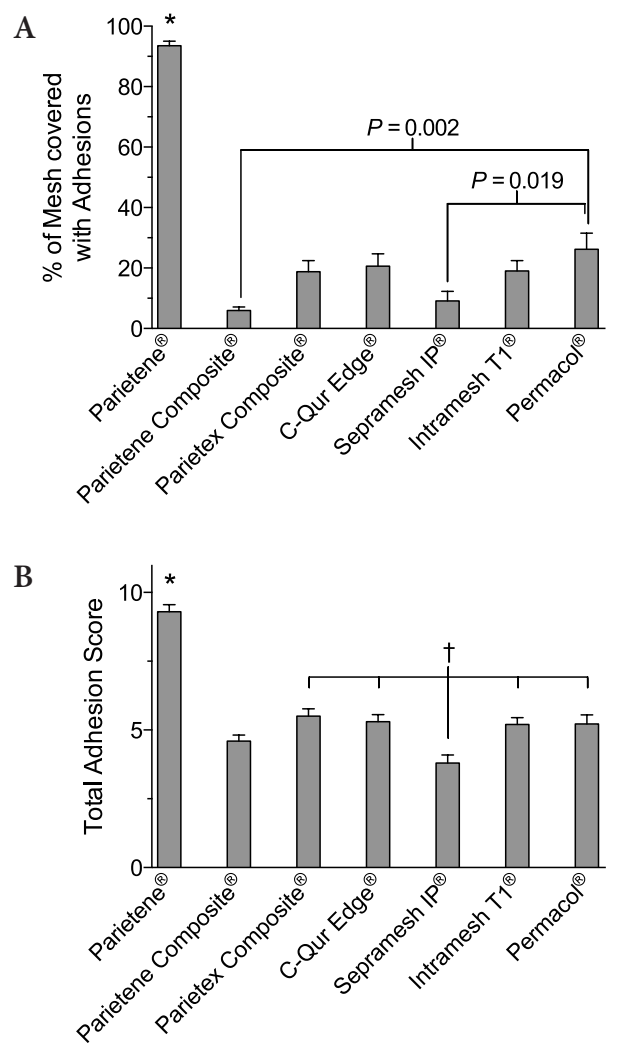

Figure 1. Comparisons between meshes at 90 days follow-up for (A) the percentage of surface covered with adhesions and (B) the total adhesion score. Results are expressed as the mean \pm standard error. $\left({ }^{*} P<0.001\right.$ compared to the other meshes, $\dagger P<0.05$ compared with Sepramesh $^{\circledR}$ ) 
The strength of fixation was comparable among all the meshes except C-Qur Edge ${ }^{\circledR}$, which showed significantly weaker incorporation (Figure 2, A). However, the mesh surface incorporated in the abdominal wall was comparable among all the meshes but was restricted mainly to the site of the fixating sutures (Figure 2, B). In addition, two clear linings of functional mesothelial cells were found between the mesh and the abdominal wall except at the suture sites (Figure 3, A).

Permacol ${ }^{\circledast}$ showed the least inflammatory reaction and very limited ingrowth of cells, with only minimal amounts of connective tissue surrounding the mesh (Figure 3, B; Table 2). Parietene ${ }^{\circledR}$ and Intramesh $\mathrm{T} 1^{\circledast}$, the two synthetic meshes with no absorbable content, showed only a minimal inflammatory reaction, especially in terms of macrophages.

The coatings of Parietene Composite ${ }^{\circledR}$, Parietex Composite ${ }^{\circledR}$, and Sepramesh $\mathrm{IP}^{\circledR}$ were no longer present. With Sepramesh $\mathrm{IP}^{\circledR}$, moderate amounts of macrophages and some foreignbody giant cells still remained. This was in contrast to Parietene Composite ${ }^{\circledR}$ and Parietex Composite $^{\circledR}$, which showed a very active inflammatory reaction with many macrophages and

A
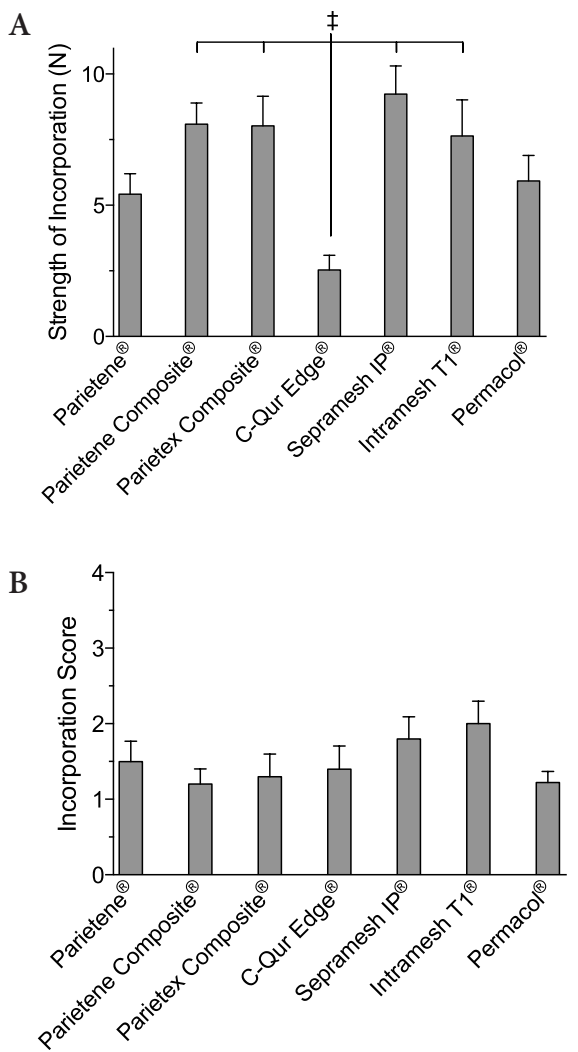

Figure 2. Comparisons between meshes at 90 days follow-up for (A) the strength of incorporation and (B) incorporation score. Results are expressed as the mean \pm standard error. $\left({ }^{*} P<0.001\right.$ compared to the other meshes, $\ddagger P<0.05$ compared with C-Qur Edge ${ }^{\circledR}$ ) 
Table 2. Histological evaluation of the meshes at the 90 days follow-up evaluation.

\begin{tabular}{|c|c|c|c|c|}
\hline & Granulocytes & Macrophages & Foreign body giant cells & Connective tissue \\
\hline Parietene $^{\circledR}$ & $-1+$ & $-1+$ & + & + \\
\hline Parietene Composite ${ }^{\circledR}$ & + & ++ & ++ & + \\
\hline Parietex Composite ${ }^{\circledR}$ & $-1+$ & +++ & +++ & ++ \\
\hline C-Qur Edge ${ }^{\circledR}$ & - & ++ & $-1+$ & ++ \\
\hline Sepramesh IP ${ }^{\circledast}$ & $-1+$ & ++ & + & $+/++$ \\
\hline Intramesh $\mathrm{T} 1^{\circledast}$ & $-1+$ & + & + & ++ \\
\hline Permacol $^{\circledR}$ & - & $-1+$ & - & $-1+$ \\
\hline
\end{tabular}

-, absent; +, slightly present; ++, moderately present; +++, abundantly present

foreign-body giant cells (Figure 3, C). With C-Qur Edge ${ }^{\circledR}$, the coating was still present and surrounded by many macrophages but almost no foreign body giant cells (Figure 3, D).

\section{Experiment 2}

When Intramesh $\mathrm{T} 1{ }^{\circledast}$ was placed upside down (i.e., with the polypropylene mesh facing the viscera while separated from the abdominal wall by the ePTFE coating), significantly fewer adhesions formed than with the uncoated polypropylene mesh (67 vs $95 \%$, respectively; $P<0.001)$.

\section{Experiment 3}

Already after 1 day, a rich inflammatory infiltrate had formed within the abdominal wall and between the mesh fibers. In the cases of Intramesh ${ }^{\circledR}$ and Sepramesh ${ }^{\circledR}$, this infiltrate was covered by the coating but extended beyond the borders of the coating. At those edges, it was associated with adhesion formation (Figure 3, E and F). With Sepramesh IP ${ }^{\circledR}$, an extensive swelling of the coating appeared after about 4 days of follow-up evaluation together with a decrease in adhesions. Then, rapid infiltration and degradation of the coating paralleled an increase in adhesions from day 8. This was in contrast to Parietene ${ }^{\circledR}$ and Intramesh $\mathrm{T} 1^{\circledast}$ (both consisting of only non-absorbable materials), which showed an increase in inflammation and adhesions at about day 4 , followed by a slow decrease in inflammation. In the case of Intramesh $\mathrm{T} 1^{\circledR}$, this coincided with a decrease in adhesions, whereas in the case of Parietene ${ }^{\circledR}$, it did not.

With regard to neoperitonealization, functional mesothelial cells were noted mainly at the mesh borders together with some spots on top of the meshes (Figure 3, F). At 16 days, a continuous lining of functional mesothelial cells was clearly identified on top of all overlying tissue, whether adhesions were present or not and irrespective of the type of mesh. Notably, the parietal peritoneum beneath the mesh regained full functional mesothelial coverage on day 16 as well. 

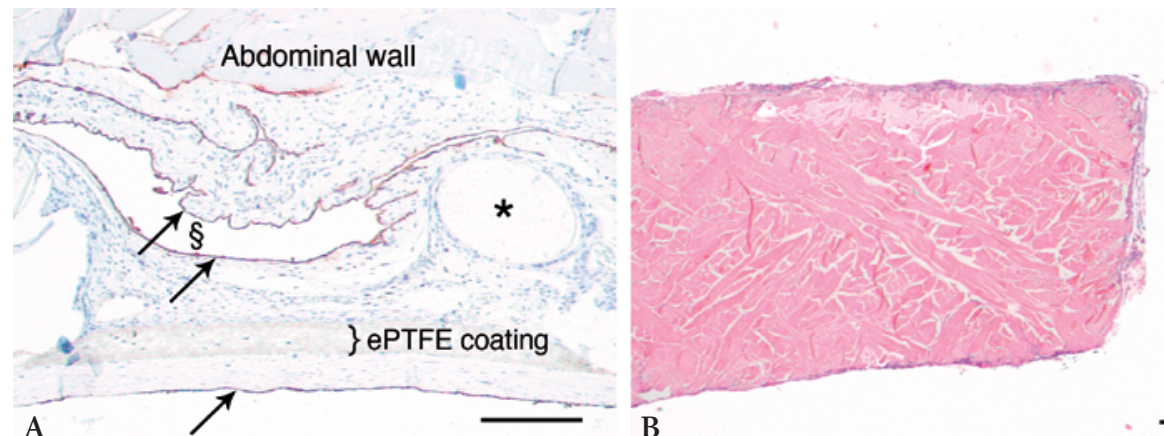

A B
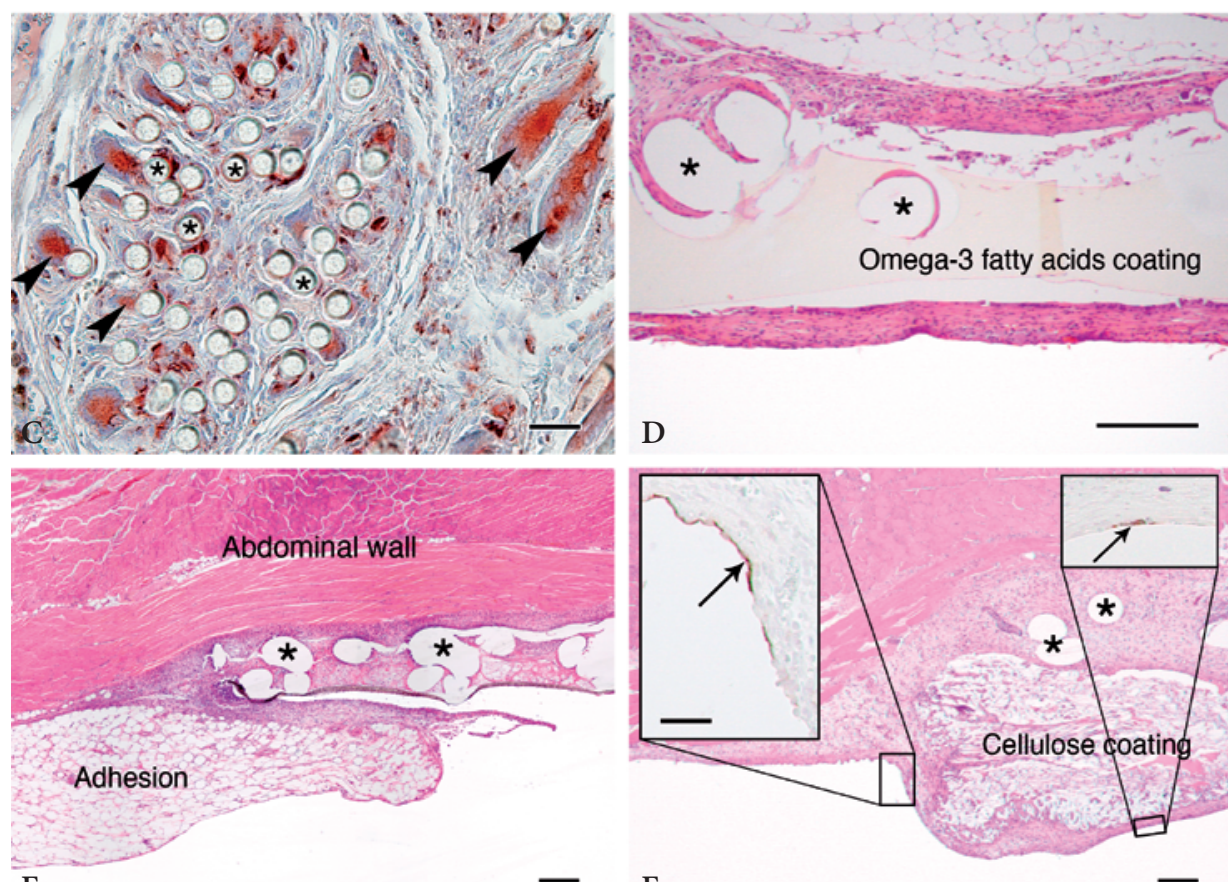

$\mathrm{D}$

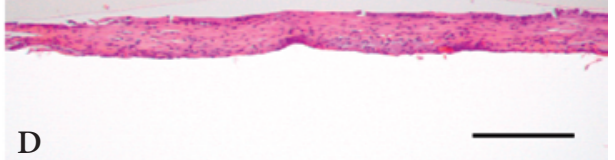

$\mathrm{E}$

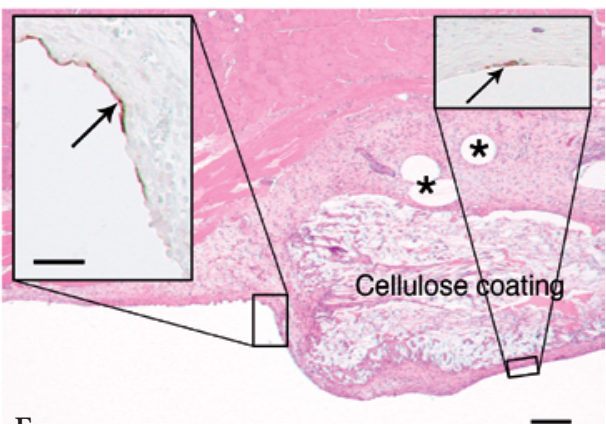

F

Figure 3. Representative histological samples with asterisks indicating mesh fibers. A shows Intramesh $\mathrm{T} 1^{\circ}$ at 90 days follow-up $(100 \times$ original magnification, anti-HBME-1). Mesothelial cell linings (arrows) were found on top of the coating, but also between the abdominal wall and the mesh ( $\$$ ). B Permacol ${ }^{\circledR}(40 \times$ original magnification, HE) was only surrounded by a very thin layer of connective tissue with no significant infiltration at 90 days follow-up. C Parietex Composite ${ }^{\circledast}$ at 90 days follow-up ( $200 \times$ original magnification, anti-ED-1) with macrophages merged into foreign body giant cells (arrowheads) surrounding the mesh fibres. D C-Qur Edge ${ }^{\circledR}$ at 90 days follow-up $(100 \times$ original magnification, HE) shows a still present omega-3 fatty acids coating. E shows Intramesh $\mathrm{T} 1^{\circledR}$ at 16 days follow-up $(40 \times$ original magnification, HE) with adhesion tissue at the mesh border. F Sepramesh $\mathrm{IP}^{\circledR}$ at 8 days follow-up ( $40 \times$ original magnification, HE). The inserts are from the consecutive slide $(200 \times$ original magnification, anti-ED- 1$)$ and show the beginning of a mesothelial cell layer (arrows) at the mesh border and on top of the mesh. (bars indicate $200 \mu \mathrm{m}$, except in $\mathrm{C}$ and in indents of $\mathrm{F}$ where they indicate $50 \mu \mathrm{m}$ ) 


\section{Discussion}

Many coated meshes are commercially available for laparoscopic intraperitoneal hernia repair. Adhesion prevention and mesh incorporation are considered some of the key features in choosing the best mesh. This experimental study showed that commercially available synthetic meshes with different coatings performed equally well in terms of intraperitoneal adhesion prevention during a 90 days follow-up period. Incorporation also was comparable except with C-Qur Edge ${ }^{\circledR}$.

Both the chemical composition and the morphology of meshes have been attributed a main role in adhesion prevention ${ }^{10,11}$. The different chemical compositions of the coatings in this study led to marked differences in the inflammatory reactions during a 90 days follow-up period. However, these differences did not lead to any significant differences in adhesion formation. This is an interesting finding that identifies the mere presence of a layered coating as the most important factor in reducing intraperitoneal adhesions. It can be hypothesized that the antiadhesive effect is due to shielding of the inflammatory infiltrate between the abdominal wall and the mesh fibres (as discussed later). In addition, the surface of the layered coatings is smooth and does not provide any physical anchor points for adhesive tissue as occurs with uncovered mesh fibres.

Sepramesh $\mathrm{IP}^{\circledR}$ showed a low extent of adhesions, the best qualitative adhesion score, and good incorporation, as already confirmed in other studies ${ }^{15}$, 16 . Histologically, we found that the early swelling of the coating burst off the early-formed adhesions. However, the inflammation in the following days caused degradation of the coating together with a small increase of adhesions.

Parietene Composite ${ }^{\circledR}$ and Parietex Composite ${ }^{\circledR}$ performed comparably well. Regarding Parietex Composite ${ }^{\circledR}$, we and others had already established good experimental and clinical results $^{14,17,18}$. Surprisingly, however, a very intense inflammation was noted for both meshes at the 90 days follow-up evaluation, a finding recently reported by others as well ${ }^{19}$. Given the absence of such reaction with bare polypropylene and the fact that both meshes are coated with collagen, this reaction must be ascribed to the collagen coating. Importantly, adhesions were not increased after 90 days in either group. This also might be explained by a thicker tissue layer on top of the mesh, which increases the distance from the inflammation to the intraperitoneal interface ${ }^{20}$.

At the 90 days follow-up evaluation, Intramesh $\mathrm{T} 1^{\circledR}$ with the nonabsorbable layer of ePTFE provoked adhesions similar to those of the other meshes coated with an absorbable layer. A major concern with ePTFE is the risk for infection and the associated need for mesh explantation. In this study, no infections were observed with Intramesh $\mathrm{T} 1^{\circledR}$ or any other type of mesh. Clinically, the infection rates of ePTFE-based meshes are indeed higher after open repair but not after laparoscopic repair ${ }^{21,22}$.

Permacol ${ }^{\circledR}$, a partly cross-linked porcine dermal collagen mesh, was chosen as an extra control condition because it induces only a minimal inflammatory reaction. In this study, Permacol $^{\circledR}$ and C-Qur Edge ${ }^{\circledR}$ showed the least inflammatory reaction. With C-Qur Edge ${ }^{\circledast}$, 
the omega-3 fatty acids in the coating are already known for their potential to temper the inflammatory reaction ${ }^{23}$. However despite the low inflammatory state associated with both meshes, adhesion formation was not reduced. On the other hand, the incorporation strength of C-Qur Edge ${ }^{\circledR}$ was reduced. In clinical application, this type of mesh should therefore probably be accompanied with extra fixation.

One of the preferential sites for adhesion formation with coated meshes is the mesh border. Close observation of the mesh borders showed that the inflammatory infiltrate originating from the abdominal wall ranged beyond the mesh border and thus the coating. This way, the infiltrate became unshielded from the peritoneal cavity and a lead point for adhesion formation. We showed the relevance of this abdominal wall infiltrate because shielding it (with coated mesh placed upside down) produced significantly fewer adhesions.

In addition, even when the infiltrate is minimal, the omission of a coating produces detrimental results. This was recently illustrated by Fortelny et $\mathrm{al}^{24}$ in patients who had a non-coated reticular mesh of polyvinylidene fluoride implanted intraperitoneally. Despite a favourable inflammatory reaction against the material per se, surgical reintervention due to adhesions was required for 5 of 29 patients $^{25}$.

A continuous lining of mesothelial cells generally is regarded as protective against adhesions ${ }^{10}$. However, adhesions had developed already on postoperative day 1 between structures that already were physiologically lined with a layer of mesothelial cells (e.g., omentum and abdominal wall). Next, the development of a full microvilli-bearing mesothelial cell lining was completed at 8-16 days of the follow-up period. Interestingly, this was also true in the case of uncoated polypropylene mesh, for which it seemed that a continuous mesothelial cell lining was positioned over the adhesion-free areas and the extensive adhesions alike. It would therefore be a mechanism that occurs later than the mechanisms leading already to these early adhesions. Consequently, the role of physiologic remesothelialization should be scrutinized in terms of early adhesion prevention.

Mesh incorporation strengths did not differ significantly from those of uncoated polypropylene except for C-Qur Edge ${ }^{\circledast}$. The incorporation area was limited mainly to the areas directly surrounding the fixating sutures. This is in line with the finding that mesh incorporation in an acute wound (i.e., fixating suture site) is more robust than in a chronic wound $^{26}$. As a clinical consequence, scraping of the parietal peritoneum and use of a sufficiently high number of fixation methods might improve incorporation strengths.

This study had some shortcomings. First, the meshes were placed via laparotomy in rats, whereas they are intended mainly for laparoscopic use in humans. Nevertheless, all the meshes were implanted under the same conditions, enabling a comparison between the meshes. In addition, the meshes were placed against an intact peritoneum, comparable with laparoscopic surgery.

Second, the meshes were placed free of any significant forces, as would be the case if defects had been present. The lack of tension might have negatively influenced the stimulus for ingrowth.

Finally, the rats used in this study are not known to have any significant collagen disease. Differences in wound healing may exist in patients with a systemic collagen disorder. 
In conclusion, when a mesh is chosen for intraperitoneal use, most currently available commercial meshes with a layered coating prevent adhesion formation equally. Choosing a mesh for laparoscopic intraperitoneal hernia repair should therefore be based on other parameters such as costs and mesh handling, among others.

\section{Acknowledgments}

The meshes were supplied unconditionally by the respective manufacturers, whereas none of these were involved in the study design or analysis of results.

\section{Disclosures}

All authors have no conflicts of interest or financial ties to disclose. 


\section{References}

1 Kuhry E, Schwenk WF, Gaupset R, Romild U, Bonjer HJ. Long-term results of laparoscopic colorectal cancer resection. Cochrane Database Syst Rev 2008;(2):CD003432.

2 Burger JWA, Luijendijk RW, Hop WCJ, Halm JA, Verdaasdonk EGG, Jeekel J. Long-term followup of a randomized controlled trial of suture versus mesh repair of incisional hernia. Ann Surg 2004;240(4):578-83.

3 Israelsson LA, Smedberg S, Montgomery A, Nordin P, Spangen L. Incisional hernia repair in Sweden 2002. Hernia 2006;10(3):258-61.

4 Hawn MT, Snyder CW, Graham LA, Gray SH, Finan KR, Vick CC. Long-term follow-up of technical outcomes for incisional hernia repair. J Am Coll Surg 2010;210(5):648-57.

5 JenkinsED, Yom V, Melman L, Brunt LM, Eagon JC, Frisella MM, Matthews BD. Prospective evaluation of adhesion characteristics to intraperitoneal mesh and adhesiolysis-related complications during laparoscopic re-exploration after prior ventral hernia repair. Surg Endosc 2010;24(12):3002-7.

6 Ellis H. Intraabdominal and postoperative peritoneal adhesions. J Am Coll Surg 2005;200(5):641-4.

7 Muysoms FE, Bontinck J, Pletinckx P. Complications of mesh devices for intraperitoneal umbilical hernia repair: a word of caution. Hernia 2011;15(4):463-8.

8 Broek ten RPG, Schreinemacher MHF, Jilesen APJ, Bouvy N, Bleichrodt RP, van Goor $\mathrm{H}$. Enterotomy risk in abdominal wall repair: a prospective study. Ann Surg 2012;256(2):280-7.

9 Schreinemacher MHF, Broek ten RP, Bakkum $\mathrm{EA}$, van Goor $\mathrm{H}$, Bouvy ND. Adhesion awareness: a national survey of surgeons. World J Surg 2010;34(12):2805-12.

10 Bellon JM, Garcia-Honduvilla N, Lopez $\mathrm{R}$, Corrales C, Jurado F, Bujan J. In vitro mesothelialization of prosthetic materials designed for the repair of abdominal wall defects. J Mater Sci Mater Med 2003;14(4):359-64.

11 Deeken CR, Faucher KM, Matthews BD. A review of the composition, characteristics, and effectiveness of barrier mesh prostheses utilized for laparoscopic ventral hernia repair. Surg Endosc 2012;26(2):566-75.

12 van't Riet M, Burger JW, Bonthuis F, Jeekel J, Bonjer HJ. Prevention of adhesion formation to polypropylene mesh by collagen coating: a randomized controlled study in a rat model of ventral hernia repair. Surg Endosc 2004;18(4):681-5.

13 Conze J, Junge K, Klinge U, Weiss C, Polivoda M, Oettinger AP, Schumpelick V. Intraabdominal adhesion formation of polypropylene mesh. Influence of coverage of omentum and polyglactin. Surg Endosc 2005;19(6):798-803.

14 Schreinemacher MHF, Emans PJ, Gijbels MJJ, Greve JWM, Beets GL, Bouvy ND. Degradation of mesh coatings and intraperitoneal adhesion formation in an experimental model. Br J Surg 2009;96(3):305-13.

15 Burger JWA, Halm JA, Wijsmuller AR, Raa ten S, Jeekel J. Evaluation of new prosthetic meshes for ventral hernia repair. Surg Endosc 2006;20(8):1320-5.

16 Gaertner WB, Bonsack ME, Delaney JP. Visceral adhesions to hernia prostheses. Hernia 2010;14(4):375-81.

17 Chelala E, Debardemaeker Y, Elias B, Charara F, Dessily M, Allé J-L. Eighty-five redo surgeries after 733 laparoscopic treatments for ventral and incisional hernia: adhesion and recurrence analysis. Hernia 2010;14(2):123-9.

18 Judge TW, Parker DM, Dinsmore RC. Abdominal Wall Hernia Repair: A Comparison of Sepramesh and Parietex Composite Mesh in a Rabbit Hernia Model. J Am Coll Surg 2007;204(2):276-81.

19 Zinther NB, Wara P, Friis-Andersen H. Shrinkage of intraperitoneal onlay mesh in sheep: coated polyester mesh versus covered polypropylene mesh. Hernia 2010; 14(6):611-5.

20 Rodríguez M, Pascual G, Sotomayor S, PérezKöhler B, Cifuentes A, Bellón JM. Chemical Adhesion Barriers: -Do They Affect the Intraperitoneal Behavior of a Composite Mesh? J Invest Surg 2011;24(3):115-22.

21 Sanchez VM, Abi-Haidar YE, Itani KMF. Mesh Infection in Ventral Incisional Hernia Repair: Incidence, Contributing Factors, and Treatment. Surg Infect (Larchmt) 2011;12(3):205-10.

22 Hawn MT, Gray SH, Snyder CW, Graham LA, Finan KR, Vick CC. Predictors of mesh explantation after incisional hernia repair. Am J Surg 2011;202(1):28-33.

23 Boutros C, Somasundar P, Razzak A, Helton S, Espat NJ. Omega-3 fatty acids: investigations from cytokine regulation to pancreatic cancer gene suppression. Arch Surg 2010;145(6):515-20.

24 Fortelny RH, Petter-Puchner AH, Glaser KS, Offner F, Benesch T, Rohr M. Adverse effects of 
polyvinylidene fluoride-coated polypropylene mesh used for laparoscopic intraperitoneal onlay repair of incisional hernia. $\mathrm{Br} J$ Surg 2010;97(7):1140-5.

25 Klink CD, Junge K, Binnebosel M, Alizai HP, Otto J, Neumann UP, Klinge U. Comparison of long-term biocompability of PVDF and PP meshes. J Invest Surg 2011;24(6):292-9.
26 Dubay DA, Wang X, Adamson B, Kuzon WM, Dennis RG, Franz MG. Progressive fascial wound failure impairs subsequent abdominal wall repairs: a new animal model of incisional hernia formation. Surgery 2005;137(4):463-71. 


\title{
Chapter 6
}

\section{Adhesions to sutures, tackers, and glue for intraperitoneal mesh fixation: an experimental study}

\author{
M. H. Schreinemacher ${ }^{1}$ \\ K. W. van Barneveld ${ }^{1}$ \\ E. Peeters ${ }^{2}$ \\ M. Miserez ${ }^{2}$ \\ M. J. Gijbels ${ }^{3,4}$ \\ J.-W. M. Greve \\ N. D. Bouvy ${ }^{1}$
}

Hernia 2013

\section{Affiliations}

${ }^{1}$ Department of Surgery, Maastricht University Medical Centre, Maastricht, The Netherlands.

${ }^{2}$ Department of Abdominal Surgery, Catholic University of Leuven, Louvain, Belgium.

${ }^{3}$ Department of Molecular Genetics, Maastricht University Medical Centre, Maastricht, The Netherlands.

${ }^{4}$ Department of Pathology, Maastricht University Medical Centre, Maastricht, The Netherlands.

${ }^{5}$ Department of Surgery, Atrium Medisch Centrum, Heerlen, The Netherlands. 


\section{Abstract}

\section{Purpose}

Intraperitoneal mesh fixation for hernia repair is associated with adhesion formation. In this experimental study, adhesions against absorbable and non-absorbable fixation methods were compared.

\section{Methods}

Six commercially available fixation methods were placed intraperitoneally in rats with a small pore polypropylene mesh coated on one side with ePTFE $\left(\operatorname{Intramesh} \mathrm{T}^{\circledR}{ }^{\circledR}\right.$ ). Two non-absorbable fixation methods: Prolene ${ }^{\circledR}$ (polypropylene) sutures and Protack ${ }^{\circledR}$ (titanium) tackers. Four

6 absorbable methods: Vicryl ${ }^{\circledR}$ sutures (polyglactin), Absorbatack ${ }^{\circledR}$ and Permasorb ${ }^{\circledR}$ tackers (both mixes of lactic and glycolic acids) and Tisseel Duo ${ }^{\circledR}$ (fibrin glue). Adhesions and histology were studied at 7 and 90 days follow-up. In addition, fixation methods were placed without mesh, in order to study the reaction to the fixation method on itself.

\section{Results}

No adhesion formation, but also inadequate mesh fixation was found with Tisseel Duo ${ }^{\circledR}$, which had been completely resorbed at 7 days follow-up. Vicryl ${ }^{\circledR}$ sutures could no longer be detected at 90 days follow-up and were associated with a favourable adhesion profile. All other fixation methods were still intact 90 days after implantation. When placed without mesh, adhesion formation was significantly less than placed with a mesh (18 vs 93\%, $P<$ 0.001). Without mesh, adhesions were worst with Permasorb ${ }^{\circledR}$ tackers.

\section{Conclusions}

Absorbable fixation methods such as polyglactin sutures and fibrin glue show a favourable adhesion profile compared to longer-term absorbable or non-absorbable fixation methods. However, before using fibrin glue as a single fixation method more research is required. 


\section{Introduction}

Incisional hernias still remain one of the most frequent complications of abdominal surgery $^{1,2}$. Laparoscopic repair of these hernias seems to hold an advantage over open repair with reduced wound complications and hospital stay ${ }^{3-5}$.

In laparoscopic hernia repair, the mesh is secured to the abdominal wall intraperitoneally using fixation methods such as transabdominal sutures, tackers, or a combination of both. Transabdominal sutures pass through all layers of the abdominal wall and are therefore expected to provide the most durable repair, though they have been associated with chronic postoperative pain due to nerve entrapment. Clinically, however, sutures and tackers have shown equal results in terms of recurrences ${ }^{3,6,7}$ and chronic postoperative pain ${ }^{3,8-10}$.

Another relevant outcome is intraperitoneal adhesion formation, which is considered to be the consequence of an inflammatory reaction ${ }^{11}$. Adhesions are of great clinical importance since they lead to bowel obstructions, chronic pain, and infertility ${ }^{12-14}$. Both clinical and experimental studies have identified sutures and tackers as a preferential site for adhesion formation and even fistula or perforations of viscera ${ }^{6,15-17}$.

In view of these clinically significant problems, new fixation methods (e.g., absorbable tackers, fibrin glue) have been developed that are degraded over time. This way, detrimental effects such as pain related to perforation of the abdominal wall are expected to subside together with absorption of the fixation method. Indeed, application of fibrin glue for mesh fixation seems to decrease pain, though no differences between absorbable and nonabsorbable sutures have been observed ${ }^{10,18}$.

Whether these absorbable fixation methods result in a beneficial adhesion profile has scantly been researched. For this experimental study, we hypothesized that absorbable fixation methods induce less adhesions than a standard titanium tacker or polypropylene suture. We therefore compared several commercially available fixation methods with and without the presence of mesh so that adhesion formation to the fixation method per se could be evaluated.

\section{Methods and Materials}

Male Wistar rats weighing 350-400 g were housed and cared for at the Central Animal Facilities of Maastricht University, the Netherlands. All animals had free access to water and food. The experimental protocol was approved by the Animal Ethics Committees of Maastricht University.

One hundred and eight rats were randomly divided in two groups. In the first group, all animals received two pieces of polypropylene mesh (woven monofilament threads, 0.73-0.76 mm pore size, $100 \mathrm{~g} / \mathrm{m}^{2}$ ) coated with a non-absorbable layer of ePTFE (Intramesh $\mathrm{T} 1{ }^{\circledR}$; Cousin, Wervicq-Sud, France) (Figure 1, D), each fixated by two out of six available fixation methods (Table 1), following a predefined random distribution. In the second group, animals only received the fixation methods. At 7 and 90 days follow- up, half of the animals were killed in each group. 

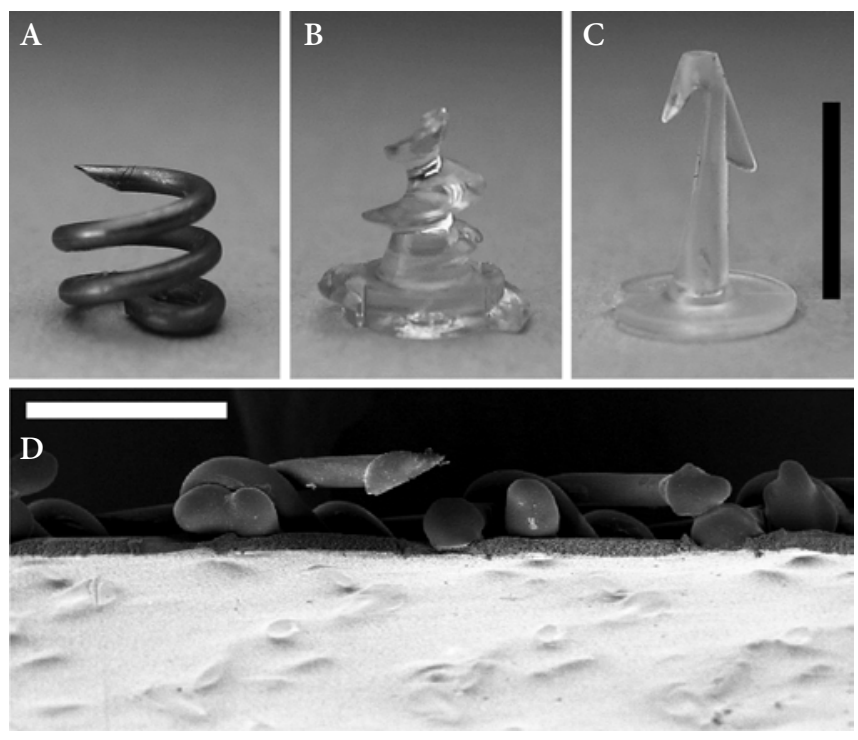

Figure 1. Protack ${ }^{\circledR}(\mathrm{A})$, Absorbatack $^{\circledR}$ (B) and Permasorb ${ }^{\circledR}$ (C) tackers at the same magnification. D depicts an oblique bottom view of Intramesh $\mathrm{T}^{\circledR}{ }^{\circledR}$ with the laminar ePTFE surface on the bottom (intraperitoneal side) shielding the reticular polypropylene structure on top (abdominal wall side). Bars represent $5 \mathrm{~mm}$ in black and $1 \mathrm{~mm}$ in white.

Table 1. Specifications of fixation methods

\begin{tabular}{|c|c|c|c|}
\hline Brand name & Appearance & Main Components & Manufacturer \\
\hline Prolene ${ }^{\circledR} 2 \times 0$ & $\begin{array}{l}\text { Monofilament suture, } \\
\text { variable length }\end{array}$ & $\begin{array}{l}\text { Polypropylene, not } \\
\text { absorbable }\end{array}$ & $\begin{array}{l}\text { Ethicon, Johnson \& Johnson, } \\
\text { Somerville, New Jersey, USA }\end{array}$ \\
\hline $\operatorname{Vicryl}^{\circledR} 2 \times 0$ & $\begin{array}{l}\text { Multifilament suture, } \\
\text { variable length }\end{array}$ & Polyglactin, absorbable & $\begin{array}{l}\text { Ethicon, Johnson \& Johnson, } \\
\text { Somerville, New Jersey, USA }\end{array}$ \\
\hline Protack $^{\circledR}$ & $\begin{array}{l}\text { Tacker, } 3.8 \mathrm{~mm} \\
\text { vertical length }\end{array}$ & Titanium, not absorbable & $\begin{array}{l}\text { Covidien, Mansfield, } \\
\text { Massachussets, USA }\end{array}$ \\
\hline Absorbatack $^{\circledR}$ & $\begin{array}{l}\text { Tacker, } 5.1 \mathrm{~mm} \\
\text { vertical length }\end{array}$ & $\begin{array}{l}\text { Poly(L-lactide-co-glycolide), } \\
\text { absorbable }\end{array}$ & $\begin{array}{l}\text { Covidien, Mansfield, } \\
\text { Massachussets, USA }\end{array}$ \\
\hline Permasorb $^{\circledR}$ & $\begin{array}{l}\text { Tacker, } 6.4 \mathrm{~mm} \mathrm{v} \\
\text { ertical length }\end{array}$ & $\begin{array}{l}\text { Poly(DL-lactide-co-glycolide), } \\
\text { absorbable }\end{array}$ & $\begin{array}{l}\text { Bard, Covington, } \\
\text { Georgia, USA }\end{array}$ \\
\hline Tisseel Duo $^{\circledR} 500$ & Glue, does not penetrate tissue & $\begin{array}{l}\text { Thrombin and fibrinogen, } \\
\text { absorbable }\end{array}$ & Baxter, Vienna, Austria \\
\hline
\end{tabular}

All fixation methods were placed in accordance with manufacturer's guidelines and correct positioning was verified before closing the abdomen. Fibrin glue was applied using a $1 \mathrm{~cm}^{2}$ circular mould in which four drips of fibrinogen and four drips of thrombin were instilled simultaneously on the parietal peritoneum (Tisseel Duo ${ }^{\circledR}$ ). Both components were at $37^{\circ} \mathrm{C}$ before application. The mesh was brought into contact with the solution directly after application and held in place for at least $30 \mathrm{~s}$. 


\section{Operative procedures}

Animals were anesthetized with isoflurane $2.5 \%$ and received buprenorphine $0.1 \mathrm{mg} / \mathrm{kg}$ perioperatively for pain relief. The abdomen was shaved and the skin disinfected with $1 \%$ iodine before covering with sterile drapes. We accessed the abdomen through a 4.0 $\mathrm{cm}$ midline incision. In the first group, two pieces of Intramesh $\mathrm{T} 1^{\circledR}(1.5 \times 4.0 \mathrm{~cm})$ were implanted on each side of the midline incision. Each piece of mesh was fixated by two fixation methods $1.5 \mathrm{~cm}$ apart. In the second group, the fixation methods were placed without mesh. All fixation methods were placed according to manufacturer's guidelines and sutures passed through all layers of the abdominal wall, except the skin. After application of the fixation methods, the muscular layers were closed with a running suture of Vicryl ${ }^{\circledR}$ $4 \times 0$. The skin was closed intracutaneously with a running suture of polyglecaprone $4 \times 0$ (Monocryl ${ }^{\circledR}$; Ethicon, Johnson and Johnson).

Rats received an overdose of carbon dioxide by inhalation after they were killed. After opening the abdomen, the presence of the fixation method at the original fixation site was evaluated.

\section{Adhesions}

The presence of adhesions to each fixation method was assessed and a qualitative score (range $0-7$ ) was applied based on type (0, no adhesions; 1 , filmy; 2, dense; 3 capillaries present; 4, larger vessels) and tenacity (0, no adhesions; 1 , adhesions fall apart easily; 2, require traction; 3 , require sharp dissection) of adhesions ${ }^{19,20}$. Scoring was performed by two independent observers (M.S. and K.B.). When different scores were attributed to a sample, the score of a third researcher was obtained and the median score recorded (N.B.).

\section{Microscopy}

Representative specimens were processed for light or scanning electron microscopy. For light microscopy, specimens were fixated in formaldehyde $4 \%$, dehydrated and embedded in methylmethacrylate (Technovit $9100^{\circledR}$, Heraeus Kulzer, Wehreim, Germany). Slices 15-20 $\mu \mathrm{m}$ thick were cut and hematoxylin-eosin stained. An experienced animal pathologist evaluated the sections for inflammation. For scanning electron microscopy, specimens were fixated in glutaraldehyde $2.5 \%$, dehydrated and metalized with palladium gold. Mesothelial cells were visualized using high magnification views from a scanning electron microscope (Philips XL30 ${ }^{\circledR}$, Philips, Eindhoven, the Netherlands).

\section{Statistical analysis}

Yielding a power of $80 \%, 17$ samples per fixation method would be required in order to detect a $50 \%$ difference in the incidence of adhesions between fixation methods. We performed statistical analyses using SPSS ${ }^{\circledR}$ version 17.0 (SPSS Inc., Chicago, IL, USA). Fisher's exact and Chi square tests were used for comparing proportions, t-tests and oneway ANOVA for all other comparisons. Bonferroni corrected $P<0.050$ were considered significant. 


\section{Results}

Two rats died directly postoperatively, presumably due to an overdose of anaesthesia. No skin perforation or erosion occurred at the level of the implanted fixation methods.

\section{Durability and dislocation of fixation methods}

After 90 days, all fixation methods except Tisseel Duo ${ }^{\circledR}$ and Vicryl ${ }^{\circledR}$ could still be identified macroscopically and Absorbatack ${ }^{\circledR}$ was easily crushed by little pressure of a forceps. Of note, only areas directly adjacent to the fixation method were found incorporated into the abdominal wall.

Remarkably, at 90 days follow-up, 52\% of the tackers placed without mesh had dislocated while no dislocation was noted with tackers fixating a mesh $(P<0.001)$ (Table 2). Absorbatack $^{\circledast}(54 \%)$ dislocated significantly more often than Protack ${ }^{\circledast}(26 \%, P=0.027)$ and Permasorb $^{\circledR}(17 \%, P=0.002)$.

\section{Adhesions}

Except for Tisseel Duo ${ }^{\circledR}$, all fixation methods induced adhesions that consisted of omentum or scrotal fat (Table 3). Tisseel Duo ${ }^{\circledR}$ induced no adhesions at all, leading to a significant difference in both the incidence as well as the quality of adhesions compared to all other fixation methods $(P<0.043)$.

At 90 days, Vicryl ${ }^{\circledast}$ induced significantly less adhesions than Permasorb ${ }^{\circledast}$ or Protack ${ }^{\circledast}$ when used for mesh fixation (both $P=0.029)$ (Figure 2). Furthermore, Vicryl ${ }^{\circledR}$ performed best in terms of the qualitative score $(P<0.040)$ compared to the other fixation methods that demonstrated comparable results (Table 3 ).

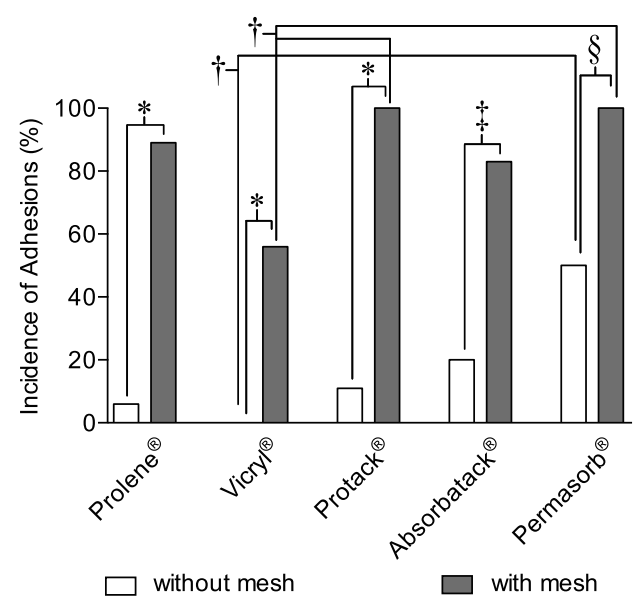

Figure 2. The incidence of adhesions with and without mesh at 90 days follow-up. No adhesions were noted at 90 days after placement of Vicryl ${ }^{\circledR}$ without a mesh, nor at any time with Tisseel Duo ${ }^{\circledR}$ (not shown). $P$-values were calculated by Fisher's exact and Chi square tests. ${ }^{\star} P<0.001, \dagger P=0.029, \ddagger P=0.017, \S P=0.002$. 
Table 2. Dislocation rates of tackers

\begin{tabular}{lccc}
\hline Fixation & Day & $\begin{array}{c}\text { With mesh } \\
\text { Incidence (n) }\end{array}$ & $\begin{array}{c}\text { Without mesh } \\
\text { Incidence (n) }\end{array}$ \\
\hline Protack $^{\circledR}$ & 7 & $6 \%(1 / 17)$ & $0 \%(0 / 17)$ \\
Absorbatack $^{\circledR}$ & 90 & $0 \%(0 / 18)$ & $50 \%(9 / 18)$ \\
& 7 & $0 \%(0 / 18)$ & $35 \%(6 / 17)$ \\
Permasorb $^{\circledR}$ & 90 & $0 \%(0 / 18)$ & $72 \%(13 / 18)$ \\
& 7 & $0 \%(0 / 18)$ & $0 \%(0 / 17)$ \\
& 90 & $0 \%(0 / 18)$ & $33 \%(6 / 18)$ \\
\hline
\end{tabular}

Table 3. Incidences and qualitative scores of adhesions to sutures and tackers

\begin{tabular}{lcccccc}
\hline & & \multicolumn{2}{c}{ With mesh } & & \multicolumn{2}{c}{ Without mesh } \\
\cline { 3 - 4 } \cline { 6 - 7 } Fixation & Day & Incidence (n) & Qualitative Score & & Incidence (n) & Qualitative Score \\
\hline Prolene $^{\circledR}$ & 7 & $100 \%(16 / 16)$ & $3.25(1.44)$ & & $6 \%(1 / 18)$ & $0.17(0.71)$ \\
& 90 & $89 \%(16 / 18)$ & $3.50(1.38)$ & & $6 \%(1 / 18)$ & $0.11(0.47)$ \\
Vicryl $^{\circledR}$ & 7 & $100 \%(17 / 17)$ & $3.12(1.11)$ & & $11 \%(2 / 18)$ & $0.44(1.34)$ \\
& 90 & $56 \%(10 / 18)$ & $2.06(1.98)$ & & $0 \%(0 / 18)$ & $0.00(0.00)$ \\
Protack $^{\circledR}$ & 7 & $100 \%(17 / 17)$ & $4.24(1.25)$ & & $24 \%(4 / 17)$ & $0.59(1.21)$ \\
& 90 & $100 \%(18 / 18)$ & $4.39(0.78)$ & & $11 \%(1 / 9)$ & $0.22(0.67)$ \\
Absorbatack $^{\circledR}$ & 7 & $100 \%(18 / 18)$ & $4.06(1.31)$ & & $9 \%(1 / 11)$ & $0.27(0.91)$ \\
& 90 & $83 \%(15 / 18)$ & $3.67(1.85)$ & & $20 \%(1 / 5)$ & $0.40(0.89)$ \\
Permasorb $^{\circledR}$ & 7 & $100 \%(18 / 18)$ & $3.83(1.25)$ & & $53 \%(9 / 17)$ & $1.76(1.92)$ \\
& 90 & $100 \%(18 / 18)$ & $4.22(0.88)$ & & $50 \%(6 / 12)$ & $1.33(1.44)$ \\
Tisseel Duo $^{\circledR}$ & 7 & $0 \%(0 / 18)$ & $0.00(-)$ & & $0 \%(0 / 18)$ & $0.00(-)$ \\
& 90 & $0 \%(0 / 18)$ & $0.00(-)$ & & $0 \%(0 / 18)$ & $0.00(-)$ \\
\hline
\end{tabular}

* expressed as mean (standard deviation)

Without the presence of a mesh, adhesions only rarely formed: 18 versus $93 \%$ in the presence of a mesh $(P<0.001)$ (Figure 2). Furthermore at 90 days follow-up, Permasorb ${ }^{\circledR}$ induced significantly more adhesions than Vicryl ${ }^{\circledR}(P=0.029)$ and performed worst in terms of the qualitative score $(P<0.005)$ compared to the other fixation methods that again showed comparable results (Table 3 ).

At 7 days, no significant differences in the incidences of adhesions were observed compared with 90 days follow-up $(P=0.364)$. Nor were the incidences of adhesions different between the abdominal quadrants in which the fixation methods had been placed $(P=0.590)$.

\section{Microscopy}

When placed without a mesh, the intraperitoneal part of the fixation method became integrated within the abdominal wall as soon as 7 days after application (Figure 3, A). When placed together with a mesh this process was obviously obstructed due to the interposition of mesh (Figure 3, B). 
Microscopic examinations of the loci where Tisseel Duo ${ }^{\circledR}$ had been applied showed no or only a very limited inflammatory response both 7 and 90 days after implantation. At 7 days follow-up, a severe inflammatory response with necrosis appeared in the muscle in the inner circle of the spiral Protack ${ }^{\circledR}$ tacker while the inflammation outside of the tacker was very mild (Figure 3, C). Also at 7 days follow-up, it was found that the central pinhole along the full length of the Permasorb ${ }^{\circledR}$ tacker - used for passing of a guide wire- was readily filled with inflammatory cells at 7 days. For all other fixation methods, the inflammatory response was moderate as well and showed a clear decrease from 7 to 90 days follow-up. At 90 days follow-up, there were virtually no signs of any reaction at the sites where Vicryl ${ }^{\circledR}$ secured the mesh. With the long-term absorbable fixation methods only a small fibrotic capsule surrounded the fixation, whereas essentially any inflammatory reaction was absent with the non-absorbable methods (Figure 4, A and B).

Finally, scanning electron microscopy showed mesothelial cells already adhering to the surface irrespective of the fixation method at 7 days follow-up. At 90 days follow-up these cells had flattened to form a continuous layer (Figure 4, C and D).
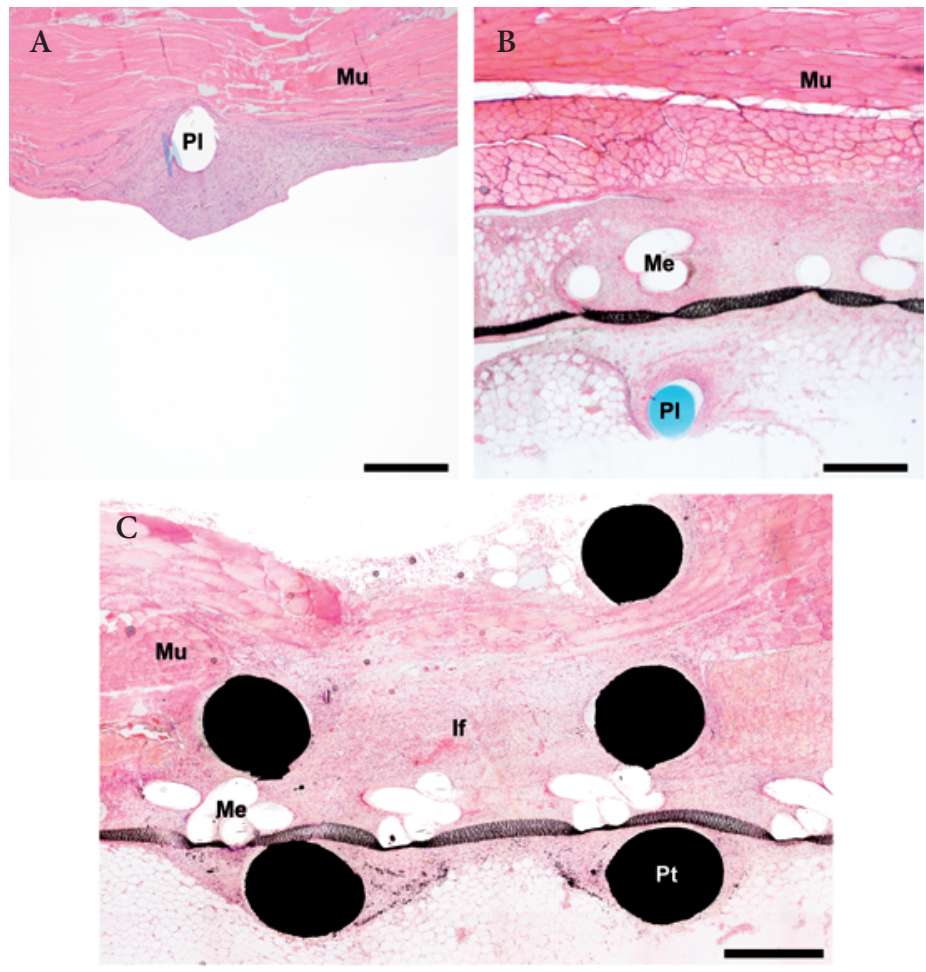

Figure 3. At 7 days follow-up, Prolene ${ }^{\circledR}$ sutures leveled with the abdominal musculature when placed without a mesh (A), but not when placed with a mesh (B). At 7 days follow-up, Protack ${ }^{\circledR}$ elicited a severe inflammatory response in the muscle in the inner circle of this spiral tacker (C). (Mu: muscle; Pl: Prolene ${ }^{\circledR} ; \mathrm{Me}$ : mesh; Pt: Protack $^{\circledR}$; If: Inflammation) (Hematoxylin eosin staining; bars represent $100 \mu \mathrm{m}$ in $\mathrm{A}, \mathrm{B}$, and $1 \mathrm{~mm}$ in C) 

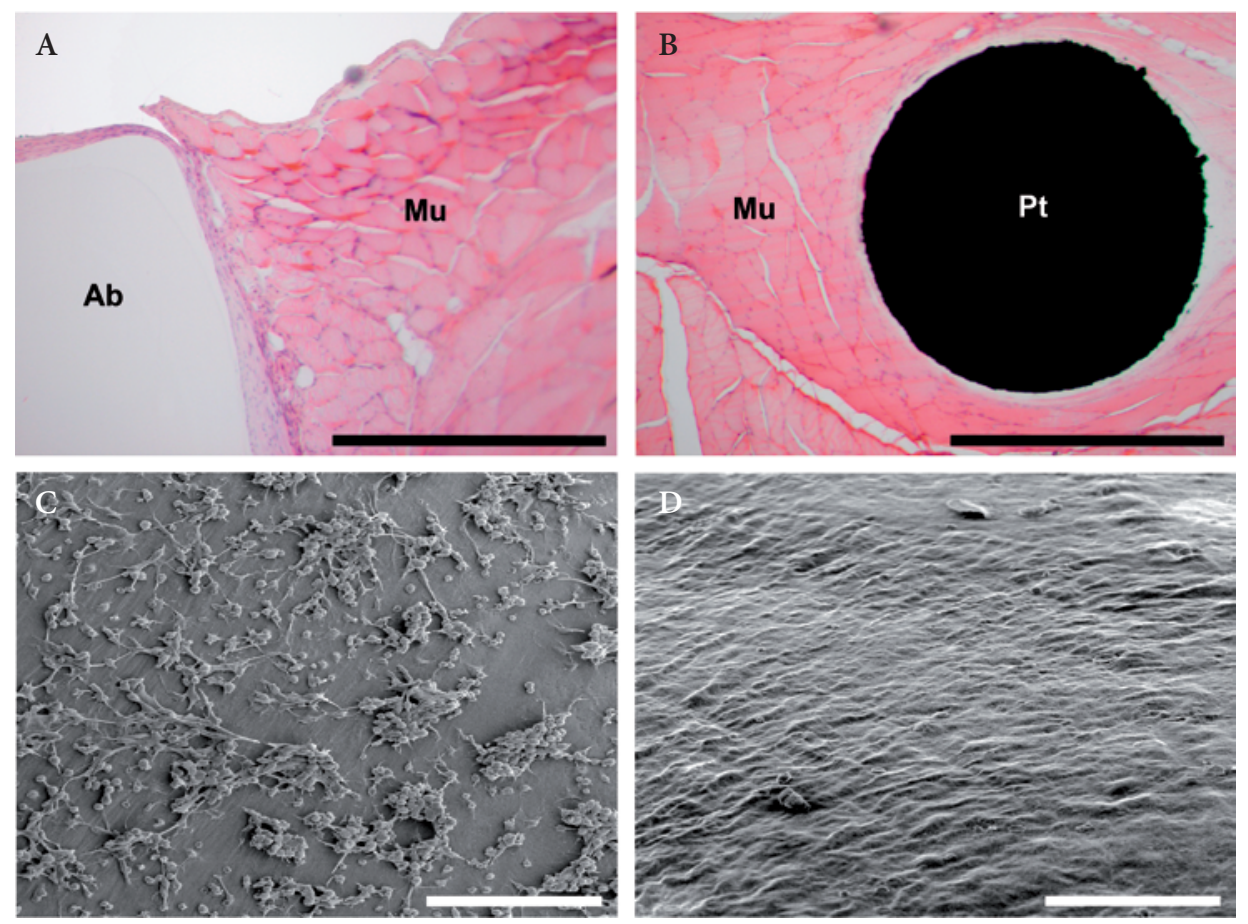

Figure 4. At 90 days follow-up, Absorbatack ${ }^{\circledR}$ (A) and $\operatorname{Protack}^{\circledR}$ (B) showed mild and essentially no signs of fibrosis, respectively. Scanning electron microscopy showed cells attaching to the intraperitoneal part of Absorbatack $^{\circledR}$ at 7 days (C) and a confluent layer of cells at 90 days follow-up (D). (Mu: muscle; Ab: Absorbatack ${ }^{\circledR}$; Pt: Protack ${ }^{\circledR}$ ) (A and B hematoxylin eosin staining; bars represent $1 \mathrm{~mm}$ in $\mathrm{A}$ and $\mathrm{B}$, and $100 \mu \mathrm{m}$ in $\mathrm{C}$ and D)

\section{Discussion}

Earlier experimental and clinical studies have shown that methods used for intraperitoneal fixation of a mesh are a specific lead point for adhesion formation, potentially even more so than the actual mesh surface $e^{6,7,16,17,21}$. For this experimental study, we hypothesized that absorbable fixation methods induce less adhesions than a standard titanium tacker or polypropylene suture. Our results show that a more favourable adhesion profile is reached if fixation methods are absorbed within less than 90 days (polyglactin sutures and fibrin glue) compared to long-term absorbable or non-absorbable fixation methods that are still intact after 90 days (long-term absorbable and non-absorbable).

Considering adhesion formation as the result of an inflammatory process ${ }^{11}$, the beneficial adhesiogenic effects of both fixation methods can probably be explained by early complete absorption of the material and the absence of any inflammation at 90 days followup. Accordingly, the increased adhesions found with Permasorb ${ }^{\circledR}$ might be related to the central pinhole in the tacker since it provides a direct passage between the inflammatory environment within the perforated muscle and the intraperitoneal part of the tacker. 
Remarkably, only minimal adhesions developed when fixation methods were placed without a mesh. This might be explained by the finding that the intraperitoneal part of the fixation methods became quickly integrated within the abdominal wall when placed without mesh. That way the incompletely mesothelialized, intraperitoneal surface of the fixation method likely became obscured, preventing adhesions from anchoring. However, this finding seems to be of limited clinical value currently since fixation methods are only rarely used intraperitoneally for measures other than mesh fixation such as peritoneal closure after TAPP.

An unexpected and interesting finding was the high dislocation rates when tackers, not sutures, were placed without mesh. In case of Protack ${ }^{\circledR}$, complications due to tacker dislocation have also been described in several clinical studies and can be explained by the muscle necrosis in the inner circle of the tacker that we observed ${ }^{6,13}$. What is more, unpublished data from our group have shown identical dislocation patterns with the same types of tackers implanted laparoscopically in goats. Furthermore, correct placement in the abdominal wall was ascertained before closing the abdomen. Sutures on the other hand can be placed in more challenging sites since they can penetrate the tissue as deep as required by the surgeon. This is especially true in subjects with a thick preperitoneal (adipose) layer where fascia may be situated beyond the penetration depth of a tacker.

Fibrin glue (Tisseel Duo ${ }^{\circledR}$ ) is quickly absorbed and provides a large surface of fixation without penetrating the abdominal wall. Although no adhesions were noted, meshes fixated with fibrin glue were consistently found detached from the abdominal wall. Inferior results with fibrin glue have been reported by others as well22,23, while some experimental studies, though not performed in rats, found solid tissue integration comparable to sutures and tackers ${ }^{24,25}$. These contradictory findings may be related to the small pore size of the current mesh that may hamper diffusion of the fibrin glue into the pores, leading to early dislocation of the meshes. In larger pore meshes and meshes without an anti-adhesive barrier, diffusion of the fibrin glue into the pores might be improved, possibly leading to better incorporation ${ }^{26}$.

Clinically, only limited experience with fibrin glue for mesh fixation is available for incisional hernia repair. Results in terms of safety and pain at short-term follow up are good $^{18,27}$. Yet at 1 year follow-up fibrin glue has shown recurrences in $26 \%$ of mesh fixations in umbilical hernia repair, performing significantly worse than titanium tackers ${ }^{28}$. In inguinal hernia repair some studies have shown comparable results in terms of recurrences comparing glue with suture and tacker fixation ${ }^{29,30}$. However, a very large retrospective study showed short-term absorbable suture fixation to result in a doubled recurrence rate compared with long-term absorbable or non-absorbable suture fixation in inguinal hernia repair ${ }^{31}$. Therefore, feasibility of mesh fixation based solely on short-term absorbable fixation methods remains uncertain. Considering the current result for adhesion outcomes, fibrin glue may at least have a role in adhesion prevention at the fixation sites or even the complete mesh border or as an adjunct to reduce the number of sutures or tackers ${ }^{26,32}$.

Some limitations apply to this study. First of all, fixation methods were applied to the abdominal wall of rats, differing significantly from the human abdominal wall in thickness among others. However, none of the fixation methods penetrated skin and conditions were 
the same for all methods justifying a comparison between the different fixation methods. In addition, we recently found very similar results in adhesion formation and dislocation rates when performing the same experiments in goats. Secondly, follow up times past the absorption time of long-term absorbable tackers might influence on adhesion scores. Thirdly, fixation of the meshes was performed free from any forces exerted on the meshes since no abdominal wall defects were created. Nevertheless, this was the same for all methods tested. Finally, only a handful of available fixation methods have been tested. As new fixation methods are introduced regularly, sometimes replacing established methods, independently performed premarketing research should be available for all new devices.

In conclusion, longer-term resorbable fixation methods seem to induce more adhesions than short-term resorbable fixation methods. However, even though fibrin glue seems to be an excellent anti-adhesive barrier, its use as a sole fixation method is questionable and requires further research. Possibly, a combination of several absorbable fixation methods would yield optimal results in terms of adhesion formation and recurrence prevention. 


\section{References}

1 Kuhry E, Schwenk WF, Gaupset R, Romild U, Bonjer HJ. Long-term results of laparoscopic colorectal cancer resection. Cochrane Database Syst Rev 2008;(2):CD003432.

2 Mudge $M$, Hughes LE. Incisional hernia: a 10 year prospective study of incidence and attitudes. Br J Surg 1985;72(1):70-1.

3 Sajid MS, Bokhari SA, Mallick AS, Cheek E, Baig MK. Laparoscopic versus open repair of incisional/ventral hernia: a meta-analysis. Am J Surg 2009; 197(1):64-72.

4 Forbes SS, Eskicioglu C, McLeod RS, Okrainec A. Meta-analysis of randomized controlled trials comparing open and laparoscopic ventral and incisional hernia repair with mesh. Br J Surg 2009;96(8):851-8.

5 Burger JWA, Luijendijk RW, Hop WCJ, Halm JA, Verdaasdonk EGG, Jeekel J. Long-term followup of a randomized controlled trial of suture versus mesh repair of incisional hernia. Ann Surg 2004;240(4):578-83.

6 Chelala E, Debardemaeker Y, Elias B, Charara F, Dessily M, Allé J-L. Eighty-five redo surgeries after 733 laparoscopic treatments for ventral and incisional hernia: adhesion and recurrence analysis. Hernia 2010;14(2):123-9.

7 Joels CS, Matthews BD, Kercher KW, Austin C, Norton HJ, Williams TC, Heniford BT. Evaluation of adhesion formation, mesh fixation strength, and hydroxyproline content after intraabdominal placement of polytetrafluoroethylene mesh secured using titanium spiral tacks, nitinol anchors, and polypropylene suture or polyglactin 910 suture. Surg Endosc 2005;19(6):780-5.

8 Shabbir J, Chaudhary BN, Dawson R. A systematic review on the use of prophylactic mesh during primary stoma formation to prevent parastomal hernia formation. Colorectal Disease 2012;14(8):931-6.

9 Beldi G, Wagner M, Bruegger LE, Kurmann A, Candinas D. Mesh shrinkage and pain in laparoscopic ventral hernia repair: a randomized clinical trial comparing suture versus tack mesh fixation. Surg Endosc 2011;25(3):749-55.

10 Wassenaar E, Schoenmaeckers E, Raymakers J, van der Palen J, Rakic S. Mesh-fixation method and pain and quality of life after laparoscopic ventral or incisional hernia repair: a randomized trial of three fixation techniques. Surg Endosc 2010;24(6):1296-302.
11 Hellebrekers BWJ, Kooistra T. Pathogenesis of postoperative adhesion formation. Br J Surg 2011;98(11):1503-16.

12 Hollinsky C, Kolbe T, Walter I, Joachim A, Sandberg S, Koch T, Rülicke T, Tuchmann A. Tensile strength and adhesion formation of mesh fixation systems used in laparoscopic incisional hernia repair. Surg Endosc 2009;24(6):1318-24.

13 Fitzgerald HL, Orenstein SB, Novitsky YW. Small bowel obstruction owing to displaced spiral tack after laparoscopic TAPP inguinal hernia repair. Surg Laparosc Endosc Percutan Tech 2010;20(3):e132-5.

14 Ellis $H$. Intraabdominal and postoperative peritoneal adhesions. J Am Coll Surg 2005;200(5):641-4.

15 Ladurner R, Mussack T. Small bowel perforation due to protruding spiral tackers: a rare complication in laparoscopic incisional hernia repair. Surg Endosc 2004;18(6):1001.

16 Wassenaar EB, Schoenmaeckers EJP, Raymakers JTFJ, Rakic S. Subsequent abdominal surgery after laparoscopic ventral and incisional hernia repair with an expanded polytetrafluoroethylene mesh: a single institution experience with 72 reoperations. Hernia 2010;14(2):137-42.

17 Schreinemacher MHF, Emans PJ, Gijbels MJJ, Greve JWM, Beets GL, Bouvy ND. Degradation of mesh coatings and intraperitoneal adhesion formation in an experimental model. Br J Surg 2009;96(3):305-13.

18 Eriksen JR, Bisgaard T, Assaadzadeh S, Jorgensen LN, Rosenberg J. Randomized clinical trial of fibrin sealant versus titanium tacks for mesh fixation in laparoscopic umbilical hernia repair. Br J Surg 2011;98(11):1537-45.

19 van't Riet M, Burger JW, Bonthuis F, Jeekel J, Bonjer HJ. Prevention of adhesion formation to polypropylene mesh by collagen coating: a randomized controlled study in a rat model of ventral hernia repair. Surg Endosc 2004;18(4):681-5.

20 Conze J, Junge K, Klinge U, Weiss C, Polivoda M, Oettinger AP, Schumpelick V. Intraabdominal adhesion formation of polypropylene mesh. Influence of coverage of omentum and polyglactin. Surg Endosc 2005;19(6):798-803.

21 Zinther NB, Wara P, Friis-Andersen $\mathrm{H}$. Intraperitoneal onlay mesh: an experimental study of adhesion formation in a sheep model. Hernia 2010;14(3):283-9. 
22 Jenkins ED, Melman L, Frisella MM, Deeken CR, Matthews BD. Evaluation of acute fixation strength of absorbable and nonabsorbable barrier coated mesh secured with fibrin sealant. Hernia 2010;14(5):505-9.

23 Schug-Pass C, Lippert H, Kockerling F. Fixation of mesh to the peritoneum using a fibrin glue: investigations with a biomechanical model and an experimental laparoscopic porcine model. Surg Endosc 2009;23(12):2809-15.

24 Fortelny RH, Petter-Puchner AH, Glaser KS, Keibl C, Gruber-Blum S, Ohlinger W, Redl H. Fibrin sealant (Tisseel) for hiatal mesh fixation in an experimental model in pigs. J Surg Res 2010;162(1):68-74.

25 Clarke T, Katkhouda N, Mason RJ, Cheng BC, Algra J, Olasky J, Sohn HJ, Moazzez A, Balouch M. Fibrin glue for intraperitoneal laparoscopic mesh fixation: a comparative study in a swine model. Surg Endosc 2010;25(3):737-48.

26 Rieder E, Stoiber M, Scheikl V, Poglitsch M, Dal Borgo A, Prager G, Schima H. Mesh fixation in laparoscopic incisional hernia repair: glue fixation provides attachment strength similar to absorbable tacks but differs substantially in different meshes. $J$ Am Coll Surg 2011;212(1):80-6.

27 Olmi S, Scaini A, Erba L, Croce E. Use of fibrin glue (Tissucol) in laparoscopic repair of abdominal wall defects: preliminary experience. Surg Endosc 2007;21(3):409-13.

28 Eriksen JR, Bisgaard T, Assaadzadeh S, Jorgensen LN, Rosenberg J. Fibrin sealant for mesh fixation in laparoscopic umbilical hernia repair: 1-year results of a randomized controlled double-blinded study. Hernia 2013;17(4):511-4.

29 Sajid MS, Ladwa N, Kalra L, McFall M, Baig MK, Sains P. A meta-analysis examining the use of tacker mesh fixation versus glue mesh fixation in laparoscopic inguinal hernia repair. Am J Surg 2013;206(1):103-11.

30 de Goede B, Klitsie PJ, van Kempen BJH, Timmermans L, Jeekel J, Kazemier G, Lange JF. Meta-analysis of glue versussutured mesh fixation for Lichtenstein inguinal hernia repair. Br J Surg 2013;100(6):735-42.

31 Novik B, Nordin P, Skullman S, Dalenback J, Enochsson L. More recurrences after hernia mesh fixation with short-term absorbable sutures: A registry study of 82015 Lichtenstein repairs. Arch Surg 2011;146(1):12-7.

32 Martin-Cartes JA, Morales-Conde S, Suarez-Grau JM, Bustos-Jimenez M, Cadet-Dussort JM, LopezBernal F, Morcillo-Azcarate J, Tutosaus-Gomez JD, Morales-Mendez S. Role of fibrin glue in the prevention of peritoneal adhesions in ventral hernia repair. Surg Today 2008;38(2):135-40. 


\title{
Chapter 7
}

\section{Polypropylene meshes to prevent abdominal herniation: Can stable coatings prevent adhesions in the long term?}

\author{
P. J. Emans $s^{1,2,3}$ \\ M. H. Schreinemacher ${ }^{1}$ \\ M. J. Gijbels ${ }^{4,5}$ \\ G. L. Beets ${ }^{1}$ \\ J.-W. M. Greve ${ }^{1}$ \\ L. H. Koole ${ }^{3}$ \\ N. D. Bouvy ${ }^{1}$
}

Annals of Biomedical Engineering 2009

\section{Affiliations}

1 Department of Surgery, Maastricht University Medical Centre, Maastricht, The Netherlands. 2 Department of Orthopaedic Surgery, Maastricht University Medical Centre, Maastricht, The Netherlands. 3 Centre for Biomaterials Research, Maastricht University Medical Centre, Maastricht, The Netherlands. 4 Department of Molecular Genetics, Maastricht University Medical Centre, Maastricht, The Netherlands.

5 Department of Pathology, Maastricht University Medical Centre, Maastricht, The Netherlands. 


\begin{abstract}
Abdominal surgery is associated with a significant risk for incisional herniation. Hernia repair is routinely performed by implantation of synthetic meshes. Such meshes may cause serious adhesions between the implanted material and organs leading to intestinal obstruction or enterocutaneous fistulas. This study compares three knitted meshes for their capacity to prevent adhesion formation in an in vivo study.

The meshes evaluated are polypropylene $\left(\right.$ Prolene $\left.^{\circledR}\right)$, polypropylene coated with oxygenated regenerated cellulose -in principle- a biodegradable biomaterial (Proceed ${ }^{\circledR}$ ), and Prolene ${ }^{\circledR}$ coated with a non-degradable copolymer of the hydrophilic building block $\mathrm{N}$-vinyl pyrrolidone (NVP) and the hydrophobic building block n-butylmethacrylate (BMA). The meshes were implanted in the abdomen of rats (7 or 30 days follow-up).

After 7 days, the formation of adhesions decreased in the order: Prolene ${ }^{\circledR}>$ NVP/BMAcoated Prolene $^{\circledast}>$ Proceed $^{\circledR}$; after 30 days, this order changed into: Proceed ${ }^{\circledast}>$ Prolene $^{\circledR}$

$7>$ NVP/BMA-coated Prolene ${ }^{\circledR}$. Both at 7 and at 30 days, Proceed ${ }^{\circledR}$ was the only mesh surrounded by macrophage cells that contained foreign materials, presumably degradation products of the (biodegradable) surface coating.

The data indicate that long-term protection of implanted meshes against excessive adhesions may be achieved through stable biocompatible hydrogel surface coatings.
\end{abstract}




\section{Introduction}

It is well known that abdominal surgery is associated with a significant risk for incisional hernia; the incidence has been estimated in the range of $10-20 \%^{1,2}$. The best method to repair these hernias is to implant a synthetic mesh that bridges the abdominal wall defect in a tension-free manner ${ }^{3-6}$. Such meshes are implanted in an open procedure or, with increasing frequency, laparoscopically. Despite important clinical successes, it is obvious that the 'ideal' mesh is still not available. For instance, meshes can become contracted and/or infected after implantation ${ }^{7-9}$. Furthermore, adhesions between the visceral side of the mesh and adjacent organs can occur ${ }^{8,10,11}$. These complications may have serious consequences, such as chronic pain, recurrence of the hernia or even intestinal obstruction and enterocutaneous fistulas ${ }^{11,12}$.

A review of the literature on the use of polymer meshes for incisional hernia repair learned that studies of biomaterial-tissue interactions have hardly played a role in the development of these implants. The majority of the commercial meshes are made out of knitted polypropylene (PP) fibers (e.g. Prolene ${ }^{\circledast}$, Marlex $^{\circledR}$, Trelex ${ }^{\circledR}$ ). PP is strong, chemically stable, and highly hydrophobic, but the material is by no means designed to engage in any favorable interaction with adjacent cells or tissues ${ }^{8,13}$. Clinical experience, as well as animal experimentation, revealed extensive adhesions of tissues to the mesh as a frequent complication. However, there are clear indications that surface modifications of PP meshes can help to influence tissue reaction and thereby reduce adhesion formation ${ }^{11,14}$. Also, the frequent occurrence of adhesive interactions between the visceral side of the mesh and the bowel, leads one to suspect that the mesh surface may be too hydrophobic. This could explain why cells show an exceptionally strong affinity for these meshes.

The ideal mesh would have to show integration with the tissue of the abdominal wall (primarily to prevent mesh migration and hernia recurrence), but no adhesions whatsoever on the visceral side. Based on this idea, van 't Riet et al recently performed an interesting in vivo model study, in which they implanted mesh structures that were coated with collagen on their visceral side ${ }^{11}$. There was a clear positive effect of the collagen coating, with less visceral adhesions. Others have more or less successfully used different coatings from a biological origin such as sodium hyaluronate/ carboxymethylcellulose $\mathrm{e}^{11,15}$ or an absorbable layer of oxidized regenerated cellulose ${ }^{11,12,16}$. Of course, it remains to be established whether or not these coatings are capable of adhesion prevention in the long term. In view of the fact that biological coatings are susceptible to hydrolytic or enzymatic degradation, it must be expected that these coatings will not provide long-term non-adhesiveness.

We hypothesized that a stable, synthetic, and biocompatible hydrophilic coating might be the biomaterial of choice in this respect. Herein, we report a study in which commercial PP mesh (Prolene ${ }^{\circledR}$, Ethicon, Johnson \& Johnson, Somerville, NJ, USA) was coated with an adherent hydrophilic copolymer, which was designed, synthesized, and fully characterized in our laboratory. The material was prepared from $\mathrm{N}$-vinylpyrrolidinone (NVP) and N-butylmethacrylate (BMA) as the hydrophilic and hydrophobic building blocks, respectively. The choice for this biomaterial was based on our previous experience 
that these copolymers feature excellent biocompatibility, e.g., in contact with blood, ocular epithelium, and bone ${ }^{17-20}$. The coated mesh was compared in a series of experiments in vivo (using a rat model) with the uncoated Prolene ${ }^{\circledR}$ and coated Proceed ${ }^{\circledR}$ mesh (Ethicon, Johnson \& Johnson, Somerville, NJ, USA). The latter is a three-layer composite of a PP mesh, an absorbable layer of oxidized regenerated cellulose, and an intermediate layer of polydioxanone. Adhesion formation was scored macroscopically and host response reactions were evaluated through histology.

\section{Methods and Materials}

\section{Coating preparation}

The hydrophilic copolymer was prepared from NVP and BMA (both monomers were purified by vacuum distillation), as described previously ${ }^{21}$. Briefly, the monomers were mixed (molar ratio 1:1), radical initiator (AIBN, 1.5 molar\%) was added, and the mixture was transferred into a Teflon tube that was closed with a stopper on one end. The tube was immersed in an oil bath interfaced with a time/ temperature control system. After $24 \mathrm{~h}$, the materials were obtained as glassy rods. These were cut in pieces, and dissolved in ethanol $(10 \mathrm{~g}$ of copolymer in $500 \mathrm{~mL}$ ) under continuous mechanical stirring. The resulting viscous solution was mixed with the same volume of ethanol, and $500 \mathrm{mg}$ of triethyleneglycoldimethacrylate (TEGDMA) was added. After homogenization, the solution was applied as an all-around coating onto the PP mesh (Prolene $\left.{ }^{\circledR}\right)$. The coated mesh was dried in an oven $\left(65-70{ }^{\circ} \mathrm{C}\right)$ for $24 \mathrm{~h}$. This led to polymerization of the TEGDMA as a non-soluble three-dimensional macromolecular network. This network prevents the dissolution of the hydrophilic biomaterial after implantation. All meshes were sterilized by treatment with ethylene oxide, degassed for at least 1 week and subsequently packed individually in sterile pouches.

\section{Water contact angle measurement}

The water contact angle was measured by the sessile drop method. First, the NVP-BMA coating was applied to a glass surface as a thin homogeneous layer. A standard object glass for light microscopy was used for this purpose. Then, after thorough drying as described above, we placed approximately 10 water drops of $10 \mu \mathrm{L}$ onto the surface. The resulting drops were photographed from the side, using a digital camera with a macro lens. The water contact angles were measured from the images.

\section{Experiment and animals}

Thirty-nine rats of the Wistar strain, weighing 250-300 g were housed and cared for at the Central Animal Facilities of the University of Maastricht according to the appropriate standards. The experimental protocol was approved by the Committee of Animal Experiments of Maastricht University. The meshes were randomly implanted in the abdomen of rats; (i) implantation of a standard PP mesh (Prolene $\left.{ }^{\circledR}\right)(n=15)$, (ii) a coated 
PP mesh $\left(\right.$ Proceed $\left.^{\circledR}\right)(n=12)$, or (iii) a NVP/BMA-coated Prolene ${ }^{\circledR}$ mesh $(n=11)$. Meshes were all sized $30 \times 20 \mathrm{~mm}^{2}$. With the Proceed ${ }^{\circledR}$ and NVP/BMA-coated Prolene ${ }^{\circledR}$ mesh the coating was adjacent to the viscera. At 7 and 30 days post implantation rats were sacrificed, adhesions were scored macroscopically, and the meshes were harvested to be processed for histology. This study was performed independently from all the manufacturers.

\section{Surgical Procedure}

Throughout the procedure, non-powdered sterile gloves were used. Rats were anaesthetized with ketamine hydrochloride ( $100 \mathrm{mg} / \mathrm{kg}$ ) and xylazine $(5 \mathrm{mg} / \mathrm{kg})$. The abdomen was shaved and the skin disinfected with $2 \%$ iodine, and covered with sterile drapes. The abdomen was opened through a midline incision of $4 \mathrm{~cm}$. The mesh was introduced intraperitoneally and fixated with two sutures of polypropylene $4 \times 0$ (Prolene ${ }^{\circledR}$, Ethicon, Johnson \& Johnson, Somerville, NJ, USA). Thereafter, the peritoneum and fascia were closed with a running suture of polyglactin $4 \times 0$ (Vicryl $^{\circledR}$, Ethicon, Johnson \& Johnson, Somerville, NJ, USA). The skin was closed intracutaneously with a running suture of polyglecaprone $4 \times 0$ (Monocryl ${ }^{\circledR}$, Ethicon, Johnson \& Johnson, Somerville, NJ, USA).

\section{Functional Macroscopic Evaluation}

Rats were sacrificed by an overdose of $\mathrm{CO}_{2}$ inhalation. Directly after sacrifice, the abdomen was opened widely along the circumference of the mesh. The incisions were made along three of the four sides of a rectangle; the fourth side served as a hinge for the mesh and adherent tissues. This procedure ensured that the meshes were not damaged, and that proper evaluation of any adherence between the mesh and adjacent tissues was possible. The amount of adhesion formation was then scored macroscopically. In the case of adhesions the organs involved were recorded and a photograph was taken. A qualitative scoring system according to the literature was used ${ }^{10,11,22}$. For each implant, adhesion scores were determined by two independent researchers, on the basis of three subscores: (i) extent ( 0 , no adhesions; $1,1-25 \% ; 2,26-50 \% ; 3,51-75 \% ; 4,76-100 \%$ of the mesh surface involved); (ii) type ( 0 , no adhesions; 1 , filmy; 2 , dense; 3 , capillaries present), and (iii) tenacity ( 0 , no adhesions; 1 , easily fall apart; 2 , require traction; 3 , require sharp dissection). When different scores were attributed to a sample, the score of a third independent researcher, blinded to the study group and the scores of the first two researchers, gave a majority for one of the two first scores. The percentage of meshes which had an adhesion with organs including liver, spleen, bowel, and stomach was also examined. Hereafter all implanted meshes along with surrounding tissues were retrieved for histological examination.

\section{Microsc opy}

Scanning electron microscopy was performed with a Philips $\mathrm{XL}^{\circledR} 30$ instrument, $12 \mathrm{keV}$. Fluorescence and bright field microscopy was performed with a Nikon Eclipse ${ }^{\circledR}$ E800 instrument (fluorescence setting; Texas Red filter (excitation, 540-580 nm; dichroic mirror 595). 


\section{Histology}

After macroscopic evaluation the mesh was locally excised with the surrounding tissue $(\sim 1$ $\mathrm{cm})$. Each excised specimen was split in four equal pieces and fixated in vials with a $4 \%$ formaldehyde solution. After dehydration in increasing concentrations of alcohol, two pieces of each specimen were embedded in glycol methacrylate (Technovit $7100^{\circledR}$; Heraeus Kulzer, Wehrheim, Germany). These were then sectioned at $5 \mu \mathrm{m}$ and stained with hematoxylin \& eosin (H\&E). The samples were evaluated by an experienced animal pathologist not familiar with the specific background of the different meshes. Tissue adjacent to the visceral side (i.e., PP with Prolene ${ }^{\circledR}$, oxidized regenerated cellulose with Proceed ${ }^{\circledR}$, and NVP/BMA with the NVP/BMA-coated Prolene ${ }^{\circledR}$ mesh) was scored for inflammation at 7 days, granulation tissue at 30 days, and intestinal organ (e.g., bowel, liver, etc.) adhesion formation (- meaning absent, + slightly present, ++ moderately present, +++ abundantly present). Presence of (i) giant cells, (ii) granulocytes, (iii) fibroblasts, and (iv) macrophages was also scored accordingly $y^{10,23}$.

\section{Statistics}

Based on pilot work, the sample size was determined based on the power analysis of Sachs, with a power of $80 \%$, two-tailed and a confidence interval of $95 \%$. This resulted in a minimum of six meshes per group for the qualitative adhesion scoring system as described in literature ${ }^{10,11,22}$. Statistics were performed by Mann-Whitney U test. $P<0.05$ were considered significant.

\section{Results}

\section{Mesh coating}

Figure 1 shows the Prolene ${ }^{\circledR}$, Proceed ${ }^{\circledR}$, and NMP/BMA-coated Prolene ${ }^{\circledR}$ mesh structures. Note that the knitted patterns for Prolene ${ }^{\circledR}$ and Proceed ${ }^{\circledR}$ are markedly different, also with respect to pore density and pore size. Application of the NVP/BMA copolymer as a thin adherent coating onto the Prolene ${ }^{\circledR}$ mesh structure proceeded without difficulties. It was found to be essential that the concentration of the copolymer in the alcohol solution was kept below 1.5 mass\%. At higher concentrations (i.e., at higher viscosities), it was unavoidable that pores were partially or completely filled with copolymer. Scanning electron microscopy, especially suitable for evaluating the surface morphology, revealed a smooth and very regular surface (Figure 1, C). In order to evaluate distribution of the coating, a piece of PP mesh was only partly coated with NVP/BMA solution to which a trace of the fluorescent dye rhodamine 6 was added. With fluorescence microscopy, the coating was clearly identified on the treated and not on the untreated side (Figure 2). A uniform distribution of the coating can therefore be ascertained. As for hydrophilic features, the application of the NVP/BMA coating resulted in a moderately hydrophilic surface, as was shown in our previous work ${ }^{21}$. Specifically, the NVP/BMA coating used in this work (molar ratio NVP:BMA = 9:1) gives a water contact angle in the range of $32-36^{\circ}$. In comparison with PP (water contact angle of $\left.85-87^{\circ}\right)^{21}$, the surface hydrophilicity has increased substantially as a result of the surface 

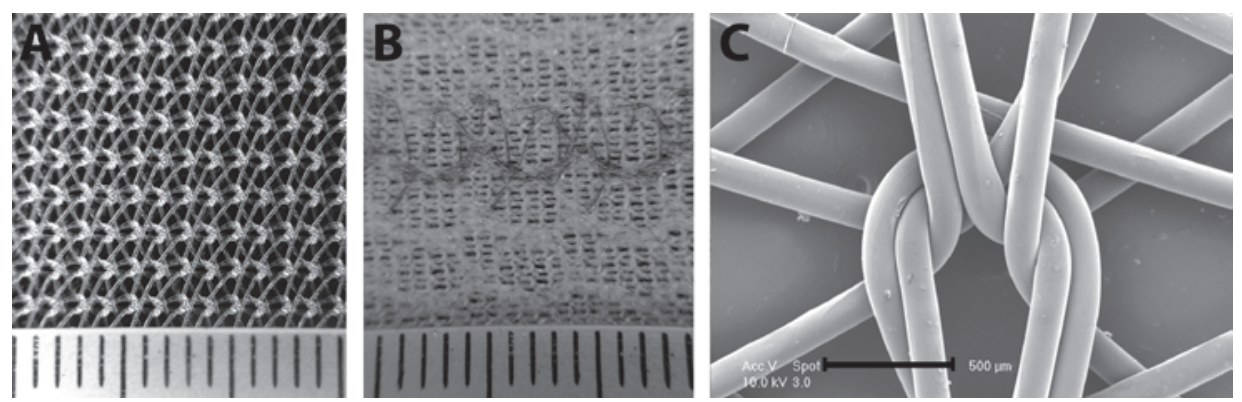

Figure 1. Photographs of Prolene ${ }^{\circledR}(\mathrm{A})$ and $\operatorname{Proceed}^{\circledR}$ (B) mesh. Note the difference in knitted patterns. (the ruler in A and B shows mm-scale). C Scanning electron micrograph of a NVP/BMA-coated Prolene ${ }^{\circledR}$ mesh. Note that the coating results in a smooth and regular surface. (Scale bar corresponds with $500 \mu \mathrm{m}$ )
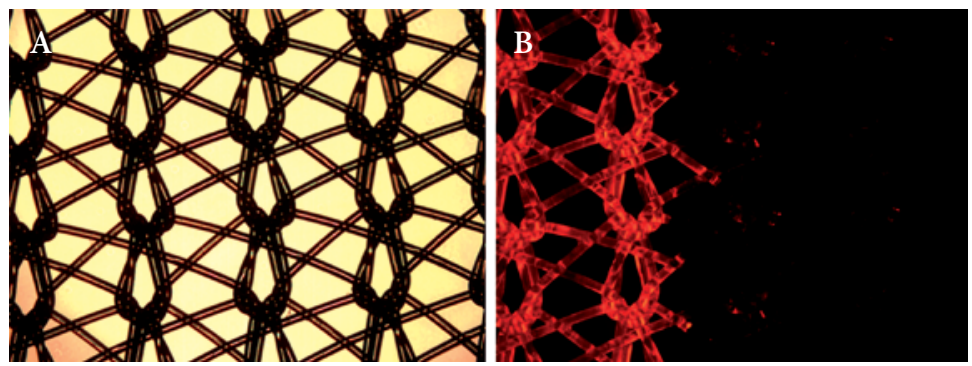

Figure 2. A Microscopic photograph (bright field) of the PP mesh partly treated with NVP/BMA solution containing the fluorescent dye rhodamine. The coating was applied on the left side of the mesh. B Fluorescence microscopy of the same sample as A, illuminated with ultraviolet light that excites the dye. The image reveals that rhodamine is spread evenly over the treated part of the mesh.

treatment. Furthermore, flexibility of the mesh was not influenced by NVP/BMA coating although this was not verified in any quantitative manner. Both the increased hydrophilicity and the surface smoothness resulting from the coating are responsible for the observed differences in biomaterial-tissue interactions (see below).

\section{General observations}

All animals recovered quickly of anaesthesia and were thriving and well during the entire experiment. One rat (Proceed ${ }^{\circledR}$ group) died just after implantation, most likely due to anaesthetic overdose.

\section{Functional macroscopic evaluation}

A typical example of an explanted NVP/BMAcoated Prolene ${ }^{\circledR}$ mesh (30 days follow-up) is depicted in Figures 3, A and B. In this particular case, extent (0, no adhesions; 1, 1-25\%; 2, $26-50 \% ; 3,51-75 \% ; 4,76-100 \%$ of the mesh surface involved), tenacity ( 0 , no adhesions; 1 , 
easily fall apart; 2 , require traction; 3 , require sharp dissection), and type ( 0 , no adhesions; 1, filmy; 2, dense; 3 , capillaries present) of adhesions were scored as 2, 2, and 3, respectively. Figure 4 presents total adhesion scores with different meshes at 7 and 30 days follow-up. At 7 days follow-up, the adhesion scores decreased in the following order: Prolene ${ }^{\circledR}$ (9.3 $\pm 0.5)>$ NVP/BMA-coated Prolene ${ }^{\circledR}(7.3 \pm 0.5)>$ Proceed $^{\circledR}(3.3 \pm 0.5)$; all differences are statistically significant $(P<0.05)$. Adhesions with omentum or scrotal fat were observed with virtually all meshes. Adhesions with abdominal organs like liver, spleen, stomach, and bowel were observed in $87 \%$ of the Prolene ${ }^{\circledR}$ meshes, $83 \%$ of the NVP/BMA-coated Prolene ${ }^{\circledR}$ meshes, and 50\% of the Proceed ${ }^{\circledR}$ meshes. At 30 days follow-up, the order changed into: Proceed ${ }^{\circledast}(7.2 \pm 1.1)>$ Prolene $^{\circledast}(7.0 \pm 1.2)>$ NVP/BMA-coated Prolene ${ }^{\circledR}(5.4 \pm 0.5)$. At 30 days, the total adhesion score of NVP/BMA-coated Prolene ${ }^{\circledR}$ meshes was significantly lower than Prolene ${ }^{\circledast}$ and Proceed ${ }^{\circledR}$. This finding was in concordance with the adhesions found with abdominal organs (liver, spleen, stomach, and bowel); 0\% with NVP/BMAcoated Prolene $^{\circledast}, 29 \%$ with Prolene ${ }^{\circledast}$, and 50\% with Proceed ${ }^{\circledast}$.

\section{Histological evaluation}

At 7 days follow-up, all implants initiated a comparable inflammatory response. This was accompanied by neovascularization, influx of mainly granulocytes, and fibroblast proliferation. Macrophages were abundantly present with Proceed ${ }^{\circledR}$ and only slightly or not present with NVP/BMA-coated Prolene ${ }^{\circledR}$ and Prolene ${ }^{\circledR}$ meshes, respectively. The macrophages near the Proceed ${ }^{\circledR}$ mesh were also found to contain foreign material. This probably indicates that phagocytosis of the Proceed ${ }^{\circledR}$ coating (oxidized regenerated cellulose and polydioxanone) is occurring. The macrophages observed in the NVP/BMAcoated Prolene ${ }^{\circledR}$ group were large and swollen but not filled with foreign material (Figure 5 ). The number of granulocytes and giant cells were comparable for all groups (Table 1).

At 30 days follow-up, the NVP/BMA-coated Prolene ${ }^{\circledR}$ meshes showed a mild reaction, consisting of some granulation tissue with mostly fibroblasts, giant cells, and macrophages. A fibrous capsule encapsulated the NVP/BMA-coated Prolene ${ }^{\circledR}$ mesh forming all around the NVP/ BMA-coated Prolene ${ }^{\circledR}$ mesh (Figure 5) and no adhesions were observed (Table 1). The Prolene ${ }^{\circledR}$ meshes showed adhesions together with more granulation tissue, mostly more fibroblasts.

The Proceed ${ }^{\circledR}$ meshes still provoked a reaction attended with many fibroblasts, giant cells, and macrophages. Again, macrophages filled with a foreign material from the mesh were observed, together with a clearly degraded coating (Figure 5, C).

\section{Discussion}

This study shows that modification of the mesh surface can modulate the inflammatory response provoked by implantation of a mesh. Our clearest observation of this effect was made through histology on the 30-day follow-up samples of meshes and surrounding tissues. The uncoated Prolene ${ }^{\circledR}$ meshes were found to invoke a moderate inflammatory 
Table 1. Histological assessment

\begin{tabular}{|c|c|c|c|c|c|c|c|}
\hline 7 days follow-up & $\mathbf{n}$ & 胥 & 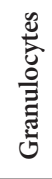 & $\begin{array}{l}\frac{0}{0} \\
\frac{0}{0} \\
0 \\
0 \\
0\end{array}$ & 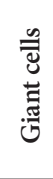 & 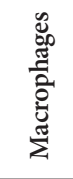 & 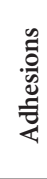 \\
\hline Prolene $e^{\circledR}$ & 8 & ++ & ++ & ++ & $-1+$ & $-1+$ & ++ \\
\hline Proceed $^{\circledast}$ & 6 & ++ & + & +++ & ++ & +++ & $-1+$ \\
\hline NVP/BMA coated & 7 & ++ & ++ & +++ & $-1+$ & + & ++ \\
\hline 30 days follow-up & $\mathrm{n}$ & 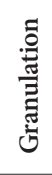 & 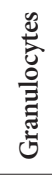 & 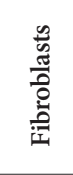 & 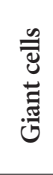 & 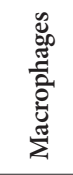 & 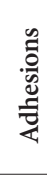 \\
\hline Prolene ${ }^{\circledR}$ & 7 & ++ & $-1+$ & ++ & + & $-1+$ & + \\
\hline Proceed $^{\circledR}$ & 5 & - & - & +++ & ++ & +++ & $-/+$ \\
\hline NVP/BMA coated & 5 & $-1+$ & $-1+$ & + & + & + & - \\
\hline
\end{tabular}

- means absent, + slightly present, ++ moderately present, +++ abundantly present

response in their immediate vicinity, characterized by the presence of active macrophages. A stronger inflammatory response was observed with the Proceed ${ }^{\circledR}$ meshes, presumably due to ongoing phagocytosis of the oxidized regenerated cellulose and polydioxanone coating. Remnants of foreign material were observed in macrophages and giant cells. The NVP/BMA-coated Prolene ${ }^{\circledR}$ mesh initially provoked a profound acute inflammation. After 30 days, only a mild inflammatory reaction was left. At this stage, these meshes were found to be surrounded by a fibrous capsule. Although not exclusively proven, encapsulation of the mesh may prevent adhesion formation in the long term.

Macroscopically, different grades of adhesions were observed at 7 and 30 days follow-up. Most remarkable were the adhesions with Proceed ${ }^{\circledR}$. Although adhesion scores were the lowest at day 7, they increased by day 30 and exceeded adhesion scores of NVP/BMA-coated Prolene ${ }^{\circledR}$ mesh and Prolene $e^{\circledast}$. The adhesion scores of the NVP/BMA-coated Prolene ${ }^{\circledR}$ and Prolene ${ }^{\circledR}$ mesh, however, declined toward day 30. A possible explanation might be the prolonged activation of the macrophages with Proceed ${ }^{\circledR}$. Activation of macrophages induces the release of inflammatory cytokines and attracts cells like fibroblasts. Prolonged presence of active fibroblasts then might induce more tenacious adhesions, as observed ${ }^{11,12}$. Overall, the results of the microscopic analyses (histology) and the macroscopic adhesion scores were consistent.

Interestingly, Baptista et al have reported that inflammation leads to adhesions, generally within 7 days $^{24}$. We observed, in most cases, fewer adhesions after 30 days, as compared to 7 days follow-up, which is in agreement with findings of Burger et $\mathrm{al}^{14}$ who also showed that adhesion formation may decrease at 30 days follow-up. The only exception was the Proceed mesh, with an increase in the adhesion effect between 7 and 30 days follow-up. It is generally accepted that evaluation of meshes at 7 and 30 days represents different phases 

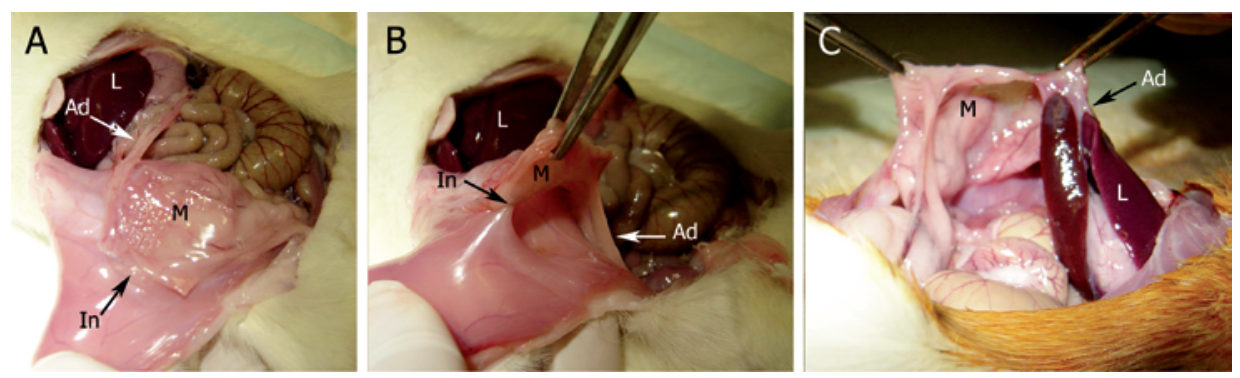

Figure 3. Representative macroscopic views of the meshes after implantation in the rat abdomen. A NVP/ BMA-coated Prolene ${ }^{\circledR}$ mesh 30 days post-implantation, the abdomen is opened in a U shape enabling a good macroscopic evaluation. The mesh is indicated by the letter ' $\mathrm{M}$ ' and the liver by the letter 'L'. Note the site of incorporation (In) and the typical adhesions (Ad) at the uncoated edges of the mesh. B The same rat as in A, the mesh is lifted, again note the site of incorporation (In) and adhesion (Ad) formation to the uncoated edges of the mesh. C Prolene ${ }^{\circledR}$ mesh (M) 7 days post implantation, showing adhesion formation to the liver (L), similar observations were made for Proceed ${ }^{\circledast}$ and Prolene ${ }^{\circledR} 30$ days post implantation.

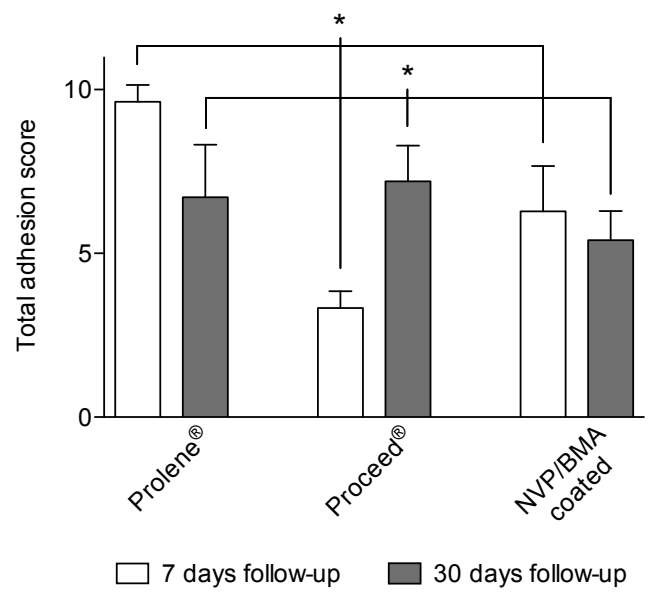

Figure 4. Macroscopic adhesion scores at 7 and 30 days post implantation. After 7 days follow-up, Proceed ${ }^{\circledR}$ had a significantly $(P<0.05)$ better score $(3.3)$ compared to Prolene ${ }^{\circledR}$ and NVP/BMA-coated Prolene ${ }^{\circledR}(9.6$ and 6.3, respectively). Interestingly, while adhesion scores of Prolene ${ }^{\circledast}$ and NVP/BMA-coated Prolene ${ }^{\circledR}$ meshes improved, the adhesion score of Proceed ${ }^{\circledR}$ meshes worsened. At this time the adhesion score of the NVP/BMA-coated Prolene ${ }^{\circledast}$ mesh $(5.4)$ was significantly $(P<0.05)$ better compared to Proceed ${ }^{\circledR}(7.2)$ and Prolene ${ }^{\circledR}(6.7)$. ( ${ }^{*}$ indicates $\left.P<0.05\right)$

of wound healing. At 7 days, the inflammatory phase has just ended, and the proliferative phase has just started. At 30 days, the remodelling phase has started and prosthetic material covered with a lining of autologous cells (neoperitoneum) is expected not to form any new adhesions ${ }^{14}$. Adhesions that have formed before, however, will remain a persistent inflammatory process, even in adhesions aging over 20 years ${ }^{25}$. It is tempting to argue that the remodelling phase may lead to a decreased adhesion formation. 


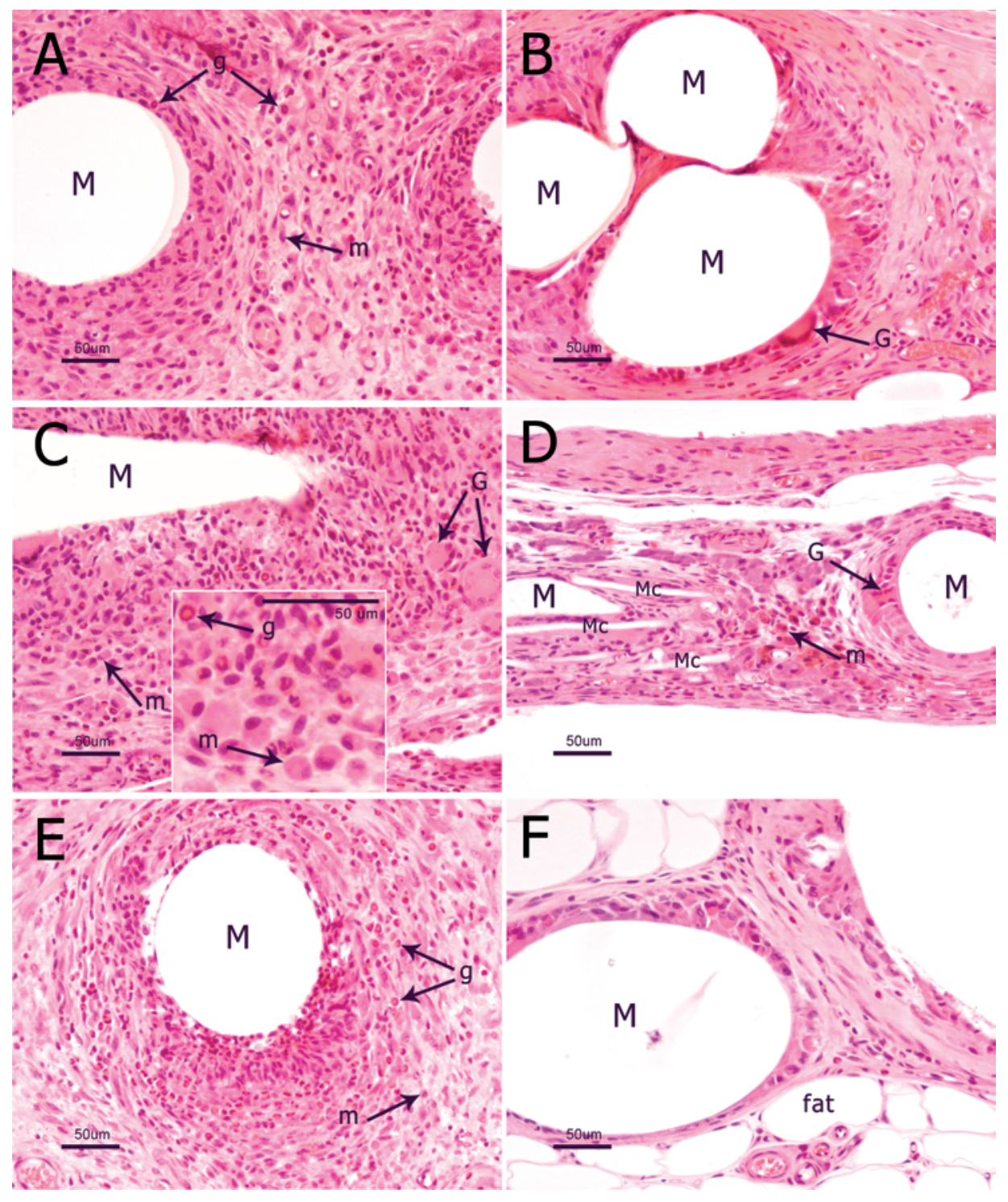

Figure 5. Representative H\&E stained sections. Prolene ${ }^{\circledR}$ mesh at 7 days (A) and at 30 days follow-up (B). Proceed ${ }^{\circledR}$ mesh at 7 days (C) and at 30 days follow-up (D). Insert shows macrophages containing foreign material. NVP/BMA-coated Prolene ${ }^{\circledR}$ mesh at 7 days (E) and at 30 days follow-up (F). (M mesh, Mc mesh coating present in giant cells, $m$ macrophage, $g$ granulocyte, $G$ giant cell)

Since adhesion formation changes even until 30 days follow-up, it is hard to predict when the remodeling phase will end, what should be defined as long-term follow-up, and what will be the final adhesion formation. Our data reveal that the stable hydrophilic polymer mesh coating has a beneficial effect on adhesion formation after implantation of 
a mesh, albeit that our experiments were carried out in a validated rat model deviating from the actual application: repair of incisional hernias. Incisional hernias are a major surgical complication occurring in at least $10-20 \%$ of all abdominal operations and need to be repaired in about one third of these patients ${ }^{3,26}$. Large trials have shown that hernia repair should be performed by mesh placement and no longer by primary resuturing of the hernia because of unacceptably high recurrence rates ${ }^{4,27}$. Mesh repair, however, is not free from complications, with significant factors being technical failure such as insufficient fixation of the mesh to the abdominal wall and complications which are a result of the mesh biomaterial itself. The latter is especially true if the biomaterial provokes inflammation, or if its surface is prone to bacterial infection. Biomaterials which are currently used in this particular application (i.e., PP and poly(tetrafluoro)ethylene) may be optimized using a stable coating and this may ultimately translate into decreased failure rates for incisional hernia repair, to the benefit of a large group of patients.

Finally, four remarks may be appropriate:

1. The predictive value of this study may be more specific for clinical cases in which the mesh is implanted in direct contact with the viscera and not separated from the viscera by an intact peritoneum.

2. In this study the aim was to examine the biocompatibility and adhesion formation of three different mesh surfaces. Fixation of the mesh to the abdominal wall is clinically relevant to prevent hernias to reoccur. In our study, the two Prolene ${ }^{\circledR}$ sutures used for fixation always resulted in a good local incorporation. This aspect will be examined in future studies.

3. Since it is not clear if adhesion formation changes after 30 days, a follow-up beyond 30 days is needed to precisely evaluate the performance of the NVP/BMA-coated Prolene ${ }^{\circledR}$ meshes over the course of time.

4. A hydrophilic coating (degradable or stable) may be exploited in another manner as well, i.e. as a reservoir for controlled release of an antibiotic agent. A hydrophilic surface per se may play a role in the prevention of bacterial adhesion ${ }^{7}$, while controlled swelling of the coating after implantation provides a means to engineer and control the release kinetics, at least in principle.

Points 1, 3, and 4 are subjects of further investigations in our laboratories. 


\section{References}

5 Kingsnorth A. The management of incisional hernia. Ann R Coll Surg Engl 2006;88(3):252-60.

6 Mudge M, Hughes LE. Incisional hernia: a 10 year prospective study of incidence and attitudes. Br J Surg 1985;72(1):70-1.

7 Burger JWA, Luijendijk RW, Hop WCJ, Halm JA, Verdaasdonk EGG, Jeekel J. Long-term followup of a randomized controlled trial of suture versus mesh repair of incisional hernia. Ann Surg 2004;240(4):578-83.

8 Cassar K, Munro A. Surgical treatment of incisional hernia. Br J Surg 2002;89(5):534-45.

9 Eisner L, Harder F. Incisional hernias. Chirurg 1997;68(4):304-9.

10 Luijendijk RW, Hop WC, van den Tol MP, de Lange DC, Braaksma MM, JN IJ, Boelhouwer RU, de Vries BC, Salu MK, Wereldsma JC, Bruijninckx CM, Jeekel J. A comparison of suture repair with mesh repair for incisional hernia. N Engl J Med 2000;343(6):392-8.

11 Engelsman AF, van der Mei HC, Ploeg RJ, Busscher HJ. The phenomenon of infection with abdominal wall reconstruction. Biomaterials 2007;28(14):2314-27.

12 Scheidbach H, Tamme C, Tannapfel A, Lippert $\mathrm{H}$, Köckerling F. In vivo studies comparing the biocompatibility of various polypropylene meshes and their handling properties during endoscopic total extraperitoneal (TEP) patchplasty: an experimental study in pigs. Surg Endosc 2004;18(2):211-20.

13 Scheidbach H, Tannapfel A, Schmidt U, Lippert $\mathrm{H}$, Köckerling F. Influence of titanium coating on the biocompatibility of a heavyweight polypropylene mesh. An animal experimental model. Eur Surg Res 2004;36(5):313-7.

14 Hooker GD, Taylor BM, Driman DK. Prevention of adhesion formation with use of sodium hyaluronate-based bioresorbable membrane in a rat model of ventral hernia repair with polypropylene mesh--a randomized, controlled study. Surgery 1999;125(2):211-6.

15 van't Riet M, Burger JW, Bonthuis F, Jeekel J, Bonjer HJ. Prevention of adhesion formation to polypropylene mesh by collagen coating: a randomized controlled study in a rat model of ventral hernia repair. Surg Endosc 2004;18(4):681-5.

16 Judge TW, Parker DM, Dinsmore RC. Abdominal Wall Hernia Repair: A Comparison of Sepramesh and Parietex Composite Mesh in a Rabbit Hernia Model. J Am Coll Surg 2007;204(2):276-81.

17 Zheng F, Lin Y, Verbeken E, Claerhout F, Fastrez M, De Ridder D, Deprest J. Host response after reconstruction of abdominal wall defects with porcine dermal collagen in a rat model. Am J Obstet Gynecol 2004;191(6):1961-70.

18 Burger JWA, Halm JA, Wijsmuller AR, Raa ten S, Jeekel J. Evaluation of new prosthetic meshes for ventral hernia repair. Surg Endosc 2006;20(8):1320-5.

19 Greenawalt KE, Butler TJ, Rowe EA, Finneral AC, Garlick DS, Burns JW. Evaluation of sepramesh biosurgical composite in a rabbit hernia repair model. J Surg Res 2000;94(2):92-8.

20 Kayaoglu HA, Ozkan N, Hazinedaroglu SM, Ersoy OF, Erkek AB, Koseoglu RD. Comparison of adhesive properties of five different prosthetic materials used in hernioplasty. I Invest Surg 2005;18(2):89-95.

21 Aldenhoff YBJ, Knetsch MLW, Hanssen JHL, Lindhout T, Wielders SJH, Koole LHLH. Coils and tubes releasing heparin. Studies on a new vascular graft prototype. Biomaterials 2004;25(16):3125-33.

22 Jansen EJP, Sladek REJ, Bahar $H$, Yaffe A, Gijbels MJ, Kuijer R, Bulstra SK, Guldemond NA, Binderman I, Koole LH. Hydrophobicity as a design criterion for polymer scaffolds in bone tissue engineering. Biomaterials 2005;26(21):4423-31.

23 Knetsch MLW, AldenhoffYBJ, Koole LH. The effect ofhigh-density-lipoprotein on thrombusformation on and endothelial cell attachement to biomaterial surfaces. Biomaterials 2006;27(14):2813-9.

24 Pijls RT, Sonderkamp T, Daube GW, Krebber R, Hanssen HHL, Nuijts RMMA, Koole LH. Studies on a new device for drug delivery to the eye. Eur J Pharm Biopharm 2005;59(2):283-8.

25 Hanssen $\mathrm{HH}$, Wetzels GM, Benzina A, van der Veen FH, Lindhout T, Koole LH. Metallic wires with an adherent lubricious and bloodcompatible polymeric coating and their use in the manufacture of novel slippery-when-wet guidewires: possible applications related to controlled local drug delivery. J Biomed Mater Res B Appl Biomater 1999;48(6):820-8.

26 Adhesion Scoring Group. Improvement of interobserver reproducibility of adhesion scoring systems. Adhesion Scoring Group. Fertil Steril 1994;62(5):984-8. 
27 Matthews BD, Mostafa G, Carbonell AM, Joels CS, Kercher KW, Austin C, Norton HJ, Heniford BT. Evaluation of adhesion formation and host tissue response to intra-abdominal polytetrafluoroethylene mesh and composite prosthetic mesh. J Surg Res 2005;123(2):227-34. Baptista ML, Bonsack ME, Felemovicius I, Delaney JP. Abdominal adhesions to prosthetic mesh evaluated by laparoscopy and electron microscopy. J Am Coll Surg 2000;190(3):271-80.

29 Binnebösel M, Rosch R, Junge K, Lynen-Jansen P, Schumpelick V, Klinge U. Macrophage and
T-lymphocyte infiltrates in human peritoneal adhesions indicate a chronic inflammatory disease. World J Surg 2008;32(2):296-304.

30 Kingsnorth A, LeBlanc K. Hernias: inguinal and incisional. Lancet 2003;362(9395):1561-71.

31 Korenkov M, Sauerland S, Arndt M, Bograd L, Neugebauer EA, Troidl H. Randomized clinical trial of suture repair, polypropylene mesh or autodermal hernioplasty for incisional hernia. Br J Surg 2002;89(1):50-6. 


\title{
Chapter 8
}

\section{Preoperative, oral cromolyn treatment for adhesion reduction to intraperitoneal meshes: an experimental study}

\author{
M. H. Schreinemacher ${ }^{1,2}$ \\ R. M. Vogels ${ }^{2}$ \\ K. W. van Barneveld ${ }^{2}$ \\ J. W. Bosmans² \\ M. J. Gijbels $s^{3,4}$ \\ N. D. Bouvy ${ }^{2}$
}

Submitted

Affiliations

${ }^{1}$ Department of Surgery, Tergooi Hospital, Hilversum, The Netherlands.

${ }^{2}$ Department of General Surgery, Maastricht University Medical Center, Maastricht, The Netherlands.

${ }^{3}$ Departments of Molecular Genetics and Pathology, Maastricht

University Medical Center, Maastricht, The Netherlands.

${ }^{4}$ Department of Medical Biochemistry, Amsterdam Medical Centre, Amsterdam, The Netherlands. 


\begin{abstract}
Objectives

Incisional hernias can be repaired by intraperitoneal mesh. In such cases, the mesh is a specific lead point for adhesion formation, which may be the source of future adhesion related complications.
\end{abstract}

\title{
Summary background data
}

New insights into the earliest stages of adhesion formation and biomaterial related fibrosis have been developed. With the former, interferon gamma (IFN- $\gamma$ ) and with the latter, fibrinogen adsorption at the foreign body surface leading to mast cell activation were found crucial. In this study, the attenuation of these earliest immune reactions was explored as a possible target for adhesion reduction.

\section{Methods}

8 In a series of mice experiments we assessed adhesions to uncoated intraperitoneal polypropylene mesh at 7 days follow-up. IFN- $\gamma$ knockout mice, mice depleted from fibrinogen, and mice treated with histamin receptor antagonists were studied. Sodium cromoglycate (cromolyn), regarded as a mast cell stabiliser, was also administered orally. In contrast to most interventions, treatments were initiated preoperatively so that optimal intensity was reached at the time of mesh implantation.

\section{Results}

Only cromolyn administration significantly reduced adhesion formation (45\% vs $97 \%$ of mesh surface covered with adhesions, $P<0.001)$. Interestingly, the antiadhesive effect was only observed if therapy was initiated 2 days preoperatively, not postoperatively. Wound healing was otherwise unchanged. However, the supposed influence on mast cell mediated inflammation, fibrinolysis and fibrosis could not be clarified.

\section{Conclusions}

Oral, preoperative administration of cromolyn drastically reduces intraperitoneal mesh related complications without apparent side effects and translation of these findings to the clinical setting should be attempted. 


\section{Introduction}

Up to $20 \%$ of patients undergoing a midline laparotomy develop an incisional herniation and over a third of these patients require repair for functional or cosmetic reasons $s^{1,2}$. Hernia repair should be performed with mesh in order to reduce recurrences ${ }^{3}$. In case of intraperitoneal implantation, adhesion formation occurs to a certain extent $t^{4-6}$.

Postoperative adhesions and incisional herniation continue to be the most common long-term complications of abdominal surger ${ }^{1,7}$. Postoperative adhesions occur in up to $90 \%$ of patients, are a result from an inflammatory process and may cause small bowel obstruction, infertility and inadvertent bowel injuries exists at reoperations ${ }^{8,9}$.

Interferon gamma (IFN- $\gamma$ ) produced by natural killer $\mathrm{T}$ (NKT)-cells was recently shown to be a very early, indispensible factor for the formation of adhesions in a murine model ${ }^{10,11}$. In addition, within hours after surgical trauma NKT cells have also been confirmed at the site in a human hemihepatectomy model ${ }^{12}$.

Adhesion formation to meshes is often found to be in line with the severity of the foreign body reaction induced by the biomaterial. The foreign body reaction constitutes a complex inflammatory process and has already been the subject of much research. Protein adsorption, the very first biomaterial-host interaction, has been recognized to be of major importance. Especially fibrinogen is considered an important protein that adheres to the biomaterial surface after which a change in its structure exposes epitopes that initiate the recruitment and activation of phagocytes ${ }^{13,14}$. Furthermore, the initial recruitment of inflammatory cells to experimental implants seems to be dependent on mast cells that release a number of pro-inflammatory and pro-fibrotic signals ${ }^{15,16}$. This finding has also been confirmed in a human model ${ }^{15}$.

We hypothesised that the very first host response to the intraperitoneal mesh implantation is of key importance to successfully prevent or reduce postoperative adhesion formation. At the time of proliferation too many factors are active so that attenuating only one pathway will upregulate others or disrupt wound repair beyond desired levels. The IFN- $\gamma$ and fibrinogen-mast cell pathways were found to be of interest since both have been demonstrated to be applicable to humans and focus on the very first steps in the onset of the inflammatory reaction.

In this study, we explored the applicability of the IFN- $\gamma$ and fibrinogen-mast cell pathways on adhesion formation with intraperitoneal meshes. Using a rodent model for intraperitoneal mesh implantation, the extent of mesh surface covered with adhesions was evaluated at 7 days follow-up.

\section{Methods and Materials}

\section{Animals}

Male Balb/c mice, aged 10-12 weeks, were housed and cared for at the animal facilities of the Maastricht University Medical Centre, Maastricht, The Netherlands. IFN- $\gamma$ knockout (KO) Balb/c mice and their wild-type (WT) littermates were housed and cared for at the 
animal facilities of the Catholic University of Leuven, Leuven, Belgium. The animal ethical committees of the respective universities approved the protocols.

\section{Operative procedures}

Animals were anesthetized using isoflurane $2.5 \%$. In case of IFN- $\gamma$ KO and WT mice, mice were anesthetized with intraperitoneal ketamine hydrochloride $(100 \mathrm{mg} / \mathrm{kg})$ and xylazine $(10 \mathrm{mg} / \mathrm{kg})$. The abdomen was shaved, disinfected with $2 \%$ iodine and covered with sterile drapes. Through a midline incision of about $1.5 \mathrm{~cm}$ the abdomen was accessed and a $1 \times 1.5 \mathrm{~cm}$ sterile mesh (Prolene ${ }^{\circledR}$ mesh; Ethicon, Johnson \& Johnson, Somerville, NJ, USA) placed intraperitoneally. The mesh was oriented along the longitudinal axis and secured to the abdominal wall using two single polypropylene $6 \times 0$ sutures (Prolene ${ }^{\circledR}$; Ethicon), one on each side of the midline. The muscles were then approximated with a running suture of polypropylene $6 \times 0\left(\right.$ Prolene $\left.^{\circledR}\right)$ and the skin closed with interrupted polyglactin $4 \times 0$ sutures (Vicryl ${ }^{\circledR}$; Ethicon). No antibiotics were administered.

At the time of follow-up, mice were administered an overdose of carbon dioxide by inhalation. Afterwards, the abdomen was opened through an U-shaped incision extending lateral and caudal to the meshes.

\section{Cromolyn administration}

Mice were administered sodium cromoglycate (cromolyn; Sigma-Aldrich, St. Louis, MO, USA) through oral gavage. Doses ranging from 2 to $500 \mathrm{mg} / \mathrm{kg}$ were dissolved in $1.5 \mathrm{ml}$ of $\mathrm{NaCl} 0.9 \%$ and administered once daily from 2 days preoperatively until 1 day postoperatively, unless otherwise specified. At the day of operation, cromolyn was given 2-4 hours before operation. Control mice were treated identically, but with $\mathrm{NaCl} 0.9 \%$.

\section{Forced mast cell degranulation}

One day after mesh placement with cromolyn treatment (20 mg/kg), compound 48/80 was administered intraperitoneally at a single dose of $1 \mathrm{mg} / \mathrm{kg}$ for forced mast cell degranulation.

\section{Intraperitoneal mast cell therapies and fibrinogen depletion}

Histamin receptors 1 (H1) and 2 (H2) were blocked using cetirizine and ranitidine, respectively (both Sigma-Aldrich), at doses of $10 \mathrm{mg} / \mathrm{kg}$ of each compound administered intraperitoneally twice daily. In order to deplete mice from fibrinogen, ancrod $\left(1^{\text {st }}\right.$ International Reference Preparation, NIBSC code 74/581, National Institute for Biological Standards and Control, Hertfordshire, UK) was employed at an intraperitoneal dose of 100 IU/kg once daily. All substances were dissolved in boluses of $1.5 \mathrm{ml} \mathrm{NaCl} 0.9 \%$ and injected from 2 days preoperatively until 1 day postoperatively, except for ancrod injections that started from 3 days preoperatively. At the day of operation, injections were given 2-4 hours before operation. Control mice were treated identically, but with $\mathrm{NaCl} 0.9 \%$.

For comparison, cromolyn was also used at an intraperitoneal dose of $20 \mathrm{mg} / \mathrm{kg}$ once daily. 


\section{Adhesion scoring}

At 7 days follow-up, mice were sacrificed for adhesion quantification. Once the abdomen was opened, a standardized picture of the mesh was taken for computer quantification of the extent of adhesions by a blinded observer (see supplementary data for an example). The extent of adhesions was expressed as the percentage of the mesh surface covered with adhesions.

\section{Histology}

Mice were sacrificed at 7 days and, in a separate experiment for histology and immunoassay purposes, at 3 hours, 1 day and 7 days postoperatively. Then, meshes were excised together with the underlying abdominal wall. In addition, pieces of small and large bowel and omentum were resected as well. Specimens were fixated in formaldehyde $4 \%$, dehydrated, and embedded in paraffin. Tissue sections $5 \mu \mathrm{m}$ thick were cut and hematoxylin-eosin (HE) stained. Sections were also stained with toluidin blue and picrosirius red for mast cell and collagen identification, respectively. Histology was assessed by an experienced animal pathologist familiar with intraperitoneal mesh placement and the associated foreign body host response. In accordance with many of our former studies ${ }^{17,18}$ histologic scoring was focused on inflammatory cells (neutrophils, macrophages, foreign body giant cells) and fibroblasts. These were quantified as follows: not present, slightly present (only directly around mesh material), moderately present (also between mesh material), or abundantly present (thick layer of reactive tissue around all mesh material).

\section{Immunoassays}

At 3 hours, 1 day and 7 days postoperatively the abdomen was instilled with $3 \mathrm{cc}$ of Phosphate Buffered Solution (PBS), following anaesthesia. After 3 minutes of gentle massaging the abdomen was opened and the fluid collected. Then the aorta was located and 1-1.5 cc of blood aspirated until total exsanguination. Both peritoneal dialysate and blood were spun and stored at $-80^{\circ} \mathrm{C}$ until processing. A monocyte chemotactic protein 1 (MCP-1) ELISA kit (Thermo Scientific, Cleveland, OH, USA) was used for measuring MCP-1 in peritoneal dialysate as a pro-inflammatory protein. For the quantitative determination of functionally active tissue plasminogen activator (tPA) a mouse tPA ELISA kit (Innovative research, Novi, MI, USA) was used on plasma. Active plasminogen activator inhibitor type 1 (PAI-1) was measured in plasma with the PAI-1 total mouse ELISA kit (Abcam, Cambridge, MA, USA). All assays were performed according to the manufacturer's instructions.

\section{Statistical analysis}

Data are expressed as per cent of the mesh surface covered with adhesions and in medians with interquartile range. Group size was six or more. Comparisons between groups were calculated by two-sided Mann-Whitney and Kruskal-Wallis tests using Graphpad Prism ${ }^{\circledR}$ (GraphPad Software, La Jolla, CA, USA). $P<0.050$ was considered significant. 


\section{Results}

\section{Preoperative administration of cromolyn reduces postoperative}

adhesion formation to intraperitoneal mesh

The supposed mast cell stabilizer cromolyn $(20 \mathrm{mg} / \mathrm{kg}$ ) was administered preoperatively to mice by oral gavage. At the time of follow-up, adhesions were significantly reduced to mice that had only received $\mathrm{NaCl}$ ( $45 \%$ vs $97 \%$, respectively)(Figure 1, A). The same was true when cromolyn was delivered intraperitoneally, resulting in comparable adhesion reduction as if delivered orally ( $54 \%$ vs $45 \%$, respectively; $P=0.255$ )(Figure $1, \mathrm{~B}$ ). Midline incision strengths were found to be unaffected by cromolyn treatment (supplementary data).

\section{Intraperitoneal mesh adhesion formation is not $\mathrm{H} 1 / \mathrm{H} 2$ receptor, fibrinogen or IFN- $\gamma$ dependent}

The combination of $\mathrm{H} 1$ and $\mathrm{H} 2$ receptor antagonists did not significantly reduce adhesions compared to controls (65\% vs $77 \%$, respectively)(Figure 1, B). Neither did fibrinogen depletion 8 through ancrod administration result in any significant differences in adhesion formation ( $75 \%$ vs $77 \%$, respectively)(Figure 1, B). In addition, the findings by others that IFN- $\gamma$ is required for initiating the process of intraperitoneal adhesion formation ${ }^{11}$ could not be confirmed. In fact, adhesion formation in IFN- $\gamma$ KO mice was even found to be significantly increased compared to their wild-type littermates ( $94 \%$ vs $74 \%$, respectively)(Figure 1, C).

\section{Preoperative, low dose administration of cromolyn is essential for intraperitoneal mesh adhesion reduction}

Starting cromolyn treatment two days before operation was effective in reducing adhesions, whereas starting the day after implantation had no effect (38\% vs $96 \%$, respectively)(Figure 3). Starting treatment 2-4 hours before operation resulted only in an intermediate effect on adhesion reduction (64\% of mesh surface covered). Apart from the moment of starting treatment, continuing treatment until 2-4 hours before or until 1 day after the operation did not result in any significant differences. Interestingly though, continuing treatment until 7 days postoperatively nullified the beneficial effect of cromolyn resulting in an adhesion coverage of the mesh of $95 \%$ (Figure 3). Furthermore, doses from 4 to $500 \mathrm{mg} / \mathrm{kg}$ were found to give comparable results, though a trend was seen for high doses $(500 \mathrm{mg} / \mathrm{kg})$ to be less effective than low doses ( $4 \mathrm{mg} / \mathrm{kg})(52 \%$ vs $38 \%$, respectively; $P=0.054)$ (Figure 2, B).

\section{The mode of action of cromolyn in reducing intraperitoneal mesh adhesion formation remains unclear}

In order to confirm the hypothesized pathway of 'cromolyn-mast cell release inhibitionattenuated inflammation', an experienced animal pathologist evaluated histologic sections. However, no marked differences could be observed in either the inflammatory or foreign 

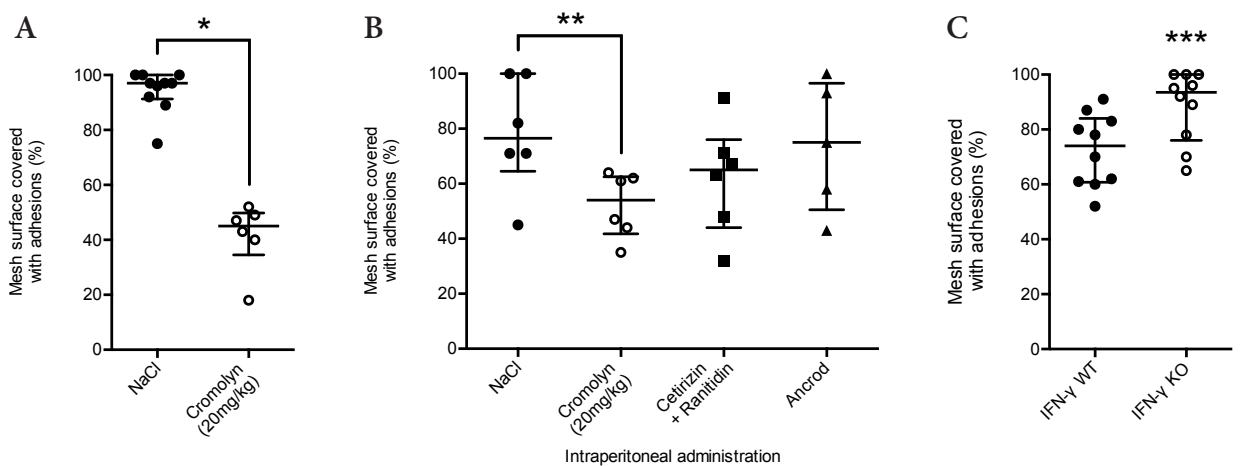

Figure 1. Preoperative administration of cromolyn significantly reduced adhesion formation to mesh at 7 days follow-up (A). Intraperitoneal administration of cromolyn also resulted in a significant reduction of adhesions (B). However, H1 (ranitidin) and H2 (cetirizin) receptor antagonists and fibrinogen depletion through ancrod administration did not (B). In addition, IFN- $\gamma$ deficiency did not protect from intraperitoneal adhesion formation with mesh $(\mathrm{C})$. Every data point represents a single animal. $\left({ }^{\star} P<0.001,{ }^{* *} P=0.022,{ }^{* *} P=0.121\right)$

A

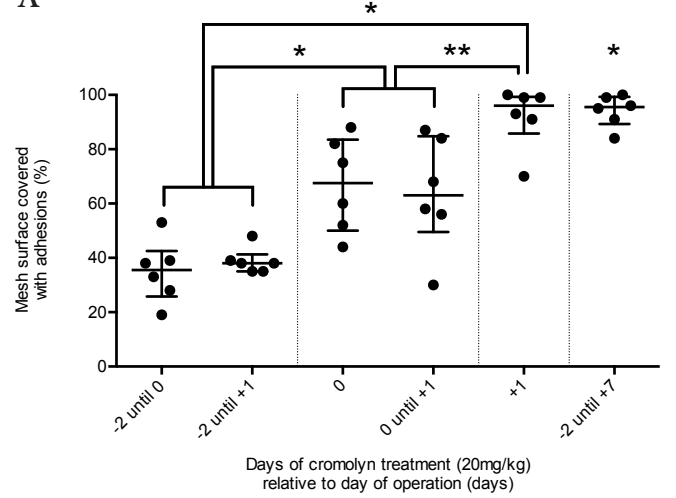

B

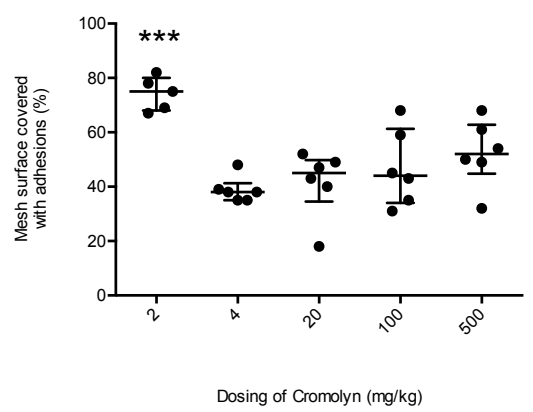

Figure 2. Starting oral cromolyn treatment 2 days before the operation (“- 2 until 0 " and "- 2 until +1 ") was found essential for adhesion reduction at 7 days follow-up (A). Starting treatment only 2-4 hours before the operation (" 0 " and " 0 until +1 ") or only after the operation (" +1 ") resulted in intermediate and no effects, respectively. Continuing cromolyn treatment until 1 day postoperatively did not improve results ("- 2 until 0 ” vs "- 2 until +1 ”, and " 0 " vs " 0 until +1 "), but continuing treatment until 7 days follow-up nullified the effect on adhesion reduction. The oral dosing was found to be effective in doses of $4 \mathrm{mg} / \mathrm{kg}$ and higher, though higher doses did not result in more adhesion reduction (B). Every data point represents a single animal. $\left({ }^{\star} P<0.001,{ }^{* *} P=0.002,{ }^{* *} P=0.005\right)$

body reaction in particular. Nor did the number and morphology of mast cells in abdominal wall, bowel wall of omentum differ.

Immunoassays were used to detect more subtle changes in early signs of inflammation (MCP-1) as well as the fibrinolytic balance (tPA/PAI-1 ratio). Higher tPA/PAI-1 ratios mark a more fibrinolytic response leading to breakdown of adhesions. As expected, control mice showed significantly higher MCP-1 levels in peritoneal dialysate at 3 hours and 1 day 
A

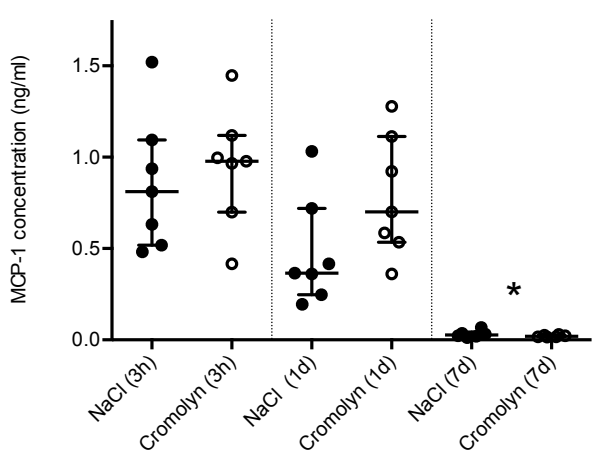

B

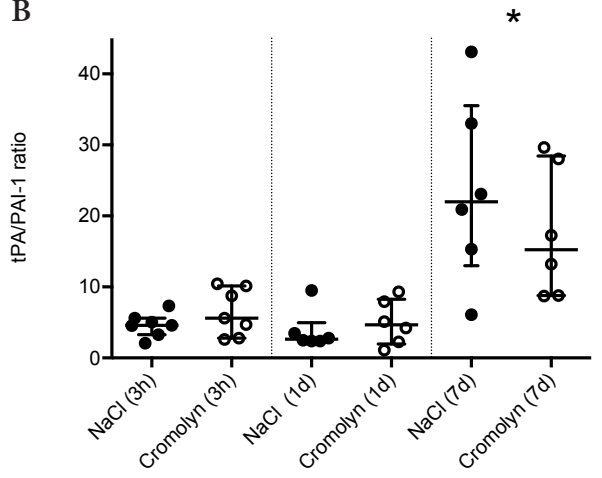

Figure 3. Both MCP-1 and tPA/PAI-1 ratios were determined in peritoneal dialysate and serum, respectively. At all postoperative time points (3h: 3 hours; $1 \mathrm{~d}$ : 1 day; $7 \mathrm{~d}$ : 7 days) no significant differences existed between cromolyn treated mice and controls. As expected however, acute inflammation (MCP-1) was significantly less intense and fibrinolysis (tPA/PAI-1 ratio) significantly more intense at 7 days follow-up for both cromolyn treated mice and controls. Every data point represents a single animal. $\left({ }^{*} P<0.001\right)$

postoperatively than at 7 days (Figure $4, \mathrm{~A}$ ). Also expected were the significantly lower tPA/PAI- 1 ratios in plasma at 3 hours and 1 day postoperatively than at 7 days (Figure 4, B). Yet, the cromolyn treated groups showed almost identical values at all time points for both MCP-1 and tPA/PAI-1 ratios. Therefore, our histological findings and immunoassays at 3 hours and 1 and 7 days follow-up did not provide supporting evidence for attenuated inflammation or a more pronounced fibrinolytical effect after cromolyn treatment. Though the direct impact on mast cells could not be verified, forced mast cell degranulation caused by compound $48 / 80$ did induce adhesion formation up to levels comparable with controls (adhesion coverage $79 \%$ vs $97 \%$, respectively; $P=0.195$ ).

\section{Discussion}

As intraperitoneal mesh repair of incisional herniation is frequently performed, the prevention of complications such as adhesion formation with the mesh is of great clinical importance. With this study we found that cromolyn, commonly known as a mast cell stabilizer, significantly reduces such adhesion formation. IFN $-\gamma$ and fibrinogen did not prove to be useful targets for adhesion reduction.

The fact that cromolyn reduces adhesions only when administered preoperatively and not postoperatively confirms our hypothesis that a very early inflammatory process is involved. Also, a 1 to 2 day preparation with cromolyn was required for optimal results whereas a single preoperative dose resulted in a moderate effect. This preoperative conditioning is a new concept in the prevention of adhesion. Current adhesion reduction therapies typically involve a local release of drugs or barrier sheets and fluids administered right after inflicting the trauma ${ }^{19,20}$. With cromolyn a less severe onset of inflammation at the time of mesh implantation 
is supposed to be induced. This way, all or most of the many downstream pathways that eventually lead to a rich variety of inflammatory cells are beneficially influenced ${ }^{21}$.

The exact mechanism of cromolyn treatment remains a major question. Cromolyn is commonly regarded as an anti-inflammatory agent acting mainly on suppressing mast cell mediator release. Yet, numerous alternative pathways have been elucidated so far. For instance, cromolyn may dampen the IgE antibody interaction with mast cells, basophils and eosinophils. Furthermore, a cell-selective suppressive effect on macrophages, eosinophils, and monocytes has been shown, as well as eicosanoid suppression through annexin-A1 release $\mathrm{e}^{22,23}$. The findings in this study that no differences in quantity and quality of mast cells were observed, that $\mathrm{H} 1$ and $\mathrm{H} 2$ receptor antagonists were ineffective and that prolonged cromolyn administration leads to less or no beneficial results, would suggest other pathways than a general mast cell effect. However, forced mast cell degranulation did induce adhesion formation and others have detected significant changes in intraperitoneal proinflammatory mediators only at 30 minutes and not at 2 hours after peritonitis induction ${ }^{24}$. We only measured MCP-1 at 3 hours after mesh implantation.

The role of cromolyn in the fibrotic response to foreign bodies has been clearly established by others. In the fibrotic response, $\mathrm{cd} 45^{+} /$collagen- $1^{+}$fibrocytes recruitment is reduced by cromolyn $n^{16,25}$. Also, fibrinogen depletion has been shown to effectively attenuate the fibrotic response $^{13}$. However, we observed no marked differences in the adhesive tissue to the mesh, nor did fibrinogen depletion reduce adhesion formation. This might be due to the fact that the intraperitoneal milieu is markedly different from the subcutaneous position that is typically used in most studies ${ }^{25,26}$. For instance, most cells in the adhesion tissue originate from the omentum which is a rich source for mesenchymal cells after activation by intraperitoneal mesh ${ }^{18,27}$.

An alternative explanation for the cromolyn effect could be found in a mechanical approach. As mast cell stabilization promotes earlier bowel movements after operation, adhesion formation might be hindered because of constant mechanic disruption of the fibrinous bands by early peristaltic movements ${ }^{28}$. In this study we did not consider functional bowel movement as an outcome parameter. Histological assessment of bowel tissue did not show any marked differences.

Recently, IFN- $\gamma$ has been identified to affect the fibrinolytic response after cecal cauterization leading to a highly significant reduction or even absence of adhesions ${ }^{11}$. Interestingly, in the presence of mesh we observed the opposite, i.e. increased adhesion formation. The nature of this reaction is uncertain, but IFN- $\gamma$ is known to be an important cytokine in the immune system with bidirectional immunoregulatory effects ${ }^{29}$. An important consequence of our findings is the fact that tissue-tissue adhesions might be distinctly different from biomaterialtissue adhesions. Adhesion models should therefore be chosen with care $\mathrm{e}^{27,30}$.

The mesh material used for these experiments was a commercially available, polypropylene mesh without coating. However, most meshes for intraperitoneal use are coated on the side that faces the viscera. This surface modification leads to a significant reduction in adhesions which might in fact be further improved by cromolyn use ${ }^{18,31}$. In addition, the meshes without coating and other foreign bodies placed intraperitoneally 
by intention such as catheters for dialysis and suture material could benefit from the preoperative treatment with cromolyn.

For this study, we investigated adhesion reduction at one week follow-up because adhesion formation with the used mesh will not further increase after this week ${ }^{27}$. Whether the observed outcome in adhesion reduction is clinically relevant remains an open question since no exact scoring systems with an established clinical correlation is available. Nevertheless, reducing extent and severity of adhesions is highly plausible to decrease the risk of adhesion related events, at least in terms of infertility and enterotomy risk in reoperations $s^{9,32}$.

Lastly, oral cromolyn is a FDA approved drug that can be used in the treatment of mastocytosis without significant side effects ${ }^{33}$. The current findings support its use extended to the prevention of intraperitoneal tissue-biomaterial adhesions without affecting normal wound healing as in midline incision strength. Furthermore, the oral administration, limited to the preoperative period, makes it highly appealing for clinical implementation.

\section{Conclusions}

8 Adhesion formation to intraperitoneal biomaterials such as meshes for hernia repair is a clinically relevant problem that can be significantly reduced by short, preoperative, oral cromolyn treatment. The pathogenesis seems to differ significantly from intraperitoneal tissuetissue adhesions. The exact influence of cromolyn on biomaterial induced inflammation, fibrinolysis and fibrosis remains unknown. However, the observed adhesion reduction through an easily applicable and low risk intervention warrants further clinical confirmation.

\section{Acknowledgements}

The authors would like to acknowledge Prof. Patrick Matthys (Department of microbiology and immunology at the Catholic University of Leuven, Belgium) for providing the IFN- $\gamma$ KO mice and their littermates. 


\section{References}

1 Fink C, Baumann P, Wente MN, Knebel P, Bruckner T, Ulrich A, Werner J, Büchler MW, Diener MK. Incisional hernia rate 3 years after midline laparotomy. BrJ Surg 2014;101(2):51-4.

2 Bartels SAL, Vlug MS, Hollmann MW, Dijkgraaf MGW, Ubbink DT, Cense HA, van Wagensveld BA, Engel AF, Gerhards MF, Bemelman WA, Collaborative LAFA Study Group. Small bowel obstruction, incisional hernia and survival after laparoscopic and open colonic resection (LAFA study). Br J Surg 2014;101(9):1153-9.

3 Burger JWA, Luijendijk RW, Hop WCJ, Halm JA, Verdaasdonk EGG, Jeekel J. Long-term followup of a randomized controlled trial of suture versus mesh repair of incisional hernia. Ann Surg 2004;240(4):578-83.

4 van Barneveld KWY, Vogels RRM, Beets GL, Breukink SO, Greve J-WM, Bouvy ND, Schreinemacher MHF. Prophylactic intraperitoneal mesh placement to prevent incisional hernia after stoma reversal: a feasibility study. Surg Endosc 2014;28(5):1522-7.

5 Chelala E, Debardemaeker Y, Elias B, Charara F, Dessily M, Allé J-L. Eighty-five redo surgeries after 733 laparoscopic treatments for ventral and incisional hernia: adhesion and recurrence analysis. Hernia 2010;14(2):123-9.

6 Jenkins ED, Melman L, Desai S, Brown SR, Frisella MM, Deeken CR, Matthews BD. Evaluation of intraperitoneal placement of absorbable and nonabsorbable barrier coated mesh secured with fibrin sealant in a New Zealand white rabbit model. Surg Endosc 2011;25(2):604-12.

7 Broek ten RPG, Issa Y, van Santbrink EJP, Bouvy ND, Kruitwagen RFPM, Jeekel J, Bakkum EA, Rovers MM, van Goor H. Burden of adhesions in abdominal and pelvic surgery: systematic review and met-analysis. BMJ 2013;347:f5588.

8 Hellebrekers BWJ, Kooistra T. Pathogenesis of postoperative adhesion formation. Br J Surg 2011;98(11):1503-16.

9 Broek ten RPG, Strik C, Issa Y, Bleichrodt RP, van Goor H. Adhesiolysis-related morbidity in abdominal surgery. Ann Surg 2013;258(1):98-106.

10 Tzianabos AO, Holsti MA, Zheng X-X, Stucchi AF, Kuchroo VK, Strom TB, Glimcher LH, Cruikshank WW. Functional Th1 cells are required for surgical adhesion formation in a murine model. J Immunol 2008;180(10):6970-6.

11 Kosaka H, Yoshimoto T, Yoshimoto T, Fujimoto J, Nakanishi K. Interferon-gamma is a therapeutic target molecule for prevention of postoperative adhesion formation. Nat Med 2008;14(4):437-41.

12 Ohashi K, Yoshimoto T, Kosaka H, Hirano T, Iimuro Y, Nakanishi K, Fujimoto J. Interferon $\gamma$ and plasminogen activator inhibitor 1 regulate adhesion formation after partial hepatectomy. Br J Surg 2014;101(4):398-407.

13 Hu WJ, Eaton JW, Ugarova TP, Tang L. Molecular basis of biomaterial-mediated foreign body reactions. Blood 2001;98(4):1231-8.

14 Tang L, Eaton JW. Fibrin(ogen) mediates acute inflammatory responses to biomaterials. J Exp Med 1993;178(6):2147-56.

15 Zdolsek J, Eaton JW, Tang L. Histamine release and fibrinogen adsorption mediate acute inflammatory responses to biomaterial implants in humans. J Transl Med 2007;5(1):31.

16 Thevenot PT, Baker DW, Weng H, Sun M-W, Tang L. The pivotal role of fibrocytes and mast cells in mediating fibrotic reactions to biomaterials. Biomaterials 2011;32(33):8394-403.

17 Schreinemacher MHF, Emans PJ, Gijbels MJ, Greve JWM, Beets GL, Bouvy ND. Degradation of mesh coatings and intraperitoneal adhesion formation in an experimental model. Br J Surg 2009;96(3):305-13.

18 Schreinemacher MHF, van Barneveld KWY, Dikmans REG, Gijbels MJJ, Greve J-WM, Bouvy ND. Coated meshes for hernia repair provide comparable intraperitoneal adhesion prevention. Surg Endosc 2013;27(11):4202-9.

19 Broek ten RPG, Stommel MWJ, Strik C, van Laarhoven CJHM, Keus F, van Goor H. Benefits and harms of adhesion barriers for abdominal surgery: a systematic review and meta-analysis. Lancet 2014;383(9911):48-59.

20 Aarons CB, Cohen PA, Gower A, Reed KL, Leeman SE, Stucchi AF, Becker JM. Statins (HMGCoA reductase inhibitors) decrease postoperative adhesions by increasing peritoneal fibrinolytic activity. Ann Surg 2007;245(2):176-84.

21 Klinge U, Dietz U, Fet N, Klosterhalfen B. Characterisation of the cellular infiltrate in the foreign body granuloma of textile meshes with its impact on collagen deposition. Hernia 2014;18(4):571-8.

22 Netzer NC, Küpper T, Voss HW, Eliasson AH. The actual role of sodium cromoglycate in the treatment of asthma--a critical review. Sleep Breath 2012;16(4):1027-32. 
23 Yazid S, Solito E, Christian H, McArthur S, Goulding N, Flower R. Cromoglycate drugs suppress eicosanoid generation in U937 cells by promoting the release of Anx-A1. Biochem Pharmacol 2009;77(12):1814-26.

24 Kolaczkowska E, Seljelid R, Plytycz B. Role of mast cells in zymosan-induced peritoneal inflammation in Balb/c and mast cell-deficient WBB6F1 mice. J Leukoc Biol 2001;69(1):33-42.

25 Orenstein SB, Saberski ER, Klueh U, Kreutzer DL, Novitsky YW. Effects of mast cell modulation on early host response to implanted synthetic meshes. Hernia 2010;14(5):511-6.

26 Mendes JB, Campos PP, Ferreira MAND, Bakhle YS, Andrade SP. Host response to sponge implants differs between subcutaneous and intraperitoneal sites in mice. J Biomed Mater Res 2007;83(2):408-15.

27 Gómez Gil V, Pascual G, García Honduvilla N, Rodríguez M, Buján J, Bellón JM. Characterizing omental adhesions by culturing cells isolated from a novel in vivo adhesion model. Wound Repair Regen 2009;17(1):51-61.

28 The FO, Buist MR, Lei A, Bennink RJ, Hofland J, van den Wijngaard RM, de Jonge WJ, Boeckxstaens
GE. The role of mast cell stabilization in treatment of postoperative ileus: a pilot study. $A m J$ Gastroenterol 2009;104(9):2257-66.

29 Kelchtermans H, Billiau A, Matthys P. How interferon-gamma keeps autoimmune diseases in check. Trends in Immunology 2008;29(10):479-86.

30 Rajab TK, Smaxwil L, Wallwiener M. Animal model for local pharmacotherapy in adhesion prophylaxis-a proof of concept. I Invest Surg 2013;26(4):200-3.

31 Junge K, Binnebösel $M$, Trotha von KT, Rosch R, Klinge U, Neumann UP, LynenJansen P. Mesh biocompatibility: effects of cellular inflammation and tissue remodelling. Langenbecks Arch Surg 2012;397(2):255-70.

32 Diamond MP, Wexner SD, diZereg GS, Korell $\mathrm{M}$, Zmora O, van Goor H, Kamar M. Adhesion prevention and reduction: current status and future recommendations of a multinational interdisciplinary consensus conference. Surg Innov 2010;17(3):183-8.

33 Ramsay DB, Stephen S, Borum M, Voltaggio L, Doman DB. Mast cells in gastrointestinal disease. Gastroenterol Hepatol (N Y) 2010;6(12):772-7. 


\section{Supplementary data}

\section{Adhesion coverage calculations}

Mesh coverage with adhesions was calculated by taking a standardized picture of the mesh. Then an independent and blinded observer prepared a two-colour overlay of the picture depicting the borders of the mesh and the surface of the mesh that was free from adhesions. Thereafter, the number of pixels representing adhesions (yellow) were expressed relative to the total number of pixels of the overlay image. In Figure S1, 69\% of the mesh surface was covered with adhesions.
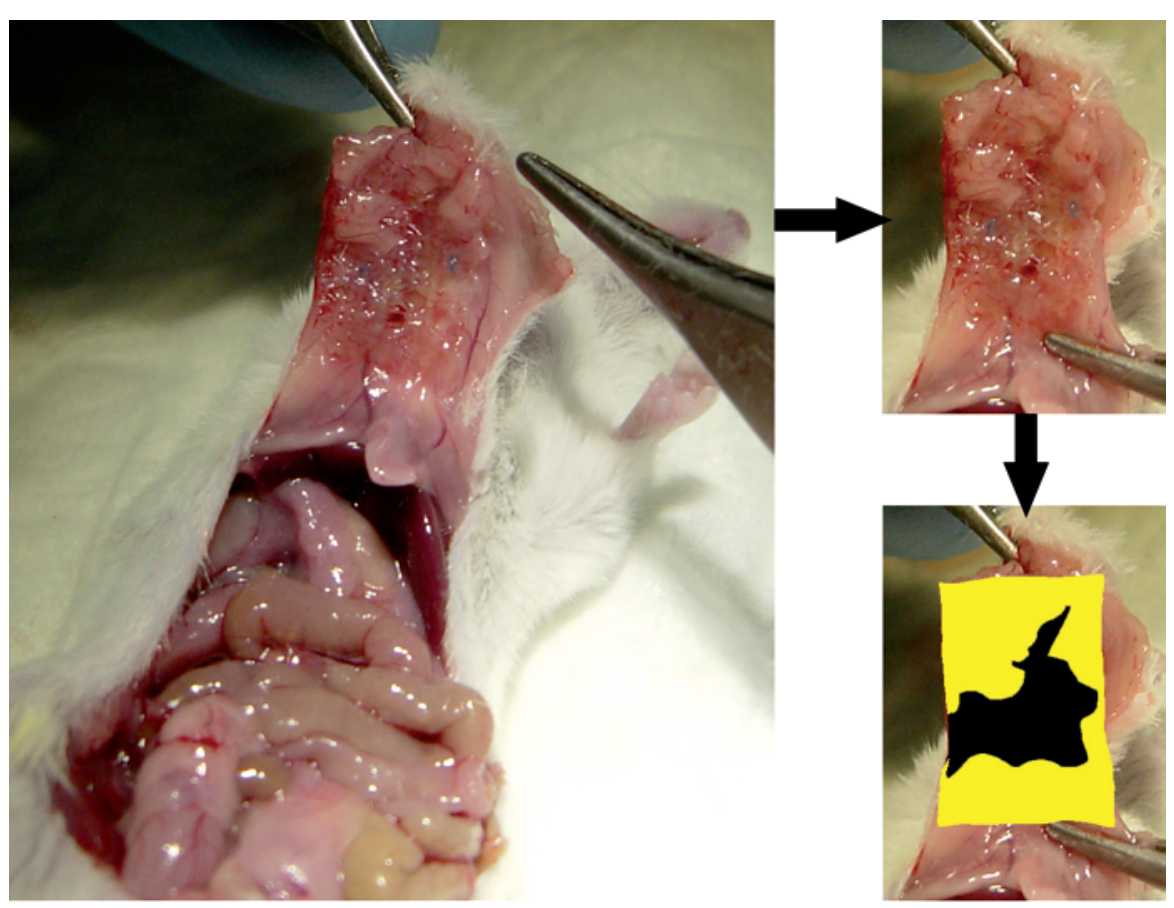

\section{Fibrinogen depletion}

In a pilot experiment we evaluated the efficacy of ancrod administration for the depletion of $\mathrm{Balb} / \mathrm{c}$ mice from fibrinogen. Three mice were administered ancrod for 3 days and sacrificed thereafter. Fibrinogen levels in these mice were undetectable (below $0.2 \mathrm{~g} / \mathrm{l}$ ). Three more mice were administered ancrod for 4 days and were sacrificed 6 days after the last administration. By then, fibrinogen levels were restored again (all three $1.5 \mathrm{~g} / \mathrm{l}$ ) and were almost identical to three mice that received only $\mathrm{NaCl} 0.9 \%$ for 4 days (two $1.5 \mathrm{~g} / \mathrm{l}$ and one $1.4 \mathrm{~g} / \mathrm{l}$ ). 


\section{Effect of intraperitoneal $\mathrm{NaCl}$ administration}

In order to examine the effect of intraperitoneal $\mathrm{NaCl} 0.9 \%$ injections on itself we compared three groups of mice implanted with a mesh and injected with (i) nothing, (ii) $\mathrm{NaCl} 0.9 \%$ until day 1 postoperatively, or (iii) $\mathrm{NaCl} 0.9 \%$ until day 7 postoperatively. Mice were sacrificed at 7 days postoperatively and adhesions assessed. No significant differences between the three groups were observed $(P=0.307)$ (Figure S2).

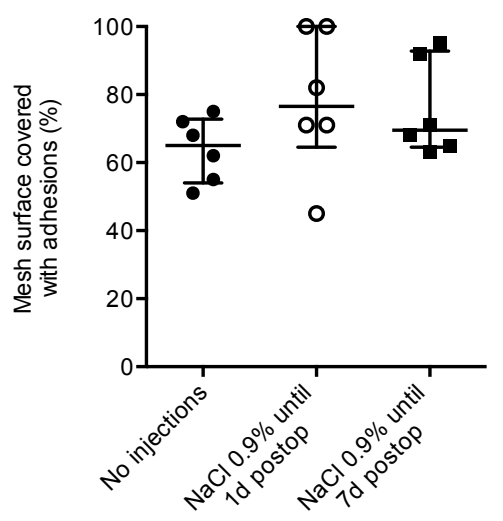

\section{Midline closure strength measurement}

Midline closure strength was defined as the maximum tensile strength needed to tear apart the two sides of the healing midline incision at 7 days postoperatively. For this, a $1 \mathrm{~cm}$ long part of the incision was excised and clamped on both sides. The Prolene $e^{\varpi} 6 \times 0$ sutures were cut. Then both clamps moved apart at a constant uniaxial pulling rate of $1 \mathrm{~mm} / \mathrm{s}$ (Figure S3). A digital tensiometer was used (Advanced Force Gauge; Mecmesin, Slinfold, UK). At 7 days postoperatively, no significant differences were observed between tensile strengths for control and cromolyn treated mice $(0.290 \mathrm{~N}$ vs $0.400 \mathrm{~N}$, respectively; $P=0.697)$.

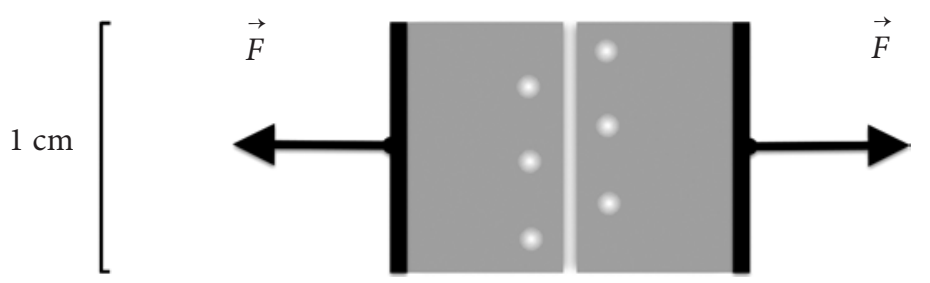




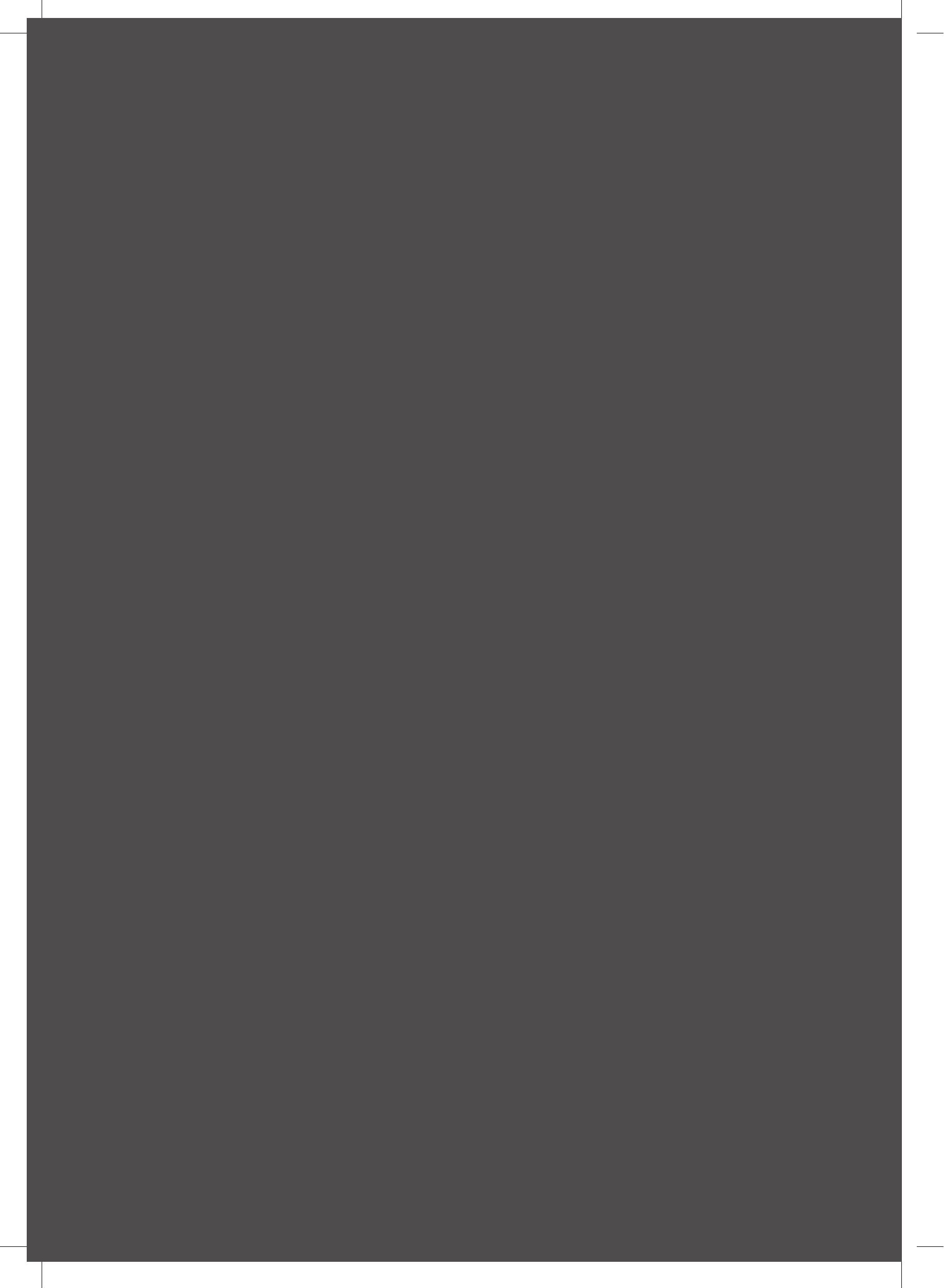




\title{
PART 3
}

\author{
A human model \\ for the evaluation \\ of adhesions to meshes
}

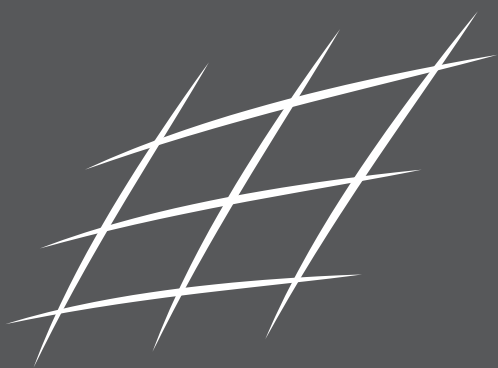




\title{
Chapter 9
}

\author{
Incisional hernias \\ in temporary stoma wounds: \\ a cohort study
}

\author{
M. H. Schreinemacher ${ }^{1}$ \\ G. H. Vijgen ${ }^{1}$ \\ P. C. Dagnelie ${ }^{2}$ \\ J. G. Bloemen ${ }^{1}$ \\ B. F. Huizinga ${ }^{1}$ \\ N. D. Bouvy ${ }^{1}$
}

Archives of Surgery 2011

\section{Affiliations}

1 Department of Surgery, Maastricht University Medical Centre, Maastricht, The Netherlands. 2 Department of Epidemiology, Maastricht University Medical Centre, Maastricht, The Netherlands. 


\section{Abstract}

\section{Hypothesis}

The prevalence of and risk factors for incisional hernias among temporary stoma wounds have implications for clinical practice.

\section{Design}

Retrospective cohort study.

\section{Setting}

University tertiary care hospital.

\section{Patients}

All adult patients with a stoma closed between January 1, 2000, and August 1, 2004. Of 150 living patients, 111 (74.0\%) were included for analysis after follow-up at the outpatient clinic.

\section{Main outcome measures}

9 The main outcome was incisional hernia in a temporary stoma wound, defined as a defect within the musculature and fascia detected by ultrasonographic examination. Risk factors for incisional hernias and the diagnostic validity of clinical symptoms and palpation during the Valsalva manoeuvre were determined.

\section{Results}

After a median follow-up of 35 months (range, 5-77 months), hernia prevalence was $32.4 \%$. Among patients with a body mass index (calculated as weight in kilograms divided by height in meters squared) of less than 30 , hernia prevalence was $25.8 \%$; among patients with a body mass index of 30 or higher, hernia prevalence was $59.1 \%$. Palpation demonstrated the highest sensitivity (58.3\%). One in 6 patients had discomfort at the temporary stoma site and no palpable defect but showed an incisional hernia on ultrasonographic examination. Obesity was the sole significant risk factor identified in this study (odds ratio, 5.53; 95\% confidence interval, 1.72-17.80). The presence of a stoma in situ for less than 6 months showed a trend toward being a risk factor (odds ratio, 2.38; 95\% confidence interval, 0.96-5.99).

\section{Conclusion}

Incisional hernias occur in 1 of 3 temporary stoma wounds, and a body mass index of 30 or higher is a risk factor. 


\section{Introduction}

The first recorded surgical creation of a stoma was in 1776 by the French surgeon Pillore; today stoma formation is considered a valuable and frequently used tool in intestinal surgery to bypass a diseased or anastomosed bowel segment ${ }^{1,2}$. Despite the advantages provided by the use of stomas, up to $48 \%$ of patients with a stoma face complications, such as high output, prolapse, retraction, or parastomal hernia, leading to skin irritation, pain, unpleasant odours, difficulties with stoma bag application, aesthetic complaints, limitations on physical activity, and decreased quality of life $\mathrm{e}^{3-5}$. The best method for resolving these problems is closure of the stoma, which is performed in about two thirds of temporary stomas ${ }^{6}$. However, stoma closure carries an often underestimated rate of morbidity and mortality, with complications, such as postoperative bowel obstruction, infection, and anastomotic leakage, occurring in $20 \%$ to $27 \%$ of patients ${ }^{7,8}$. A subsequent complication is incisional hernia at the temporary stoma site. The prevalence of incisional hernias was thought to be about $2 \%$ to $7 \%$ based on earlier findings ${ }^{9,10}$. However, the prevalence was found to be $31 \%$ to $48 \%$ in recent research ${ }^{11,12}$. Compared with the general hernia rate among abdominal incisions (10\%), the incisional hernia rate at temporary stoma sites is unfavourable and warrants further investigation ${ }^{13,14}$. First, it is important to determine the true prevalence of these hernias by assessing the diagnostic validity of physical complaints and by physically examining each patient. Therefore, physicians will be better able to link symptoms to a specific condition (i.e. incisional hernia). Second, identification of risk factors for incisional hernias in temporary stoma wounds may lead to new strategies for hernia prevention in high risk patients. So far, diagnostic validity and risk factors have been addressed only among small study groups, with low follow-up rates or with questionable methods ${ }^{11,12,15}$. Therefore, we conducted a retrospective cohort study among patients who had undergone closure of a temporary stoma at our institution and who responded to our invitation for clinical and ultrasonographic examination of their stoma wound. The diagnostic validity of clinical symptoms and palpation was established, and multiple variables were explored for risk factor analysis. Based on these results, we formulated implications for clinical practice.

\section{Methods and Materials}

\section{Participants}

All adult patients who had a surgical stoma closed between January 1, 2000, and August 1, 2004, at the Department of General Surgery, Maastricht University Medical Centre, Maastricht, the Netherlands, were identified by operation code in the hospital database. The national registry was checked to eliminate patients who were deceased. The remaining patients were invited by letter to visit the outpatient clinic for clinical and ultrasonographic examination of their temporary stoma wounds. Patients who did not respond initially were telephoned and invited to participate. In cases of multiple temporary stoma wounds, only the first stoma site closed between January 1, 2000, and August 1, 2004, was used for analysis. 
Patients who had undergone mesh repair of an incisional hernia in the temporary stoma wound were included in the study if data were available about the initial presentation of the incisional hernia. Patients with mesh repair at sites other than the stoma wound underwent ultrasonographic examination and were excluded if the mesh borders were within $3 \mathrm{~cm}$ of the temporary stoma site. Follow-up of patients was conducted between January 18, 2005, and July 28, 2007. The study was performed in compliance with the Declaration of Helsinki.

\section{Clinical examination}

At the outpatient clinic, all patients were first evaluated for physical discomfort at the temporary stoma wound site, followed by clinical examination. Clinical examination and palpation was performed in an erect position and a supine position during the Valsalva manoeuvre. Any palpable defect and need for repositioning due to the hernia were recorded. Ultrasonographic examination was then performed.

\section{Ultrasonographic examination}

Ultrasonographic examination was performed while the patient was in a supine position during the Valsalva manoeuvre. The abdominal wall surrounding the temporary stoma wound was imaged with an ultrasonographic system (SSD-2000; Aloka, Tokyo, Japan) using a $7.5-\mathrm{MHz}$ linear array probe. A hernia was defined as a defect within the abdominal musculature and both fascia as detected by ultrasonographic examination (Figure 1) ${ }^{16,17}$. All patients were examined by the same physician (M.S.), who was experienced in clinical and ultrasonographic examination of midline abdominal scars for herniation.

\section{Risk factors}

Information concerning possible risk factors was obtained from the hospital database, operative notes, ward notes, medication lists, hospital discharge summary, and the patient. The following demographic characteristics were recorded: sex, age at stoma site closure ( $<65$ or $\geq 65$ years), and body mass index (BMI [calculated as weight in kilograms divided by height in meters squared]) $(<25,25-29.9$, or $\geq 30)$. The recorded preoperative risk factors were as follows: underlying disease (malignant neoplasm, inflammatory bowel disease, fistula, or other), American Society of Anesthesiologists (ASA) index at stoma closure (1, 2, 3, or 4), diabetes mellitus (yes or no), chronic obstructive pulmonary disease (yes or no), aortic aneurysm (yes or no), collagen disease (yes or no), parastomal hernia (yes or no), hernia other than a parastomal hernia (yes or no), corticosteroid use (yes or no), smoking (yes or no), prior laparotomies $(<4$ or $\geq 4$ ), peritonitis at the time of stoma creation (yes or no), type of stoma (ileostomy or colostomy), and interval (in months) during which the stoma was in situ. The recorded intraoperative risk factors were suture material for closure of the fascia (non-absorbable or absorbable) and skin closure (open or closed). The recorded postoperative risk factors were as follows: length of hospital stay in days after stoma closure; wound infection defined as the presence of erythema, induration, and discharge of serous fluid or pus (yes or no); and reoperation within 30 days (yes or no). 


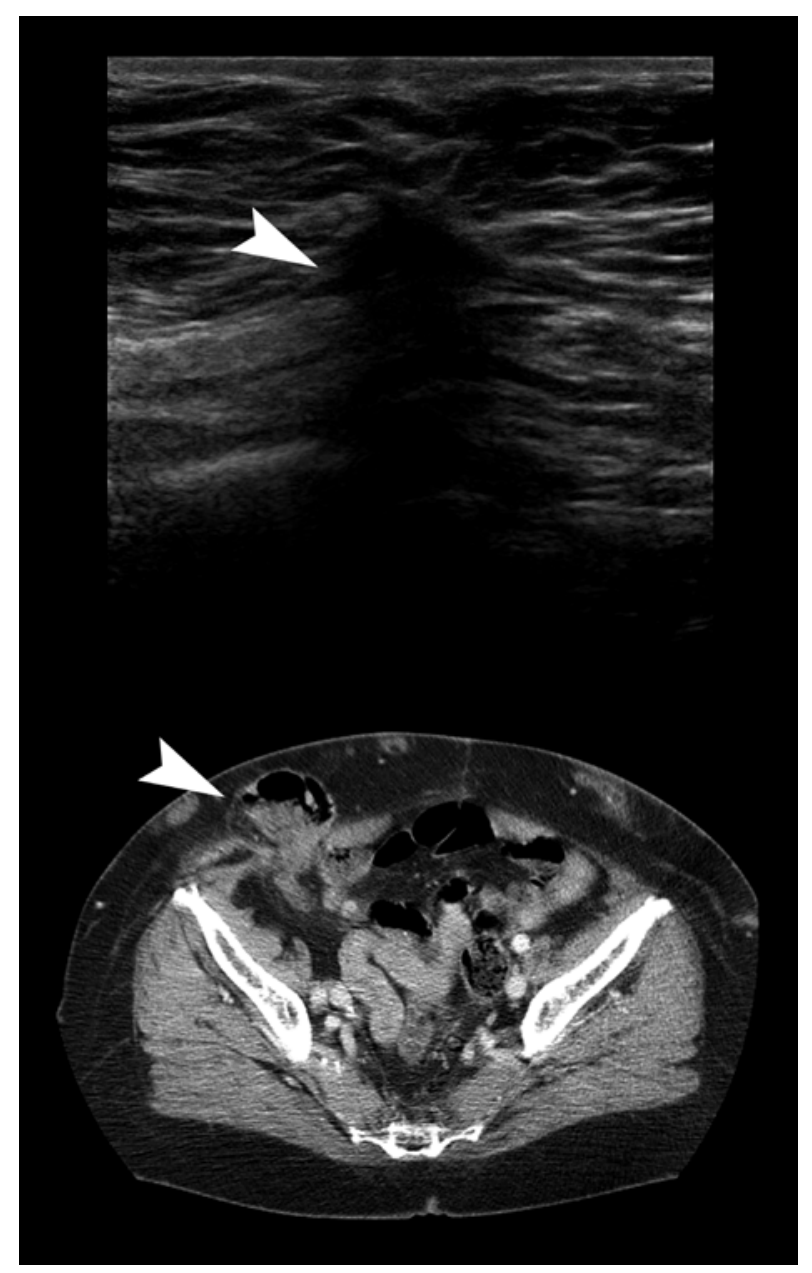

Figure 1. Incisional hernia on ultrasonography (A) and on computed tomography (B). Arrowheads indicate the hernia.

\section{Statistical analysis}

Statistical analysis was performed using commercially available software (SPSS for Windows ${ }^{\circledR}$, version 15.0; SPSS Inc, Chicago, Illinois). Diagnostic validity of physical discomfort, the presence of a palpable defect, and the combination of both was determined using sensitivity, specificity, positive and negative predictive values, and odds ratios (OR) calculated by logistic regression analysis. Subgroup analyses were performed using two sided Fisher's exact tests. To identify risk factors for incisional hernias, univariate ORs were first calculated using logistic regression analysis for all risk factors. A final multivariate logistic regression model was then fitted, including all risk factors with $P<0.20$ as covariates. $P<0.05$ was considered statistically significant. Unless stated otherwise, data are expressed as the median (range). 


\section{Results}

Between January 1, 2000, and August 1, 2004, a total of 186 patients underwent closure of a stoma site. By the time of follow-up, 36 patients had died, leaving 150 patients for evaluation. Of these, $11(7.3 \%)$ refused consent, 11 (7.3\%) were unable to attend the outpatient clinic, and $12(8.0 \%)$ could not be contacted, despite multiple attempts. The remaining 116 patients were followed up in our outpatient clinic. Of these, 5 patients were excluded because of mesh repair at a site other than the temporary stoma wound (the mesh border was within $3 \mathrm{~cm}$ of the temporary stoma wound). Therefore, 111 patients $(74.0 \%$ of 150) comprised the study cohort, including 1 patient who had undergone mesh repair of an incisional hernia in the temporary stoma wound. This operation was performed after the presentation of physical discomfort and a palpable defect in the temporary stoma wound. The patient was free of discomfort at follow-up. Among patients with multiple temporary stoma wounds, none showed the presence of an incisional hernia.

All risk factors were recorded for all patients except for the following: ASA index at stoma closure (87.4\% complete), interval during which the stoma was in situ $(96.4 \%$ complete), suture material for closure of the fascia ( $88.3 \%$ complete), length of hospital stay after stoma closure ( $97.3 \%$ complete), and wound infection ( $92.8 \%$ complete).

\section{Patient characteristics}

The patients (56 male and 55 female) were aged 62 (18-84) years at stoma site closure and were followed up for 35 (5-77) months after closure of the stoma. Temporary ileostomies (42.3\%) and colostomies (57.7\%) had been created for the indications of malignant neoplasms (47.7\%), inflammatory bowel disease (29.7\%), fistula (9.0\%), or other underlying diseases after 3 (2-12) laparotomies. Peritonitis was present in $24.3 \%$ of all patients at the time of stoma creation. Comorbidities and risk factors included diabetes mellitus (14.4\%), chronic obstructive pulmonary disease (4.5\%), smoking (24.3\%), and corticosteroid use $(8.1 \%)$. No patients had collagen disease or an aortic aneurysm. Almost $60 \%$ of patients were overweight $(\mathrm{BMI} \geq 25)$, while $19.8 \%$ of patients were obese (BMI $\geq 30$ ). Parastomal hernia had been present in $13.5 \%$ of patients, and other hernias were present in $28.8 \%$ of patients. The ASA index at stoma closure was 1 or 2 for most patients $(93.8 \%)$.

The stomas remained in place for 6 (1-48) months, and the suture material for closure of the fascia was absorbable (79.6\%) or non-absorbable (20.4\%). Wound infection (10.7\%) was associated with a BMI of 30 or higher $(P=0.04)$, but not with skin closure $(P=0.60)$. Reoperations were performed in 5 patients for fistula $(n=2)$, anastomotic dehiscence, deep space abscess, and suspicion of an incisional hernia, which proved to be a collection of subcutaneous fat. The length of hospital stay at the time of stoma reversal was 7 (2-217) days. 


\section{Ultrasonographic examination}

On ultrasonographic examination, 35 of 110 patients were found to have an incisional hernia. One patient had already undergone mesh repair of the temporary stoma wound. The total incisional hernia prevalence was $32.4 \%$ (36 of 111 patients).

\section{Clinical examination}

Diagnostic validity was compared among physical discomfort at the temporary stoma wound, the presence of a palpable defect, and the combination of both (Table 1 and 2). Palpation demonstrated the highest sensitivity, yet only $58.3 \%$ of patients with an incisional hernia were seen with a palpable defect. Positive and negative predictive values and ORs were comparable for the presence of a palpable defect alone and the combination of physical discomfort at the temporary stoma wound and a palpable defect.

Of 27 patients with physical discomfort at the temporary stoma wound, 10 patients (37.0\%) had a palpable defect confirmed on ultrasonography. Another 5 patients (18.5\%) with physical discomfort had no palpable defect but were identified to have an incisional hernia on ultrasonography. These 5 patients and the remaining 12 patients with physical discomfort (but with no detectable defect on ultrasonography) demonstrated no morbid obesity as a risk factor $(P=0.13$ and $P=0.45$, respectively).

Table 1. Diagnostic validity of palpation and physical complaints using ultrasound as the reference.

\begin{tabular}{cccccc}
\hline & & \multicolumn{2}{c}{ Ultrasound } & \\
\cline { 3 - 4 } & & Palpable defect & Defect & No defect & Total \\
\hline \multirow{2}{*}{ Physical discomfort } & Yes & Yes & 10 & 1 & 11 \\
& & No & 5 & 11 & 16 \\
& No & Yes & 11 & 1 & 12 \\
& No & 10 & 62 & 72 \\
\hline & Total & & 36 & 75 & 111 \\
\hline
\end{tabular}

Table 2. Sensitivity, specificity, and positive and negative predictive values for incisional hernia.

\begin{tabular}{lccc}
\hline & Physical discomfort (95\% CI) & Palpable defect (95\% CI) & $\begin{array}{c}\text { Physical discomfort and } \\
\text { palpable defect (95\% CI) }\end{array}$ \\
\hline Sensitivity (\%) & $41.7(26.7-57.9)$ & $58.3(42.1-73.3)$ & $41.7(26.7-57.9)$ \\
Specificity (\%) & $84.0(74.5-90.9)$ & $97.3(91.7-99.4)$ & $98.7(93.9-99.9)$ \\
Positive PV (\%) & $55.6(37.1-72.9)$ & $91.3(74.9-98.2)$ & $93.8(74.3-99.3)$ \\
Negative PV (\%) & $75.0(65.0-83.3)$ & $83.0(74.1-89.7)$ & $77.9(68.8-85.3)$ \\
Odds Ratio & $3.75(1.52-9.28)$ & $51.10(10.81-241.52)$ & $52.86(6.59-423.70)$ \\
\hline
\end{tabular}

PV: predictive value. CI: confidence interval. 


\section{Risk factors for incisional hernias}

On univariate analysis, the following were unrelated to incisional hernia risk $(P>0.40)$ : sex, age at stoma site closure (including various cut-offs between 55 and 75 years), ASA index at stoma closure, underlying disease, the presence of chronic obstructive pulmonary disease, type of stoma, peritonitis at the time of stoma creation, suture material for closure of the fascia, open skin, length of hospital stay after stoma closure, and wound infection (Table 3). Factors potentially impairing wound healing (the presence of diabetes mellitus, corticosteroid use, and smoking) were unrelated to incisional hernia risk either in total $(P=0.33)$ or individually ( $P=0.22, P=0.95$, and $P=0.41$, respectively). The number of prior laparotomies and a history of hernia (parastomal, other, or combined) also did not increase hernia risk $(P>0.30)$. Reoperation after stoma closure was no significant risk factor $(P=0.20)$, nor did it reach significance or improve the model on multivariate analysis. Hernia prevalence was $23.8 \%$ among patients having malignant neoplasms and elective clean operations at the time of stoma creation.

Therefore, the only 2 risk factors that were entered into the multivariate analysis were BMI and the interval during which the stoma was in situ (Table 3). In the resulting model, obesity (BMI $\geq 30$ vs $<25$ ) was the sole significant risk factor for an incisional hernia in a temporary stoma wound (OR 5.53; 95\% confidence interval 1.72-17.80). Hernia prevalence among patients with a BMI of 30 or higher was $59.1 \%$ (13 of 22 ) compared with $25.8 \%$ (23 of 89) among patients with a BMI of less than 30 . The presence of a stoma in situ for less than 6 months showed a trend toward being a risk factor for an incisional hernia in a temporary stoma wound (OR 2.38; 95\% confidence interval 0.96-5.99).

\section{Discussion}

In this retrospective cohort study, incisional hernias were confirmed in almost 1 of 3 temporary stoma wounds $(32.4 \%)$ by ultrasonography. With the largest cohort to date (111 patients), a high rate of follow-up (74.0\%), and a lengthy follow-up (35 months), this rate seems to be a valid approximation of the true incisional hernia rate in patients with closed stoma wounds. It is also close to the $31.4 \%$ and $32.3 \%$ rates found in 2 recent smaller studies ${ }^{11,15}$ that focused on incisional hernias in temporary stoma wounds. However, the rate compares unfavourably with the $10 \%$ to $15 \%$ incisional hernia rates observed in temporary midline laparotomy wound $s^{13,14}$. The rate also compares unfavourably with older studies $^{9,10}$ reporting a $2 \%$ to $7 \%$ prevalence of incisional hernia among temporary stoma wounds. This might be explained by the fact that the older studies focused mainly on the early complications of stoma closure, such as anastomotic leakage or wound infection.

Ultrasonography was used in this study and in a recent study by Cingi et al ${ }^{15}$. Traditionally, the occurrence of hernia was defined as a palpable protrusion at the old incision site. Using diagnostic modalities such as ultrasonography or computed tomography, additional defects (covert on palpation) can be identified. The sensitivity of palpation during the Valsalva manoeuvre was also assessed herein; only $58.3 \%$ of all hernias identified on ultrasonography 
Table 3. Logistic regression analysis of risk factors for incisional hernia.

\begin{tabular}{|c|c|c|c|}
\hline Variable & Prevalence (\%) & $\begin{array}{c}\text { Univariate } \\
\text { Odds Ratio (95\% CI) }\end{array}$ & $P$ \\
\hline \multicolumn{4}{|l|}{ Sex } \\
\hline female vs male & 49.5 & $0.87(0.39-1.93)$ & 0.73 \\
\hline \multicolumn{4}{|l|}{ Age } \\
\hline$\geq 65$ years vs $<65$ years & 42.3 & $0.81(0.36-1.82)$ & 0.61 \\
\hline Body mass index ${ }^{\mathrm{a}}\left(\mathrm{kg} / \mathrm{m}^{2}\right)$ & & & 0.02 \\
\hline$<25$ & 40.5 & 1.00 (reference) & \\
\hline $25-29.9$ & 39.6 & $0.92(0.36-2.37)$ & \\
\hline 30 & 19.8 & $3.97(1.35-11.66)$ & \\
\hline ASA-index & & & 0.40 \\
\hline 1 & 53.6 & 1.00 (reference) & \\
\hline 2 & 40.2 & $1.57(0.66-3.73)$ & \\
\hline 3 & 6.2 & $0.45(0.05-4.17)$ & \\
\hline Underlying disease & & & 0.46 \\
\hline Malignant neoplasm & 47.7 & 1.00 (reference) & \\
\hline Inflammatory bowel disease & 29.7 & $1.39(0.54-3.59)$ & \\
\hline Fistula & 9.0 & $2.79(0.70-11.09)$ & \\
\hline Other & 13.5 & $1.86(0.56-6.17)$ & \\
\hline Factors for wound impairment ${ }^{\mathrm{b}}$ & & & 0.33 \\
\hline 0 & 61.3 & 1.00 (reference) & \\
\hline 1 & 31.5 & $0.48(0.19-1.21)$ & \\
\hline 2 & 6.3 & $0.27(0.03-2.37)$ & \\
\hline 3 & 0.9 & n.c. & \\
\hline \multicolumn{4}{|l|}{ Prior laparotomies } \\
\hline$<4$ vs $\geq 4$ & 54.1 & $1.50(0.68-3.34)$ & 0.32 \\
\hline \multicolumn{4}{|c|}{ Peritonitis at the time of stoma creation } \\
\hline yes vs no & 24.3 & $0.84(0.33-2.16)$ & 0.72 \\
\hline \multicolumn{4}{|l|}{ COPD } \\
\hline yes vs no & 4.5 & $1.41(0.23-8.85)$ & 0.71 \\
\hline \multicolumn{4}{|l|}{ History of hernia } \\
\hline yes vs no & 37.8 & $1.51(0.67-3.39)$ & 0.32 \\
\hline \multicolumn{4}{|l|}{ Type of stoma } \\
\hline colostomy vs ileostomy & 57.7 & $1.04(0.47-2.33)$ & 0.92 \\
\hline \multicolumn{4}{|c|}{ Interval during which the stoma was in place ${ }^{c}$} \\
\hline$<6$ months vs $\geq 6$ months & 50.5 & $1.92(0.85-4.35)$ & 0.12 \\
\hline \multicolumn{4}{|c|}{ Suture material for closure of the fascia } \\
\hline \multicolumn{4}{|l|}{ Skin closure } \\
\hline open vs closed & 10.8 & $1.05(0.29-3.74)$ & 0.94 \\
\hline \multicolumn{4}{|c|}{ Length of hospital stay after stoma closure } \\
\hline$\geq 7$ days vs $<7$ days & 54.6 & $0.76(0.34-1.69)$ & 0.50 \\
\hline \multicolumn{4}{|l|}{ Wound infection } \\
\hline yes vs no & 10.7 & $0.78(0.19-3.13)$ & 0.72 \\
\hline \multicolumn{4}{|l|}{ Reoperation within 30 days } \\
\hline yes vs no & 4.5 & $3.32(0.53-20.81)$ & 0.20 \\
\hline
\end{tabular}

ASA: American Society of Anesthesiologists. COPD: Chronic Obstructive Pulmonary Disease. n.c.: ranges from 0 to infinity. CI: confidence intervals.

${ }^{a}$ Multivariate odds ratio (95\% CI): 1.15 (0.43-3.12), $P=0.01$

${ }^{\mathrm{b}}$ Factors for wound impairment include diabetes mellitus, steroid use and smoking.

${ }^{c}$ Multivariate odds ratio (95\% CI): 2.38 (0.96-5.99), $P=0.06$ 
were detected by palpation in this study. This finding has clinical relevance because at least 1 in 6 patients with discomfort at the temporary stoma site had an incisional hernia that was identifiable only by ultrasonography.

Almost $60 \%$ of all patients with morbid obesity were found to have developed an incisional hernia. Obesity was the only risk factor for incisional hernias identified in our cohort of patients with closed stomas. Morbid obesity had previously been identified in other studies ${ }^{18}$ as the most common risk factor for incisional hernias in laparotomy wounds. Although this association has become apparent, the actual cause remains unclear. On the one hand, there may be a mechanical explanation for early fascial dehiscence among patients with obesity. Abundant subcutaneous fat tissue can hinder a good overview of the operation site and may become necrotic underneath sutures, leading to their loosening. Furthermore, the tangential force on the abdominal wall is higher in these patients due to the increased abdominal wall radius ${ }^{19}$. On the other hand, the disease process might be associated with or influenced by the state of obesity itself, as incisional hernias can be regarded as a disease of the extracellular matrix, regulated by inflammatory cytokines ${ }^{20,21}$.

The interval during which stomas remained in situ was 6 months, which is comparable to other studies ${ }^{6,15}$. A trend was observed for patients with a stoma in situ for less than 6 months to develop more incisional hernias. No other risk factors were observed among these patients in subgroup analyses except for a higher proportion of younger patients and the presence of fewer hernias other than parastomal hernias. A longer period of convalescence for incisional hernias may lead to better results. However, stomas carry significant morbidity, which is best resolved by closure.

Additional risk factors such as smoking, corticosteroid use, chronic obstructive pulmonary disease, history of hernia, and type of stoma have been suggested to influence the incisional hernia rate ${ }^{18,22}$, but we did not observe this in our study. Similarly, suture material (absorbable vs non-absorbable) did not affect incisional hernia rates in our study. A recent trial on closure of midline laparotomy wounds also found no significant difference in the effect of absorbable vs non-absorbable sutures ${ }^{23}$. Furthermore, we observed a wound infection rate of $10.7 \%$ that was associated with high BMI but not with skin closure, which is in accord with a prospective study by Lahat et al ${ }^{24}$ comparing primary vs delayed skin closure after ileostomy reversal.

Together, the results of this study and previous investigations indicate that patients undergoing stoma reversal, especially in the case of obesity, are at high to very high risk of incisional herniation. Prophylactic mesh is implanted in high-risk patients undergoing aortic aneurysm repair or open bariatric surgery ${ }^{25,26}$. Moreover, mesh is placed in definitive stoma formations to prevent parastomal hernias ${ }^{27,28}$. The next step may be placement of mesh in temporary stomas to prevent parastomal hernias and incisional hernias after stoma reversal. However, insertion of a foreign object poses risk for infection or fistulisation, which should be clearly communicated to patients.

Limitations of this study are its design (as a cohort study with data gathered retrospectively) and the sole measurement of incisional herniation. Patients deceased at the time of the investigation were excluded according to our study variables. Among the 
surviving patients, a high rate of follow-up (74.0\%) was achieved, and the duration (35 months) was sufficient to capture at least $80 \%$ of all hernias that can be expected to originate from the procedure ${ }^{18}$. More hernias might have been detected with the use of computed tomography. Nevertheless, ultrasonography is an easily accessible, inexpensive, fast, and minimally invasive imaging technique that possesses high accuracy. In cases of negative ultrasonographic findings, computed tomography could be used.

In conclusion, a high rate of incisional hernia formation occurs after stoma closure, affecting 1 in 3 patients. As many as 1 in 6 patients with physical discomfort may have a non-palpable incisional hernia revealed on ultrasonographic examination. A BMI of 30 or higher is a risk factor for herniation of the temporary stoma wound. Future research should focus on the cause of incisional hernias, particularly in the case of obesity, and on prophylactic mesh placement.

\section{Financial Disclosures}

None reported. 


\section{References}

1 Matthiessen P, Hallböök O, Rutegård J, Simert G, Sjödahl R. Defunctioning stoma reduces symptomatic anastomotic leakage after low anterior resection of the rectum for cancer: a randomized multicenter trial. Ann Surg 2007;246(2):207-14.

2 Forgione P, Cataldo P. Colostomy. Oper Tech Gen Surg 2003;5(4):264-72.

3 Carne PWG, Robertson GM, Frizelle FA. Parastomal hernia. Br J Surg 2003;90(7):784-93.

4 Duchesne JC, Wang YZ, Weintraub SL, Boyle M, Hunt JP. Stoma complications: a multivariate analysis. Am Surg 2002;68(11):961-6.

5 Nugent KP, Daniels P, Stewart B, Patankar R, Johnson CD. Quality of life in stoma patients. Dis Colon Rectum 1999;42(12):1569-74.

6 Kairaluoma M, Rissanen H, Kultti V, Mecklin JP, Kellokumpu I. Outcome of temporary stomas. A prospective study of temporary intestinal stomas constructed between 1989 and 1996. Dig Surg 2002;19(1):45-51.

7 Chow A, Tilney HS, Paraskeva P, Jeyarajah S, Zacharakis E, Purkayastha S. The morbidity surrounding reversal of defunctioning ileostomies: a systematic review of 48 studies including 6,107 cases. Int J Colorectal Dis 2009;24(6):711-23.

8 Pokorny H, Herkner H, Jakesz R, Herbst F. Mortality and complications after stoma closure. Arch Surg 2005;140(10):956-60.

9 van de Pavoordt HD, Fazio VW, Jagelman DG, Lavery IC, Weakley FL. The outcome of loop ileostomy closure in 293 cases. Int J Colorectal Dis 1987;2(4):214-7.

10 Edwards DP, Leppington-Clarke A, Sexton R, Heald RJ, Moran BJ.Stoma-related complications are more frequent after transverse colostomy than loop ileostomy: a prospective randomized clinical trial. Br J Surg 2001;88(3):360-3.

11 Guzmán-Valdivia G. Incisional hernia at the site of a stoma. Hernia 2008;12(5):471-4.

12 Cingi A, Cakir T, Sever A, Aktan AO. Enterostomy site hernias: a clinical and computerized tomographic evaluation. Dis Colon Rectum 2006;49(10):1559-63.

13 Kuhry E, Schwenk WF, Gaupset R, Romild U, Bonjer HJ. Long-term results of laparoscopic colorectal cancer resection. Cochrane Database Syst Rev 2008;(2):CD003432.

14 Kingsnorth A, LeBlanc K. Hernias: inguinal and incisional. Lancet 2003;362(9395):1561-71.
15 Cingi A, Solmaz A, Attaallah W, Aslan A, Aktan AO. Enterostomy closure site hernias: a clinical and ultrasonographic evaluation. Hernia 2008;12(4):401-5.

16 Jamadar DA, Jacobson JA, Morag Y, Girish G, Dong Q, Al-Hawary M, Franz MG. Characteristic locations of inguinal region and anterior abdominal wall hernias: sonographic appearances and identification of clinical pitfalls. Am J Roentgenol 2007;188(5):1356-64.

17 Young J, Gilbert AI, Graham MF. The use of ultrasound in the diagnosis of abdominal wall hernias. Hernia 2007;11(4):347-51.

18 Hoer J, Lawong G, Klinge U, Schumpelick V. Factors influencing the development of incisional hernia. A retrospective study of 2,983 laparotomy patients over a period of 10 years. Chirurg 2002;73(5):474-80.

19 de Ruiter P, Bijnen AB. Successful local repair of paracolostomy hernia with a newly developed prosthetic device. Int J Colorectal Dis 1992;7(3):132-4.

20 Rosch R, Binnebosel M, Junge K, Lynen-Jansen P, Mertens PR, Klinge U, Schumpelick V. Analysis of c-myc, PAI-1 and uPAR in patients with incisional hernias. Hernia 2008;12(3):285-8.

21 Guillen-Marti J, Diaz R, Quiles MT, Lopez-Cano M, Vilallonga R, Huguet P, Ramon-y-Cajal S, Sanchez-Niubo A, Reventós J, Armengol M, Arbos MA. MMPs/TIMPs and inflammatory signalling de-regulation in human incisional hernia tissues. J Cell Mol Med 2009;13(1112):4432-43.

22 Tilney HS, Sains PS, Lovegrove RE, Reese GE, Heriot AG, Tekkis PP. Comparison of outcomes following ileostomy versus colostomy for defunctioning colorectal anastomoses. World $J$ Surg 2007;31(5):1142-51.

23 Bloemen A, van Dooren P, Huizinga BF, Hoofwijk AGM. Randomized clinical trial comparing polypropylene or polydioxanone for midline abdominal wall closure. Br J Surg 2011;98(5):633-9.

24 Lahat G, Tulchinsky H, Goldman G, Klauzner JM, Rabau M. Wound infection after ileostomy closure: a prospective randomized study comparing primary vs. delayed primary closure techniques. Tech Coloproctol 2005;9(3):206-8.

25 Bloemen A, van Dooren P, Huizinga BF, Hoofwijk AGM. Randomized clinical trial comparing polypropylene or polydioxanone 
for midline abdominal wall closure. Br J Surg 2011;98(5):633-9.

26 O'Hare JL, Ward J, Earnshaw JJ. Late results of mesh wound closure after elective open aortic aneurysm repair. Eur J Vasc Endovasc Surg 2007;33(4):412-3.

27 Janes A, Cengiz Y, Israelsson LA. Preventing parastomal hernia with a prosthetic mesh: a
5 -year follow-up of a randomized study. World J Surg 2009;33(1):118-21.

28 Serra-Aracil X, Bombardo-Junca J, MorenoMatias J, Darnell A, Mora-Lopez L, AlcantaraMoral M, Ayguavives-Garnica I, Navarro-Soto S. Randomized, controlled, prospective trial of the use of a mesh to prevent parastomal hernia. Ann Surg 2009;249(4):583-7. 


\title{
Chapter 10
}

\author{
Prophylactic intraperitoneal \\ mesh placement to prevent \\ incisional hernia after stoma reversal: \\ a feasibility study
}

K. W. van Barneveld ${ }^{1}$

R. M. Vogels ${ }^{1}$

G. L. Beets ${ }^{1}$

S. O. Breukink ${ }^{1}$

J.-W. M. Greve ${ }^{2}$

N. D. Bouvy ${ }^{1}$

M. H. Schreinemacher ${ }^{1}$

Surgical Endoscopy 2013

\author{
Affiliations
}

${ }^{1}$ Department of Surgery, Maastricht University Medical Centre, Maastricht, The Netherlands.

${ }^{2}$ Department of Surgery, Atrium Medisch Centrum, Heerlen, The Netherlands. 


\section{Abstract}

\section{Background}

Incisional hernias in old stoma wounds occur in one third of former stoma patients and pose a significant clinical problem. Parastomal hernias can be prevented by prophylactic mesh placement; however, no trial results are available for incisional hernia prevention after stoma reversal. In this feasibility study, we explore the safety of placing an intraperitoneal mesh to prevent incisional herniation after temporary stoma reversal.

\section{Methods}

Ten patients who underwent a low anterior resection with a deviating double-loop stoma for rectal cancer received an intraperitoneal parastomal mesh at the time of stoma formation. At stoma reversal, laparoscopy was performed and adhesions were scored. After reversal, the mesh defect was closed. Mesh and stoma complications were closely monitored. Incisional herniation was assessed at the 2 year follow-up after stoma reversal using ultrasonography.

\section{Results}

No infections occurred after mesh placement. After a median of 6 months, stomas were reversed. Laparoscopy could be performed in seven patients; all patients had adhesions (median of $25 \%$ of mesh surface). In three patients, the bowel was involved; one required a

10 laparotomy for bowel mobilization during stoma reversal. No adhesion related morbidity was noted at any time. Except for one superficial wound infection after stoma reversal, no infectious complications were observed. After a median follow-up of 26 months, no incisional herniations were demonstrated.

\section{Conclusions}

Prophylactic mesh placement in temporary stoma formations seems safe and feasible and likely prevents incisional herniation 2 years after stoma reversal. 


\section{Introduction}

Deviating proximal double-loop stomas reduce anastomotic leaks and the need for reoperation after construction of bowel anastomoses ${ }^{1}$. Two major problems caused by the formation of these stomas is the occurrence of parastomal hernias or incisional hernias after stoma reversal. Parastomal herniation occurs in one of three patients and negatively impacts quality of life ${ }^{2,3}$. Incisional hernias at the site of the old stoma wound have received less attention but have recently been reported to occur in one of three patients as well ${ }^{4,5}$. Up to half of affected patients may even require surgical repair ${ }^{4}$.

To date, parastomal hernia prevention has been attempted and has already been shown to be effective in three randomized controlled trials by placing a preperitoneal mesh around the stoma at the time of stoma creation ${ }^{6}$. These trials were performed mainly in patients with a definitive single-loop stoma, though a few patients have had their stoma reversed. Of these patients, no further follow-up has been reported ${ }^{7,8}$.

Considering the high risk of incisional herniation after stoma reversal, we hypothesized that prophylactic mesh should be placed in temporary deviating stomas as well. For this, a mesh placed at the time of stoma creation serves as parastomal hernia prophylaxis and can be closed at the time of stoma reversal through the same peristomal incision. This way, the continuity of the mesh is restored and serves as a prophylactic for incisional herniation. Moreover, the meshes that are specially designed for intraperitoneal use enable easy intraperitoneal mesh placement at the time of stoma formation in both open and laparoscopic bowel surgery.

Implantation of prophylactic mesh may also have drawbacks, however. Mesh infection, erosion, adhesion, or fistula formation can occur. Difficult placement techniques may lead to technical failures. Finally, dissecting the stoma from the abdominal wall at the time of stoma reversal may be difficult because of adhesions.

In view of the above concerns, a study was designed to assess the safety and feasibility of intraperitoneal synthetic mesh placement at the time of temporary stoma formation. Here, we report the technical aspects of this new procedure, the related morbidity, and the 2 year follow-up of patients who underwent stoma reversal after prophylactic intraperitoneal parastomal mesh placement.

\section{Methods and Materials}

The design of this trial was evaluated and approved by the medical ethical committee of Maastricht University Medical Centre, Maastricht, The Netherlands. This trial was prospectively registered at ClinicalTrials.gov with reference NCT00907842.

\section{Patient selection and characteristics}

Ten consecutive patients who were to undergo a low anterior resection of the rectum with a high likelihood of having a temporary deviating double-loop stoma were invited 
to participate. Patients who were unable to give informed consent, undergoing peritoneal dialysis, pregnant, or current or recent users of antibiotics, or had a contraindication for laparoscopy, American Society of Anesthesiologists (ASA) class higher than 3, immunodeficiency, ascites, chemotherapy within the previous 3 weeks, corticosteroids or other immunosuppressive drugs, an intraperitoneal mesh in place, or a damaged abdominal wall at the future stoma site were not eligible for inclusion.

\section{Mesh and tackers}

We used a circular Parietex Composite Parastomal ${ }^{\circledR}$ mesh, $20 \mathrm{~cm}$ in diameter (Covidien, Mansfield, MA, USA). This mesh consisted of a monofilament polyester structure with a one-sided layer of absorbable collagen for adhesion prevention. For use with Sugarbaker's parastomal hernia repair method ${ }^{9}$, a central band of collagen was also applied to the other side of the mesh (Figure 1). The mesh was fixated using AbsorbaTack ${ }^{\circledR}$ (Covidien) absorbable tackers.

\section{Temporary stoma creation}

Preoperatively, a stoma nurse marked the preferential stoma sites on the skin. At induction of anaesthesia, patients received a single dose of antibiotics (cefazolin-metronidazole). After performing the bowel resection and subsequent anastomosis through a midline laparotomy, a bacterial swab of the peritoneum at the future stoma site was taken. Then, a small circular piece of skin was excised and a passage of sufficient size was created through all layers of

10 the abdominal wall using diathermia. In the middle of the mesh piece, a cross-cut was made just large enough to pass the bowel through; the cross-cut resulted in the creation of four mesh flaps (Figure 2, A). Next, the mesh was hydrated with $0.9 \%$ sterile saline and placed intra-abdominally against the peritoneum with the coated side facing the viscera. The cross-cut was positioned over the stoma site. Outer and inner rings of tackers were

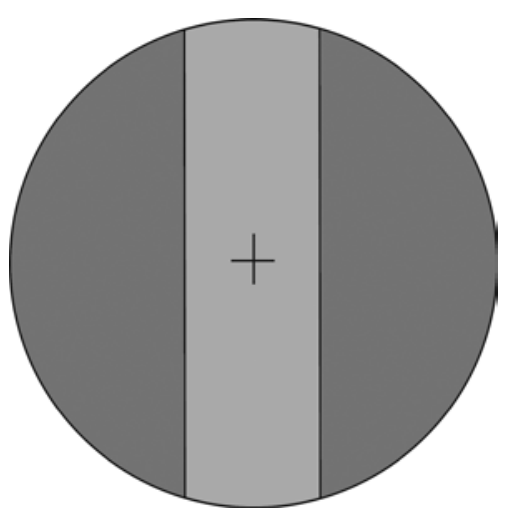

Figure 1. Parietex Composite Parastomal ${ }^{\circledR}$ mesh. The mesh is coated on one side with absorbable collagen, except for a central band of the mesh that is coated on both sides. A cross-cut was made in the center of the mesh to allow passage of the bowel. 
placed for mesh fixation. The bowel loop was gently pulled outward. Care was taken to direct the four mesh flaps in an outward direction within the abdominal wall musculature. Finally, the abdomen was closed, the bowel loop opened, and the stoma sutured in place. Postoperatively, all patients received antibiotics (amoxicillin-clavulanate) for 5 days.

\section{Temporary stoma reversal}

At induction of anaesthesia, patients received a single dose of antibiotics (cefazolinmetronidazole). Before initiating stoma reversal, laparoscopy was performed. A $12-\mathrm{mmHg}$ pneumoperitoneum was achieved via an open introduction at the most cranial part of the old midline scar. Using a $30^{\circ}$ optic, the extent (estimated per cent of mesh surface covered with adhesions, expressed in increments of 10\%), severity (no, mild, or severe adhesions), and organs involved in adhesions against the mesh were assessed and recorded by the surgeon and one of the investigators. Next, through a standard circular peristomal incision that was extended laterally when required, the stoma loop was dissected free from the subcutaneous tissue, abdominal wall, and mesh flaps, and bowel continuity was restored with either a hand-sewn or stapled anastomosis. A small piece of the mesh (approximately $10 \times 5 \mathrm{~mm}$ ) was harvested for later histological analysis. The defect in the fascia and mesh was closed using a running non-absorbable polypropylene 1 or long-term absorbable polydioxanone (PDS) 1 suture. The subcutaneous tissue was sutured with poliglecaprone sutures $2 \times 0$. Closure of the skin was left to the discretion of the surgeon. Postoperatively, all patients received antibiotics (amoxicillin-clavulanate) for 5 days.

\section{Outcome parameters}

Mesh infection, mesh erosion, fistula formation, peristomal infections, prolapse, retraction, stricture of the stoma, and parastomal herniation were assessed during the hospital stay and at every outpatient clinic visit after stoma creation. Patients visited the outpatient clinic 2 weeks, 1 month, 6 months, and 12 months after stoma creation or until their stoma was reversed.

Mesh infection, mesh erosion, fistula formation, and incisional herniation at the old stoma wound were assessed during the hospital stay and at every outpatient clinic visit after stoma reversal. Patients visited the outpatient clinic 2 weeks, 1 month, 6 months, and 12 months after stoma reversal.

Physical examination for herniation included the Valsalva manoeuvre in erect and supine positions. From December 2012 to February 2013, all patients were invited for a physical examination by one of the investigators and ultrasonography by an experienced radiologist. Ultrasonography of the closed stoma wound was performed with the Valsalva manoeuvre to detect potential abdominal wall hernias.

\section{Statistics}

No statistical analyses were planned for this pilot study. Group results are described using medians, followed by the lowest and highest values within brackets. 


\section{Results}

\section{Baseline characteristics}

Between 20 April 2010 and 4 October 2010, there were four male and six female patients who underwent a low anterior resection for advanced rectal cancer and were included in the study, and two patients refused participation. All patients had received preoperative chemoradiation therapy. The median age was 66 (58-77) years, ASA class was 2 (2-3), and body mass index (BMI) was $25(20-28) \mathrm{kg} / \mathrm{m}^{2}$. One patient was an active smoker.

\section{Temporary stoma creation}

Five loop ileostomies and five loop colostomies were created. The median duration of the operation was 240 (204-533) min, with a median time needed for stoma creation of 17 (15-25) min. Stoma creation was rated as an easy to perform procedure, except for one surgeon who experienced average difficulty. All operations were classified as cleancontaminated, and none of the swabs taken from the parietal peritoneum at the stoma site showed any bacterial growth. Cross-cutting the mesh resulted in a median surface of 6 (2-16) $\mathrm{cm}^{2}$ for passing the bowel through. Fixation of the mesh was performed with 20 (10-30) tackers. Postoperatively, patients were hospitalized for 8 (6-13) days with faecal stoma production starting after 2.5 (2-8) days. One patient was reoperated on for acute abdominal wound dehiscence, resulting in no other complications.

\section{Temporary stoma reversal}

After a median of 6 (2-15) months, all ten patients had their stomas reversed. The median duration of the operation was 82 (50-225) min, including the time needed for laparoscopy. Laparoscopy was not performed in one patient because of newly diagnosed aortic valve stenosis. Laparoscopy was attempted in two patients but dense adhesions at the midline prevented further introduction of the scope. For the other seven patients, adhesions were seen covering a median of $25 \%(10-90 \%)$ of the mesh surface. Tackers were seen in situ in all patients (Figure 2, B) but tended to break off easily when touched. In three of the seven patients (Figure 2, C), adhesions with viscera could not be lysed bluntly and were therefore classified as severe (Figure 2, D). Nine stomas were reversed extraperitoneally through the circular peristomal incision, and the difficulty of the procedure was rated as average $(n=5)$ or hard $(n=4)$. One surgeon experienced no difficulties (easy). In one patient, curling up of the mesh border due to insufficient fixation had caused severe adhesions of the bowel loop requiring a laparotomy to mobilize the loop.

All operations were classified as clean-contaminated. Mesh and fascia were closed with nonabsorbable polypropylene in seven patients and long-term absorbable PDS in the other patients. The skin was fully closed in four patients, leading to one superficial wound infection for which no intervention was necessary. In the six remaining patients, the wound was left partially open. One patient developed an early anastomotic stricture for which she was reoperated on (resection 

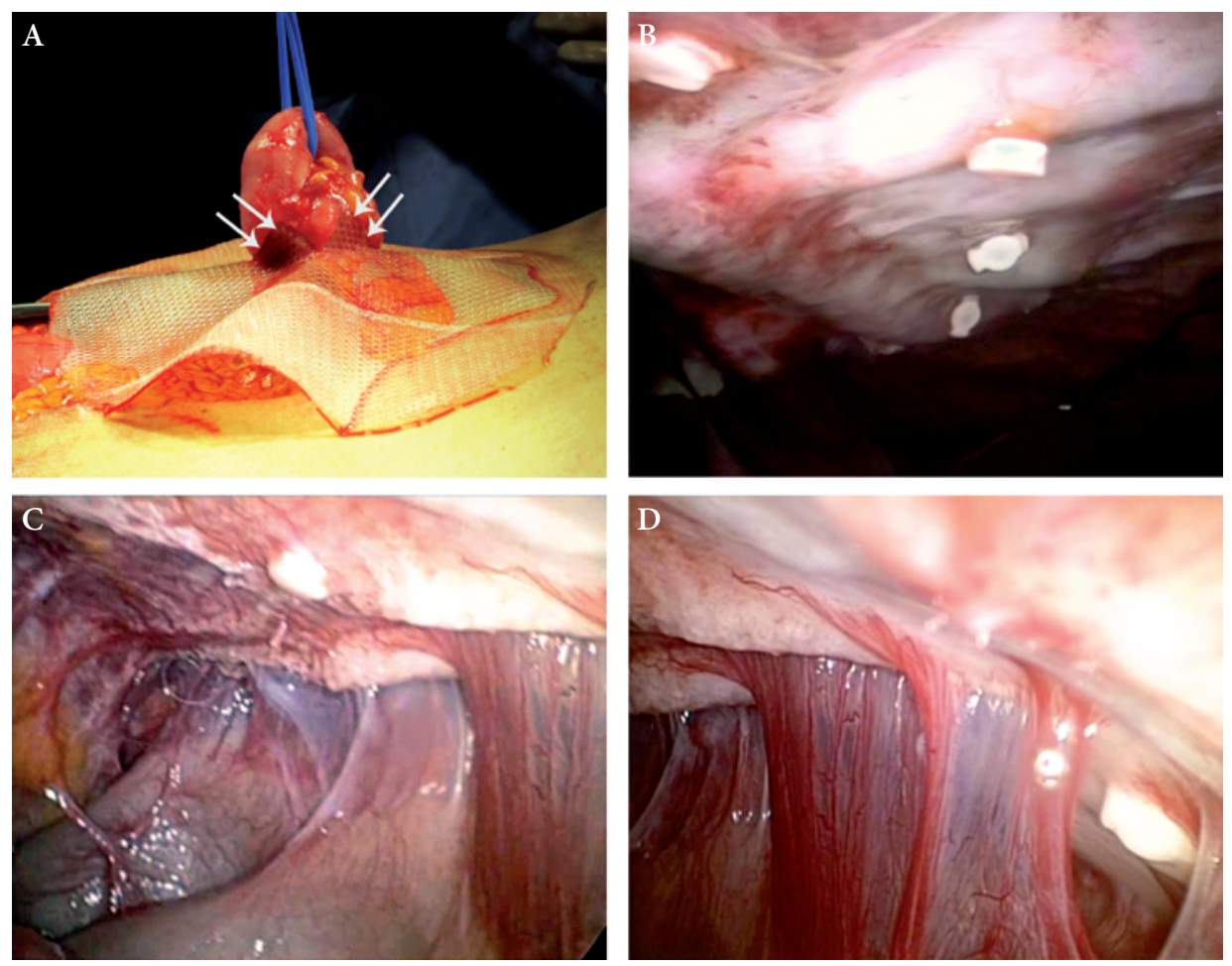

Figure 2. A-D Mesh preparation and adhesion assessment. A bowel loop passing through the mesh before mesh implantation. Flaps (arrows) that result from cross-cutting the mesh face toward the abdominal wall. B Tackers and absence of adhesions. C, D The presence of adhesions.

and creation of new anastomosis) and spent a total of 28 days in the hospital. The other patients left the hospital after their first defecation had passed at a median of 3 (2-5) days.

\section{Outcome parameters}

No serious mesh complications were observed at any time. One superficial wound infection occurred, as mentioned above. During follow-up between temporary stoma creation and reversal, no parastomal hernia or other evident stomal complications were observed, except for one patient who developed a stoma prolapse. This was the patient with the largest passage in the mesh (i.e. $16 \mathrm{~cm}^{2}$ ). At the regular outpatient clinic visits after stoma reversal, no signs of complications were noted. At a median follow-up of 26 (14-29) months after stoma reversal, both physical and ultrasonographic examinations found no incisional hernias in nine patients. One patient was undergoing palliative chemotherapy for progressive disease and declined the long-term follow-up visit. 


\section{Discussion}

In this study, we assessed the safety and feasibility of placing a parastomal mesh intraperitoneally at the time of temporary stoma formation to prevent incisional herniation after stoma reversal. No infectious complications related to the mesh were observed at any time. In addition, 2 years after stoma reversal, no incisional herniations were detected at the old stoma wounds.

The absence of mesh-related infectious complications is in line with the overall findings from other groups that have used prosthetic mesh for parastomal hernia prevention in well over 150 patients thus far ${ }^{6,8,10-12}$. Even with peritonitis, there were no infectious complications after prophylactic mesh placement ${ }^{13}$. This finding is particularly interesting because the gastrointestinal tract was opened during our procedure, classifying the operation as cleancontaminated. Therefore, we continued antibiotic prophylaxis for 5 days postoperatively. A recent large retrospective review showed that in clean-contaminated procedures, surgical site infections (superficial, deep, or organ) occurred in $12.6 \%$ of cases with and $8.9 \%$ of cases without meshes, resulting in an absolute risk increase of $3.7 \%{ }^{14}$. However, that review was prone to bias because the types of mesh, types of patients (acute or elective), and antibiotic regimens are unknown.

Nevertheless, any prosthetic material remains at increased risk for infection because bacteria may form a biofilm on the biomaterial surface, which is difficult or impossible for the immune system to penetrate ${ }^{15}$. Some authors therefore advocate the use of biological meshes in contaminated and potentially contaminated fields ${ }^{16,17}$. However, current clinical data do not sufficiently support the use of biological meshes in these situations, especially

10 as their use is expensive and they have a high rate of recurrence after hernia repair. More research comparing prosthetic and biological meshes is needed ${ }^{18,19}$.

For this study, we used a relatively new mesh that is commercially available for parastomal hernia repair, including the Sugarbaker technique. The mesh structure is composed of monofilamentous polyester fibers, a feature that has proven to decrease susceptibility to infection $^{20,21}$. Experimental data have shown that this mesh may even outperform some of the biological meshes in infectious conditions ${ }^{22,23}$. Furthermore, the mesh is coated with an absorbable layer of collagen, a feature that has proven beneficial effects on the reduction of adhesions when placed intraperitoneally $\mathrm{y}^{24,25}$.

Adhesions to the mesh were present in all patients and covered a median of $25 \%$ of the mesh surface. The bowel was involved in three of seven patients, but no adhesion related morbidity was noted in any patient. These findings are in line with earlier findings in both clinical and experimental studies that assessed meshes for laparoscopic hernia repair ${ }^{24,26}$. Unfortunately, one patient required a laparotomy for bowel mobilization at the time of stoma reversal, partly because of adhesions to the curled up mesh border that exposed the bare polyester. Additionally, some technical difficulties were experienced while dissecting the stoma free from the surrounding tissue. However, there was no control group in our study and peristomal adhesions are a known problem at the time of stoma reversal ${ }^{27}$.

Though no adhesion related morbidity was noted, placing meshes extraperitoneally may avoid some potential intraperitoneal adhesion related morbidity. This technique can be performed in 
both open and laparoscopic procedures at the time of stoma creation by using the exterior stoma aperture for digitally dissecting a plane between the rectus muscle and posterior fascia ${ }^{28}$.

In parastomal hernia mesh repair, the Sugarbaker technique has shown superiority to the keyhole technique in terms of hernia recurrence? ${ }^{9}$ However, for parastomal hernia prevention, the keyhole technique also shows excellent results and can be applied in an extraperitoneal position ${ }^{6}$. The mechanism used may depend on the indirect bridging of the fascial defect by the mesh. This way, the load-bearing forces on the fascial edges are conserved thereby preventing the selection of abnormal fibroblasts that could contribute to defective wound healing at the time of wound closure ${ }^{29}$.

Thus far, only a few surgeons have placed meshes intraperitoneally for parastomal hernia prevention and no follow-up is available on intraperitoneal adhesion formation ${ }^{11,12}$. This clinical study prospectively reports adhesions related to only one type of mesh and all placed following the same technique. Outcomes were assessed after comparable amounts of time and not because of any mesh or viscera related emergencies.

There are some shortcomings to this study. First, the small number of patients and restriction to rectal cancer patients possibly limit generalizability. Nevertheless, a majority of the patients who undergo bowel resection suffer from cancer. Second, follow-up for incisional herniation at the old stoma site was limited to 2 years. Though approximately $75 \%$ of all incisional hernias are expected to become evident by this time, hernias may develop up to 10 years after fascial closure ${ }^{30}$. Lastly, closure of the fascial defect was performed with both non-absorbable and slowly absorbable sutures, though this is unlikely to have a significant effect on the incisional herniation rate ${ }^{31}$.

In conclusion, prophylactic intraperitoneal mesh placement for temporary stoma formation seems safe and feasible and prevents incisional herniation 2 years after stoma reversal. Considering the current results in hernia prophylaxis, a randomized controlled trial to further confirm safety and effectiveness seems justified.

\section{Disclosures}

All authors have no conflicts of interest or financial ties to disclose. 


\section{References}

1 Tan WS, Tang CL, Shi L, Eu KW. Meta-analysis of defunctioning stomas in low anterior resection for rectal cancer. Br J Surg 2009;96(5):462-72.

2 Pilgrim CHC, McIntyre R, Bailey M. Prospective audit of parastomal hernia: prevalence and associated comorbidities. Dis Colon Rectum 2010;53(1):71-6.

3 Kald A, Juul KN, Hjortsvang H, Sjodahl RI. Quality of life is impaired in patients with peristomal bulging of a sigmoid colostomy. Scand J Gastroenterol 2008;43(5):627-33.

4 Bhangu A, Nepogodiev D, Futaba K, West Midlands Research Collaborative. Systematic review and meta-analysis of the incidence of incisional hernia at the site of stoma closure. World J Surg 2012;36(5):973-83.

5 Schreinemacher M, Vijgen GH, Dagnelie, P. C., Bloemen JG, Huizinga BF, Bouvy ND. Incisional hernias in temporary stoma wounds: a cohort study. Arch Surg 2011;146(1):94-9.

6 Shabbir J, Chaudhary BN, Dawson R. A systematic review on the use of prophylactic mesh during primary stoma formation to prevent parastomal hernia formation. Colorectal Disease 2012;14(8):931-6.

7 Hammond TM, Chin-Aleong J, Navsaria H, Williams NS. Human in vivo cellular response to a cross-linked acellular collagen implant. $\mathrm{Br} \mathrm{J}$ Surg 2008;95(4):438-46.

8 Vijayasekar C, Marimuthu K, Jadhav V, Mathew G. Parastomal hernia: Is prevention better than cure? Use of preperitoneal polypropylene mesh at the time of stoma formation. Tech Coloproctol 2008;12(4):309-13.

9 Hansson BME, Slater NJ, van der Velden AS, Groenewoud HMM, Buyne OR, de Hingh IHJT, Bleichrodt RP. Surgical Techniques for Parastomal Hernia Repair: A Systematic Review of the Literature. Ann Surg 2012;255(4):685-95.

10 Gögenur I, Mortensen J, Harvald T, Rosenberg J, Fischer A. Prevention of parastomal hernia by placement of a polypropylene mesh at the primary operation. Dis Colon Rectum 2006;49(8):1131-5.

11 Berger D. Prevention of parastomal hernias by prophylactic use of a specially designed intraperitoneal onlay mesh (Dynamesh IPST ${ }^{\circledast}$ ). Hernia 2007;12(3):243-6.

12 Lopez-Cano M, Lozoya-Trujillo R, Quiroga S, Sánchez JL, Vallribera F, Martí M, Jiménez LM, Armengol-Carrasco M, Espín E. Use of a prosthetic mesh to prevent parastomal hernia during laparoscopic abdominoperineal resection: a randomized controlled trial. Hernia 2012;16(6):661-7.

13 Kurmann A, Barnetta C, Candinas D, Beldi G. Implantation of prophylactic nonabsorbable intraperitoneal mesh in patients with peritonitis is safe and feasible. World J Surg 2013;37(7):1656-60.

14 Choi JJ, Palaniappa NC, Dallas KB, Rudich TB, Colon MJ, Divino CM. Use of Mesh During Ventral Hernia Repair in CleanContaminated and Contaminated Cases. Ann Surg 2012;255(1):176-80.

15 Engelsman AF, van der Mei HC, Ploeg RJ, Busscher HJ. The phenomenon of infection with abdominal wall reconstruction. Biomaterials 2007;28(14):2314-27.

16 Shankaran V, Weber DJ, Reed RL II, Luchette FA. A Review of Available Prosthetics for Ventral Hernia Repair. Ann Surg 2011;253(1):16-26.

17 Ventral Hernia Working Group, Breuing K, Butler CE, Ferzoco S, Franz M, Hultman CS, Kilbridge JF, Rosen M, Silverman RP, Vargo D. Incisional ventral hernias: review of the literature and recommendations regarding the grading and technique of repair. Surgery 2010;148(3):544-58.

18 Montgomery A. The battle between biological and synthetic meshes in ventral hernia repair. Hernia 2013;17(1):3-11.

19 Primus FE, Harris HW. A critical review of biologic mesh use in ventral hernia repairs under contaminated conditions. Hernia 2013;17(1):21-30.

20 Engelsman AF, van Dam GM, van der Mei HC, BusscherHJ,PloegRJ.Invivoevaluation ofbacterial infection involving morphologically different surgical meshes. Ann Surg 2010;251(1):133-7.

21 Engelsman AF, van der Mei HC, Busscher HJ, Ploeg RJ. Morphological aspects of surgical meshes as a risk factor for bacterial colonization. Br J Surg 2008;95(8):1051-9.

22 Deerenberg EB, Mulder IM, Grotenhuis N, Ditzel M, Jeekel J, Lange JF. Experimental study on synthetic and biological mesh implantation in a contaminated environment. $\mathrm{Br} J$ Surg 2012;99(12):1734-41.

23 Ditzel M, Deerenberg EB, Grotenhuis N, Harlaar JJ, Monkhorst K, Bastiaansen-Jenniskens YM, Jeekel J, Lange JF. Biologic meshes are not superior to synthetic meshes in ventral hernia repair: an experimental study with long-term follow-up evaluation. Surg Endosc 2013;27(10):3654-62. 
24 Schreinemacher MHF, Emans PJ, Gijbels MJJ, Greve JWM, Beets GL, Bouvy ND. Degradation of mesh coatings and intraperitoneal adhesion formation in an experimental model. Br J Surg 2009;96(3):305-13.

25 Deeken CR, Faucher KM, Matthews BD. A review of the composition, characteristics, and effectiveness of barrier mesh prostheses utilized for laparoscopic ventral hernia repair. Surg Endosc 2012;26(2):566-75.

26 Chelala E, Debardemaeker Y, Elias B, Charara F, Dessily M, Allé J-L. Eighty-five redo surgeries after 733 laparoscopic treatments for ventral and incisional hernia: adhesion and recurrence analysis. Hernia 2010;14(2):123-9.

27 Tjandra JJ, Chan MKY. A Sprayable Hydrogel Adhesion Barrier Facilitates Closure of
Defunctioning Loop Ileostomy: A Randomized Trial. Dis Colon Rectum 2008;51(6):956-60.

28 Janson AR, Jänes A, Israelsson LA. Laparoscopic stoma formation with a prophylactic prosthetic mesh. Hernia 2010;14(5):495-8.

29 Franz MG. The biology of hernia formation. Surgical Clinics of NA 2008;88(1):1-15.

30 Hoer J, Lawong G, Klinge U, Schumpelick V. Factors influencing the development of incisional hernia. A retrospective study of 2,983 laparotomy patients over a period of 10 years. Chirurg 2002;73(5):474-80.

31 Bloemen A, van Dooren P, Huizinga BF, Hoofwijk AGM. Randomized clinical trial comparing polypropylene or polydioxanone for midline abdominal wall closure. Br J Surg 2011;98(5):633-9. 


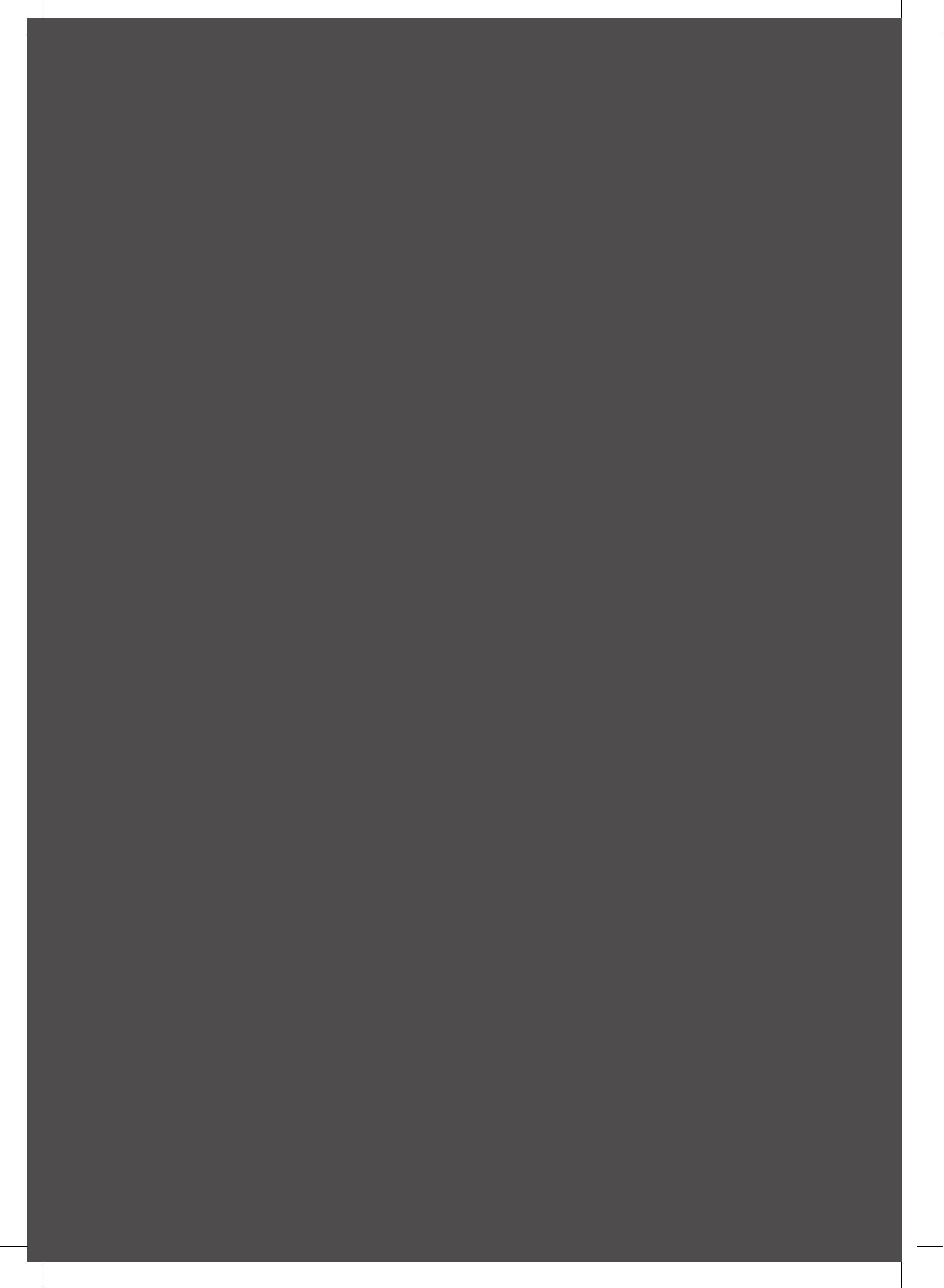




\section{GENERAL DISCUSSION AND FUTURE PERSPECTIVES}

Chapter 11

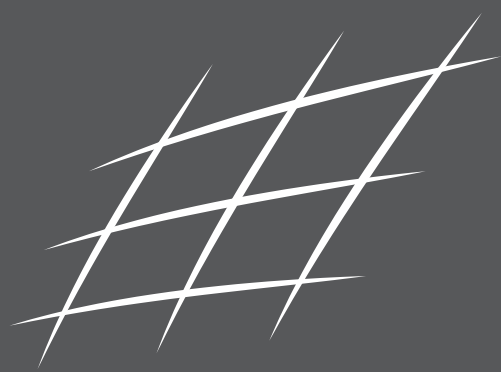


Abdominal wall hernias and intraperitoneal adhesions are the most common long-term complications of abdominal surgery. In this thesis the problem of adhesions in abdominal wall hernia repair was addressed with special emphasis on mesh related adhesions.

\section{Clinical problem and awareness}

Intraperitoneal adhesions are a known cause of infertility, small bowel obstructions, and inadvertent enterotomies at the time of reoperation ${ }^{1}$. In our prospective observational study, about one in eight patients undergoing abdominal wall hernia repair experienced an inadvertent enterotomy. This rate was higher than in other series $(3-7 \%)^{2,3}$ and may have been due to a higher amount of complicated cases, though inadvertent enterotomy rate was $10.3 \%$ in uncomplicated cases as well. Perhaps the most likely explanation is the prospective nature of our study with an independent researcher overseeing each operation while recording adhesions. Nevertheless, even the lower incidences of inadvertent enterotomies and related morbidity in other series warrant a clear statement on adhesions during the informed consent process. The necessity of discussing these adverse events is also evidenced by successful negligence claims in adhesion related complications in the United Kingdom ${ }^{4}$. Moreover, $83 \%$ of German gynaecologists indicate to inform patients preoperatively about adhesions ${ }^{5}$. However, we found that up to $40-60 \%$ of Dutch surgeons and surgeons in training do not routinely inform patients about adhesions or adhesion related morbidity.

Both the time needed for adhesiolysis and the presence of mesh were identified as risk factors for inadvertent enterotomies in uncomplicated cases (i.e. no wound infection, no enterocutaneous fistula and no further surgical procedure at repair). For mesh presence, a 7 -fold risk increase was observed. This finding is in line with a large retrospective study in which a much higher enterotomy rate $(20.3 \%)$ was observed in patients with prior mesh repair, compared to patients with primary hernia repair $(5.3 \%)^{2}$. A likely explanation would be that adhesions related to meshes are more tenacious and therefore more difficult to dissect from adhered bowel which again would result in longer adhesiolysis time and a higher enterotomy rate ${ }^{6}$. Yet, we found similar adhesiolysis times and only non-significantly elevated adhesion scores with mesh present. These findings could be related to the fact that our study was not solely designed for mesh related adhesions. As such, no exact recording of these particular adhesions was made apart from the note that adhesiolysis was related to the operating field or not. Finally, the higher adhesion scores with meshes in situ might have proven statistically significant if patient numbers would have been higher.

Interestingly, there were no significant differences in adhesiolysis time, time needed to harm, and adhesion severity between meshes placed intraperitoneally or extraperitoneally. This is in contrast with others who have found intraperitoneal meshes to result in longer adhesiolysis times or increased bowel resections compared to meshes placed extraperitoneally ${ }^{7,8}$. Of note, $73-100 \%$ of the meshes used in those studies consisted of uncovered polypropylene. In our study, uncoated polypropylene had only been used in $11 \%$ of patients with an intraperitoneal mesh which may have resulted in improved outcomes. 
What our results do show is that even an extraperitoneal mesh position does not fully prevent from adhesiolysis related complications. Besides from a peritoneal protrusion of an extraperitoneal mesh border through an incompletely closed aponeurosis and peritoneum, the peritoneal layer itself may become more adhesiogenic as it takes part in the inflammatory response elicited by the surgery and the foreign body implanted ${ }^{9}$. Possibly, the addition of a shielding or immunomodulatory coating even in the extraperitoneal position could further improve results in terms of adhesion related complications at later times surgery.

\section{Experimental findings on intraperitoneal mesh related adhesions}

The intraperitoneal implantation of meshes induces adhesion formation to a certain extent in both clinical and experimental studies ${ }^{3,10,11}$. In this thesis, we investigated some of the commercially available meshes together with an experimental mesh at different follow-up times in a preclinical model to more fully understand the complex pathogenesis of adhesions to intraperitoneal meshes. Follow-ups were chosen at 7, 30 and 90 days as representations of different phases of wound healing. Around 7 days after implantation, the transition from acute inflammatory reaction to proliferation occurs and earlier research has shown that the process of adhesion formation has reached a peak at that point as well ${ }^{12-14}$. Thereafter, the amount of adhesive tissue to the mesh diminishes. At around 30 days, the remodelling phase has started and the mesh material and surrounding tissue have become covered with a lining of mesothelial cells (the so-called "neoperitoneum") that should protect from new adhesions forming. These findings were confirmed by others and us, but only when bare polypropylene meshes were studied. In case composite meshes were used, i.e. meshes coated with substances intended for adhesion reduction, some meshes still showed signs of acute inflammation at 30 days follow-up. For this reason, we also included follow-ups at 90 days.

\section{Mesh coatings}

In general, the coatings applied to meshes can be described in terms of their ability to be absorbed and the physical appearance and location of the coating. With regard to absorption, we noted that the process of phagocytosis of the coating leads to an increase in adhesions from 7 to 30 days follow-up. We attributed these findings to the fact that phagocytosis involved a marked influx of macrophages, closely followed by fibroblasts. In this proinflammatory milieu, adhesions are likely to form ${ }^{15}$. Remarkably, some of the coated meshes (polypropylene and polyester coated with an absorbable layer of collagen) showed a pronounced increase in foreign body giant cells from 30 to 90 days follow-up. However, these meshes showed excellent clinical behaviour in terms of adhesion reduction. The reason for this might be the fact that at later times more granulation tissue has already formed around the mesh. This increases the distance from the inflammatory mesh-tissue interface to the intraperitoneal interface ${ }^{16}$. On the other hand, the exact function of the macrophages and foreign body giant cells may change over time depending 
on the neighbouring tissues and as a result from the chemical and physical properties of the mesh and coating ${ }^{12,17}$. In line with this are the findings with our experimental, non-absorbable, hydrophilic coating that may have induced a phenotypic switch of the macrophages resulting in different cytokine profiles or even anti-inflammatory properties ${ }^{12,18}$. At 7 days follow-up, this coating induced a very intense acute inflammation. Yet at 30 days, adhesions were significantly reduced and macrophages, foreign body giant cells and fibroblasts were less or equal to control and commercially coated meshes for intraperitoneal use.

As for the physical appearance and location of the coatings we found a smooth, nonporous layer on one side of the mesh to be the most important determinant for successful adhesion prevention. Meshes without such coating failed to perform well in terms of adhesion reduction even when in vitro studies had shown a favourable cellular response to the mesh material itself ${ }^{19,20}$. The physical presence of a barrier between the non-absorbable, often reticular mesh structure and the intraperitoneal contents can be considered to have several functions. Not only does it simply prevent the intraperitoneal contents to react with the mesh material, but it also prohibits direct interaction between the intraperitoneal contents and the abdominal wall. This is of relevance as we noticed that the abdominal wall has a significant role in the adhesion formation process (Figure 1). It is likely that the abdominal wall inflammatory infiltrate elicited by the mesh forms a specific lead point for adhesion formation. In case reticular mesh without coating is employed, adhesions may then form through all the pores. In case of meshes with a layered coating this will only be the case at the border of the mesh where the infiltrate extends beyond the coating. Indeed, the mesh borders are known to be preferential sites for adhesion formation. Furthermore, with uncoated reticular meshes a multitude of anchorage sites are available for adhesions to attach to and the strands may also induce trauma to the intraperitoneal organs by chafing against them.

\section{Mesh incorporation and fixation}

Both for bare polypropylene and coated meshes, consistently poor ingrowth of the meshes into the abdominal wall was observed when meshes were placed intraperitoneally and fixated with two to four sutures. Incorporation only took place at the site of fixation and was unrelated to the amount of inflammation induced by the mesh itself. At the rest of the mesh-abdominal wall interface, both the mesh and the abdominal wall surface were covered with mesothelial cells making future ingrowth highly unlikely. These findings could be related to the fact that only at the site of fixation the abdominal wall is truly injured. If so, creating an acute wound by scraping the abdominal wall at the site of mesh placement could stimulate incorporation ${ }^{21}$. On the other hand, one could also argue that the limited number of fixations in our study could not approximate the mesh close enough to the abdominal wall for sufficient incorporation. Yet, our test animals were four-footed so that abdominal contents pressed the mesh against the abdominal wall most of the time.

Because of the poor incorporation, the importance of mesh fixation must be underscored. Quite probably, the number of fixations should be high enough ${ }^{22}$ and the fixation method should remain in place for a long time or not resolve at all. Furthermore, the combination 
A

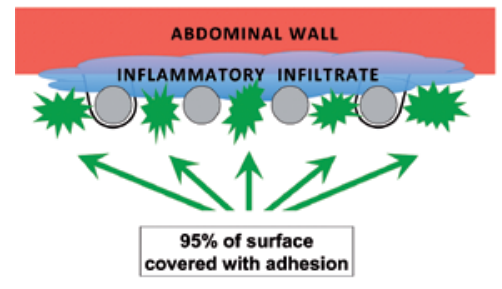

B

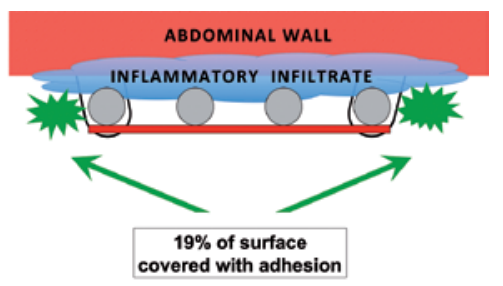

C

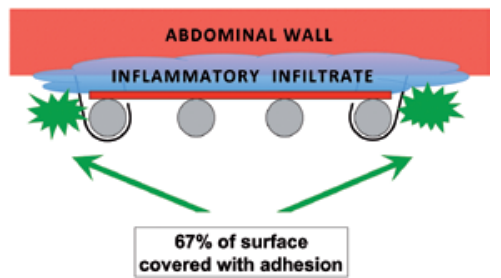

Figure 1. The abdominal wall has a significant role in the adhesion formation process. In A, uncoated mesh is sutured against the abdominal wall resulting in a high number of mesh pores exposing the inflammatory infiltrate (green jagged clouds). In B and C, coated mesh is placed against the abdominal wall resulting in significantly less adhesion formation compared to A (Chapter 5). The coating faces the abdominal wall in B, or the viscera in C.

of different fixation methods, i.e. transfascial sutures and tackers, could provide extra benefit in terms of mesh incorporation and maximal strength ${ }^{23}$. Even though transfascial sutures have been found to be responsible for some cases of chronic pain based on nerve entrapment ${ }^{24}$, a recent systematic review on clinical data concerning mesh fixation methods did not find any differences in hernia recurrence or abdominal wall pain ${ }^{25}$.

As for adhesion prevention, we showed that only fixation methods that are quickly absorbed result in less adhesion formation. Fibrin glue especially was of interest since it's absorption within 7 days after implantation seemed to have an anti-adhesive effect that could be used clinically for adhesion prevention at mesh borders or otherwise damaged parts of peritoneum. Unfortunately, the effectiveness of intraperitoneal mesh fixation with fibrin glue is questionable $e^{26,27}$.

\section{The early immune response}

From the very first moment a biomaterial comes into contact with the host tissue, the immune system is triggered and a complex inflammatory cascade starts. The adherence of fibrinogen to the biomaterial surface and the recruitment of inflammatory cells through mast cell activation have both been shown to be among the earliest and most crucial steps in this early immune response $\mathrm{e}^{28-31}$. Furthermore, the formation of intraperitoneal adhesions in the absence of a foreign body has been shown to be dependent on interferon gamma ${ }^{32}$. However in our studies, we failed to show that these pathways are also crucial in the formation of adhesions to intraperitoneal mesh. Important differences with former research is the fact that we evaluated a foreign body in an intraperitoneal position, as opposed to the subcutaneous position ${ }^{28-31}$ or adhesions related to induced tissue trauma ${ }^{32}$. 
Until now, most approaches to reduce mesh related adhesions involved locally acting compounds. We have now shown a novel approach with systemic, preoperative administration of the orally delivered drug cromolyn to work as well. Cromolyn's mode of action is likely to be related to the very first stages of biomaterial induced adhesion formation since starting therapy only slightly before or after mesh implantation did not show any benefits. Even though we did not uncover the exact mechanisms involved, we do believe that cromolyn needs further attention and clinical testing as the positive effects can be easily obtained without apparent side effects.

Another interesting phenomenon is the tissue comprised of immunomodulatory cells that surrounds the mesh after the first days of implantation. The tissue is further enriched with fibroblasts, adipose cells and vascular endothelial cells with a single layer of mesothelial cells on top. Remarkably, the exact origin of all these cells is unknown. Yet, their appearance around the mesh material from the very early moments after implantation and the increase in number and variety are intriguing. Understanding this process might be of interest in the search for adhesion reductive measures. Both omental and mesothelial cells are of particular interest.

As the omentum is consistently found attached to intraperitoneal meshes, it has been studied in more detail in several experimental studies. Besides the favourable response to intraperitoneal trauma and infection ${ }^{33}$, more recent research has shown that the omentum undergoes reversible adipose tissue remodelling in response to tissue trauma ${ }^{34}$. In response to foreign bodies, the omentum enlarges and immunomodulatory myeloid derived suppressor cells increase together with omnipotent stem cells, indistinguishable from mesenchymal stem cells $s^{35}$. Depending on the local environment, these stem cells may at least develop into highly vascularized adipose tissue or fibrous tissue with large amounts of collagen and myofibroblasts ${ }^{36}$. Even endodermal and ectodermal lineages can arise from these stem cells ${ }^{35}$.

The peritoneum is also thought provoking because irrespective of the size of trauma to this layer, the layer is re-established about 7 days after the trauma. Several hypotheses, that might in fact all be true, exist for this phenomenon ${ }^{37}$. First of all, omnipotent stem cells or perivascular cells in the mesothelium can transform into mesothelial cells. Second, transplantation of mesothelial cells coming from the mesothelium of adjacent structures or from free floating mesothelial cells can occur. These modes of action may also relate to an intraperitoneal foreign body on which mesothelial cells can be deposited. In addition, mesothelial cells can undergo epithelial-to-mesenchymal transition, e.g. adopting a fibroblast phenotype, which is associated with fibrosis ${ }^{38}$.

Further experimental research on the exact point of action of cromolyn should include the effects of cromolyn on omental and peritoneal tissue.

\section{A human model for the evaluation of adhesions to meshes}

By definition, stoma formation involves the formation of an abdominal wall hernia. As such, stoma reversal can be regarded as a hernia repair. Though unlike hernia repair, stoma reversal is typically performed without mesh since the pathophysiology of the "hernia" is significantly different. However, whether mesh can be omitted remains to be determined 
as we and others have found incisional hernia rates after stoma closure of around $30 \%^{39,40}$. These rates are much higher than the rates observed in studies with shorter or inadequate follow-up and without employing imaging as gold standard ${ }^{39}$. Yet, only $42 \%$ of the hernias we detected were symptomatic in terms of physical discomfort and $58 \%$ in terms of a palpable defect. Maybe these proportions will rise at later time points as it is believed that the natural course of hernias is to enlarge over time ${ }^{41}$.

In our study, morbid obesity was found to be the only significant risk factor for the development of an incisional hernia. Interestingly, obesity seems to be one of the most constant risk factors for primary and recurrent incisional hernias throughout a wide array of studies ${ }^{42-45}$. Several factors can be reasoned to have substantial influence. For instance, abundant subcutaneous fat can hinder a good overview of the operation site and may become necrotic underneath sutures, leading to their loosening. Also, the tangential force on the abdominal wall is higher in obese patients due to the increased abdominal wall radius ${ }^{46}$. From a metabolic point of view, incisional hernias can be regarded as a disease of the extracellular matrix, regulated by inflammatory cytokines, which may be influenced by the state of obesity itself ${ }^{47,48}$. In addition, peristomal atrophy of the abdominal rectus muscle together with a shift of the midline away from the stoma can necessitate additional force at the time of stoma reversal ${ }^{49,50}$. Moreover, the atrophy and changes in forces executed on the abdominal wall may lead to the selection of abnormal fibroblasts that could contribute to a defective wound healing ${ }^{50,51}$.

In line with studies focusing on other patient groups at high risk for incisional hernia formation ${ }^{52}$ (e.g. aortic abdominal aneurysm disease, obesity) we performed an interventional study in which patients received a parastomal mesh at the time of stoma creation. Although this procedure has already proven to decrease the occurrence of parastomal hernias in definitive stomas ${ }^{53}$, we chose to include only temporary stomas. At the time of stoma reversal the mesh was then left in place, suture closed and served as a prophylactic measure for incisional herniation.

Results at two year after stoma reversal showed no incisional hernias and no mesh infections at any time. Nevertheless, the introduction of a prosthetic mesh carries with it the risk of a foreign body that can be a safe haven for bacteria ${ }^{54}$. For this reason, some authors advocate the use of biological meshes in these potentially contaminated fields ${ }^{55,56}$. However, their use is expensive, hernias may occur after absorption of the mesh ${ }^{57,58}$, and certainly not all of these meshes are immune to infection ${ }^{59,60}$. In our study, a monofilament polyester mesh with a layered collagen coating was chosen to reduce infection and adhesions ${ }^{10,61}$.

In one patient severe adhesions had formed between the bowel and a curled up border of the mesh necessitating a midline laparotomy. Placing meshes extraperitoneally could probably avoid such complications. Apart from this, no significant adverse events were observed at any time during the study. Now, the question is whether the potential benefits of standard prophylactic mesh placement for temporary stomas outweigh the detrimental effects in terms of quality of life and cost effectiveness ${ }^{62}$. Randomized controlled trials with sufficiently long follow-up and quality of life assessment are therefore needed before parastomal mesh can be applied as a standard prophylactic measure in temporary stoma formation. 
Finally, adhesions were of particular interest and therefore evaluated laparoscopically and small parts of mesh sampled at the time of stoma reversal. By doing so we have established a clinical model that allows for the prospective study of intraperitoneal mesh related adhesion formation. Until now, the interpretation of clinical mesh related adhesions was limited because of (very) large variation in follow-up times or the fact that reoperations were performed for emergencies related to the mesh or viscera. Additionally, the sampled pieces of mesh will prove valuable in comparing the foreign body reaction between humans and animals. If the reactions prove to be similar, it adds to the scientific basis of performing experimental studies that are aimed at translational medicine.

\section{Future perspectives}

Some intriguing issues merit further attention. A selection of these has been elaborated on as follows.

\section{Improving adhesion awareness}

Being aware of adhesions and adhesion related morbidity requires a state of mind that acknowledges the huge burden of adhesions. Even though the related complications may only become overt at much later times, providing patients with adequate information preoperatively and attempting adhesion prevention at all times are necessary. However, in order to change current behaviour both knowledge and attitude need to be addressed ${ }^{63}$. Information on the burden of adhesions can be disseminated from as soon as medical students are taught about surgical concepts. Even more important is the incorporation of the subject in training programmes for surgical specialty residents. For current surgical specialists continuous medical education modules should be developed. As for attitude, ambiguous results from published studies, as well as personal beliefs and experiences can be regarded as major barriers. Hopefully, the results of some excellent meta-analyses on the burden of adhesions ${ }^{1}$ and antiadhesive agents ${ }^{64}$ as well as the conception of a consensus document with clinically relevant recommendations will improve attitude. Yet, behaviour may remain unchanged until evidence based guidelines on adhesions, adhesion counselling and adhesion prevention are adopted by the relevant surgical societies. An important question that remains is whether all patients or only patients at particularly high risk for adhesions should have antiadhesive agents applied. For this, the general appraisal of risks and benefits prevails. The apparent lack of serious adverse side effects might in fact support the use as a widely used secondary preventive (i.e. no adhesions yet), instead of tertiary prevention (i.e. adhesions already present).

Lastly, updated studies on cost effectiveness and quality of life should be communicated to health insurance companies and patients. Apart from antiadhesive agent manufacturers that are currently involved, these groups may then actively engage in raising awareness among surgeons as well. 


\section{Mesh biocompatibility}

The term biocompatibility addresses both a device's ability to perform its intended function, as well as the absence of any undesirable local or systemic effect in the host ${ }^{65}$. Biocompatibility is also a contextual term implying that the specific situation (i.e. placement technique, location of the mesh, patient factors) is of great importance too. Thus, the term biocompatibility is all-embracing, characterizing the net result of mesh implantation. Therefore, biocompatibility is ideally assessed by using clinically relevant outcome measures such as pain or foreign body sensation, improvement of quality of life, adhesion related complications, and clinical recurrences against a background of certain diseases like collagen disease. Although some standardized methods for the measurement of quality of life after incisional hernia repair are available ${ }^{66}$, consensus is urgently needed on which method is most suited and at which time point. A separate appreciation on the subject of adhesion related complications following intraperitoneal mesh placement follows below.

Our observations that most of the currently available meshes with a layered coating provide comparable adhesion prevention together with limited ingrowth are of particular interes $\mathrm{t}^{10}$. It probably shows that the different combinations of already known coatings and plastics are unlikely to further enhance biocompatibility. As a result, collagen based meshes have been introduced to better withstand a potentially infected or infected milieu. However, as stated before, their ability to do so may be limited and their ability to be absorbed might be of more relevance since the infection then no longer has a biomaterial based nidus. Apart from improved patient risk factor management, future developments in this field should involve the development of new materials and coatings, possibly enriched with bioactive substances. These substances could involve antibiotics ${ }^{67,68}$ or chemokines, cytokines, antibodies or other substances (e.g. statins, cromolyn, ... ) $^{32,69,70}$ that target different phases of inflammation and wound healing. Obviously, such new constructs would require extensive testing and should be regarded as drug trials even though it involves a significant investment of time and resources.

Clinical studies, including prospective registries, offer the ultimate testing model but their use is associated with many practical and ethical limitations. Experimental studies thus have an important role in testing hypotheses, exploring pathways and comparing promising treatment methods and devices before clinical testing. Comparing meshes that are identical in all but one characteristic can greatly improve our understandings of relevant characteristics. Yet, it also demands a commitment from industry, as commercially available meshes typically vary in more than one characteristic and the required custommade meshes can be out of scope for many research centres.

Furthermore, premarket testing of new meshes should be conducted on at least a European level involving multiple test centres that have proven expertise in this field. A standardised set of tests, to be consented by an independent panel of mesh specialists, must be determined and could involve variables from in vitro (e.g. flexibility, effective pore size, bacterial resistance) and in vivo testing (e.g. adhesion formation, foreign body reaction, strength of incorporation). In the absence of solid evidence for only one or two predictors of biocompatibility, surgeons must be able to consult these test results, for instance through 
a freely available web site, before choosing a mesh for implantation. Ideally, new legislation that is underway should mandate these tests before devices are cleared for human use.

\section{Scoring mesh related adhesions}

As discussed above, clinically relevant outcomes are of utmost concern when evaluating different methods of treatment. In case of adhesions such endpoints include infertility, small bowel obstructions, and inadvertent enterotomies at the time of reoperation. However, employing these endpoints for clinical research may in fact be prone for confounders and require high numbers of patients with a lengthy follow-up. As a result, surrogate markers are used. The occurrence of adhesions, scored as a simple yes or no, is probably the best surrogate endpoint since even a single adhesion may cause a bowel obstruction and the total absence of adhesions precludes the patient from adhesion related complications. However, it is also acknowledged that a total absence of adhesions after major large bowel surgery with peritonitis may be a far-fetched idea. In such cases, a decrease in extent, type, and severity of adhesions is generally acknowledged to possibly result in significant clinical benefits as well. In fact, a score based on the incidence, severity and extent of adhesions involving the ovaries and tubes has shown good correlation with pregnancy rates, even though this score is also still susceptible to some degree of subjectivity ${ }^{71}$. For non-gynaecological studies, it has been shown that adhesiolysis time is correlated with the number of inadvertent enterotomies ${ }^{6}$. As adhesion severity and extent increase, the time needed for adhesiolysis will increase as well. Therefore, severity and extent of adhesions have value as surrogate markers for adhesion related enterotomies. Whether this also holds for small bowel obstruction remains unknown.

Unfortunately, at the moment there seems to be no consensus on the exact adhesion scores for non-gynaecological adhesions, both in clinical and experimental research. For instance, systematically scoring adhesions to meshes in a clinical setting has been based on 6 different scoring systems in 8 published studies ${ }^{3,72-77}$. In the experimental setting the number of scores is even larger and many subgroups of scores have been created. This lack of consensus leads to a loss of clinical relevance, translatability, efficiency and comparability among different study results. Clearly, it is high time to obtain consensus on experimental models and definitions used for studying mesh adhesions. This consensus should however not limit creativity, nor the study of different outcomes. Instead, it is envisioned to be included in the studies as a standard report and it's use should be reinforced by the journals publishing on these subjects.

\section{Prevention of abdominal wall hernias}

Preventing incisional hernias to the fullest is achieved by natural orifice transluminal endoscopic surgery in which no incision in the abdominal wall is used. Furthermore, minimizing the extent (laparoscopy) ${ }^{78}$ and optimizing the direction (transverse instead of midline $)^{79}$ of the incisions helps to reduce the incidence of abdominal wall hernias. Nevertheless, midline laparotomies are still a much preferred and often used route to the abdomen. In the past decade a large amount of well-performed randomized controlled 
trials have become available on this subject. Key findings include the use of a continuous (vs. interrupted) technique with non or slowly absorbable (vs. rapid-absorbable) suture material ${ }^{80}$. Currently, most surgeons seem to have adopted this way of elective midline closure. A newer concept that has been thoroughly tested as well is the small-bites-smallsteps technique (5-8 $\mathrm{mm}$ from the wound edge, $4-5 \mathrm{~mm}$ apart) resulting in a suture to wound length ratio of 4 or higher ${ }^{81}$. Moreover, only the aponeuroses should be included in the stitch, not muscle or other tissue, and the suture needs not to be any thicker than $2 \times 0$ on a small needle ${ }^{81}$. This way, incisional hernia rates of the electively closed midline can be reduced by two thirds ${ }^{82}$. These concepts are still relatively new and seem to require more time for wide adaptation. Even recent polling among surgeons active in the field of hernia surgery showed only a minority to currently use this technique, though proportions seem to increase. Like with adhesion awareness, the dissemination of these results for midline closure needs incorporation in training and continuous medical education programmes as well as in a guideline on abdominal closure. With the latter, even the addition of prophylactic mesh in patients at particularly high risk for incisional hernia should be considered ${ }^{52}$. 


\section{References}

1 Broek ten RPG, Issa Y, van Santbrink EJP, Bouvy ND, Kruitwagen RFPM, Jeekel J, Bakkum EA, Rovers MM, van Goor H. Burden of adhesions in abdominal and pelvic surgery: systematic review and met-analysis. BMJ 2013;347:f5588.

2 Gray SH, Vick CC, Graham LA, Finan KR, Neumayer LA, Hawn MT. Risk of complications from enterotomy or unplanned bowel resection during elective hernia repair. Arch Surg 2008;143(6):582-6.

3 JenkinsED, Yom V, Melman L, Brunt LM, Eagon JC, Frisella MM, Matthews BD. Prospective evaluation of adhesion characteristics to intraperitoneal mesh and adhesiolysis-related complications during laparoscopic re-exploration after prior ventral hernia repair. Surg Endosc 2010;24(12):3002-7.

4 Ellis H, Crowe A. Medico-legal consequences of post-operative intra-abdominal adhesions. Int $J$ Surg 2009;7(3):187-91.

5 Hackethal A, Sick C, Brueggmann D, Tchartchian G, Wallwiener M, Muenstedt K, Tinneberg HR. Awareness and perception of intra-abdominal adhesions and related consequences: survey of gynaecologists in German hospitals. Eur J Obstet Gynecol Reprod Biol 2010;150(2):180-9.

6 Broek ten RPG, Strik C, Issa Y, Bleichrodt RP, van Goor H. Adhesiolysis-related morbidity in abdominal surgery. Ann Surg 2013;258(1):98-106.

7 Snyder CW, Graham LA, Gray SH, Vick CC, Hawn MT. Effect of mesh type and position on subsequent abdominal operations after incisional hernia repair. J Am Coll Surg 2011;212(4):496-502.

8 Halm JA, de Wall LL, Steyerberg EW, Jeekel J, Lange JF. Intraperitoneal polypropylene mesh hernia repair complicates subsequent abdominal surgery. World J Surg 2007;31(2):423-9.

9 Nazik H, Narin MA, Narin R, Dağlığlu K, Ünal İ, Tap Ö, Aytan H. Investigating the clinical significance of mesh peritonization in abdominal vault suspension surgery using a comparative rabbit model. Eur J Obstet Gynecol Reprod Biol 2014;175:199-204.

10 Schreinemacher MHF, van Barneveld KWY, Dikmans REG, Gijbels MJJ, Greve J-WM, Bouvy ND. Coated meshes for hernia repair provide comparable intraperitoneal adhesion prevention. Surg Endosc 2013;27(11):4202-9.

11 Franconi F, Roux J, Lefebvre-Lacoeuille C, Lemaire L. Imaging visceral adhesion to polymeric mesh using pneumoperitoneal-MRI in an experimental rat model. Surg Endosc 2014;:1-7.
12 Anderson JM, Rodriguez A, Chang DT. Foreign body reaction to biomaterials. Semin Immunol 2008;20(2):86-100.

13 Abdominal adhesions to prosthetic mesh evaluated by laparoscopy and electron microscopy. J Am Coll Surg 2000;190(3):271-80.

14 Gómez Gil V, García Honduvilla N, Pascual G, Rodríguez M, Buján J, Bellón JM. Peritoneal adhesion formation and reformation tracked by sequential laparoscopy: optimizing the time point for adhesiolysis. Surgery 2010;147(3):378-91.

15 Hellebrekers BWJ, Kooistra T. Pathogenesis of postoperative adhesion formation. Br J Surg 2011;98(11):1503-16.

16 Rodríguez M, Pascual G, Sotomayor S, PérezKöhler B, Cifuentes A, Bellón JM. Chemical Adhesion Barriers: Do They Affect the Intraperitoneal Behavior of a Composite Mesh? J Invest Surg 2011;24(3):115-22.

17 Brodbeck WG, Anderson JM. Giant cell formation and function. Curr Opin Hematol 2009;16(1):53-7.

18 Anderson JM, Jones JA. Phenotypic dichotomies in the foreign body reaction. Biomaterials 2007;28(34):5114-20.

19 Fortelny RH, Petter-Puchner AH, Glaser KS, Offner F, Benesch T, Rohr M. Adverse effects of polyvinylidene fluoride-coated polypropylene mesh used for laparoscopic intraperitoneal onlay repair of incisional hernia. Br J Surg 2010;97(7):1140-5.

20 Klink CD, Junge K, Binnebosel M, Alizai HP, Otto J, Neumann UP, Klinge U. Comparison of long-term biocompability of PVDF and PP meshes. J Invest Surg 2011;24(6):292-9.

21 Dubay DA, Wang X, Adamson B, Kuzon WM, Dennis RG, Franz MG. Progressive fascial wound failure impairs subsequent abdominal wall repairs: a new animal model of incisional hernia formation. Surgery 2005;137(4):463-71.

22 van'tRiet M, de Vosvan SteenwijkPJ, Kleinrensink GJ, Steyerberg EW. Tensile strength of mesh fixation methods in laparoscopic incisional hernia repair. Surg Endosc 2002;16(12):1713-6.

23 Orenstein SB, Dumeer JL, Monteagudo J, Poi MJ, Novitsky YW. Outcomes of laparoscopic ventral hernia repair with routine defect closure using "shoelacing" technique. Surg Endosc 2011;25(5):1452-7.

24 Wassenaar EB, Raymakers JT, Rakic S. Removal of transabdominal sutures for chronic pain 
after laparoscopic ventral and incisional hernia repair. Surg Laparosc Endosc Percutan Tech 2007;17(6):514-6.

25 Laparoscopic ventral hernia repair: is there an optimal mesh fixation technique? A systematic review. Langenbecks Arch Surg 2014;399(1):55-63. Peeters E, Miserez M, Gijbels MJJ, Greve JWM, Bouvy ND. Adhesions to sutures, tackers, and glue for intraperitoneal mesh fixation: an experimental study. Hernia 2013;:1-8.

27 Eriksen JR, Bisgaard T, Assaadzadeh S, Jorgensen LN, Rosenberg J. Fibrin sealant for mesh fixation in laparoscopic umbilical hernia repair: 1-year results of a randomized controlled double-blinded study. Hernia 2013;17(4):511-4.

28 Tang L, Eaton JW. Fibrin(ogen) mediates acute inflammatory responses to biomaterials. J Exp Med 1993;178(6):2147-56.

29 Tang L, Eaton JW. Fibrin(ogen) mediates acute inflammatory responses to biomaterials. J Exp Med 1993;178(6):2147-56.

30 Zdolsek J, Eaton JW, Tang L. Histamine release and fibrinogen adsorption mediate acute inflammatory responses to biomaterial implants in humans. J Transl Med 2007;5(1):31.

31 Thevenot PT, Baker DW, Weng H, Sun M-W, Tang L. The pivotal role of fibrocytes and mast cells in mediating fibrotic reactions to biomaterials. Biomaterials 2011;32(33):8394-403.

32 Kosaka H, Yoshimoto T, Yoshimoto T, Fujimoto J, Nakanishi K. Interferon-gamma is a therapeutic target molecule for prevention of postoperative adhesion formation. Nat Med 2008;14(4):437-41.

33 Liebermann-Meffert D. The greater omentum: anatomy, embryology, and surgical applications. Surg Clin North Am 2000;80(1):275-93.

34 Wilkosz S. Remodelling of adipose tissue during experimental omental adhesion formation. $\mathrm{Br} \mathrm{J}$ Surg 2008;95(3):387-96.

35 Shah S, Lowery E, Braun RK, Martin A, Huang N, Medina M, Sethupathi P, Seki Y, Takami M, Byrne K, Wigfield C, Love RB, Iwashima M. Cellular basis of tissue regeneration by omentum. PLoS One 2012;7(6):e38368.

36 Gómez Gil V, Pascual G, García Honduvilla N, Rodríguez M, Buján J, Bellón JM. Characterizing omental adhesions by culturing cells isolated from a novel in vivo adhesion model. Wound Repair Regen 2009;17(1):51-61.

37 Duron JJ. Postoperative intraperitoneal adhesion pathophysiology. Colorectal Dis 2007;9 Suppl 2(s2):14-24.
38 Yáñez-Mó M, Lara-Pezzi E, Selgas R, RamírezHuesca M, Domínguez-Jiménez C, JiménezHeffernan JA, Aguilera A, Sánchez-Tomero JA, Bajo MA, Álvarez V, Castro MA, del Peso G, Cirujeda A, Gamallo C, Sánchez-Madrid F, LópezCabrera M. Peritoneal dialysis and epithelial-tomesenchymal transition of mesothelial cells. $N$ Engl J Med 2003;348(5):403-13.

39 Nguyen MT, Phatak UR, Li LT, Hicks SC, Moffett JM, Arita NA, Berger RL, Kao LS, Liang MK. Review of stoma site and midline incisional hernias after stoma reversal. J Surg Res 2014;190(2):504-9.

40 Schreinemacher M, Vijgen GH, Dagnelie, P. C., Bloemen JG, Huizinga BF, Bouvy ND. Incisional hernias in temporary stoma wounds: a cohort study. Arch Surg 2011;146(1):94-9.

41 Nieuwenhuizen J, Halm JA, Jeekel J, Lange JF. Natural course ofincisionalhernia and indications for repair. Scand J Surg 2007;96(4):293-6.

42 Hoer J, Lawong G, Klinge U, Schumpelick V. Factors influencing the development of incisional hernia. A retrospective study of 2,983 laparotomy patients over a period of 10 years. Chirurg 2002;73(5):474-80.

43 Langer C, Schaper A, Liersch T, Kulle B, Flosman M, Füzesi L, Becker H. Prognosis factors in incisional hernia surgery: 25 years of experience. Hernia 2005;9(1):16-21.

44 Sauerland S, Sauerland S, Korenkov M, Korenkov M, Kleinen T, Kleinen T, Arndt M, Arndt M, Paul A, Paul A. Obesity is a risk factor for recurrence after incisional hernia repair. Hernia 2004;8(1):42-6.

45 Hesselink VJ, Luijendijk RW, de Wilt JH, Heide R, Jeekel J. An evaluation of risk factors in incisional hernia recurrence. Surg Gynecol Obstet 1993;176(3):228-34.

46 de Ruiter P, Bijnen AB. Successful local repair of paracolostomy hernia with a newly developed prosthetic device. Int J Colorectal Dis 1992; 7(3):132-4.

47 Guillen-Marti J, Diaz R, Quiles MT, Lopez-Cano M, Vilallonga R, Huguet P, Ramon-y-Cajal S, Sanchez-Niubo A, Reventós J, Armengol M, Arbos MA. MMPs/TIMPs and inflammatory signalling de-regulation in human incisional hernia tissues. J Cell Mol Med 2009;13(1112):4432-43.

48 Rosch R, Binnebosel M, Junge K, Lynen-Jansen P, Mertens PR, Klinge U, Schumpelick V. Analysis of c-myc, PAI-1 and UPAR in patients with incisional hernias. Hernia 2008;12(3):285-8. 
49 Timmermans L, Deerenberg EB, van Dijk SM, Lamme B, Koning AH, Kleinrensink G-J, Jeekel J, Lange JF. Abdominal rectus muscle atrophy and midline shift after colostomy creation. Surgery 2014;155(4):696-701.

50 Dubay DA, Choi W, Urbanchek MG, Wang X, Adamson B, Dennis RG, Kuzon WM, Franz MG. Incisional herniation induces decreased abdominal wall compliance via oblique muscle atrophy and fibrosis. Ann Surg 2007;245(1):140-6.

51 Franz MG. The biology of hernia formation. Surgical Clinics of NA 2008;88(1):1-15.

52 Timmermans L, de Goede B, Eker HH, van Kempen BJH, Jeekel J, Lange JF. Meta-analysis of primary mesh augmentation as prophylactic measure to prevent incisional hernia. Dig Surg 2013;30(4-6):401-9.

53 Shabbir J, Chaudhary BN, Dawson R. A systematic review on the use of prophylactic mesh during primary stoma formation to prevent parastomal hernia formation. Colorectal Disease 2012;14(8):931-6.

54 Engelsman AF, van der Mei HC, Ploeg RJ, Busscher HJ. The phenomenon of infection with abdominal wall reconstruction. Biomaterials 2007;28(14):2314-27.

55 Ventral Hernia Working Group, Breuing K, Butler CE, Ferzoco S, Franz M, Hultman CS, Kilbridge JF, Rosen M, Silverman RP, Vargo D. Incisional ventral hernias: review of the literature and recommendations regarding the grading and technique of repair. Surgery 2010;148(3):544-58.

56 Shankaran V, Weber DJ, Reed RL II, Luchette FA. A Review of Available Prosthetics for Ventral Hernia Repair. Ann Surg 2011;253(1):16-26.

57 Bellows CF, Smith A, Malsbury J, Helton WS. Repair of incisional hernias with biological prosthesis: a systematic review of current evidence. Am J Surg 2013;205(1):85-101.

58 Montgomery A. The battle between biological and synthetic meshes in ventral hernia repair. Hernia 2013;17(1):3-11.

59 Deerenberg EB, Mulder IM, Grotenhuis N, Ditzel M, Jeekel J, Lange JF. Experimental study on synthetic and biological mesh implantation in a contaminated environment. Br J Surg 2012;99(12):1734-41.

60 Ditzel M, Deerenberg EB, Grotenhuis N, Harlaar JJ, Monkhorst K, Bastiaansen-Jenniskens YM, Jeekel J, Lange JF. Biologic meshes are not superior to synthetic meshes in ventral hernia repair: an experimental study with long-term follow-up evaluation. Surg Endosc 2013;27(10):3654-62.

61 Engelsman AF, van Dam GM, van der Mei HC, Busscher HJ, Ploeg RJ. In vivo evaluation of bacterial infection involving morphologically different surgical meshes. Ann Surg 2010;251(1):133-7.

62 Lee L, Saleem A, Landry T, Latimer E, Chaudhury P, Feldman LS. Cost effectiveness of mesh prophylaxis to prevent parastomal hernia in patients undergoing permanent colostomy for rectal cancer. J Am Coll Surg 2014;218(1):82-91.

63 Cabana MD, Rand CS, Powe NR, Wu AW, Wilson MH, Abboud PA, Rubin HR. Why don't physicians follow clinical practice guidelines? A framework for improvement. JAMA 1999;282(15):1458-65.

64 Broek ten RPG, Stommel MWJ, Strik C, van Laarhoven CJHM, Keus F, van Goor H. Benefits and harms of adhesion barriers for abdominal surgery: a systematic review and meta-analysis. Lancet 2014;383(9911):48-59.

65 Williams DF. On the mechanisms of biocompatibility. Biomaterials 2008;29(20):294153.

66 Jensen KK, Henriksen NA, Harling H. Standardized measurement of quality of life after incisional hernia repair: a systematic review. Am J Surg 2014;208(3):485-93.

67 Junge K, Klinge U, Rosch R, Lynen P, Binnebösel M, Conze J, Mertens PR, Schwab R, Schumpelick V. Improved collagen type I/III ratio at the interface of gentamicin-supplemented polyvinylidenfluoride mesh materials. Langenbecks Arch Surg 2007;392(4):465-71.

68 Carbonell AM, Matthews BD, Dreau D, Foster M, Austin CE, Kercher KW, Sing RF, Heniford BT. The susceptibility of prosthetic biomaterials to infection. Surg Endosc 2004;19(3):430-5.

69 Aarons CB, Cohen PA, Gower A, Reed KL, Leeman SE, Stucchi AF, Becker JM. Statins (HMGCoA reductase inhibitors) decrease postoperative adhesions by increasing peritoneal fibrinolytic activity. Ann Surg 2007;245(2):176-84.

70 Reed KL, Fruin AB, Gower AC, Stucchi AF, Leeman SE, Becker JM. A neurokinin 1 receptor antagonist decreases postoperative peritoneal adhesion formation and increases peritoneal fibrinolytic activity. Proc Natl Acad Sci U S A 2004;101(24):9115-20.

71 Diamond MP, Wexner SD, diZereg GS, Korell M, Zmora O, van Goor H, Kamar M. Adhesion prevention and reduction: current status and 
future recommendations of a multinational interdisciplinary consensus conference. Surg Innov 2010;17(3):183-8.

72 Chelala E, Debardemaeker Y, Elias B, Charara F, Dessily M, Allé J-L. Eighty-five redo surgeries after 733 laparoscopic treatments for ventral and incisional hernia: adhesion and recurrence analysis. Hernia 2010;14(2):123-9.

73 Chelala E, Thoma M, Tatete B, Lemye AC, Dessily M, Alle JL. The suturing concept for laparoscopic mesh fixation in ventral and incisional hernia repair: Mid-term analysis of 400 cases. Surg Endosc 2006;21(3):391-5.

74 Rosen M, Brody F, Ponsky J, Walsh RM, Rosenblatt S, Duperier F, Fanning A, Siperstein A. Recurrence after laparoscopic ventral hernia repair. Surg Endosc 2003;17(1):123-8.

75 Wassenaar EB, Schoenmaeckers EJP, Raymakers JTFJ, Rakic S. Subsequent abdominal surgery after laparoscopic ventral and incisional hernia repair with an expanded polytetrafluoroethylene mesh: a single institution experience with 72 reoperations. Hernia 2010;14(2):137-42.

76 Koehler RH, Begos D, Berger D, Carey S, LeBlanc K, Park A, Ramshaw B, Smoot R, Voeller G. Minimal adhesions to ePTFE mesh after laparoscopic ventral incisional hernia repair: reoperative findings in 65 cases. Zentralbl Chir 2003;128(8):625-30.
77 Uranues S, Salehi B, Bergamaschi R. Adverse events, quality of life, and recurrence rates after laparoscopic adhesiolysis and recurrent incisional hernia mesh repair in patients with previous failed repairs. J Am Coll Surg 2008;207(5):663-9.

78 Duepree H-J, Senagore AJ, Delaney CP, Fazio VW. Does means of access affect the incidence of small bowel obstruction and ventral hernia after bowel resection? Laparoscopy versus laparotomy. J Am Coll Surg 2003;197(2):177-81.

79 Bickenbach KA, Karanicolas PJ, Ammori JB, Jayaraman S, Winter JM, Fields RC, Govindarajan A, Nir I, Rocha FG, Brennan MF. Up and down or side to side? A systematic review and meta-analysis examining the impact of incision on outcomes after abdominal surgery. Am J Surg 2013;206(3):400-9.

80 Diener MK, Voss S, Jensen K, Büchler MW, Seiler CM. Elective midline laparotomy closure: the INLINE systematic review and metaanalysis. Ann Surg 2010;251(5):843-56.

81 Israelsson LA, Millbourn D. Prevention of incisional hernias: how to close a midline incision. Surg Clin North Am 2013;93(5):1027-40.

82 Millbourn D, Cengiz Y, Israelsson LA. Effect of stitch length on wound complications after closure of midline incisions: a randomized controlled trial. Arch Surg 2009;144(11):1056-9. 


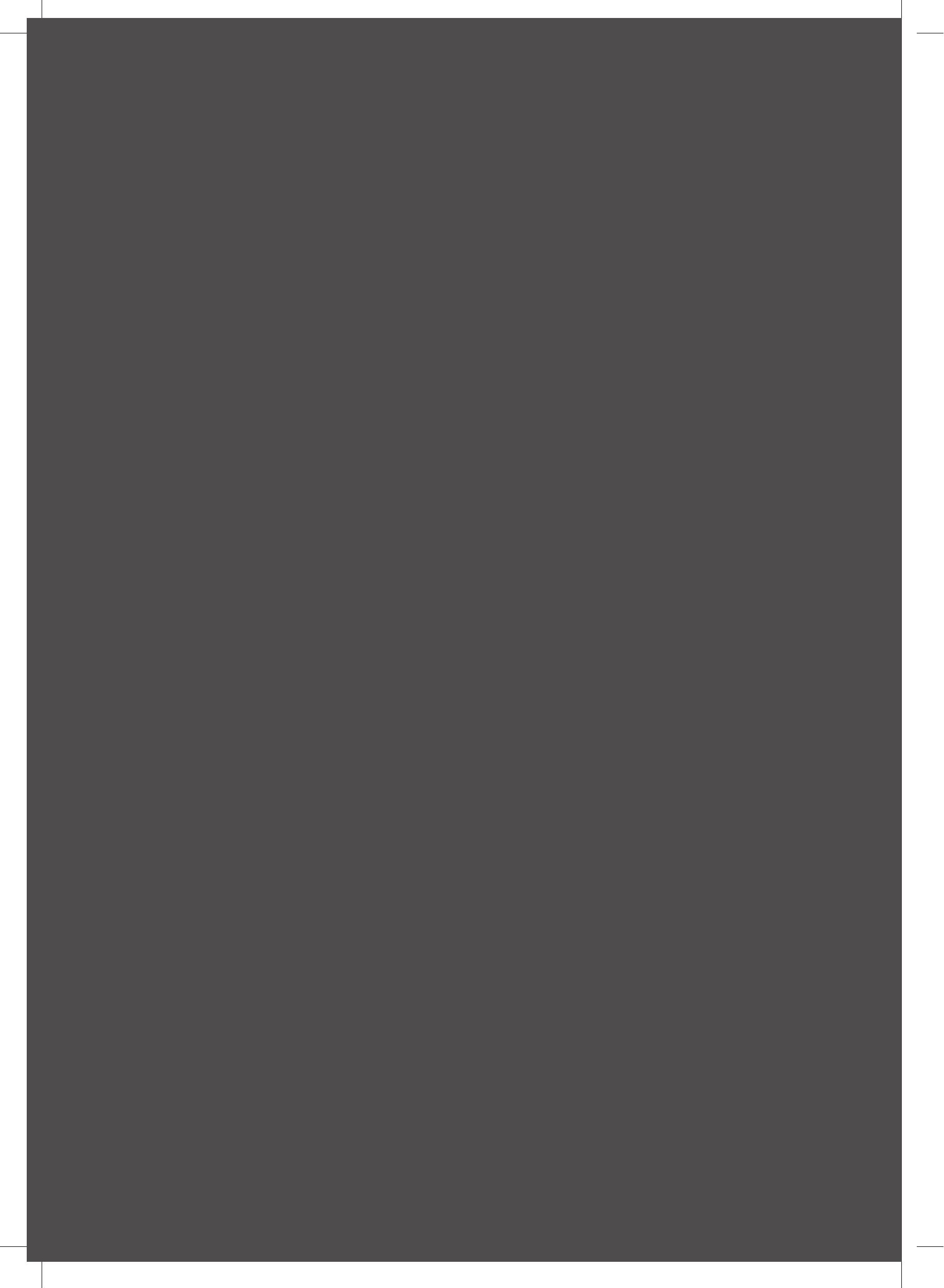


APPENDICES

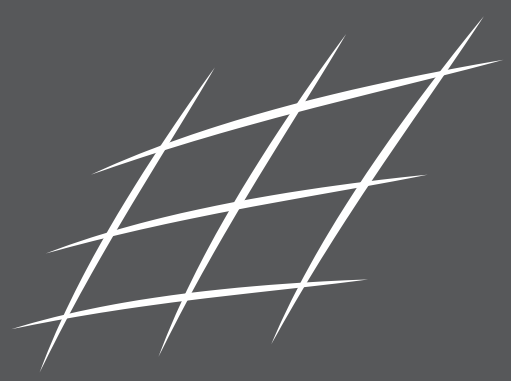




\section{SUMMARY}

Abdominal wall hernia repair is a frequently performed procedure that often requires the management of adhesions and mesh placement. This thesis explored the scope of the problem of adhesions in a clinical setting, then evaluated intraperitoneal adhesion formation to meshes in an experimental setting, and eventually developed a model for translating our experimental results to a clinical setting.

\section{Part 1: Clinical problem and awareness}

Firstly, we aimed to substantiate the burden of adhesions in abdominal wall hernia repair. In Chapter 2 we evaluated adhesions and related complications through a prospective, observational study of abdominal wall hernia repairs. In uncomplicated hernia repairs, i.e. no fistula or wound infection and no further surgical procedures, $10.3 \%$ of all patients experienced an inadvertent enterotomy. When complicated hernia repairs were included, $12.8 \%$ of all patients experienced one or more enterotomies. Adhesiolysis time was the most significant risk factor for enterotomy in all patients. As adhesiolysis time exceeded 30 minutes, even without an inadvertent enterotomy, more wound infections, reinterventions, ICU admissions, and episodes of parenteral feeding occurred, together with longer ICU and hospital stay and higher medication costs. With mesh from a previous repair still in place, the risk for an inadvertent enterotomy in uncomplicated repairs increased about 7-fold.

Despite the extensive morbidity, surgeons seem to underestimate the problem of adhesions. In Chapter 3 we surveyed all Dutch surgeons and surgical trainees for their knowledge, attitudes and behaviour towards adhesions. Although about two thirds of all respondents indicated that adhesions exert a negative and clinically relevant effect, comparable amounts of respondents significantly underestimated the extent and impact of adhesions. Nevertheless, a more negative perception of adhesions correlated with a more positive attitude regarding adhesion prevention. Also, less knowledge about adhesions correlated with more uncertainty about when to use antiadhesive agents which, in turn, correlated with never having used any of these agents. For abdominal wall hernia repair, an extraperitoneal mesh position and the use of coated meshes was agreed to reduce adhesion formation by 85 and $70 \%$ of respondents, respectively. Four in 10 respondents indicated that they never inform patients on adhesions preoperatively and only one in 10 indicated to inform patients routinely. Interestingly, knowledge and perception of the clinical relevance of adhesions did not correlate with informed consent behaviour.

\section{Part 2: Experimental findings on intraperitoneal mesh related adhesions}

After establishing the clinical problem of adhesions, the second part of this thesis studied adhesion formation with intraperitoneal meshes.

The first study, presented in Chapter 4, compared adhesion formation against several intraperitoneal meshes in a rat model at 7 and 30 days follow-up. The uncoated polypropylene 
mesh (Prolene ${ }^{\circledR}$ ) showed extensive adhesion formation with the mesh at 7 days followup. At 30 days, adhesions diminished slightly and inflammation normalized. Comparable results were seen with 2 other meshes $\left(\right.$ TiMesh $^{\circledR}$, Ultrapro ${ }^{\circledR}$ ) that had no continuous layer of coating either. The three meshes with an absorbable layered coating (Proceed ${ }^{\circledR}$, C-Qur ${ }^{\circledR}$, Parietex Composite ${ }^{\circledR}$ ) showed very limited adhesion formation at 7 days followup. However at 30 days, adhesions increased significantly as phagocytosis of the absorbable coatings occurred. The fixation points and mesh borders seemed to be preferential sites for adhesion formation. Incorporation into the abdominal wall was insufficient for all meshes.

In Chapter 5, four meshes with an absorbable layered coating (Parietene Composite ${ }^{\circledR}$, Parietex Composite ${ }^{\circledR}$, C-Qur Edge ${ }^{\circledast}$, Sepramesh IP $^{\circledR}$ ) and one with a non-absorbable layered coating (Intramesh $\mathrm{Tl}^{\circledR}$ ) were compared at 90 days follow-up. Uncoated polypropylene $\left(\right.$ Prolene ${ }^{\circledast}$ ) and collagen meshes $\left(\right.$ Permacol $\left.^{\circledR}\right)$ served as controls. All coated and collagen meshes performed equally well and significantly better than Prolene ${ }^{\circledR}$ in terms of adhesion prevention. Yet, the intensity of inflammation related to the absorbable coating differed highly. Incorporation was again mostly limited to the site of fixation that, together with the mesh borders, proved to be a preferential site for adhesion formation. In addition, the inflammatory reaction of the abdominal wall to the mesh significantly induced adhesion formation.

Apart from the meshes, we also compared adhesion formation to several fixation methods at 7 and 90 days follow-up. In Chapter 6, we found that fibrin glue (Tisseel Duo ${ }^{\circledR}$ ) was resorbed in less than 7 days and provided a strong antiadhesive effect, though mesh fixation was inadequate. Sutures that were resorbed before 90 days follow-up were also associated with a favourable adhesion profile. All other fixation methods (Protack ${ }^{\circledR}$ tackers, Absorbatack ${ }^{\circledR}$ tackers, Permasorb ${ }^{\circledR}$ tackers, Prolene ${ }^{\circledR}$ sutures) that were still intact at 90 days showed comparable and less favourable adhesion formation. Fixation methods were also placed without mesh to study the influence of the fixation methods on itself. Interestingly, in these cases adhesion formation was significantly reduced, but in the meantime fixation methods dislocated in up to $72 \%$ of tackers placed.

Following our observations of adhesion formation associated with phagocytosis of absorbable coatings, we tested the hypothesis if the addition of a non-absorbable coating could reduce adhesion formation. In Chapter 7 an experimental coating with an increased hydrophilicity was applied to standard polypropylene mesh. The coating was not applied as a continuous layer on one side of the mesh, but rather around every string of mesh. Even though at 7 days a more intense inflammatory reaction was noted than with uncoated polypropylene, adhesions were significantly reduced. Moreover, adhesions were still significantly reduced at 30 days at which point inflammation, and fibroblast numbers in particular, decreased.

Finally, some recent breakthroughs in the understanding of adhesion formation and foreign body response were evaluated with regards to intraperitoneal mesh and adhesions. In Chapter 8, mice were treated orally with cromolyn, commonly known as a mast cell stabiliser, and followed up for 7 days after intraperitoneal polypropylene mesh (Prolene ${ }^{\circledR}$ ) implantation. As a result, adhesions were reduced by about $50 \%$, but only with cromolyn administered preoperatively. Although the exact method of action remained unclear, we 
found that the pathogenesis of tissue-biomaterial adhesions differs significantly from intraperitoneal tissue-tissue adhesions. Because oral cromolyn is already available as a registered drug, the adhesion preventive effect is significant and the side effects are second to none, further clinical testing should be attempted.

\section{Part 3: A human model for the evaluation of adhesions to meshes}

The final chapter establishes a human model to allow for standardized clinical evaluation of adhesions to intraperitoneal meshes.

Firstly, in Chapter 9, the abdominal wall of patients who had undergone stoma reversal was examined by ultrasound for the presence of an incisional hernia at the site of the old stoma wound. After a median follow-up of almost 3 years, one in 3 patients had developed an incisional hernia. With obese patients hernias were present in 6 out of 10, compared to one in 4 patients without obesity. Consequently, obesity was identified as the sole risk factor for hernia occurrence. Of note, palpation of the abdominal wall had a limited sensitivity of $58 \%$, so that one in 6 patients with complaints but without a palpable hernia would show a hernia on ultrasound.

The high risk for incisional hernia after stoma reversal was reason to consider extra measures of prophylaxis. Therefore, we explored the feasibility and safety of placing a parastomal mesh at the time of temporary stoma creation in Chapter 10. This mesh was placed intraperitoneally and with the intent to prevent incisional hernias after stoma reversal. At the time of stoma reversal, laparoscopy was performed and adhesions scored. Then the stoma was reversed and the mesh defect closed. At a median of 2 years follow-up after stoma reversal no incisional hernias or mesh infections had occurred. Furthermore, laparoscopy revealed adhesions against all meshes involving a median of $25 \%$ of the mesh surface. In more than half of all patients, adhesions could not be lysed blunted and were appreciated as severe. Altogether, this model allowed for the clinical evaluation of adhesions against intraperitoneal meshes and can be used for translation of our experimental results. 


\section{SAMENVATTING}

Ondanks de vooruitgang in geneesmiddelen en chirurgische technieken treden na buikoperaties nog steeds veel complicaties op. Doorgaans ligt veel nadruk op de complicaties die binnen de eerste 30 dagen na de operatie optreden, zoals wond-, blaas- en longinfecties. De complicaties die echter pas na 30 dagen optreden verdienen net zoveel aandacht aangezien ze minstens zo talrijk zijn en gepaard kunnen gaan met veel ziekte. Het merendeel van deze "late" complicaties betreft buikwandbreuken en verklevingen binnen de buik. In dit proefschrift wordt gezocht naar de verdieping op het gebied van het herstel van buikwandbreuken middels matjes en de verklevingen die daarbij optreden.

\section{Buikwandbreuken}

Buikwandbreuken zijn defecten in de buikwandspieren en de stevige peesbladen die de spieren omvatten. Door een dergelijk defect kunnen buikvet en ingewanden zich tot vlak onder de huid bewegen waardoor er een zwelling zichtbaar wordt aan de buitenkant. Deze breuken, ook wel hernia's genoemd, kunnen aanleiding geven tot pijnklachten, een negatief lichaamsbeeld en in sommige gevallen levensgevaarlijke darmbeknellingen. Buikwandbreuken kunnen spontaan ontstaan (bijvoorbeeld navelbreuken, liesbreuken) of na medisch handelen (bijvoorbeeld littekenbreuken, breuken rond stoma's). Littekenbreuken zijn buikwandbreuken ter plaatse van een litteken en komen voor bij ongeveer 1 op de 5 patiënten na een buikoperatie en meestal binnen de eerste 3-5 jaar na de ingreep.

Herstel van een buikwandbreuk gebeurt doorgaans met behulp van een geweven kunststof matje dat na verloop van tijd vergroeit met de buikwand en zorgt voor overbrugging of versteviging van het defect in de buikwand. Door gebruik te maken van een matje wordt de kans op het terugkeren van de buikwandbreuk tweemaal kleiner dan wanneer het defect enkel opnieuw wordt gehecht.

\section{Verklevingen in de buik}

Verklevingen in de buik, ook wel adhesies genoemd, komen voor bij ongeveer 90\% van alle patiënten die in de buik geopereerd werden. Verklevingen ontstaan vooral als het gevolg van chirurgisch trauma aan het buikvlies (het peritoneum). Tot zeker 10 jaar na de operatie loopt een derde van deze patiënten het risico om één of meerdere malen opgenomen te worden in verband met klachten veroorzaakt door verklevingen.

Verklevingen kunnen beschouwd worden als het resultaat van een ontstekingsproces waarbij littekenweefsel ontstaat. Dit littekenweefsel kan holle organen zoals darmen met elkaar laten verkleven, maar ook deze organen dichtsnoeren. Gevolgen hiervan omvatten onvruchtbaarheid, darmobstructies, en darmbeschadigingen ten tijde van latere operaties.

Verklevingen zijn moeilijk effectief te behandelen aangezien het chirurgisch ingrijpen dat nodig is voor het behandelen van de verklevingen op zichzelf weer nieuwe verklevingen veroorzaakt. De winst is daarom te behalen in de preventie van verklevingen. 


\section{Matjes in de buik en verklevingen}

Naast chirurgisch ingrijpen zijn lichaamsvreemde materialen zoals matjes een specifieke bron van verklevingen. Wanneer het matje binnen de buikholte wordt geplaatst treden in meer of mindere mate verklevingen op. In een poging deze verklevingen te beperken worden vaak coatings toegepast. Deze coatings bestaan uit een dun laagje materiaal dat qua vorm en/of chemische eigenschappen minder verklevingen veroorzaakt. Tegenwoordig is een zeer groot assortiment aan matjes met verschillende coatings beschikbaar.

\section{Resultaten van dit proefschrift}

Hoewel reeds bekend was dat verklevingen veel problemen kunnen veroorzaken, brachten we in hoofdstuk 2 in kaart hoe groot het specifieke probleem van verklevingen is bij het herstel van buikwandbreuken. Daarvoor registreerden we het aantal darmbeschadigingen ten gevolge van het losmaken van verklevingen. Bij ruim 1 op de 10 patiënten was dit het geval. De tijd die nodig was voor het losmaken van de verklevingen was de sterkste voorspeller voor het optreden van darmbeschadigingen. Meer dan 30 minuten verklevingen losmaken resulteerde in meer wondinfecties, meer heringrepen, meer en langere intensive care opnames, vaker voeding via een infuus en meer kosten aan geneesmiddelen. Indien er reeds een matje in de buikwand aanwezig was, werd de kans op een darmbeschadiging 7 keer groter.

Dat verklevingen een klinisch relevant probleem vormen werd onderschreven door tweederde van de Nederlandse chirurgen en chirurgen in opleiding in hoofdstuk 3 . Een even grote groep onderschatte echter de totale omvang van het probleem. Wel was het zo dat hoe meer men verklevingen als klinisch probleem zag, des te belangrijker vond men ook de preventie van verklevingen. Ten aanzien van de matjes voor herstel van buikwandbreuken vond een overgrote meerderheid dat matjes liefst buiten de buikholte geplaatst worden of in ieder geval gecoat dienen te zijn indien binnen de buik geplaatst. Verder bleek dat slechts 4 op de 10 respondenten zijn of haar patiënten standaard voorlicht over de mogelijke gevolgen van verklevingen.

In het tweede gedeelte van dit proefschrift onderzochten wij in proefdieren welke factoren van invloed zijn op het ontstaan van verklevingen met matjes binnen de buik. In hoofdstuk 4 en 5 vergeleken we daarom enkele matjes die momenteel reeds gebruikt worden bij de behandeling van patiënten. In hoofdstuk 4 bleek dat matjes met een ononderbroken laag coating de minste verklevingen opleverden 30 dagen na plaatsing. Wat echter opviel is dat de verklevingen in aantal en ernst tussen 7 en 30 dagen toenamen. Deze toename ontstond op het moment dat de absorbeerbare coatings werden afgebroken door de onstekingsreactie. Naar aanleiding hiervan lieten wij in hoofdstuk 7 zien dat een experimentele coating die niet absorbeerbaar is inderdaad minder verklevingen liet zien. Voor alle typen matjes bleek daarnaast dat de randen van de matjes voorkeurslocaties waren voor de vorming van verklevingen en dat de matjes slecht in de buikwand ingroeiden. In hoofdstuk 5 werden matjes 90 dagen na plaatsing vergeleken. De ononderbroken laag coating bleek wederom het beste tegen verklevingen te beschermen. Interessant was het feit dat de ontstekingsreacties bij de verschillende coatings van matjes sterk verschilden, 
maar de mate van verklevingen toch gelijk was. Daarnaast toonden we aan dat niet alleen de ontstekingsreactie van de buikorganen, maar ook van de buikwand zelf voor een groot deel het ontstaan van verklevingen bepaalt.

Naast de matjes zijn ook de methodes voor het vastzetten van het matje in de buikwand belangrijk ten aanzien van het optreden van verklevingen. In hoofdstuk 6 zagen wij dat lijm gemaakt van bloedstollingseiwitten binnen 7 dagen werd opgelost en daarbij zelfs verklevingen leek te voorkomen. Helaas bleek dat de matjes daarbij totaal niet in de buikwand ingroeiden. Hechtingen die volledig binnen de 90 dagen werden geabsorbeerd lieten tevens betere resultaten zien dan de methoden die niet absorbeerbaar waren of meer dan 90 dagen nodig hadden voor volledige absorptie.

Tot slot kwamen we tot nieuwe inzichten over het ontstaan van verklevingen en de ontstekingsreactie van het lichaam in reactie op matjes. In hoofdstuk 8 kregen muizen een geneesmiddel toegediend voordat het matje geplaatst werd. Daardoor werd de hoeveelheid verklevingen gehalveerd. Alhoewel het geneesmiddel zich onder andere richt op mestcellen welke een belangrijke rol hebben in de vroegste stadia van de ontstekingsreactie, konden wij het precieze werkingsmechanisme nog niet ontrafelen. De resultaten zijn wel erg bemoedigend en wachten op bevestiging in patiënten.

In het derde en laatste deel van dit proefschrift beschreven we de ontwikkeling van een klinisch model voor het testen van onze resultaten uit het proefdieronderzoek. Daarvoor stelden we allereerst in hoofdstuk 9 vast dat 3 jaar na het opheffen van een darmstoma buikwandbreuken zeer vaak optreden. Voor alle patiënten samen was dit risico 3 op 10, voor de patiënten met obesitas was dit risico 6 op 10. Obesitas was de enige voorspeller voor het ontstaan van deze buikwandbreuken. Bij 1 op de 6 patiënten met klachten van de buikwand ter hoogte van het opgeheven stoma bleek een buikwandbreuk aanwezig op echo hoewel deze niet te voelen was.

Vanwege het hoge risico op een buikwandbreuk na het opheffen van een stoma besloten wij in hoofdstuk 10 te proberen om reeds een matje te plaatsen voordat een buikwandbreuk zou kunnen ontstaan. Bij 10 patiënten werd daarom bij het aanleggen van een tijdelijk darmstoma een matje geplaatst. Bij het opheffen van het stoma werd het matje gesloten en twee jaar later was er geen enkele buikwandbreuk opgetreden. Ook konden we bij het opheffen van het darmstoma de uitgebreidheid van de verklevingen met het matje vaststellen. Deze gegevens zullen we in de toekomst vergelijken met de resultaten uit ons onderzoek met proefdieren. Alleen indien er een goede overeenkomst bestaat tussen de resultaten van patiënten en dieren lijkt het zinvol proefdieronderzoek met betrekking tot matten en verklevingen in de toekomst verder te zetten. 


\section{VALORISATION}

Knowledge valorisation is the process of creating value from knowledge, by making knowledge suitable and/or available for economic and/or social use and by translating knowledge into competitive products, services, processes and new commercial activities ${ }^{1}$. A perspective on the valorisation of the work presented in this thesis follows here.

\section{Relevance}

Spontaneous hernias (e.g. epigastric, umbilical, inguinal) and iatrogenic hernias (e.g. incisional, parastomal) of the abdominal wall still are two of the most frequently encountered problems in surgery. In fact, one in four men develops an inguinal hernia at some point in his life resulting in inguinal hernia repair being the most frequently performed operation worldwide (estimated 20 million hernias repaired every year) ${ }^{2}$. The rest of the abdominal wall hernias occur less frequently, though over 1.8 million patients with an abdominal wall hernia are operated per year in the USA and numbers seem to be increasing ${ }^{3}$.

Most abdominal wall hernia repairs are regarded as minor surgery with low associated risks. Nevertheless, the high number of operations, combined with the significant risks of developing a recurrence or chronic pain, make hernia repair an intervention that has a significant influence on overall surgical morbidity and health expenditure ${ }^{2,3}$.

Postoperative adhesion formation is probably the most common long-term complication from abdominal surgery that may cause female infertility, bowel obstruction, pain and bowel injury at reoperation. The impact of adhesions on national health expenditure is estimated at more than 2 billion dollars per year in the USA ${ }^{4}$.

Foreign bodies implanted intraperitoneally, such as meshes for hernia repair, are a specific lead point for adhesion formation or even worse, fistula formation ${ }^{5}$. As a result, complications from intraperitoneal mesh placement could be significant and are worth preventing from an individual patient's as well as a societal point of view.

\section{Target groups}

The results of this thesis are of interest to a wide audience. Firstly, all medical professionals and surgical specialists in particular, should appreciate adhesions as a possible, or even likely cause of female infertility, bowel obstruction or bowel injury at reoperation with patients that underwent abdominal surgery in the past. In addition, surgical specialists should try to prevent adhesion formation and inform patients preoperatively at all times. General practitioners also have a role in recognizing patients with a history of abdominal surgery to be at risk for adhesion related complications.

With regards to the use of antiadhesive agents, the direct costs associated with these products are probably an important impediment for their widespread use ${ }^{6}$. Nevertheless, routine use of such products among high risk patients is very likely to prove cost effective? As such, health insurance companies and reimbursement agencies should consider providing adequate funding for the use of antiadhesive agents. 
With regard to the antiadhesive effects of mesh coatings, it is important to note that most of the different coatings do not show significantly different results in an experimental setting. Also in terms of other variables such as mesh incorporation, results seem to be very similar. This implies that, in the absence of sound clinical evidence, policy makers (either hospital or national) should be able to base their choice for certain mesh products also on other parameters such as costs and mesh handling.

Lastly, patients should also be encouraged to inform themselves about the operation related risks of adhesions and their prevention. An active role from these patients, preferably in the form of a patients' association, will encourage both treating surgeons and policy makers to change current practice.

\section{Activities and products}

The results on adhesion awareness showed a significant underestimation of the clinical problem of adhesions and related morbidity by general surgeons $s^{6}$. In response, a similar survey was undertaken for Dutch gynaecologists ${ }^{8}$ and general practitioners. Furthermore, the Dutch Adhesion Group was created by general surgeons and gynaecologists with a primary aim to raise awareness on abdominal adhesions. Today, reviews on the burden of adhesions and antiadhesive agents have been performed and published in outstanding clinical journals ${ }^{4,9}$. Hopefully, these publications have increased the awareness on adhesions and changed clinical practice. At this moment new surveys on adhesions are being prepared to measure these anticipated effects with the earlier studies serving as a benchmark.

As for the findings on cromolyn treatment significantly reducing postoperative adhesions, a patent has been filed for the application of cromolyn in adhesion reduction (publication number EP2638904A1, application number EP20120159348). Although cromolyn is already a long known drug in the prevention of asthmatic attacks, it was pushed aside in favour of steroids and beta 2 adrenergic agonists. Today, the indications for use seem to expand and a supposed suppression of the innate immune system helps to limit intraperitoneal adhesion formation.

Lastly, our pilot study on parastomal meshes showed that it is probably safe to place prosthetic meshes at the time of stoma creation in order to prevent incisional hernias after stoma reversal.

\section{Innovation}

In this thesis several innovative aspects in terms of valorisation have been addressed. Two of the most important innovations include the administration of cromolyn to reduce adhesions and the application of a parastomal mesh in temporary stoma formation to prevent incisional herniation after stoma reversal.

Firstly, until now, adhesion prevention in intraperitoneal mesh placement had been mainly achieved through addition of coatings that locally shield the abdominal wall and mesh from intraperitoneal contents. Despite different substances used for these coatings, no further improvements in terms of adhesion reduction seem to be obtained. Therefore, we 
decided to approach the problem from another angle. We showed that preparing the host optimally for implantation of the mesh could attain adhesion formation. What is more, the required treatment is limited to three pills, one pill per day, taken from 2 days until 4 hours before the operation. All in all, this simple treatment with pills administered preoperatively would be easily applicable and seems to be free from evident side effects.

Secondly, recent trials have shown that prophylactic parastomal mesh placement almost fully eliminates the high rates of parastomal hernias ${ }^{10}$. However, these findings are limited to definite stomas. Nevertheless, in temporary stoma formation about one in three stomas eventually turn out to be a definite stoma as well. Furthermore, we showed that the patients that have a stoma reversed are at a very high risk for incisional herniation at the site of the old stoma wound. Therefore, we conducted an interventional study on prophylactic mesh placement at the time of temporary stoma formation. The two-year follow-up results showed no signs of infection or incisional hernias. Combining our results with the findings in temporary stomas suggests that every stoma, both definite and temporary, should be reinforced with a parastomal mesh at the time of construction.

\section{Schedule and implementation}

Several interesting opportunities follow from the research described in this thesis.

As for the application of cromolyn in a clinical setting, only limited additional experimental testing in an oncological and anastomotic experimental model would be required before commencing a clinical trial. Moreover, oral cromolyn is currently already registered in the USA, and in much higher doses than the doses that can be calculated from our experimental studies. No apparent side effects, apart from allergies to the drug have been noticed. In Europe, oral cromolyn used to be registered but was pushed away by other drugs. Importantly, production costs of cromolyn are very low, comparable to acetaminophen (paracetamol). Because of the above, it seems that a phase II study can be initiated without too many hurdles. In such trial, the most important challenge will be to determine a suitable outcome parameter. Because of the long follow-up required for adequate observation of bowel obstruction, infertility rate and bowel injury at the time of reoperation, surrogate outcome parameters should be used. One such parameter could be the extent and type of adhesions as examined in our model of prophylactic parastomal mesh placement ${ }^{11}$.

Another important finding is the successful application of a parastomal mesh in temporary stomas. Together with the fact that these meshes have a role in definite stomas, and even in an infected milieu ${ }^{12}$, the application of a parastomal mesh should be a standard of care in constructing any type of stoma. A large scaled trial should confirm possible benefits in terms of quality of life and cost effectiveness.

It seems logical that for both proposed studies, the respective manufacturers of cromolyn and meshes will be engaged. In addition, governmental support should be aimed for as well, e.g. for cost effectiveness research. Important for both studies is the fact that in case of positive results high numbers of patients will be treated accordingly in the future which should help to make the case for cromolyn and mesh manufacturers. However, also because 
of the high number of affected patients, even small improvements in quality of life or cost effectiveness per patient can have major impact on societal health care (management).

Lastly, the mesh specimens taken from our human trial with parastomal mesh should be compared against the specimens from our experimental studies. If no significant correlation between the clinical and experimental setting exists, future experimental research should be further scrutinized. Until now, no such data are available in the literature. 


\section{References}

1 Interdepartementale Programmadirectie Kennis en Innovatie, Innovatieplatvorm. Van voornemens naar voorsprong: Kennis moet circuleren. Den Haag: 2009.

2 Kingsnorth A, LeBlanc K. Hernias: inguinal and incisional. Lancet 2003;362(9395):1561-71.

3 Poulose BK, Shelton J, Phillips S, Moore D, 9 Nealon W, Penson D, Beck W, Holzman MD. Epidemiology and cost of ventral hernia repair: making the case for hernia research. Hernia 2012;16(2):179-83.

4 Broek ten RPG, Stommel MWJ, Strik C, van Laarhoven CJHM, Keus F, van Goor H. Benefits and harms of adhesion barriers for abdominal surgery: a systematic review and meta-analysis. Lancet 2014;383(9911):48-59.

5 Halm JA, de Wall LL, Steyerberg EW, Jeekel J, Lange JF. Intraperitoneal polypropylene mesh hernia repair complicates subsequent abdominal surgery. World J Surg 2007;31(2):423-9.

6 Schreinemacher MHF, Broek ten RP, Bakkum EA, van Goor $\mathrm{H}$, Bouvy ND. Adhesion awareness: a national survey of surgeons. World J Surg 2010;34(12):2805-12.

7 Wilson MS, Menzies D, Knight AD, Crowe AM. Demonstrating the clinical and cost effectiveness of adhesion reduction strategies. Colorectal Disease 2002;4(5):355-60.

8 Meuleman T, Schreinemacher MHF, van Goor H, Bakkum EA, Dörr PJ. Adhesion awareness: a nationwide survey of gynaecologists. Eur J Obstet Gynecol Reprod Biol 2013;169(2):353-9.

Broek ten RPG, Issa Y, van Santbrink EJP, Bouvy ND, Kruitwagen RFPM, Jeekel J, Bakkum EA, Rovers MM, van Goor H. Burden of adhesions in abdominal and pelvic surgery: systematic review and met-analysis. BMJ 2013;347:f5588.

10 Timmermans L, de Goede B, Eker HH, van Kempen BJH, Jeekel J, Lange JF. Meta-analysis of primary mesh augmentation as prophylactic measure to prevent incisional hernia. Dig Surg 2013;30(4-6):401-9.

11 van Barneveld KWY, Vogels RRM, Beets GL, Breukink SO, Greve J-WM, Bouvy ND, Schreinemacher MHF. Prophylactic intraperitoneal mesh placement to prevent incisional hernia after stoma reversal: a feasibility study. Surg Endosc 2014;28(5):1522-7.

12 Argudo N, Pereira JA, Sancho JJ, Membrilla E, Pons MJ, Grande L. Prophylactic synthetic mesh can be safely used to close emergency laparotomies, even in peritonitis. Surgery 2014;156(5):1238-44. 


\section{LIST OF PUBLICATIONS}

Schreinemacher MH, van Barneveld KW, Vogels R, Gijbels MJ, Buurman WA, Bouvy ND. "Adhesion reduction to intraperitoneal meshes: a novel approach with preoperative, oral cromolyn treatment." Submitted. (In this thesis)

Leclercq RM, van Barneveld KW, Schreinemacher MH, Assies R, Twellaar M, Bouvy ND, Muris JW. "Post-operative abdominal adhesions and bowel obstruction. A survey among Dutch general practitioners." The European Journal of General Practice. Accepted for publication.

Schreinemacher MH, Goslings JC. "Horner Syndrome after a Traumatic Bicycle Ride.” Submitted. Graafland M, Hanna AA, Schreinemacher MH, Schijven MP. “Medical professionals exploring Google Glass ${ }^{\mathrm{Tw}}$ : perspectives on possibilities of wearable technology in hospitals." Submitted.

Vogels RR, van Barneveld KW, Gijbels MJ, Schreinemacher MH, Bouvy ND. "Long-term evaluation of adhesion formation and foreign body response to three new meshes." Surgical Endoscopy 2014. E-pub ahead of print.

Schreinemacher MH, Graafland M, Schijven MP. "Google Glass in Healthcare." Surgical Innovation 2014; 21:651-2.

van Rossem CC, Schreinemacher MH, Treskens K, van Hoogezand RM, van Geloven AA. "Duration of antibiotic treatment after appendicectomy for acute complicated appendicitis." British Journal of Surgery 2014; 101:715-9.

van Barneveld KW, Vogels RR, Beets GL, BreukinkSO, Greve JW, Bouvy ND, Schreinemacher MH. "Prophylactic intraperitoneal mesh placement to prevent incisional hernia after stoma reversal: a feasibility study.” Surgical Endoscopy 2013; 28:1522-7. (In this thesis)

Schreinemacher MH, van Barneveld KW, Peeters E, Miserez M, Gijbels MJ, Greve JW, Bouvy ND. "Adhesions to sutures, tackers and glue for intraperitoneal mesh fixation: an experimental study." Hernia 2014; 18:865-72. (In this thesis)

Reisinger KW, de Haan JJ, Schreinemacher MH. "Word of caution before implementing ketotifen for gastrointestinal transit improvement.” World Journal of Gastroenterology 2013; 19:4445-6.

Schreinemacher MH, van Barneveld KW, Dikmans R, Gijbels MJ, Greve JW, Bouvy ND. "Coated meshes for hernia repair provide comparable intraperitoneal adhesion prevention." Surgical Endoscopy 2013; 27:4202-9. (In this thesis)

Meuleman T, Schreinemacher MH, van Goor H, Bakkum EA, Dörr PJ. “Adhesion awareness: a nationwide survey of gynaecologists." European Journal of Obstetrics \& Gynecology and Reproductive Biology 2013; 169:353-9.

Peeters E, van Barneveld KW, Schreinemacher MH, De Hertogh G, Ozog Y, Bouvy N, Miserez M. "One-year outcome of biological and synthetic bioabsorbable meshes for augmentation of large abdominal wall defects in a rabbit model." Journal of Surgical Research 2013; 180:274-83. 
Schreinemacher $\mathrm{MH}^{\star}$, ten Broek RP*, Jilesen AP, Bouvy ND, Bleichrodt RP, van Goor H. "Enterotomy risk in abdominal wall repair: a prospective study." Annals of Surgery 2012; 256:280-7. In this thesis. ${ }^{\star}$ Both authors contributed equally.

Schreinemacher MH, Backes WH, Slenter JM, Xanthoulea S, Delvoux B, van Winden L, Beets-Tan RG, Evers JL, Dunselman GA, Romano A. "Towards endometriosis diagnosis by gadofosveset-trisodium enhanced magnetic resonance imaging.” PLoS One 2012; 7:e33241.

Schreinemacher MH. Invited comment on: "Postoperative adhesion prevention using a statincontaining cellulose film in an experimental model." British Journal of Surgery 2012; 99: 430.

Schreinemacher MH, Bloemen JG, van der Heijden SJ, Gijbels MJ, Dejong CH, Bouvy ND. "Collagen fleece does not improve anastomotic strength." International Journal of Colorectal Disease 2011; 26: 729-35.

Schreinemacher MH, Vijgen GH, Dagnelie PC, Huizinga BF, Bloemen JG, Bouvy ND. "Incisional hernias in old stoma wounds: a cohort study." Archives of Surgery 2011; 146: 94-9. (In this thesis)

Schreinemacher MH, Beets GL, Bouvy ND. "Prevention of parastomal hernia. It is Possible!" Annals of Surgery 2010; 252: 707-8.

Schreinemacher MH, ten Broek RP, van Goor H, Bouvy ND. "Adhesion awareness: a national survey of surgeons." World Journal of Surgery 2010; 34: 2805-12. (In this thesis)

Bloemen JG, Schreinemacher MH, de Bruïne AP, Buurman WA, Bouvy ND, Dejong CH. "Butyrate enemas improve anastomotic strength in a rat model." Diseases of the Colon and Rectum 2010; 53: 1069-75.

Koolen PJ, Schreinemacher MH, Peppelenbosch AG. "Heterotopic ossifications in midline abdominal scars: a critical review of the literature." European Journal of Vascular and Endovascular Surgery 2010; 40: 155-9.

Schreinemacher MH, Henatsch D, van Barneveld KW, Bouvy ND. "The need for standardized animal models and scoring systems in assessing mesh biocompatibility." Hernia 2010; 14: 335-6.

Schreinemacher MH, Emans PJ, Gijbels MJ, Beets GL, Greve JW, Bouvy ND. "Degradation of mesh coatings and intraperitoneal adhesion formation: an experimental study." British Journal of Surgery 2009; 96: 305-13. (In this thesis)

Emans PJ, Schreinemacher MH, Gijbels MJ, Beets GL, Greve JW, Koole LH, Bouvy ND. "Polypropylene meshes to prevent abdominal herniation. Can stable coatings prevent adhesions in the long term?" Annals of Biomedical Engineering 2009; 37: 410-8. (In this thesis)

\section{Book chapter}

Miserez M, Schreinemacher MH. “Spigelian Hernias: Diagnosis and Treatment”. In: Jacob BP, Ramshaw BJ, editors. The SAGES Manual of Hernia Repair. New York, NY: Springer New York: 2012. p. 567-82. 


\section{DANKWOORD}

Allereerst een bijzonder woord van dank aan de patiënten die participeerden in de klinische studies.

Daarnaast gaat mijn dank uit naar mijn (co)promotoren, supervisoren, beoordelingscommissie en overige leden van de promotiecommissie.

Professor Bouvy, beste Nicole, je enthousiasme bij het opereren, doceren en innoveren is ongekend. Je betrok mij direct bij het doen van onderzoek, nam me mee naar mijn eerste congres en gaf me altijd alle ruimte voor het uitwerken van eigen ideeën. Je scherpe geest en vriendelijke karakter maken het zeer prettig om met jou te discussiëren over onderzoek, vriendinnen, ... Het plezier in mijn promotie heb voor een zeer groot deel aan jou te danken.

Doctor Greve, beste Jan-Willem, 13 augustus 2007 begon ik mijn klinische loopbaan onder jouw hoede in Maastricht UMC, toen nog AZM. Al snel vonden wij elkaar ook in het onderzoek. Ik bewonder je integriteit en doelgerichtheid. Je betrokkenheid bij dit proefschrift door de jaren heen, maar ook je interesse en raadgevingen bij de laatste loodjes worden zeer gewaardeerd.

Doctor Breukink, beste Stephanie, je enthousiasme bij de klinische studies en je open blik maken je tot een waardevolle copromotor van dit proefschrift.

Professor Stassen, bedankt voor het voorzitten van de beoordelingscommissie. Alhoewel ik in 2011 besloot naar een andere regio te trekken, vier jaar later ben ik blij dat we elkaar toch weer in Maastricht ontmoeten.

Professor Bemelman, één van mijn opleiders in het AMC, dit proefschrift is een mooie gelegenheid om ook eens buiten het AMC met elkaar van gedachten te wisselen.

Professor Bonjer, reeds lange tijd een bekend gezicht in hernialand. Uw terugkeer naar Nederland betekende een belangrijke versterking voor Nederlands en Amsterdams herniaonderzoek.

Professor Dejong, een chirurg is nooit bang, hoogstens bezorgd. Zéér regelmatig denk of gebruik ik deze gevleugelde uitspraak.

Professor Lange, sinds mijn eerste congres een vast icoon bij elk herniacongres. Uw warme betrokkenheid doorheen de jaren heb ik altijd bijzonder op prijs gesteld.

Graag wil ik ook alle studenten en coauteurs bedanken voor de goede en vaak gezellige samenwerking, Kevin en Ruben natuurlijk in het bijzonder. Kevin, bedankt voor je inzet als student en promovendus. Je nauwkeurigheid en vasthoudendheid maken je ongetwijfeld tot een goede SEH-arts die hopelijk binnenkort ook gaat promoveren. Ruben, veel dank voor je hulp op afstand en enthousiasme. Wat goed dat je bij jezelf bent gebleven en op zoek gaat naar jouw ideale specialisme. Dat boekje komt er zonder twijfel!

Verder een warm woord van dank aan Richard, Absolute Adhesiekeizer; Pieter, mentor van het eerste uur; Marion, ideale microscooppartner; Ellen, Belgische vriendin op congres en OK; Johanne, 30 sec ondersteboven; Guy, een harde G; Anne-Claire, positieve en nauwgezette onderzoekskoningin; Rieky, zonnetje van Hannover; Leontine, enthousiaste opvolgster. 
Doctor Bakkum, professor Beets, professor van Goor, professor Koole en professor Miserez, dank voor jullie kritische blikken en suggesties ter verbetering van de manuscripten. Collega's van het lab in Maastricht, Annemarie, Dennis, Froukje, Geertje, Hans, Inca, Iris, Irma, Jacco, Joep en Joep, Kim en Kim, Kirsten, Konstan, Mo, Rob, Sander, Tim, en Maartje en Ruben in het bijzonder. Het was altijd gezellig om op het lab te zijn. Bedankt voor jullie bijdragen op wetenschappelijk, maar vooral ook sociaal gebied.

Bas, Charlotte, Kaatje, Nina en, vooruit dan maar, Caroline, voor jullie natuurlijk een apart plekje bij dit dankwoord. Het had toch iets bijzonders, onze onderzoekskamer. De prettige sfeer, genoeg ruimte voor ieder z'n uitspattingen (bij sommigen meer dan bij anderen), muntthee, jaargenoten met pakkende profielfoto's, ... Dank voor de mooie tijd.

Evelien, dank voor je hulp en ondersteuning bij de secretariële beslommeringen.

De buiksluiters uit Rotterdam, Eva, Joris, Julie, Gabriëlle, Hassan, Klitsie, Konstantinos, Lucas, Max, professor Jeekel, professor Kleinrensink en professor Lange, veel dank voor het openstellen van jullie groep tijdens de vele congressen. Velen van jullie zitten tegenwoordig in Amsterdam, tot spoedig!

Semi-arts in Heerlen, ANIOS in Maastricht UMC, de opleiding begonnen in Tergooi Hilversum en ondertussen in het AMC Amsterdam; elke kliniek is anders, maar overal waren het de bijzonder prettige collega's die ervoor zorgden dat ik er met veel plezier heb gewerkt.

Maastricht, augustus 2007, het begin van mijn klinisch werk, net twee weken uit de schoolbanken. Heel veel dank voor jullie geduld en positiviteit.

Tergooi Hilversum, januari 2011, het begin van de opleiding, een dag eerder verhuisd naar Amsterdam. Wat een geweldige plek om het enthousiasme voor de heelkunde verder te laten groeien. Met heel veel plezier was ik teruggekomen naar jullie ijzersterke club voor de laatste twee jaar van de opleiding ... maar toen koos ik voor de vaatchirurgie.

AMC Amsterdam, april 2013, de eerste keer bij de afdeling chirurgie in het AMC. De eerste twee jaar bevielen dermate goed dat ik er nog maar twee aan vast plak. De laagdrempeligheid in het onderlinge contact, de gedrevenheid om altijd nog iets beters neer te zetten en de goede sfeer in de assistentengroep maken het een bijzonder mooie plek.

Natuurlijk is er een nog veel grotere groep mensen indirect betrokken bij dit proefschrift. Zij waren en zijn voor mij degenen die het verschil maken. Enkelen noem ik in het bijzonder.

De jaarclub ER, Giel, Jakob, Martijn, Patrick, Sebas, Marc \& Silvie, bijzonder hoe we ooit bij elkaar kwamen en dat ondertussen nog steeds doen. In de toekomst zie ik jullie graag vaker.

De VCL, een mooie club die nog vele jaren voor zich heeft liggen. Zowel in Maastricht als in Amsterdam zullen we nog prachtige avonden beleven.

De wedstrijdboot, zeker ook collegae Jos en Guy, met jullie kwam ik voor het eerst echt in Amsterdam. Wat een mooie avonturen hebben we meegemaakt, kom een keer langs voor een avontuur bij de Hoop. 
De Boeken8, een geoliede machine qua organisatie en mede vanwege de sterke kernploeg niet meer weg te denken bij de Hoop. Met veel plezier begon ik aan mijn roeirevival, ik monster graag weer aan voor het volgende seizoen.

Vrienden in Amsterdam: de warmte van deze stad komt onder andere door jullie. Flu en Steven (we komen langs!), Brenda en Suthesh, Marie-Louise en Reinier, Dominique, Eva en Thies, Lauren en Victor, hoog tijd om af te spreken.

Beste paranimfen, sinds het begin van dit boekje was ik ervan overtuigd dat ik jullie bij de verdediging graag naast mij zou hebben staan. Oom Mick, peetoom, we schijnen in aardig wat opzichten op elkaar te lijken, zowel qua beroep (min of meer), maar ook daarbuiten. Samen met jou dit proefschrift verdedigen is een plezier op zich. Dank voor alle gezelligheid.

Patrick, vriend voor het leven, dank voor je steun op elk moment, maar vooral ook voor je niet-aflatende stroom berichten over de geneugten van het leven. Bedankt dat je erbij bent.

Lieve familie, in het bijzonder ook m'n favoriete peettante Swaas, dank voor al jullie gezelligheid en warmte, elke keer weer.

Lieve oma's en opa's, wat had ik jullie er nog graag bij gehad. Ik mis jullie meer dan eens, maar hoop dat jullie het goed hebben met elkaar. Bedankt voor alle mooie momenten doorspekt met levenswijsheden.

Lieve mama en papa, trotse ouders, in woorden valt moeilijk uit te drukken hoeveel ik jullie wil bedanken voor alles. Jullie onvoorwaardelijke liefde voel ik elke keer weer, of het nou op vakantie in Zuid-Amerika is of bij gekibbel over de telefoon als de computer het "niet doet". Weet dat het gevoel wederzijds is.

Lieve Julie, liefste zusje van de wereld, vroeger vlogen we elkaar regelmatig in de haren, nu zelden meer dan een scherpe discussie. Het kleine zusje is dan ook een volwassen vrouw geworden die mij graag met raad en daad bijstaat. Dank daarvoor en ... ik glimlach omdat ik je broer ben, ik lach me kapot omdat je er niets aan kunt doen!

Lieve Andrea, het einde van mijn promotietijd was even wat drukker en dat heb je soms geweten ook. Gelukkig heb je het zelf al een keer doorgemaakt. Nu is het weer tijd voor leuke dingen; een grote bibliotheek, reizen naar warme landen en nog vele andere mooie toekomstplannen liggen in het verschiet. Bedankt voor al je steun en liefde! 


\section{CURRICULUM VITAE AUCTORIS}

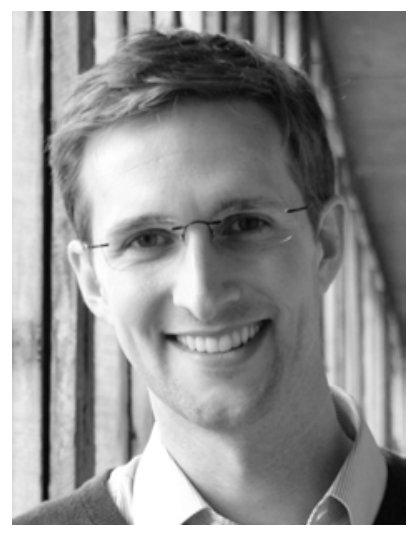

Marc Henri François Schreinemacher was born on 14 August 1983 in Maastricht, The Netherlands. He spent his younger years in Lanaken (Belgium) and graduated from high school in Dilsen-Stokkem (Belgium), where he majored in mathematics and sciences.

In 2001, Marc commenced his medicine studies at Maastricht University. Parts of his education were completed abroad with a clinical internship in Leuven (Belgium) and a scientific internship in Auckland (New Zealand). During his studies, Marc took on several extracurricular activities such as entering the Faculty Council with his own party and tutoring medical students. Other activities included competitive rowing and re-establishing and chairing the Student Golf Association. In July 2007, Marc graduated cum laude from Maastricht University.

Directly after his graduation he commenced his work as a junior house resident in General Surgery at the Maastricht University Medical Center, where in 2008 he was elected "Resident of the Year". In the same year he was awarded the "Kootstra Talent Fellowship" which he used to kick start his $\mathrm{PhD}$ in 2009. The following two years he raised a NVGE gastrostart grant, and a Collegium Chirurgicum Neerlandicum grant among others. These grants, together with the guidance and support of prof. dr. N.D. Bouvy, led up to this thesis.

In 2011 he commenced his surgical training in the region of Amsterdam. The first two years were spent at the Tergooiziekenhuizen Hilversum where he was mentored by dr. J.P. Eerenberg. In 2013, Marc has been employed at the Antoni van Leeuwenhoek Hospital, Amsterdam (Netherlands Cancer Institute) while supervised by prof. dr. E.J.Th. Rutgers. The rest of his surgical training have been and will be spent at the Academic Medical Center Amsterdam where he will finish his training as a vascular surgeon at the end of 2016 under the guidance of prof. dr. O.R.C. Busch and prof. dr. R. Balm. 